

\section{Development of Biodegradable Adhesives for Meniscus Repair}


The research described in this thesis was conducted between 2012 and 2016 in the research group Biomaterials Science and Technology at the Institute for Biomedical Technology and Technical Medicine (MIRA), University of Twente, Enschede, The Netherlands, and in the Orthopaedic Research Laboratory, Radboud Institute for Molecular Life Sciences (RIMLS), Radboudumc, Nijmegen, The Netherlands. The research was financially supported by Reumafonds, the Dutch arthritis foundation.

The printing of this thesis was sponsored by:

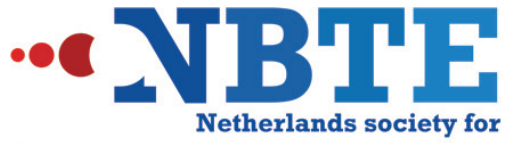
Biomaterials and Tissue Engineering

Development of biodegradable adhesives for meniscus repair Agnieszka Bochyńska

$\mathrm{PhD}$ Thesis, with references and summaries in English and Dutch University of Twente, Enschede, The Netherlands

(C) Agnieszka Bochyńska, the Netherlands, 2016

ISBN: 978-90-365-4152-7

DOI: $10.3990 / 1.9789036541527$ 


\section{DEVELOPMENT OF BIODEGRADABLE ADHESIVES FOR MENISCUS REPAIR}

\section{DISSERTATION}

to obtain

the degree of doctor at the University of Twente, on the authority of the rector magnificus, prof. dr. H. Brinksma,

on account of the decision of the graduation committee, to be publicly defended on Friday the $8^{\text {th }}$ of July 2016 at 12.45

by

\section{Agnieszka Izabela Bochyńska}

Born on the $15^{\text {th }}$ June 1987

in Radom, Poland 
The dissertation has been approved by the promotors:

Prof. Dr. D.W. Grijpma

Prof. Dr. P. Buma

Dr. G. Hannink 


\section{Promotion Committee}

\section{Chairman:}

Prof. Dr. J.W.M. Hilgenkamp

Promotors:

Prof. Dr. D.W. Grijpma

Prof. Dr. P. Buma

Co-promotor:

Dr. G. Hannink

Members:

Prof. Dr. J.F.J. Engbersen

Prof. Dr. Ir. N. Verdonschot

Prof. Dr. Ir. T.H. Smit

Prof. Dr. G.J.V.M. van Osch

Dr. C.C. van Donkelaar

Dr. T.G. van Tienen
University of Twente

University of Twente

Radboudumc

Radboudumc

University of Twente

University of Twente

VU University Medical Center

Erasmus MC

Eindhoven University of Technology

Kliniek ViaSana 



\section{Table of Contents}

Chapter $1 \quad$ General Introduction 1

Chapter 2 Tissue Adhesives for Meniscus Tear Repair - An 9

Overview of Current Advances and Prospects for Future Clinical Solutions

Chapter 3

Chapter 4

Chapter 5

Chapter 6

Chapter 7

Chapter 8

Chapter 9

Summary

Samenvatting

Acknowledgements

List of publications
Development of Tissue Adhesives Based on Amphiphilic Isocyanate-Terminated Trimethylene Carbonate Block Copolymers

Adhesion of Tissue Glues to Different Biological 63 Substrates

Development of Biodegradable Hyper-Branched 77 Tissue Adhesives for the Repair of Meniscus Tears

Evaluation of Novel Biodegradable Three-Armed- and 105 Hyper-Branched Tissue Adhesives in a Meniscus Explant Model

The Effect of Tissue Surface Modification with 121 Collagenase and Addition of TGF- $\beta 3$ on the Healing Potential of Meniscal Tears Repaired with Tissue Glues In Vitro

In Vitro and In Vivo Characterization of Biodegradable 135 Reactive Isocyanate-Terminated Three-Armed- and Hyper-Branched Block Copolymeric Tissue Adhesives Development of a Fast Curing Tissue Adhesive for Meniscus Tear Repair 

Chapter 1

General Introduction 


\section{General Introduction}

Menisci are fibrocartilaginous tissues present in the knee joint. They are crucial structural elements of the knee as they play a key role in shock absorption and load distribution, protecting the articular cartilage [1].

Meniscus tears are among the most common knee injuries. Approximately one third of middle-aged and elderly people has a damaged meniscus [2]. Such tears lead to pain, swelling and locking of the knee joint [3]. Moreover, it has been shown that in the long-term the risk of the knee osteoarthritis (OA) dramatically increases if menisci are damaged by injury or degenerative processes.

Treatment for meniscus injuries usually consists of (partial) meniscectomy. This results in instant pain relief and restoration of the knee function, but in the long-term leads to accelerated cartilage degradation due to increased peak stresses acting on the articular cartilage [4, 5]. These increased intra-articular contact stresses inevitably lead to mechanical damage and biochemical changes of the cartilage, leading to development of degenerative changes and OA in the knee [6].

The cascade of events leading to OA can be prevented by repairing the meniscus tear directly after the trauma [7]. The anatomical location of the tear in the meniscus influences the healing capacity of the tear. Tears located in the peripheral, vascularized part of the meniscus have a higher chance of successful repair $[8,9]$. However, most tears are located in the inner, highly loaded area of the meniscus with limited vascular supply. These lesions have shown only limited capacity for repair and healing [8]. The reported healing rates of meniscal tears repaired using mechanical devices, such as sutures, staples, arrows, and screws are highly variable [10]. Despite recent advances, a large proportion of meniscal tears observed during arthroscopy remains irreparable [11].

It has been recognized that tissue adhesives could provide optimal meniscal repair and facilitate tissue healing by minimizing gap formation, providing contact of the bonded surfaces and by that restore the integrity of the damaged meniscus $[12,13]$. Once brought into a meniscal tear, such an adhesive would fill the tear, bind to the meniscal tissue and hold the torn region together during the period of healing. 
Additionally, it would permit cell migration and extra-cellular matrix formation in the torn zone. After tear repair, there would be no further enlargement of the tear and no deterioration of the adjacent cartilage.

Tissue adhesives have already been used in clinical practice for other purposes, for example cyanoacrylates as topical skin adhesives, fibrin glue for pulmonary leaks, and a recently FDA approved isocyanate/polyurethane-based adhesive for abdominoplasty [14-17]. However, they are not suitable for meniscus repair as they either do not have adequate mechanical properties or are cytotoxic.

\section{Aim and outline of this thesis}

The aim of the work described in this thesis was to develop novel biodegradable polymeric materials that can be used as adhesives for meniscus tear repair. More specifically, isocyanate-terminated hyper-branched amphiphilic block copolymers based on trimethylene carbonate (TMC), polyethylene glycol (PEG) and citric acid (CA), and three-armed star block copolymers based on trimethylolpropane ethoxylate (TMPE) and TMC, were synthesized. The obtained materials were characterized in terms of their adhesion to meniscus tissue, the mechanical properties of the cured networks, and their biocompatibility in vitro and in vivo.

Chapter 2 introduces the background of the anatomy, physiology and biomechanics of the meniscus, and currently used surgical techniques to repair meniscus tears. It gives an overview of tissue adhesive materials that are currently used in clinical practice for other applications as well as new developments in the research field of tissue adhesives. The requirements for tissue adhesives suitable for meniscus repair are identified and compared with the properties of existing materials [18].

In Chapter 3 the development of isocyanate-terminated linear and three-armed starshaped amphiphilic copolymers is described. Their physical and mechanical properties are determined. Their adhesion to chamois leather (dermal sheep collagen), which is used as a tissue model, is determined and compared with that of two clinically used adhesives: fibrin glue and Dermabond ${ }^{\circledR}[19]$.

In Chapter 4 gluing of different biological substrates, which serve as tissue models, is evaluated. Three different adhesive materials: Dermabond ${ }^{\circledR}$, fibrin glue and an 
isocyanate-terminated three-armed adhesive are used to glue Achilles tendon tissue, muscle tissue, meniscus tissue, chamois leather and collagen films. The adhesive strength of the glues is compared and discussed in relation to the working mechanisms of the glues, the contact angle between the glues and the substrates, as well as in relation to the properties of the substrates such as their biochemical content and surface morphology.

Chapter 5 describes the development and characterization of a series of isocyanateterminated hyper-branched amphiphilic copolymers based on citric acid (CA), polyethylene glycol (PEG) and trimethylene carbonate (TMC). The physical properties of the newly developed cured adhesive materials are determined. Moreover, the degradation profiles of the cured network films and their tensile properties are determined. Finally, the adhesion of the copolymers to meniscus tissue is tested and their potential cytoxicity is evaluated in a cell-based in vitro assay [20].

In Chapter 6 the application of the two recently developed three-armed star-shaped and hyper-branched adhesives in a full thickness meniscus explant model is evaluated. Cylindrical meniscal explants are glued with the two new materials, Dermabond $^{\circledR}$ and fibrin glue, after which they are cultured in vitro. The adhesive strength of the glues and the tissue response are determined by a mechanical push out test and by histological screening, respectively. Moreover, the use of collagenase, which partially digests the surface of the explants to potentially enhance tissue healing and improve adhesion of the glues, is evaluated [21].

In Chapter 7 further evaluation of the newly developed three-armed and hyperbranched adhesives in a cylindrical explant model is performed. The glues are applied in such a way that the glue only partially covers the simulated tear, allowing parts of the two sides of the gap to stay in direct contact with each other. Such design allows investigating if cells are able to migrate into the gap and facilitate repair. Additionally, the influence of the TGF- $\beta 3$ and the collagenase treatment on the number and location of cells is investigated [22].

In Chapter $\mathbf{8}$ the characterization of the three-armed and hyper-branched adhesive copolymers is further assessed. The mechanical properties of the networks degrading both in vitro and in vivo and the changes of their structure are monitored by tensile 
testing and scanning electron microscopy (SEM) imaging of the surfaces of the network films. The two adhesive copolymers are injected subcutaneously in rats and their potential cytoxicity is assessed by histological evaluation at predetermined time points.

Chapter 9 describes the design and development of a fast curing adhesive composition. In order to accelerate curing times of the isocyanate-terminated glues two strategies are employed. Firstly, a double component curing adhesive composition is introduced using a double chamber syringe equipped with a static mixer. In one chamber the isocyanate-terminated copolymer is contained and in the second chamber an amine-terminated cross-linker. During extrusion of the two components from the syringe, the components are mixed and curing is initiated immediately. The second strategy employs the use of a catalyst, which is added to the isocyanate-terminated copolymers before application. The application and the adhesive properties of these newly developed adhesive compositions are evaluated in bucket-handle tears in a bovine meniscus model [23].

\section{References}

[1] Englund M, Guermazi A, Lohmander LS. The meniscus in knee osteoarthritis. Rheumatic Disease Clinics of North America, 2009;35:579-90.

[2] Englund M, Roemer FW, Hayashi D, Crema MD, Guermazi A. Meniscus pathology, osteoarthritis and the treatment controversy. Nature Reviews Rheumatology 2012;8:412-9.

[3] Englund M, Niu J, Guermazi A, Roemer FW, Hunter DJ, Lynch JA, et al. Effect of meniscal damage on the development of frequent knee pain, aching, or stiffness. Arthritis and Rheumatism 2007;56:4048-54.

[4] Koike M, Nojiri H, Ozawa Y, Watanabe K, Muramatsu Y, Kaneko H, et al. Mechanical overloading causes mitochondrial superoxide and SOD2 imbalance in chondrocytes resulting in cartilage degeneration. Scientific Reports 2015;5:11722.

[5] McDermott ID, Amis AA. The consequences of meniscectomy. Journal of Bone and Joint Surgery-British Volume 2006;88B:1549-56.

[6] Kokkonen HT, Jurvelin JS, Tiitu V, Toyras J. Detection of mechanical injury of articular cartilage using contrast enhanced computed tomography. Osteoarthritis Cartilage 2011;19:295-301.

[7] van Tienen TG, Hannink G, Buma P. Meniscus Replacement Using Synthetic Materials. Clinics in Sports Medicine 2009;28:143-156. 
[8] Longo UG, Campi S, Romeo G, Spiezia F, Maffulli N, Denaro V. Biological Strategies to Enhance Healing of the Avascular Area of the Meniscus. Stem Cells International 2012;2012:528359.

[9] Krych AJ, McIntosh AL, Voll AE, Stuart MJ, Dahm DL. Arthroscopic repair of isolated meniscal tears in patients 18 years and younger. American Journal of Sports Medicine 2008;36:1283-9.

[10] van Trommel MF, Simonian PT, Potter HG, Wickiewicz TL. Different Regional Healing Rates with the Outside-In Technique for Meniscal Repair. The American Journal of Sports Medicine 1998;26:446-52.

[11] Starke C, Kopf S, Petersen W, Becker R. Meniscal Repair. Arthroscopy-the Journal of Arthroscopic and Related Surgery 2009;25:1033-44.

[12] Szomor ZL, Murrell GAC, Appleyard RC, Tyler MJ. Meniscal repair with a new biological glue: An ex vivo study. Techniques in Knee Surgery 2008;7:261-5.

[13] Simson JA, Strehin IA, Allen BW, Elisseeff JH. Bonding and fusion of meniscus fibrocartilage using a novel chondroitin sulfate bone marrow tissue adhesive. Tissue Engineering - Part A 2013;19:1843-51.

[14] Gilbert TW, Badylak SF, Beckman EJ, Clower DM, Rubin JP. Prevention of seroma formation with TissuGlu ${ }^{\circledR}$ surgical adhesive in a canine abdominoplasty model: Long term clinical and histologic studies. Journal of Plastic, Reconstructive and Aesthetic Surgery 2013;66:414-22.

[15] Walgenbach KJ, Bannasch H, Kalthoff S, Rubin JP. Randomized, prospective study of TissuGlu ${ }^{\circledR}$ surgical adhesive in the management of wound drainage following abdominoplasty. Aesthetic Plastic Surgery 2012;36:491-6.

[16] Matar AF, Hill JG, Duncan W, Orfanakis N, Law I. Use of biological glue to control pulmonary air leaks. Thorax 1990;45:670-4.

[17] Singer AJ, Quinn JV, Hollander JE. The cyanoacrylate topical skin adhesives. The American Journal of Emergency Medicine 2008;26:490-6.

[18] Bochyńska AI, Hannink G, Grijpma DW, Buma P. Tissue adhesives for meniscus tear repair: an overview of current advances and prospects for future clinical solutions. Journal of Materials Science: Materials in Medicine 2016;27:1-18, Chapter 2 of this thesis.

[19] Bochyńska AI, Sharifi S, van Tienen TG, Buma P, Grijpma DW. Development of Tissue Adhesives Based on Amphiphilic Isocyanate-Terminated Trimethylene Carbonate Block Copolymers. Macromolecular Symposia 2013;334:40-8, Chapter 3 of this thesis.

[20] Bochyńska AI, Van Tienen TG, Hannink G, Buma P, Grijpma DW. Development of biodegradable hyper-branched tissue adhesives for the repair of meniscus tears. Acta Biomaterialia 2015;12:30256-7, Chapter 5 of this thesis. 
[21] Bochyńska AI, Hannink G, Verhoeven R, Grijpma DW, Buma P. Evaluation of novel biodegradable three-armed- and hyper-branched tissue adhesives in a meniscus explant model. Journal of Biomedical Materials Research Part A, submitted, Chapter 6 of this thesis. [22] Bochyńska AI, Hannink G, Verhoeven R, Grijpma DW, Buma P. The effect of tissue surface modification with collagenase and addition of TGF- $\beta 3$ on the healing potential of meniscal tears repaired with tissue glues in vitro. Biomedical Materials, submitted, Chapter 7 of this thesis.

[23] Bochyńska AI, Hannink G, Janssen D, Buma P, Grijpma DW. Development of a fast curing tissue adhesive for meniscus tear repair. Journal of Materials Science: Materials in Medicine, submitted, Chapter 9 of this thesis. 


\section{Chapter 2}

\section{Tissue Adhesives for Meniscus Tear Repair - An Overview of Current Advances and Prospects for Future Clinical Solutions}

Agnieszka I. Bochyńska ${ }^{1,2}$, Gerjon Hannink. ${ }^{1}$, Dirk W. Grijpma ${ }^{2,3}$, Pieter Buma ${ }^{1}$

${ }^{1}$ Orthopaedic Research Laboratory, Department of Orthopaedics, Radboud Centre for Molecular Life Sciences, Radboud University Nijmegen Medical Centre, Nijmegen, the Netherlands

${ }^{2}$ Department of Biomaterials Science and Technology, MIRA Institute, University of Twente, Enschede, the Netherlands

${ }^{3}$ University Medical Centre Groningen, University of Groningen, W.J. Kolff Institute, Department of Biomedical Engineering, Groningen, the Netherlands 


\begin{abstract}
Menisci are crucial structures in the knee joint as they play important functions in load transfer, maintaining joint stability and in homeostasis of articular cartilage. Unfortunately, ones of the most frequently occurring knee injuries are meniscal tears. Particularly tears in the avascular zone of the meniscus usually do not heal spontaneously and lead to pain, swelling and locking of the knee joint. Eventually, after a (partial) meniscectomy, they will lead to osteoarthritis. Current treatment modalities to repair tears and by that restore the integrity of the native meniscus still carry their drawbacks and a new robust solution is desired. A strong tissue adhesive could provide such a solution and could potentially improve on sutures, which are the current gold standard. Moreover, a glue could serve as a carrier for biological compounds known to enhance tissue healing. Only few tissue adhesives, e.g., Dermabond $^{\circledR}$ and fibrin glue, are already successfully used in clinical practice for other applications, but are not considered suitable for gluing meniscus tissue due to their sub-optimal mechanical properties or toxicity. There is a growing interest and research field focusing on the development of novel polymer-based tissue adhesives, but up to now, there is no material specially designed for the repair of meniscal tears. In this review, we discuss the current clinical gold standard treatment of meniscal tears and present an overview of new developments in this field. Moreover, we discuss the properties of different tissue adhesives for their potential use in meniscal tear repair. Finally, we formulate recommendations regarding the design criteria of material properties and adhesive strength for clinically applicable glues for meniscal tears
\end{abstract}

\title{
Introduction
}

Menisci are crescent shaped discs of fibrocartilage with a triangular cross-section, present in duplicate in each knee joint. The menisci have been recognized as crucial structures in maintaining knee joint stability and articular cartilage homeostasis [13]. During normal functioning, they are exposed to shear, tension and compression forces and serve a variety of (bio)mechanical functions, such as load bearing, constituting contact area, guiding rotation and stabilizing translation [4-7]. They also 
play a role in lubrication and nutrition of the underlying articular cartilage surfaces and by that might help to prevent the development of osteoarthritis [1].

The most commonly occurring injuries of the knee joint are meniscus tears. They originate either from acute injuries of the knee joint (e.g. sport, trauma) or are caused by degenerative changes (mostly in case of elderly patients) associated with early osteoarthritis [8]. Irrespective to their origin, they might cause pain, swelling and locking of the joint, and they may ultimately lead to osteoarthritis [9]. Therefore, it is of utmost importance to provide an effective treatment modality and to prevent this negative scenario.

In the past, it was believed that menisci could be removed without any immediate or long-term consequences for the function of the knee joint and consequently a (partial) meniscectomy was performed as a gold standard treatment. In fact, shortterm results were very satisfactory. It resulted in instant pain relief and restoration of knee function, but as osteoarthritis develops very slowly, it took decades to find out that even a partial meniscectomy inevitably leads to joint degeneration [10, 11]. In 1975 Krause et al. showed that menisci have a function in load transmission and stress absorption in the knee and that peak stresses acting on articular cartilage increase after meniscectomy [6]. Removal of only $15-34 \%$ of the meniscus, a partial meniscectomy, will produce a $350 \%$ increase in contact stress and lead to development of degenerative changes and eventually osteoarthritis in a majority of the patients [12]. Ever since, the preferred strategies aim at restoration of the integrity of the meniscus rather than at its removal by (partial) meniscectomy [13]. These treatment methods can only be effective if the torn parts of the tissue are kept in close proximity to each other enabling a healing process to take place. Many devices have been developed and tested in clinical practice for this purpose, such as sutures, stingers, staples, arrows and darts $[14,15]$. However, the success rate of these devices highly depend on the location of the meniscal lesion [16]. They are mainly effective in treating lesions located in the peripheral vascularized region of the meniscus $[17,18]$. Moreover, the techniques are challenging, surgical procedure is time-consuming and devices are expensive. Therefore, it would be ideal to find an alternative treatment method, which should be easier and faster to perform, and 
would allow a more universal successful treatment of tears, also those located in the avascular region of the meniscus.

Recently, much interest has been paid to tissue adhesives as an alternative to sutures. Tissue adhesives are already used in clinical practice for other purposes, such as Dermabond $^{\circledR}$ (2-octyl cyanoacrylate) as topical skin adhesive, fibrin glue for pulmonary leaks, and recently TissuGlu $\left.{ }^{(}\right)$(an FDA approved urethane-based adhesive) for abdominoplasty surgery [19, 20]. However, up to now, there is no clinically available glue suitable for the treatment of meniscal tears.

The purpose of this paper was to summarize current advances in the development of tissue adhesives, compare them with the current clinical gold standard treatments and critically evaluate their potential application in the treatment of meniscal tears. Mechanical and biological properties of the meniscus are discussed and requirements for a suitable material are formulated. Subsequently, characteristics of the main groups of tissue adhesives found in literature are discussed and conclusions and recommendations for future clinical directions are made.

\section{Biology of the meniscus}

The healthy meniscus contains $72 \%$ water, the remaining $28 \%$ are organic compounds: $22 \%$ collagen, $0.8 \%$ glycosaminoglycans (GAGs, of which the major part $(40 \%)$ is chondroitin 6-sulphate), DNA ( $2 \%)$, adhesion glycoproteins $(<1 \%)$ and elastin $(<1 \%)$ [21]. These proportions may vary depending on age or degenerative status. For instance, with increasing degeneration the water content can increase up to $85 \%$ [21] and the cellularity of the meniscus decreases [22]. The blood supply of the meniscus is also age dependent: the meniscus of an infant is fully vascularized, while an adult meniscus is only partly vascularized, i.e. the outer part. An adult meniscus can be divided into three zones: the outer (red-red), middle (red-white) and inner (white-white) zone, see Figure 1, [23-25]. The outer two-thirds of the meniscus (red-red and the red-white zone) are vascularized, the cells are fibroblast-like and the collagen fibers present there are mainly type I. The inner one-third of the meniscus (white-white zone) is avascular, contains both collagen type I and II and the cells in this region are more (fibro)chondrocyte-like [26, 27]. Moreover, the inner two thirds of the meniscus contain more GAGs, whose main function is to enable 12 
the meniscus to take up water in order to improve their visco elastic behaviour and counter compressive loads on the tissue [23]. Due to differences in the structure of the meniscus, particularly related to the vascularization and differences in cell phenotype, tears that occur in the outer red-red part of the meniscus have the ability for self-repair. Tears in the middle part are less likely to heal spontaneously, while tears in the inner white-white part are unable to repair themselves [28, 29].

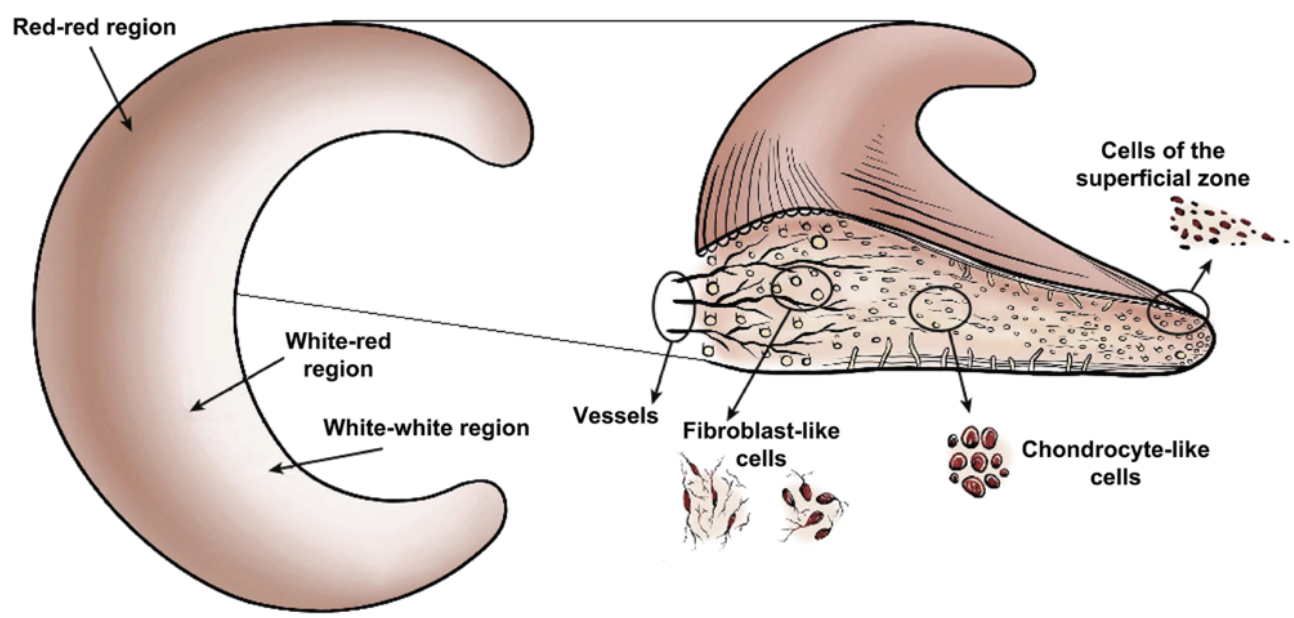

Figure 1. Regional variations in vascularization and cell populations of the meniscus, showing on the left the red-red, white-red and white-white regions, and on the right the differences in cell populations and the location of the blood vessels. Reprinted from [23].

\section{Biomechanics of the meniscus}

The two menisci cover an area of approximately $2 / 3$ of the tibial plateau [30]. They stabilize the knee, provide congruity and lubrication of the articular cartilage, and constitute a large contact area between tibial plateau and femoral condyle. The main attachment sites of the medial and lateral menisci in the joint are the menisco-tibial ligamental attachments [31]. Additional ligaments are the transverse ligament and the posterior and anterior meniscus-femoral ligaments (Wrisberg and Humphry) [31]. The medial meniscus is more firmly attached to the joint capsule than the lateral. The lateral meniscus is also more flexible. Throughout the whole range of flexion and extension of the knee joint menisci play a crucial role in transferring 
loads [32]. They are subjected to tensile, compressive and shear forces and they are displaced radially from the center of femoral condyles due to compressive forces in combination with different flexion angles of the knee [33, 34]. As a result of the compressive loading on the meniscus, the stress is transferred to a vertical force, whose radial component causes a radial displacement of the meniscus. As the meniscus is firmly connected with the tibial plateau through its anterior and posterior attachments, its displacement is constrained by the circumpherentially orientated collagen bundles resulting in a circumpherentially directed component of force and tensile stress (see Figure 2a), [34]. The collagen fibers in the meniscus structure are organized in a manner that optimally resists these tensile stresses [35]. The surface layer of the meniscus contains sheets of radially oriented collagen fibres, to cope with shear forces, while the deep zone has circumpherentially organized collagen fibres, to withstand the circumpherential forces (see Figure $2 b$ ).

a)

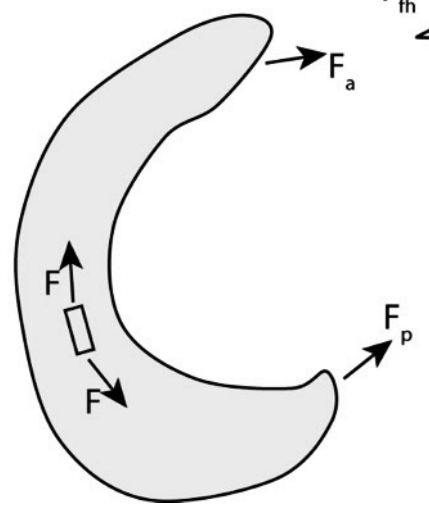

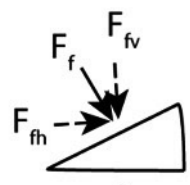
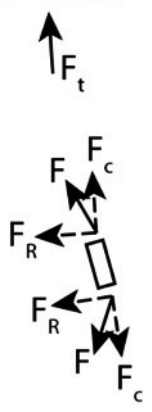

b)

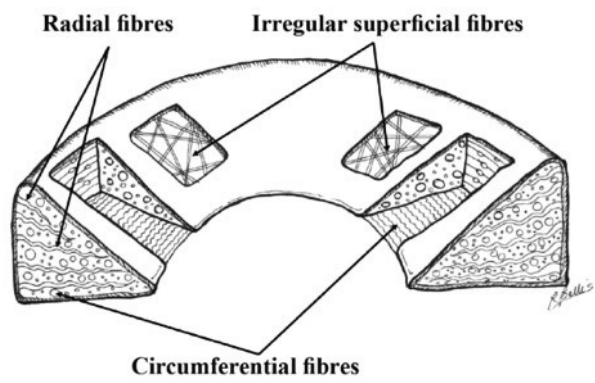

Figure 2. a) A schematic representation of the forces acting on the meniscus. $F_{f}$ is a joint load on top of the meniscus, $F_{t}$ is the reaction force at tibial plateau, radially oriented force $F_{f h}$ and vertically oriented $F_{f v}$ are balanced by forces generated by anterior and posterior horns $F_{a}$ and $F_{p} . A$ combination of these forces results in tensile hoop stress $F$ and axial and radial components of stress in the meniscus ( $F_{r}$ and $F_{c}$ ) while loading, [34], b) Schematic representation of collagen fibers alignment in meniscal tissue, reprinted from [36]. 
Biomechanical properties of meniscal tissue (see Figure 3) have been extensively described in literature. Fithian et al. reported that the tensile modulus measured in circumferential direction was in the range 100-300 $\mathrm{MPa}$ and in radial direction between 10-30 MPa. The shear modulus of the meniscus was measured to be approximately $120 \mathrm{kPa}$ [35]. Lechner et al. and Tissakht et al. reported a tensile modulus in circumferential direction ranging from 40 up to $140 \mathrm{MPa}[37,38]$.

Anterior:

Circumpherential: Radial:

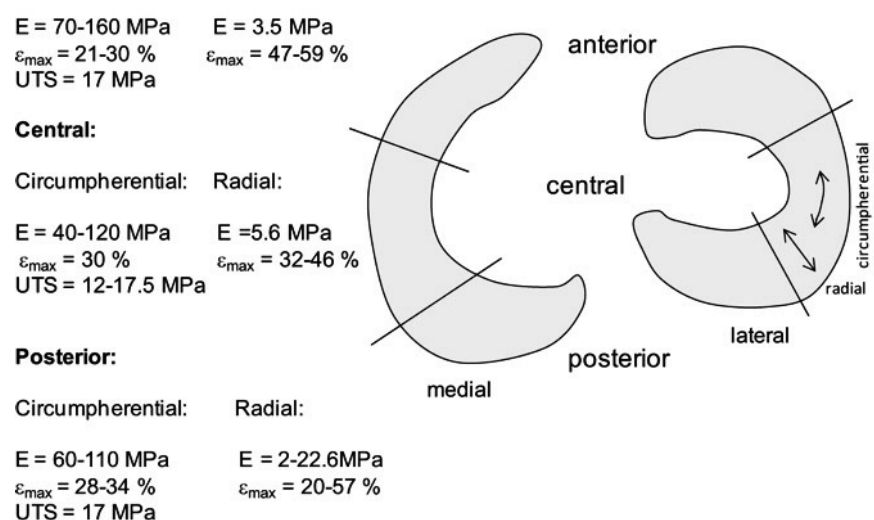

Anterior:

Circumpherential: Radial:

$\mathrm{E}=90-125 \mathrm{MPa} \quad \mathrm{E}=4-13 \mathrm{MPa}$

$\varepsilon_{\max }=17-30 \% \quad \varepsilon_{\max }=41-61 \%$

UTS $=16-18 \mathrm{MPa}$

Central:

Circumpherential: Radial:

$E=70-150 \mathrm{MPa} \quad E=10-14 \mathrm{MPa}$ $\varepsilon_{\max }=19-25 \% \quad \varepsilon_{\max }=46-58 \%$ UTS $=12.5-18.5 \mathrm{MPa}$

Posterior:

Circumpherential: Radial:

$E=100-140 \mathrm{MPa} \quad \mathrm{E}=4-21 \mathrm{MPa}$

$\varepsilon_{\max }=19-25 \%$ UTS $=17-19 \mathrm{MPa}$ $\varepsilon_{\max }=4-21 \%$

Figure 3. Overview of the tensile properties of anterior, central and posterior part of the human medial and lateral meniscus, based on [35, 37, 38]. View on the right knee. E-Elastic modulus, $\varepsilon_{\max }$ - elongation at maximum applied force, UTS ultimate tensile strength (only in circumferential direction).

\section{Meniscal tears and their healing potential}

There are two main causes of meniscus tears: trauma (e.g. sports injuries) mostly occurring in young and active patients, and degeneration, which are mainly associated with early stages of osteoarthritis and are more frequently observed in elderly patients [39]. An overview of the classification of meniscal tears is shown in Figure 4. Longitudinal tears, such as commonly occurring bucket-handle lesions, are classified as traumatic, whereas flap, horizontal and tears in menisci with deteriorating changes are classified as degenerative. Radial tears may be classified both as traumatic and degenerative [39]. Unfortunately, the tears are usually located 
in the highly loaded, avascular, inner region of the meniscus and do not heal spontaneously. Moreover, it has been reported that there are significantly better results after treating traumatic than degenerative lesions [10]. This is mainly due to the fact that degenerative tears are often associated with early stages of osteoarthritis and disturbed homeostasis of the knee joint, thus in this condition it is more difficult to successfully repair them [40]. The orientation of the tear also influences its ability to heal. Tears that disrupt the circumpherentially oriented collagen fibers may be more difficult to heal or do not heal at all since they interfere with the circumpherential mechanical properties of the meniscus tissue [41-43]. Thus, longitudinal tears are relatively the easiest to heal and the native mechanical function will be restored after healing [29, 44-46]. Therefore, as traumatic lesions are usually oriented in the circumpherential direction, only in these cases in young patients, restoration of the native tissue is the preferred treatment. Elderly patients with degenerative changes are offered alternative treatment methods, such as partial meniscectomy [29], allograft transplantation or implantation of a permanent implant, however these methods are not covered by this review, and are widely described elsewhere [47].

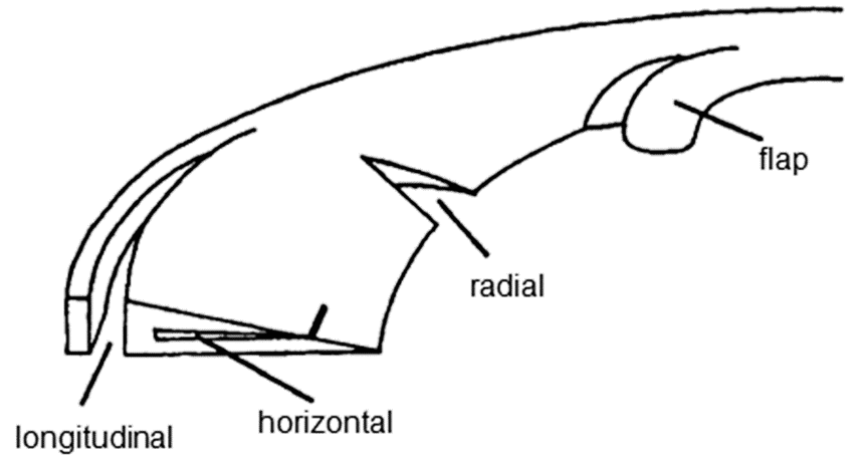

Figure 4. Classification of meniscal tears. Reprinted from [39].

\section{Current clinical treatment methods of meniscal tears}

There are numerous techniques used in clinical practice to restore the integrity and function of torn menisci, most used are sutures, staples, stingers and screws [48]. 
These devices are employed to keep the torn meniscus together enabling tissue healing. Among these techniques, suturing is superior, since it provides optimal mechanical stability and has the highest strength at failure $[8,11,48,49]$. Different suturing techniques are used: all-inside, outside-in, inside-out, in order to provide the most suitable treatment for particular tears [50]. The use of vertical sutures provides the best results and is therefore the current gold standard [51]. An alternative to sutures, which are usually difficult to apply during minimally invasive surgery as the procedure is time-consuming and may induce scarring and cause problems with healing, might be using Meniscus Arrows ${ }^{\circledR}$ or Smart Nails ${ }^{\circledR}$, which are easier to apply [52]. However, they carry the risk of chondral abrasion, due to the fact that a part of these devices remain exposed at the surface of the meniscus and harm articular cartilage [53]. In addition, these implants might fail, and as they are usually prepared from non-degradable materials, articular cartilage might be damaged due to the long-term presence of material debris in the knee joint.

In clinical practice, procedures aimed at increasing the rate of healing in the avascular zone are also proposed. Rasping the tissue to expose collagen fibers and induce vascularization, trephination and creation of access channels to facilitate new tissue ingrowth have been employed [54-58]. However, the success rate is found to mainly depend on the type and location of the tear.

\section{Advances in research of meniscal tears repair}

Recent advances in meniscus research suggest that the low cellularity, dense ECM and poor vascularity together with the inflammatory condition of the knee joint in general might also be responsible for the lack of healing potential. Reprogramming of the wound environment is one of the potential targets to increase the healing potenital of the meniscus, but this requires extra steps in treating the tissue adjacent the tear [59]. Amongst the procedures which were proposed are the delivery of therapeutics by biomaterial-based technologies and the partial digestion of the matrix in the torn region by collagenase which might enable the migration of cells to the wound margin and stimulate healing $[60,61]$. On the other hand an approach in which the level of proteolytic enzymes is controlled may also improve meniscus capacity to repair, as the present inflammation is associated with increased synovial inflammation and increased level of the proteolytic enzymes, expecially 
metalloproteinases (MMP) [62, 63]. In an in vitro repair and animal models it has been shown that by introducing inflammatory cytokines, such as interleukin-1, the integration of the meniscus can be reduced, while inhibiting MMPs and catabolic cytokines can restore its integration capability [64-66]. Another approach which was already proven to have a beneficial influence on meniscal repair is the injection of progenitor cells into the joint, a procedure which enhances tissue regeneration. Also growth factors, especially TGF- $\beta$, have been shown to increase proteoglycans synthesis by fibrochondrocytes from different zones of the meniscus in an in vitro cultures [67-69]. Further development of these techniques to clinical use could improve the healing capacity of the meniscus, potentially making the whole healing process shorter and more efficient.

In the light of the complexity of the biological modifications developed to improve the meniscus repair capacity, there might also be a great potential in the use of tissue adhesives. They could serve as an alternative or support for sutures, and would keep the wound edges of the tear close to each other. The use of slowly resorbable tissue adhesives would have numerous advantages, such as easy and fast application, no need of removal after the tissue is healed, and at the same time they could act as a carrier to deliver cells, growth factors, enzymes and other biological factors to the meniscus. Thus, they could be used in combination with the treatment modalities described in the previous section. There already have been attempts in the clinic to use fibrin gels in meniscus repair treatments, either as a glue or as a support to suturing $[50,51,70-73]$. More details of these procedures are given later. However, until now they have not been adopted in clinical practice. It remains a challenge to develop a tissue adhesive which has all the required properties for adequate meniscal tear repair. In this review we focus on a discussion on the desired properties of glues for meniscal tear repair and how current developments in the field comply with them.

\section{Requirements of tissue adhesives for use in meniscal repair}

Tissue adhesives are defined as materials capable to attach and remain on surfaces of biological substrates with ability to interact with biological factors [74]. Any tissue adhesive, regardless its intended application, should fulfil a large number of requirements to be suitable for biomedical use [75]. Most importantly, good 
attachment to (wet) tissue surfaces is a prerequisite. The material must be noncytotoxic and not induce any adverse tissue reaction. An adhesive should initially be in a liquid state with an adequate viscosity to be able to apply it only locally on the tissue in adequate amounts. There should be no need for elaborate application techniques or devices, and the adhesive should preferably be injectable. It should wet and spread over the entire surface of the tissue to be glued, resulting in effective and close contact between adhesive molecules and the surface of the tissue. Thereafter, it should solidify shortly after its application [76]. The adhesive should achieve a stable union between the tissue surfaces until proper healing has occurred. To allow this, it must withstand forces present on the site of application. Finally, it should degrade and potentially be resorbed by the body so that the two edges of the wound can reunite to accomplish complete wound healing. Biodegradation products of the cured tissue adhesives must be not cytotoxic and must have sizes allowing their clearance by the kidney (maximally $50 \mathrm{kDa}$ [77]). Moreover, the tissue adhesive should be shelf-stable and preferably coloured for easy visualization [75]. Abovementioned requirements are critical for every tissue adhesive material, regardless of the site of application. For materials intended for specific purposes, additional criteria should be formulated [78].

To formulate specific design criteria for tissue adhesives for meniscus tear repair, the particularity of the tissue in terms of its structure, vascularisation, healing potential and its performance in loaded conditions must be considered. The adhesive has to spread well on the wet surfaces of the meniscus in a synovial environment. Subsequently, it should cure forming a solid network strong enough to withstand the forces present in the knee joint. Therefore, it should be sufficiently hydrophilic to facilitate spreading on the tissue. Secondly, in order to obtain a strong network after curing, the adhesive should preferably contain hydrophobic components as well. These components will contribute to good mechanical properties of the network after curing. The tensile modulus of the cured network should be in the same range as that of meniscus tissue in the circumferential direction, as the majority of injuries fitting criteria for repair occur in the circumferential direction [79]. This means that it should be in the range of values between 40 and $150 \mathrm{MPa}$ (see Figure 3). The ultimate tensile strength (UTS) of the adhesive should be either higher or comparable 
to that of meniscus tissue, which is approximately between 12 and $19 \mathrm{MPa}$ in circumferential direction (see Figure 3).

When designing the degradation profile of the adhesive, the healing rate of the meniscus must be taken into account. In general, patients are advised to use crutches for 8-10 weeks post-surgery after repair of a meniscal tear using sutures to avoid overloading the meniscus tissue during its healing process [29]. At the same time it has been reported that visual evidence of healing of a meniscus requires a 4 month time interval [80]. Therefore, it would be beneficial if the tissue adhesive remains functional at the site of application for at least 4 months before it starts to degrade without rapid loss of its mechanical properties. Finally, the adhesive strength of the adhesive material should be sufficient to keep the torn meniscus together during this period of healing. However, it is hard to determine what exactly should be the adhesive strength due to variability of lesions, intended technique to be used and specificity of each patient's case. If referred to the mechanical strength of the currently used devices for meniscus repair (sutures, stingers, screws), those depend not only on the device itself but also on the fixation method.

Rimmer et al. compared the failure strengths of 3 arthroscopic meniscal suturing methods [81]. Depending on the technique used (a single horizontal loop, a double vertical loop, and a single vertical loop), the failure strength was between $29.3 \mathrm{~N}$ and $67.3 \mathrm{~N}$. Barber et al. compared the performance of sutures with other surgical devices [15]. The load to failure was measured of e.g. double vertical stitch $(113 \mathrm{~N})$, single vertical stitch $(80 \mathrm{~N})$, BioStinger $(57 \mathrm{~N})$, a horizontal mattress stitch $(56 \mathrm{~N})$, a meniscus arrow $(33 \mathrm{~N})$ and the Biomet staple $(27 \mathrm{~N})$. It is evident that the variation in mechanical failure strength is broad, and the use of a particular method strongly depends on the individual case, type of lesion and the number of sutures used. Moreover, it is impossible to directly relate tensile strength of sutures with the required adhesive strength of the tissue glue. In studies analysing forces on sutured menisci (both lateral and medial) in human cadaver knee models, it was reported that the distraction forces did not exceed $5 \mathrm{~N}$ on average when the applied load was $300 \mathrm{~N}$ [82, 83]. In another study, where the distraction forces were assessed indirectly on bucket-handle lesion, the occurring forces were determined to be less than $10 \mathrm{~N}$ [84]. These forces would correlate to a stress of $50-100 \mathrm{kPa}$ for a tear 
measuring $1 \mathrm{~cm}^{2}$, and in the non-weight bearing recovery period these forces would probably be even lower. Therefore, tissue adhesives should be designed to resist physiological stresses and by that stabilize the meniscus and prevent gap formation [85]. An adhesive material able to hold a torn meniscus together under a stress of 50-100 kPa should therefore be already sufficient for this application.

Another important aspect that should be taken into consideration in the design of a tissue adhesive for meniscus repair is the incorporation of cells or growth factors. These could enhance healing of the meniscus, especially in the inner a-vascular and a-cellular zone. The tissue adhesive can serve as a carrier for the molecules, which can be released on the site of application e.g. via diffusion process or, if the factors are bound to the glue, they could be released during degradation of the adhesive. The beneficial influence of incorporating both cells [86] and other biological compounds, such as bone marrow or platelet rich plasma (PRP) [85, 87], on meniscus healing have been already reported in literature.

A summary of the most important requirements of tissue adhesives to be used in the repair of meniscus tears is depicted in the Table 1 . 
Table 1. Summary of the key requirements of tissue adhesives for meniscus repair.

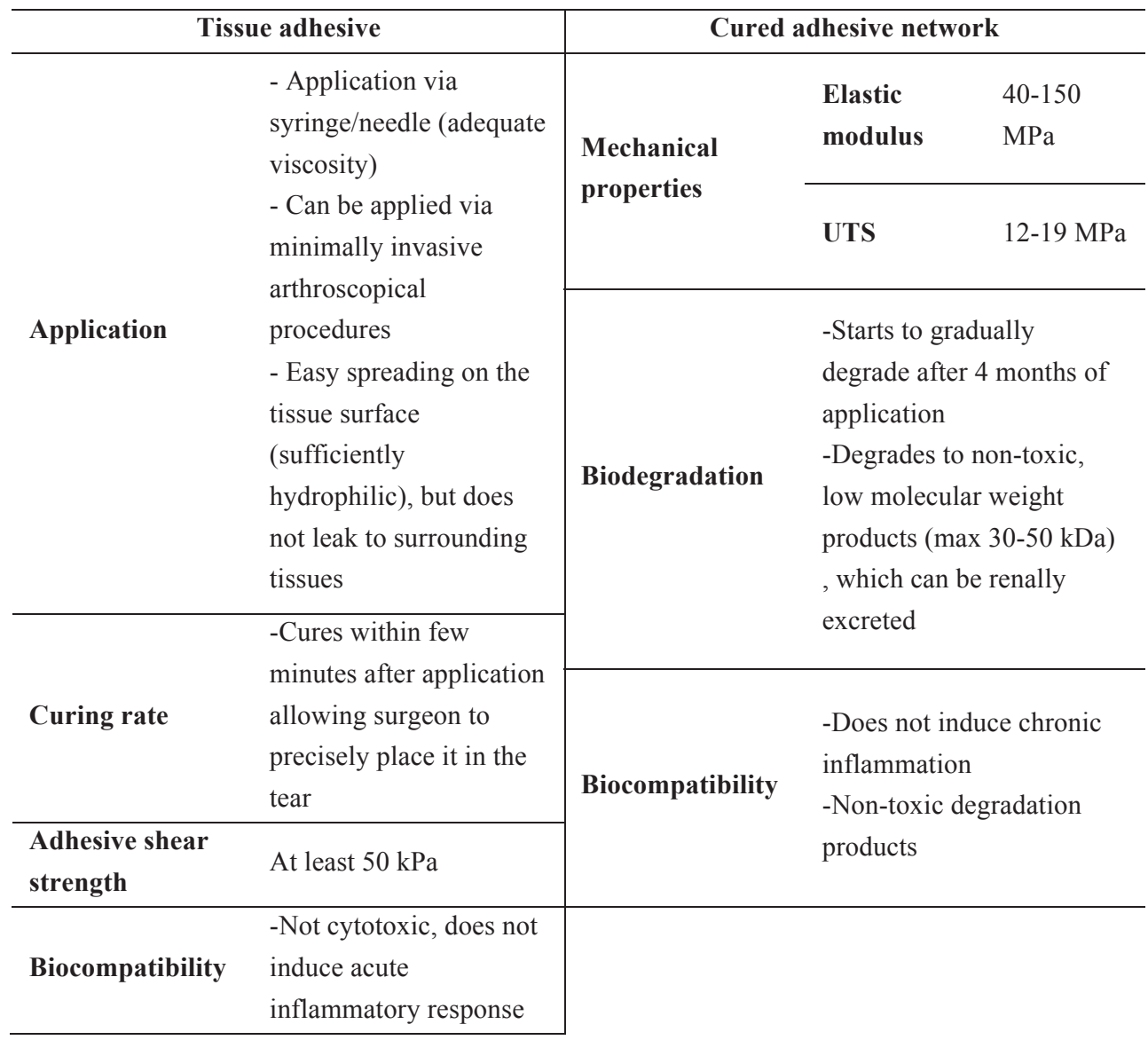

\section{Current developments in the field of tissue adhesives}

Recently, there has been much interest in the research field of tissue adhesives. Besides a few products which are already approved for clinical use (e.g. Dermabond $^{\circledR}$, Fibrin glue, TissuGlu ${ }^{\circledR}$ ), most research is directed towards the development of new adhesive biomaterials and improvement of the properties of existing ones.

In general, the biomaterials used for the synthesis of glues might be composed of natural, synthetic or combination of both types of polymeric materials [88]. Synthetic biomaterials are usually cheap and their ground substances are widely 
available, the mechanical and physico-chemical properties might be easy to control, but they can be toxic and may have a sub- optimal biocompatibility. Natural materials, on the other hand, offer better biological properties such as biocompatibility and good cell adhesion, but the production is more difficult to standardize due to variability of the ground substances, they are expensive and carry a risk of disease transmission [89]. In terms of mechanisms of curing and adhesion to the tissue, the materials can be divided into several subcategories. Since numerous reviews were published recently on the chemistry and mechanisms of tissue adhesion [90-92], here only a brief description of the basic mechanisms and examples from literature are outlined.

\section{Natural protein-based tissue adhesives}

\section{Fibrin adhesives}

The most widely used natural tissue adhesive is fibrin glue (commercially available Raplixa, Artiss, Evarrest, Tisseel). It is a mixture of fibrinogen and thrombin and its curing mechanism mimics the final stages of blood coagulation [78], (Figure 5a). Fibrin binds to the tissue by three modes: covalent bonding, hydrogen- and electrostatic bonds and mechanical interlocking [93]. Other similarly working adhesives are FloSeal and Proceed (a combination of bovine thrombin and bovine collagen that form the matrix for the clot) and CoStasis, which is a combination of autologous human plasma obtained from patients' blood and a mixture of bovine collagen and thrombin. The use of fibrin gels in meniscal tear repair has been already described in literature. Ishimura et al. reported results of a study where meniscal tears of 40 patients using a purified fibrin glue were repaired [70]. Within the follow up period of up to 11.4 years post intervention, the rate of recurrence of tears in the red-red zone or red-white zone was below $10 \%$, whereas that of tears in the whitewhite zone was $17 \%$. In another study, Henning et al. repaired a series of meniscal tears using an exogenous fibrin clot [48]. It was reported that in $64 \%$ of cases meniscus was healed. Van Trommel et al. reported on outside-in repair of a radial tear of the lateral meniscus using an exogenous fibrin clot in 5 patients. All 5 menisci were found to have healed on follow-up arthroscopy [73]. In a more recent study, $\mathrm{Ra}$ et al. described the use of a fibrin clot together with 2 sutures in the repair of 
radial meniscal tears in 12 patients [51]. Follow-up MRI performed after $11 \pm 3$ months postoperatively, revealed complete healing in 11 patients (and incomplete healing in 1 patient). Also recently, Kamimura et al. reported the use of fibrin glue together with sutures in the treatment of degenerative horizontal tears in 18 patients [94]. The follow-up results of 10 patients showed that complete healing was achieved in $70 \%$ of cases. Nevertheless, despite successful repair results of meniscal tears reported in literature, the use of fibrin has not been widely adopted in clinical practice.

\section{Gelatine adhesives}

Gel-forming mechanisms similar to blood coagulation have been further investigated. Liu et al. [95] proposed that gelatine (as a structural protein) and calcium independent transglutaminase (mTG) (as a cross-linking enzyme) can be used (Figure 5b). They reported that gelatine-mTG adhesives gelate in situ within few minutes $(<5)$, adhere to tissue in the presence of blood via covelent bonds (Figure 5c) and provide sufficient strength to be used as a surgical sealant. Also Chen et al. investigated the use of gelatine-mTG adhesives [96]. The materials did not induce structural damage of the retina after injection into the vitreous cavity in rats and their adhesive strength to bovine retinal tissue in vitro was between 15-45 $\mathrm{kPa}$. Moreover, peptide-conjugated polymer hydrogels formed by tissue transglutaminase cross-linking were evaluated as an adhesive on guinea pig skin and collagen membrane [97]. The results show that the adhesive strength to the tissue was comparable to that of fibrin glue.

Other adhesives of this class are gelatine-resorcinol-formaldehyde (GRF) and gelatine-resorcinol-formaldehyde-glutaraldehyde (GRFG) glues. The gelatine is cross-linked by aldehyde via reaction with its amine groups. At the same time, aldehyde groups form covalent bonds with amines from the tissue. These materials have been utilized in aortic dissections, liver surgeries, gastrointestinal and urinary track operations [88]. However, safety issues have arisen regarding their toxic degradation product - formaldehyde. 


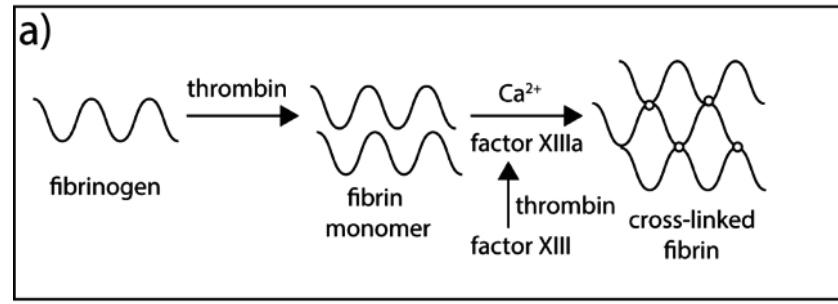

b) glutamine lysine
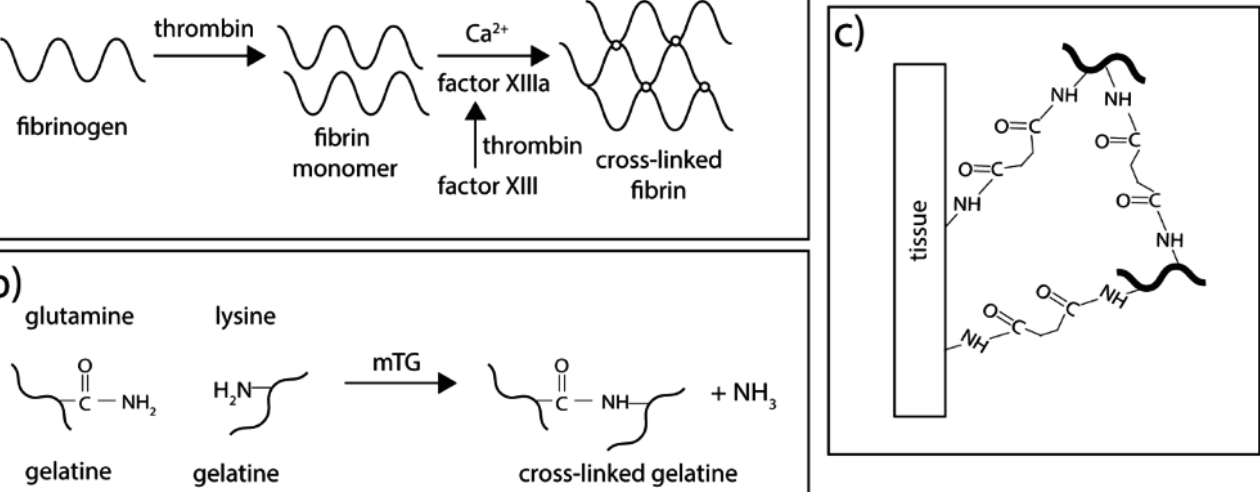

Figure 5. a) Schematic for fibrin glue cross-linking mechanism [95], b) Crosslinking mechanism of gelatine with Calcium-independent microbial transglutaminase (mTG) [95], c) Adhesion mechanism of transglutaminase-crosslinked gelatine to the tissue [98].

\section{Albumin adhesives}

In addition, albumin has been investigated as a structural protein for tissue adhesive compositions. Currently BioGlue, one such adhesive that comprises bovine serum albumin (45\%) and glutaraldehyde (10\%) (Figure 6), is approved by the FDA for the repair of aortic dissections [99]. It closes the cavity of the aorta and provides a stronger arterial wall for its repair, it binds within 30 seconds and reaches its maximum bonding strength after 3 minutes [100].

Although natural protein-based cross-linked adhesives have excellent biocompatibility, their bonding strength to the tissue is relatively low, usually in the range of 10-40 $\mathrm{kPa}$. After curing they form networks with the relatively low mechanical properties of soft hydrogels, which limit their application in load bearing sites in the body. Moreover, they are rapidly degraded by enzymes from the body. Normally they degrade within 2 weeks [101], which is too fast for meniscus repair. These glues are however applicable for pulmonary leaks, for haemostasis in vascular surgery and for treatment of cerebrospinal leaks. 


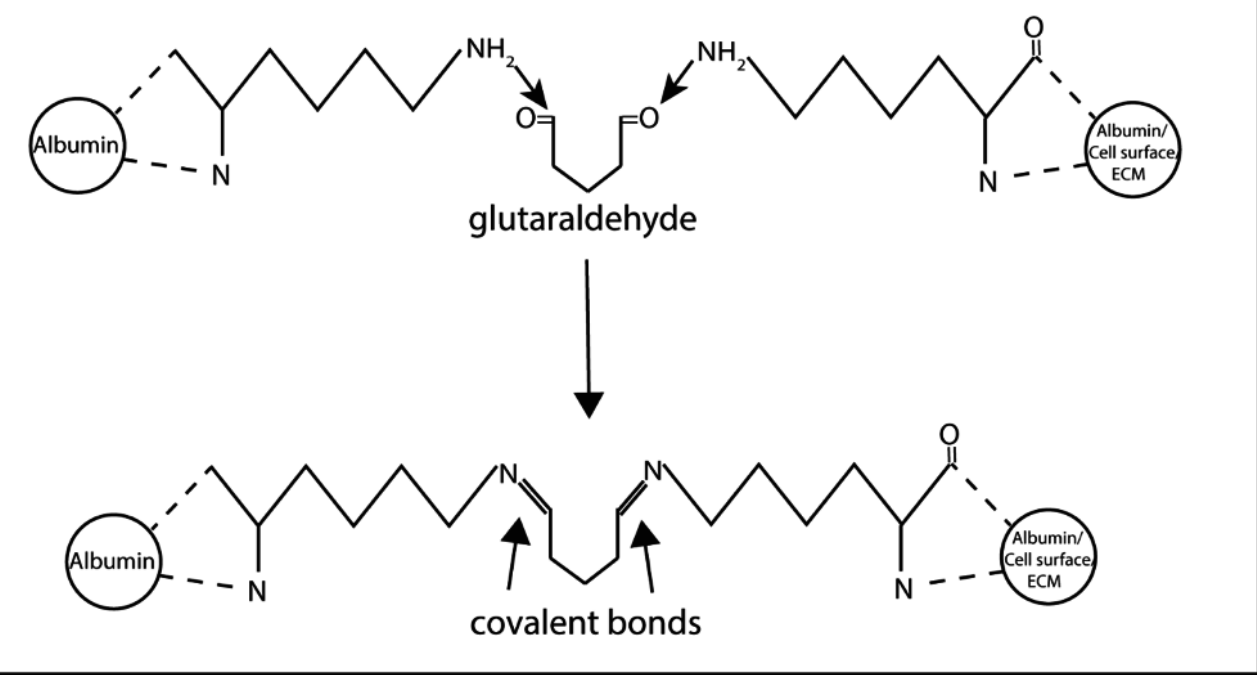

Figure 6. Cross-linking of a commercially available albumin-based adhesive $\left(\right.$ BioGlue $\left.^{\circledR}\right)$.

\section{Nature-inspired (biomimetic) tissue adhesives}

Nature-inspired adhesives, for instance based on glues secreted by marine sessile organisms (mussels, barnacles, tube worms), perform very well in hydrated conditions. The working mechanism is depicted in Figure 7. Mussels enzymatically oxidize the phenolic residues of their adhesive proteins. Then, the oxidized residue undergoes a crosslinking reaction that results in the formation of a 3-dimensional polymeric network. The attachment to the tissue takes place by bonding to amine and thiol groups present on the tissue surface [75]. Due to their high adhesion strength and ability to adhere to wet surfaces, these glues have been proposed for use in biomedical applications. These properties are mainly due to the presence of a redox functional group: 3,4-dihydroxyphenyl-L-alanine (DOPA). The key element of DOPA is ortho-dihydroxylphenyl (catechol), which exhibits strong affinity towards organic surfaces [102]. Therefore, development of biomimetic adhesives have received much attention these last years and artificial materials that mimic natural forms, such as co-polypeptides containing DOPA [103], poly (ethylene glycol) hydrogels and Pluronics functionalized with DOPA, have been synthesized [104, 105]. 


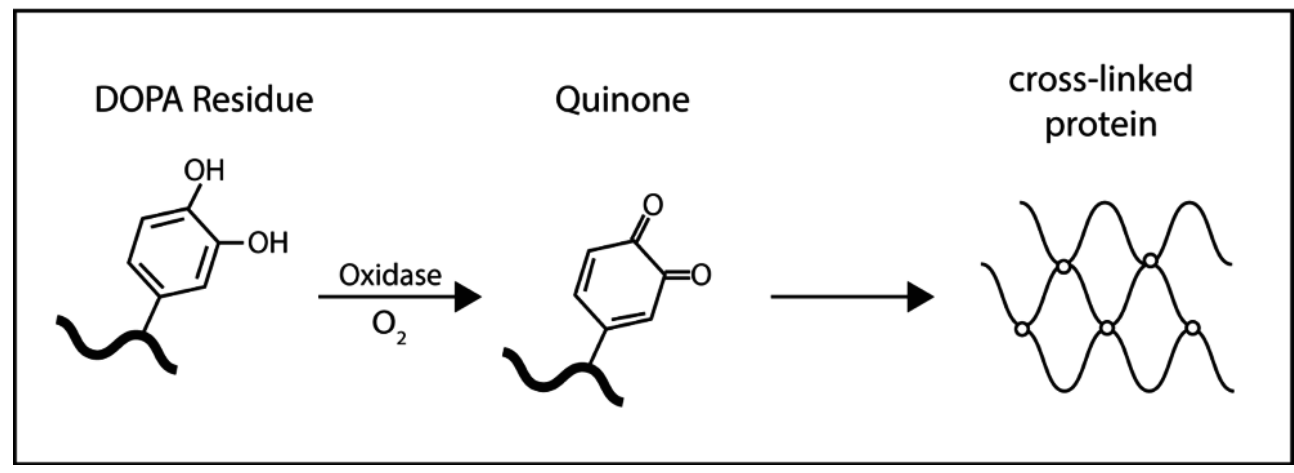

Figure 7. Working principle of a mussel adhesive. [106].

Another similar mechanism is present in red and brown algae, which also, like mussels, excrete phenolic compounds that can bind to both hydrophobic and hydrophilic surfaces in aqueous conditions. The produced polyphenols are activated by a vanadate-peroxidase type of enzyme that allows the cross-linking of the polyphenol with the extracellular carbohydrate fibers, which will finally lead to adhesion to a surface [107]. Natural algal-borne polyphenol can be successfully replaced by phloroglucinol. Formulations composed of phloroglucinol, alginate and calcium ions are capable of adhering to a variety of surfaces including porcine tissue [108].

One of the strategies to induce a better and stronger interaction with a surface is the increase of the contact area. Geckos have used this in an interesting adhesive strategy that relies on foot pads composed of keratinous foot-hairs that are split into terminal spatula of a size of $200 \mathrm{~nm}$ [109]. The adhesion mechanism is based on capillary forces and van der Waals interactions. Inspired by this natural phenomena, Geim et $a l$. developed an adhesive composed of dense arrays of flexible pillars to ensure their collective adhesion. However, problems related to their durability were encountered [110]. To resolve these problems Lee et al. developed an adhesive inspired by mussels and geckos, which combine excellent properties of both mechanisms, and can bind to the surfaces both in dry and wet environment in multiple cycles. The adhesive force in a wet environment was calculated to be equivalent to $90 \mathrm{kPa}$ [111]. Szomor and Murrel tested a naturally-sourced glue secreted by Australian frogs (genus Notaden) on sheep meniscus tissue and reported that the adhesive strength of 
this glue $(\sim 90 \mathrm{~N})$ is superior both to fibrin glue (5 times stronger) and gelatine (2.5 times stronger) [112].

Based on recent literature, it can be concluded that biomimetic tissue adhesives have the potential to be used in numerous applications. In general, the adhesive strength of this class of materials is reported to be $20-90 \mathrm{kPa}[105,111,113]$. The cytocompatibility is dependent on the amount of material added to cells, but in vivo tests showed no adverse tissue reactions [105]. However, there is almost no information about degradation profiles of the reported adhesives and of the mechanical properties of the cured networks. Therefore, it cannot be indisputably concluded that these materials could be suitable for treating meniscal tears.

\section{Synthetic and hybrid tissue adhesives}

Another group of adhesives are polymers, natural, synthetic or combination of both, whose end-groups have been modified in a way that allows simultaneous curing and attachment to the tissue. Examples of this class are cyanoacrylates, materials containing N-hydroxysuccinimide (NHS)- or isocyanate-terminated polymers, as well as polymers that can be photo cross-linked or those forming networks due to physical interactions e.g. due to thermal gelation.

\section{Cyanoacrylate adhesives}

Cyanoacrylate adhesives are very attractive materials for tissue fixation due to their high bonding strength and ability to bond in a wet environment. The cyanoacrylates monomers polymerize through contact with water (hydroxide ions) or a weak base, such as cell membranes and tissue [114], (see Figure 8). They are applied to the wound site as cyanoacrylate monomer that undergoes immediate polymerization to form a polymer film, [115]. However, cyanoacrylates still have some serious drawbacks for biomedical application. They degrade reactively in aqueous media with toxic formaldehyde as their degradation product $[116,117]$. They are brittle and rigid with the values of elastic modulus in the range of 500-1500 $\mathrm{MPa}$ [118]. Additionally, cytotoxic effects may occur due to oxidative conversion of membranous lipids [119]. Nevertheless, clinical use of cyanoacrylate adhesives has 
been reported as a good replacement for sutures, because of its better cosmetic effect, reduced pain and recovery period [120].

Commercially available Dermabond ${ }^{\circledR}$ and Histoacryl ${ }^{\circledR}$ are widely used as topical skin adhesives, but they are not bio-absorbable and therefore in clinical practice they are used only for skin wounds [99]. Still, the use of Histoacryl ${ }^{\circledR}$ has been compared with sutures in delaying the formation of a $2 \mathrm{~mm}$ meniscal gap [121]. The bovine menisci were placed in a tensile loading machine and the force needed for gap formation was measured. The tear was repaired with either vertical sutures, Histoacryl ${ }^{\circledR}$ or both. It was found that Histoacryl ${ }^{\circledR}$ gluing is superior to vertical sutures regarding gap delaying. However, the best results were obtained when glue and sutures were used together. Reckers et al. reported an in vivo study of cyanoacrylate surgical adhesives used for the fixation of transplanted menisci in rabbits [122]. It was concluded that the glue induced necrosis from the cortex to the bone marrow of transplanted bone surface. In order to improve the biocompatibility and mechanical properties of cyanoacrylates, Lim et al. mixed cyanoacrylate with poly-L-DOPA [123] in order to improve the physiochemical properties of cyanoacrylate for use as tissue glue. Lim and Kim also proposed to mix the cyanoacrylate component with poly(L-lactide-co-caprolactone) to obtain a biodegradable elastomer [124]. They reported that, although the adhesive strength was decreased compared to a pure cyanoacrylate compound, the biocompatibility and flexibility were improved. This indicates that these materials are more suitable for specific biomedical applications.

In conclusion, of all known adhesives, cyanoacrylates are the class of adhesives that form the strongest bond with tissue. Their adhesive strength values, depending on the tissue type and type of test performed, are reported to be in the range of up to a few MPa (30kPa adhesive strength to skin up to $2 \mathrm{MPa}$ to bone) $[87,125,126]$. So far, their toxicity limits their application within the body and they have been FDAapproved only for topical skin wound closure. Moreover, their high stiffness (high E modulus), limits their application in soft tissues, such as meniscus. 


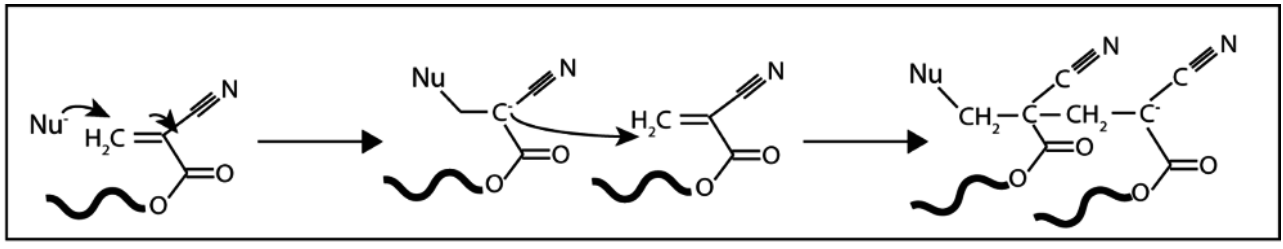

Figure 8. Schematic illustrating the polymerization principle of cyanoacrylates.

\section{Chemically cross-linkable adhesives}

In the first class of these materials, the presence of $\mathrm{N}$-hydroxysuccinimide activates carboxylic groups and allows them to react with amine groups present on the surface of the tissues to form amide bonds. In contrast, an unactivated carboxylic acid group would just lead to salt formation with an amine. Strehin et al. characterized chondroitin sulphate-PEG adhesive hydrogels (CS-PEG), which covalently adhere to tissue through an amide bond. CS-NHS was mixed with PEG- $\left(\mathrm{NH}_{2}\right)_{6}$ to tune hydrophilicity and the molecules react to form a hydrogel, but at the same time, CSNHS also reacts with tissue [127], see Figure 9a. Simson et al. described an adhesive hydrogel composed of a mixture of bone marrow aspirate and chondroitin sulphate end-functionalized with NHS to bind and stabilize the interface of bovine meniscus tissue [85]. The results showed that the adhesive strength to meniscus was in the range of $60-335 \mathrm{kPa}$, which should be enough to keep a torn meniscus together. Moreover, the viability and proliferation of fibrochondrocytes was positively influenced by the glue. Therefore, it was concluded that this system could be used to mechanically stabilize a tear and stimulate regeneration of the tissue across the injury site.

Taguchi et al. [128] investigated biodegradable adhesives composed of human serum albumin (HSA) and organic acid-based cross-linkers (trisuccinimidyl citrate, disuccinimidyl tartarate (DST) and disuccinimidyl malate) with activated NHS groups. The best results were obtained using DST. The adhesive strength of these biocompatible and bioresorbable materials was better than that of fibrin glue. The active ester groups present in DST react with the amine groups from HAS and collagen molecules from the tissue. The adhesive composed of DST/HSA was evaluated in the gluing of meniscal tears [129]. Glued and sutured porcine menisci 
were implanted subcutaneously in rabbits, and after 3 months, tensile tests and histology were done. Comparisons were made between tears treated with sutures, tears treated with sutures soaked with adhesive and tears treated with only adhesive. The results showed best performance when the sutures were soaked with adhesive $(\sim 70 \mathrm{~N})$, followed by sutures $(\sim 61 \mathrm{~N})$ and adhesive $(\sim 60 \mathrm{~N})$ only. This indicates the potential of this class of materials in meniscal repair.

Adhesives comprising isocyanate-terminated molecules have a similar bonding mechanism. They form a covalent bond with the tissue and cure to form polyurethane networks upon contact with the surrounding fluids [130], see Figure 9b. Compared with other biomaterials, polyurethanes possess many advantages, such as high tenacity, toughness, water and chemical resistance and mechanical flexibility [131]. Biodegradable polyurethanes are designed to undergo (enzymatic) hydrolytic degradation to non-cytotoxic products [132]. Mostly aliphatic diisocyanates are used in the design of biomaterials intended for biomedical use, since it has been shown that they exhibit lower toxicity comparing to aromatic ones [133].

Hadba et al. described the development of two compositions of branched isocyanatefunctional adhesives based on poly(ethylene glycol) and adipic acid functionalized with 2,4-toluene diisocyanate (TDI) or 4,40-methylene-bis(phenyl isocyanate) (MDI) [134]. The adhesive strength of the formulated materials to porcine stomach tissue depended on the specific formulation, the highest value determined was approximately $100 \mathrm{kPa}\left(1093 \mathrm{gf} / \mathrm{cm}^{2}\right)$.

Rohm et al. and Sternberg et al. [119, 135] reported the use of mixtures of 1,2ethylene glycol bis-(dilactic acid) functionalized with hexamethylene diisocyanate (HDI) with different biodegradable polymers such as hyaluronic acid, gelatin, chitosan acetate and chitosan chloride. The obtained products had promising properties in terms of biodegradability, biocompatibility and adhesive strength (which was similar or better than fibrin glue). The solidification speed could be adjusted by using aqueous solution of chitosan chloride as a second component of the adhesive system. 
Nayeb-Habib et al. developed a isocyanate pre-polymer and chitosan gel based tissue adhesive in order to combine good adhesion of isocyanates and biocompatibility and healing properties of chitosan [136]. Degradation products of this polymer did not induce any toxicity. Field et al. evaluated two isocyanate-based adhesives to repair full thickness meniscal wounds in an ovine model in vivo over a period of 1 month [137]. A $10 \mathrm{~mm}$ defect in the medial meniscus was repaired with these adhesives, and after 1 month signs of repair and tissue regeneration were observed and no adverse inflammatory reaction was present. Nevertheless, despite the progress in the development of less toxic materials with suitable mechanical properties and satisfactory curing times, until today there is only one isocyanate-based tissue adhesive commercially available: TissuGlu ${ }^{\circledR}$ (Cohera Medicals Inc ${ }^{\circledR}$ ). It is FDAapproved for use in abdominoplasty surgery. 

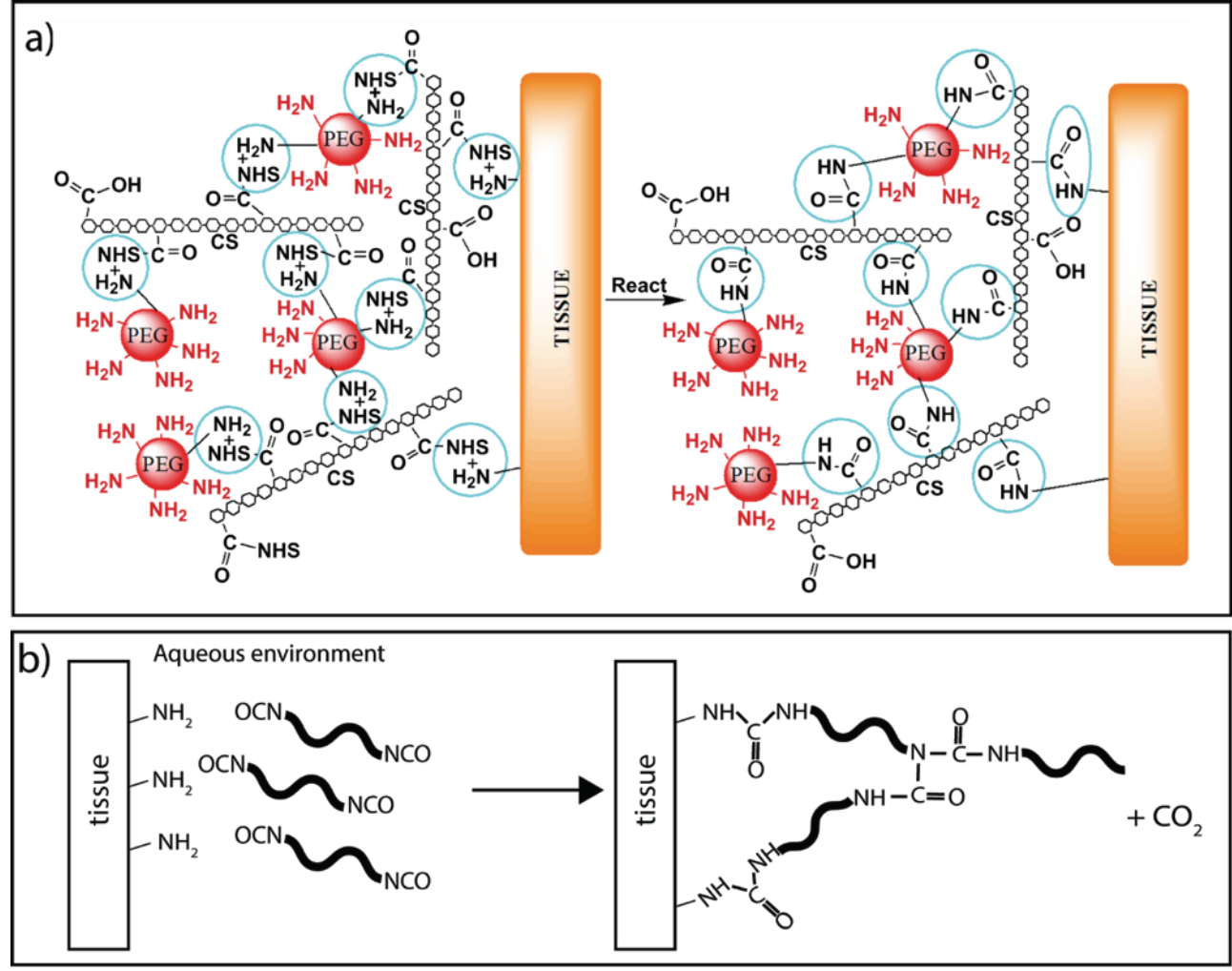

Figure 9. a) Scheme of the adhesion and network formation mechanism of CS-PEG hydrogels. These hydrogels attach via covalent bonding of the NHS-activated carboxyl groups to the amine groups of the tissue (reprinted from [127]). b) Scheme of the attachment of isocyanate-terminated polymer molecules to the surface of the tissue by covalent bonding and the formation of a polymer network by cross-linking.

\section{Photo cross-linkable adhesives}

Another interesting class of tissue adhesives are those that are photo cross-linkable, an example is commercially available FocalSeal. It is a copolymer composed of hydropihilic polyethylene glycol (PEG), and glycolide or lactide, trimethylene carbonate and acrylic acid moieties. These materials are crosslinked by light, which also initiates their adhesion to tissue [138]. The acrylate groups covalently bind to the amine groups of the tissue and form an interpenetrating network upon curing. The material is biodegradable; resorption takes approximately 3 months [99]. The 
application process, however, is complicated because delivery of a source of curing light to the application site can be technically difficult.

In another study Lang et al. developed acrylate-functionalized copolymers based on sebacic acid and glycerol that could be cross-linked with light. [139]. The materials were used in vivo to attach a polymeric patch to the beating heart of rats and pigs. The patch remained in place even under higher than normal heart beat rates.

Ishihara et al. [140] worked on chitosan derivatives that could be crosslinked with UV light. The chitosan hydrogel obtained could stop bleeding from a cut mouse tail and keep two pieces of sliced mouse skin together. Moreover, application of the chitosan hydrogel induced significant wound contraction and accelerated wound closure and healing.

In a recent study by Jeon et al. a light-activated adhesive based on mussel proteins and insect dityrosine crosslinking chemistry is reported [141]. The adhesive could be easily photo-cross-linked using visible light, the adhesion and cross-linking mechanism is depicted in Figure 10. The adhesive strength to porcine skin was around $50 \mathrm{kPa}$, and no adverse tissue response after closing incisions on the back of rats was observed. 


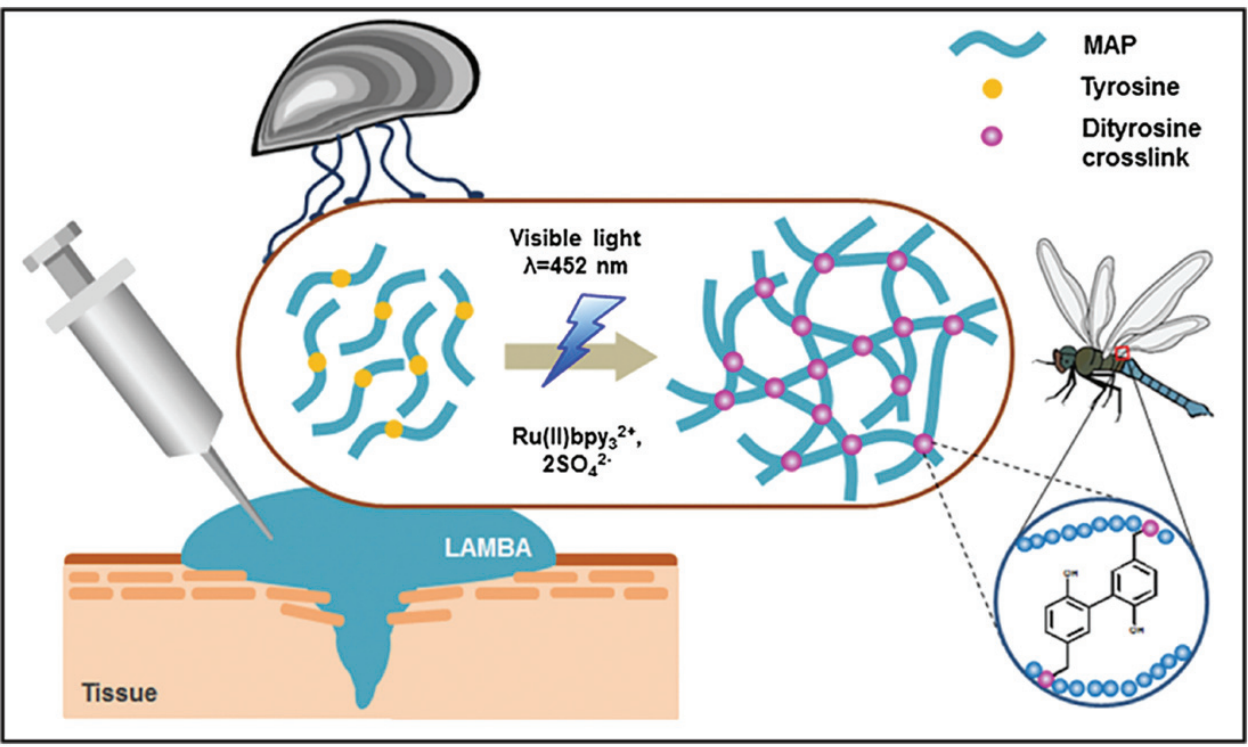

Figure 10. Network formation of a tissue adhesive with visible light using dityrosine groups (reprinted from [141]).

\section{Thermo-responsive adhesives}

A different group of materials are those, which can be cross-linked physically. Lando et al and Cohn et al. developed an interesting approach, in which thermo-responsive biodegradable copolymers based on lactide - $\varepsilon$-caprolactone and three-armed trimethylolpropane-lactide- $\varepsilon$-caprolactone were used as tissue adhesives $[142,143]$. These low molecular weight materials were in a flow state with low viscosity at the temperature of application and could attain high viscosity at the body temperature. The adhesive failure strength to polyamide (6,6-nylon) films, which was used as a model for a tissue, was measured to be up to $2 \mathrm{~N} / \mathrm{cm}$ width of the film.

Although chemically modified tissue adhesives hold great potential for use in a variety of medical applications, further studies are required to develop materials for specific applications such as the treatment of meniscus tears.

\section{Formulation of tissue adhesives with biological factors}

It has been recognized that incorporation of biological molecules, growth factors, platelet rich plasma (PRP), bone marrow (BM) and living cells to the adhesive can 
enhance healing of the tissue [87]. Ishimura et al. reported an experimental study in which they incorporated marrow cells into fibrin gel and compared the healing rate of the torn meniscus with fibrin gel that did not contain cells [86]. The results showed faster and more mature healing of defects in the group, which contained marrow cells. A similar approach was used by Scotti et al.: To improve the bonding between two swine meniscal slices, articular chondrocytes were added to a fibrin glue gel. The bonding capacity was evaluated in a nude mouse model after implantation for 4 weeks [144]. The results showed firm gross bonding in the experimental samples, while no bonding was observed in the control samples that did not contain cells. Although the success of this approach has only been described in a limited number of studies, the very promising results obtained justify the further investigation of cell-containing adhesives for meniscus repair.

\section{How do tissue adhesives compare with the requirements for repair of the damaged meniscus and the current gold standard treatment?}

The most important prerequisites for a tissue adhesive to be suitable for meniscus tear repair include: adequate mechanical properties; suitable degradation profile, sufficient adhesive strength, short curing times and good biocompatibility (see Table 1). Comparing these requirements with the properties of the tissue adhesives described above, it can be concluded that up to now no tissue adhesive material has yet been developed that fully complies with all requirements. However, this not only due to sub-optimal properties of the adhesives, such as insufficient bonding strength in the case of enzymatically cross-linked adhesives or poor biocompatibility in the case of cyanoacrylates. It is also due to lack of the data that is required to be able to conclude if a certain material is suitable for the intended application. Simson et al., for example, described a promising bone marrow-chondroitin sulphate tissue adhesive for meniscus repair, however no information regarding its biodegradability was presented.

Moreover, although lap shear adhesion tests are one of the most often employed methods to assess the adhesive strength of newly developed glues, the conditions under which these tests are conducted are not standardized. There have been many substrates and tissue models used to evaluate the adhesion strength of tissue 
adhesives, e.g. polyamide films [142, 143], gelatin pieces [145-147], collagen membranes [97], and even pig skin and wood [74]. Additionally, very different environments (wet or dry), gluing temperature and the curing times have been used. These large variations make direct comparison of the outcomes of described experiments difficult.

Up to now, there have been only few clinical studies reporting the use of tissue adhesives in the repair of meniscal tears, all studies involved fibrin glue. As this particular adhesive has poor mechanical- and adhesive properties, it cannot be used as to replace the use of sutures as gold standard. There is much interest in the development of new adhesive materials. However, more systematic (clinical) research is needed before the suitability of a newly developed tissue adhesive for the intended application can be proven.

\section{Conclusions}

Among the methods currently used to repair meniscus, the ideal solution has not yet been found. Tissue adhesives hold great potential to replace or support sutures and staples. Many new adhesive materials with a good prognosis for use in a variety of applications have been developed. However, most of them have not been sufficiently characterized to be able to qualify them as being suitable for meniscus repair. Nevertheless, chemically cross-linked adhesives seem the most versatile as these are based on existing natural or synthetic polymers and can be readily modified. Their properties can be adjusted by careful molecular design and chemical functionalization to make them suitable for the intended application.

Standardized relevant biomechanical and biological models need to be defined to compare different available and developed tissue adhesives, and to be able to address their suitability for the repair of meniscal tears. In clinical practice, the most successful treatment modality remains the use of sutures. Nevertheless, there is great need for a suitable meniscus tissue adhesive. Such adhesive should be easily applied in a meniscal tear, bind strongly to meniscal tissue, hold the torn region together, facilitate its healing, and then gradually degrade into non-toxic products. 


\section{References}

[1] Burr DB, Radin EL. Meniscal function and the importance of meniscal regeneration in preventing late medical compartment osteoarthrosis. Clinical Orthopaedics and Related Research 1982;171:1216.

[2] Cooper DE, Arnoczky SP, Warren RF. Meniscal Repair. Clin Sports Med 1991;10:529-48.

[3] Flandry F, Hommel G. Normal Anatomy and Biomechanics of the Knee. Sports Medicine and Arthroscopy Review 2011;19:82-92.

[4] Baratz ME, Fu FH, Mengato R. Meniscal tears: The effect of meniscectomy and of repair on intraarticular contact areas and stress in the human knee: A preliminary report. The American Journal of Sports Medicine 1986;14:270-5.

[5] Fukubayashi T, Kurosawa H. The contact area and pressure distribution pattern of the knee - A study of normal and osteoarthritic knee joints. Acta Orthop Scand 1980;51:871-9.

[6] Krause WR, Pope MH, Johnson RJ, Wilder DG. Mechanical changes in knee after meniscectomy. Journal of Bone and Joint Surgery-American Volume 1976;58:599-604.

[7] Voloshin AS, Wosk J. Shock absorption of meniscectomized and painful knees - a comparative in vivo study. J Biomed Eng 1983;5:157-61.

[8] Englund M. Meniscal tear - A feature of osteoarthritis. Acta Orthopaedica 2004;75:1-45.

[9] Englund M, Roemer FW, Hayashi D, Crema MD, Guermazi A. Meniscus pathology, osteoarthritis and the treatment controversy. Nature Reviews Rheumatology 2012;8:412-9.

[10] Ian Douglas M. (ii) Meniscal tears. Current Orthopaedics 2006;20:85-94.

[11] Starke C, Kopf S, Petersen W, Becker R. Meniscal Repair. Arthroscopy-the Journal of Arthroscopic and Related Surgery 2009;25:1033-44.

[12] McDermott ID, Amis AA. The consequences of meniscectomy. Journal of Bone and Joint SurgeryBritish Volume 2006;88B:1549-56.

[13] Abrams GD, Frank RM, Gupta AK, Harris JD, McCormick FM, Cole BJ. Trends in meniscus repair and meniscectomy in the United States, 2005-2011. American Journal of Sports Medicine 2013;41:2333-9.

[14] Lozano J, Ma CB, Cannon WD. All-inside Meniscus Repair: A Systematic Review. Clinical Orthopaedics and Related Research 2007;455:134-41.

[15] Barber FA, Herbert MA. Meniscal repair devices. Arthroscopy: The Journal of Arthroscopic \& Related Surgery 2000;16:613-8.

[16] van Trommel MF, Simonian PT, Potter HG, Wickiewicz TL. Different Regional Healing Rates with the Outside-In Technique for Meniscal Repair. The American Journal of Sports Medicine 1998;26:446-52.

[17] Longo UG, Campi S, Romeo G, Spiezia F, Maffulli N, Denaro V. Biological Strategies to Enhance Healing of the Avascular Area of the Meniscus. Stem Cells International 2012;2012:528359.

[18] Krych AJ, McIntosh AL, Voll AE, Stuart MJ, Dahm DL. Arthroscopic repair of isolated meniscal tears in patients 18 years and younger. American Journal of Sports Medicine 2008;36:1283-9. 
[19] Gilbert TW, Badylak SF, Beckman EJ, Clower DM, Rubin JP. Prevention of seroma formation with TissuGlu® surgical adhesive in a canine abdominoplasty model: Long term clinical and histologic studies. Journal of Plastic, Reconstructive and Aesthetic Surgery 2013;66:414-22.

[20] Walgenbach KJ, Bannasch H, Kalthoff S, Rubin JP. Randomized, prospective study of TissuGlu ${ }^{\circledR}$ surgical adhesive in the management of wound drainage following abdominoplasty. Aesthetic Plastic Surgery 2012;36:491-6.

[21] Herwig J, Egner E, Buddecke E. Chemical changes of human knee joint menisci in various stages of degeneration. Annals of the Rheumatic Diseases 1984;43:635-40.

[22] Lotz MK, Otsuki S, Grogan SP, Sah R, Terkeltaub R, D’Lima D. Cartilage Cell Clusters. Arthritis and rheumatism 2010;62:2206-18.

[23] Makris EA, Hadidi P, Athanasiou KA. The knee meniscus: structure-function, pathophysiology, current repair techniques, and prospects for regeneration. Biomaterials 2011;32:7411-31.

[24] Arnoczky SP, Warren RF. Microvasculature of the human meniscus. American Journal of Sports Medicine 1982;10:90-5.

[25] Bennet GAW, H., Bauer W. Changes in the Knee Joint at Various Ages: With Particular Reference to the Nature and Development of Degenerative Joint Disease. New York: The Commonweath Fund; 1942.

[26] McNulty AL, Guilak F. Integrative repair of the meniscus: lessons from in vitro studies. Biorheology 2008;45:487-500.

[27] McDevitt CA, Webber RJ. The ultrastructure and biochemistry of meniscal cartilage. Clinical Orthopaedics and Related Research 1990;252:8-18.

[28] Hennerbichler A, Moutos FT, Hennerbichler D, Weinberg JB, Guilak F. Repair response of the inner and outer regions of the porcine meniscus in vitro. The American journal of sports medicine 2007;35:754-62.

[29] Brindle T, Nyland J, Johnson DL. The Meniscus: Review of Basic Principles With Application to Surgery and Rehabilitation. Journal of Athletic Training 2001;36:160-9.

[30] Setton LA, Guilak F, Hsu EW, Vail TP. Biomechanical Factors in Tissue Engineered Meniscal Repair. Clinical Orthopaedics and Related Research 1999;367:S254-S72.

[31] Masouros SD, McDermott ID, Amis AA, Bull AMJ. Biomechanics of the meniscus-meniscal ligament construct of the knee. Knee Surgery, Sports Traumatology, Arthroscopy 2008;16:1121-32.

[32] Shrive NG, O'Connor JJ, Goodfellow JW. Load-bearing in the knee joint. Clinical Orthopeadics and Related Research 1978;131:279-87.

[33] Bylski-Austrow DI, Ciarelli MJ, Kayner DC, Matthews LS, Goldstein SA. Displacements of the menisci under joint load: An in vitro study in human knees. Journal of Biomechanics 1994;27:421-3,531.

[34] Sweigart MA, Athanasiou KA. Toward tissue engineering of the knee meniscus. Tissue Engineering 2001;7:111-29.

[35] Fithian DC, Kelly MA, Mow VC. Material properties and structure-function-relationships in the menisci. Clinical Orthopaedics and Related Research 1990:19-31.

[36] Scotti C, Hirschmann MT, Antinolfi P, Martin I, Peretti GM. Meniscus repair and regeneration: Review on current methods and research potential. European Cells and Materials 2013;26:150-70. 
[37] Lechner K, Hull M, Howell S. Is the circumferential tensile modulus within a human medial meniscus affected by the test sample location and cross-sectional area? Journal of Orthopaedic Research 2000;18:945-51.

[38] Tissakht M, Ahmed AM. Tensile stress-strain characteristics of the human meniscal material. Journal of Biomechanics 1995;28:411-22.

[39] Englund M, Roos EM, Roos HP, Lohmander LS. Patient-relevant outcomes fourteen years after meniscectomy: influence of type of meniscal tear and size of resection. Rheumatology 2001;40:631-9. [40] Christoforakis J, Pradhan R, Sanchez-Ballester J, Hunt N, Strachan RK. Is there an association between articular cartilage changes and degenerative meniscus tears? Arthroscopy - Journal of Arthroscopic and Related Surgery 2005;21:1366-9.

[41] Elkousy HA, Sekiya JK, Harner CD. Broadening the indications for meniscal repair. Sports Medicine and Arthroscopy Review 2002;10:270-5.

[42] Greis PE, Bardana DD, Holmstrom MC, Burks RT. Meniscal injury: I. Basic science and evaluation. Journal of the American Academy of Orthopaedic Surgeons 2002;10:168-76.

[43] Newman AP, Anderson DR, Daniels AU, Dales MC. Mechanics of the healed meniscus in a canine model. American Journal of Sports Medicine 1989;17:164-75.

[44] Jee W-H, McCauley TR, Kim J-M, Jun D-J, Lee Y-J, Choi B-G, et al. Meniscal tear configurations: categorization with MR imaging. American Journal of Roentgenology 2003;180:93-7.

[45] McDermott I. Meniscal tears, repairs and replacement: their relevance to osteoarthritis of the knee. Br J Sports Med 2011;45:292-7.

[46] Englund M, Roos EM, Lohmander L. Impact of type of meniscal tear on radiographic and symptomatic knee osteoarthritis: A sixteen-year followup of meniscectomy with matched controls. Arthritis \& Rheumatism 2003;48:2178-87.

[47] Rongen JJ, van Tienen TG, van Bochove B, Grijpma DW, Buma P. Biomaterials in search of a meniscus substitute. Biomaterials 2014;35:3527-40.

[48] Henning CE, Lynch MA, Yearout KM, Vequist SW, Stallbaumer RJ, Decker KA. Arthroscopic meniscal repair using an exogenous fibrin clot. Clin Orthop Relat Res 1990;252:64-72.

[49] Englund M. The role of biomechanics in the initiation and progression of OA of the knee. Best Practice and Research: Clinical Rheumatology 2010;24:39-46.

[50] Ishimura M, Tamai S, Fujisawa Y. Arthroscopic meniscal repair with fibrin glue. Arthroscopy: The Journal of Arthroscopic and Related Surgery 1991;7:177-81.

[51] Ra HJ, Ha JK, Jang SH, Lee DW, Kim JG. Arthroscopic inside-out repair of complete radial tears of the meniscus with a fibrin clot. Knee Surg Sports Traumatol Arthrosc 2013;21:2126-30.

[52] Wouters DB, Burgerhof JGM, de Hosson JTM, Bos RRM. Fixation of osteochondral fragments in the human knee using Meniscus Arrows (R). Knee Surgery Sports Traumatology Arthroscopy 2011;19:183-8.

[53] Barber FA, Herbert MA, Bava ED, Drew OR. Biomechanical Testing of Suture-Based Meniscal Repair Devices Containing Ultrahigh-Molecular-Weight Polyethylene Suture: Update 2011. Arthroscopy: The Journal of Arthroscopic \& Related Surgery.

[54] Okuda K, Ochi M, Shu N, Uchio Y. Meniscal rasping for repair of meniscal tear in the avascular zone. Arthroscopy 1999;15:281-6.

40 
[55] Uchio Y, Ochi M, Adachi N, Kawasaki K, Iwasa J. Results of rasping of meniscal tears with and without anterior cruciate ligament injury as evaluated by second-look arthroscopy. Arthroscopy 2003;19:463-9.

[56] Fox JM, Rintz KG, Ferkel RD. Trephination of incomplete meniscal tears. Arthroscopy 1993;9:451-5.

[57] Zhang Z, Arnold JA, Williams T, McCann B. Repairs by trephination and suturing of longitudinal injuries in the avascular area of the meniscus in goats. American Journal of Sports Medicine 1995;23:35-41.

[58] Buma P, Ramrattan NN, van Tienen TG, Veth RPH. Tissue engineering of the meniscus. Biomaterials 2004;25:1523-32.

[59] Mauck RL, Burdick JA. From Repair to Regeneration: Biomaterials to Reprogram the Meniscus Wound Microenvironment. Annals of Biomedical Engineering 2015;43:529-42.

[60] Qu F, Lin J-MG, Esterhai JL, Fisher MB, Mauck RL. Biomaterial-mediated delivery of degradative enzymes to improve meniscus integration and repair. Acta Biomaterialia 2013;9:6393-402.

[61] Qu F, Pintauro MP, Haughan JE, Henning EA, Esterhai JL, Schaer TP, et al. Repair of dense connective tissues via biomaterial-mediated matrix reprogramming of the wound interface. Biomaterials 2015;39:85-94.

[62] Struglics A, Hansson M, Lohmander LS. Human aggrecanase generated synovial fluid fragment levels are elevated directly after knee injuries due to proteolysis both in the inter globular and chondroitin sulfate domains. Osteoarthritis Cartilage 2011;19:1047-57.

[63] Tenuta JJ, Arciero RA. Arthroscopic evaluation of meniscal repairs. Factors that effect healing. American Journal of Sports Medicine 1994;22:797-802.

[64] Hennerbichler A, Moutos FT, Hennerbichler D, Weinberg JB, Guilak F. Interleukin-1 and tumor necrosis factor alpha inhibit repair of the porcine meniscus in vitro. Osteoarthritis and Cartilage 2007;15:1053-60.

[65] McNulty AL, Weinberg JB, Guilak F. Inhibition of Matrix Metalloproteinases Enhances In Vitro Repair of the Meniscus. Clinical Orthopaedics and Related Research 2009;467:1557-67.

[66] McNulty AL, Moutos FT, Weinberg JB, Guilak F. Enhanced integrative repair of the porcine meniscus in vitro by inhibition of interleukin-1 or tumor necrosis factor alpha. Arthritis Rheum 2007;56:3033-42.

[67] Tanaka T, Fujii K, Kumagae Y. Comparison of biochemical characteristics of cultured fibrochondrocytes isolated from the inner and outer regions of human meniscus. Knee Surgery, Sports Traumatology, Arthroscopy 1999;7:75-80.

[68] Collier S, Ghosh P. Effects of transforming growth factor beta on proteoglycan synthesis by cell and explant cultures derived from the knee joint meniscus. Osteoarthritis Cartilage 1995;3:127-38.

[69] Murphy JM, Fink DJ, Hunziker EB, Barry FP. Stem cell therapy in a caprine model of osteoarthritis. Arthritis Rheum 2003;48:3464-74.

[70] Ishimura M, Ohgushi H, Habata T, Tamai S, Fujisawa Y. Arthroscopic meniscal repair using fibrin glue. 2. Clinical applications. Arthroscopy-the Journal of Arthroscopic and Related Surgery 1997;13:558-63. 
[71] Kamimura T, Kimura M. Meniscal Repair of Degenerative Horizontal Cleavage Tears Using Fibrin Clots: Clinical and Arthroscopic Outcomes in 10 Cases. Orthopaedic journal of sports medicine 2014;2:2325967114555678.

[72] Rangger C, Klestil T, Gloetzer W, Kemmler G, Benedetto KP. Osteoarthritis After Arthroscopic Partial Meniscectomy. The American Journal of Sports Medicine 1995;23:240-4.

[73] van Trommel MF, Simonian PT, Potter HG, Wickiewicz TL. Arthroscopic meniscal repair with fibrin clot of complete radial tears of the lateral meniscus in the avascular zone. Arthroscopy 1998; $14: 360-5$.

[74] Sheikh N, Mirzadeh H, Katbab AA, Salehian P, Daliri M, Amanpour S. Isocyanate-terminated urethane prepolymer as bioadhesive material: Evaluation of bioadhesion and biocompatibility, in vitro and in vivo assays. Journal of Biomaterials Science-Polymer Edition 2001;12:707-19.

[75] Bouten PJM, Zonjee M, Bender J, Yauw STK, van Goor H, van Hest JCM, et al. The chemistry of tissue adhesive materials. Progress in Polymer Science 2014;39:1375-405.

[76] Chih-Chang Chu HPG, J. Anthony von Fraunhofer. Wound Closure Biomaterials and Devices. 1 ed: CRC-Press; February 1, 1997

[77] Liu J, Yu M, Zhou C, Zheng J. Renal clearable inorganic nanoparticles: a new frontier of bionanotechnology. Materials Today 2013;16:477-86.

[78] Duarte AP, Coelho JF, Bordado JC, Cidade MT, Gil MH. Surgical adhesives: Systematic review of the main types and development forecast. Progress in Polymer Science 2012;37:1031-50.

[79] DeHaven KE. Meniscus Repair. The American Journal of Sports Medicine 1999;27:242-50.

[80] Morgan CD, Wojtys EM, Casscells CD, Casscells SW. Arthroscopic meniscal repair evaluated by second-look arthroscopy. The American Journal of Sports Medicine 1991;19:632-8.

[81] Rimmer MG, Nawana NS, Keene GCR, Pearcy MJ. Failure strengths of different meniscal suturing techniques. Arthroscopy: The Journal of Arthroscopic \& Related Surgery 1995;11:146-50.

[82] Becker R, Brettschneider O, Gröbel KH, Von Versen R, Stärke C. Distraction forces on repaired bucket-handle lesions in the medial meniscus. American Journal of Sports Medicine 2006;34:1941-7. [83] Staerke C, Brettschneider O, Gröbel KH, Becker R. Tensile forces on sutures in the human lateral knee meniscus. Knee Surgery, Sports Traumatology, Arthroscopy 2009;17:1354-9.

[84] Dürselen L, Hebisch A, Claes LE, Bauer G. Gapping phenomenon of longitudinal meniscal tears. Clinical Biomechanics 2003;18:505-10.

[85] Simson JA, Strehin IA, Allen BW, Elisseeff JH. Bonding and fusion of meniscus fibrocartilage using a novel chondroitin sulfate bone marrow tissue adhesive. Tissue Engineering - Part A 2013;19:1843-51.

[86] Ishimura M, Ohgushi H, Habata T, Tamai S, Fujisawa Y. Arthroscopic meniscal repair using fibrin glue .1. Experimental study. Arthroscopy-the Journal of Arthroscopic and Related Surgery 1997; 13:551-7.

[87] Simson J, Crist J, Strehin I, Lu Q, Elisseeff JH. An orthopedic tissue adhesive for targeted delivery of intraoperative biologics. Journal of Orthopaedic Research 2013;31:392-400.

[88] Mehdizadeh M, Yang J. Design strategies and applications of tissue bioadhesives. Macromol Biosci 2013;13:271-88.

[89] Gibble JW, Ness PM. Fibrin glue: the perfect operative sealant? Transfusion 1990;30:741-7. 
[90] Bouten PJM, Zonjee M, Bender J, Yauw STK, van Goor H, van Hest JCM, et al. The chemistry of tissue adhesive materials. Progress in Polymer Science.

[91] Khanlari S, Dubé MA. Bioadhesives: A review. Macromolecular Reaction Engineering 2013;7:573-87.

[92] Ghobril C, Grinstaff MW. The chemistry and engineering of polymeric hydrogel adhesives for wound closure: A tutorial. Chemical Society Reviews 2015;44:1820-35.

[93] Sierra DH. Fibrin Sealant Adhesive Systems: A Review of Their Chemistry, Material Properties and Clinical Applications. Journal of Biomaterials Applications 1993;7:309-52.

[94] Kamimura T, Kimura M. Meniscal Repair of Degenerative Horizontal Cleavage Tears Using Fibrin Clots: Clinical and Arthroscopic Outcomes in 10 Cases. Orthopaedic Journal of Sports Medicine 2014;2.

[95] Liu Y, Kopelman D, Wu L-Q, Hijji K, Attar I, Preiss-Bloom O, et al. Biomimetic Sealant Based on Gelatin and Microbial Transglutaminase: An Initial In Vivo Investigation. Journal of Biomedical Materials Research Part B-Applied Biomaterials 2009;91B:5-16.

[96] Chen TH, Janjua R, McDermott MK, Bernstein SL, Steidl SM, Payne GF. Gelatin-based biomimetic tissue adhesive. Potential for retinal reattachment. Journal of Biomedical Materials Research Part B-Applied Biomaterials 2006;77B:416-22.

[97] $\mathrm{Hu} \mathrm{BH}$, Messersmith PB. Enzymatically cross-linked hydrogels and their adhesive strength to biosurfaces. Orthodontics \& craniofacial research 2005;8:145-9.

[98] Matsuda M, Ueno M, Endo Y, Inoue M, Sasaki M, Taguchi T. Enhanced tissue penetrationinduced high bonding strength of a novel tissue adhesive composed of cholesteryl group-modified gelatin and disuccinimidyl tartarate. Colloids and Surfaces B: Biointerfaces 2012;91:48-56.

[99] Reece TB, Maxey TS, Kron IL. A prospectus on tissue adhesives. American Journal of Surgery 2001;182:40S-4S.

[100] Kucukaksu DS, Akgul A, Cagil K, Tasdemir O. Beneficial effect of BioGlue (R) surgical adhesive in repair of latrogenic aortic dissection. Texas Heart Institute Journal 2000;27:307-8.

[101] Currie LJ, Sharpe JR, Martin R. The use of fibrin glue in skin grafts and tissue-engineered skin replacements: a review. Plast Reconstr Surg 2001;108:1713-26.

[102] Lee Y, Chung HJ, Yeo S, Ahn CH, Lee H, Messersmith PB, et al. Thermo-sensitive, injectable, and tissue adhesive sol-gel transition hyaluronic acid/pluronic composite hydrogels prepared from bioinspired catechol-thiol reaction. Soft Matter 2010;6:977-83.

[103] M. Yu and T.J. Deming. Synthetic Polypeptide Mimics of Marine Adhesives. Macromolecules $1998 ; 31$.

[104] Burke SA, Ritter-Jones M, Lee BP, Messersmith PB. Thermal gelation and tissue adhesion of biomimetic hydrogels. Biomedical Materials 2007;2:203-10.

[105] Mehdizadeh M, Weng H, Gyawali D, Tang L, Yang J. Injectable citrate-based mussel-inspired tissue bioadhesives with high wet strength for sutureless wound closure. Biomaterials 2012;33:797283.

[106] McDermott MK, Chen T, Williams CM, Markley KM, Payne GF. Mechanical properties of biomimetic tissue adhesive based on the microbial transglutaminase-catalyzed crosslinking of gelatin. Biomacromolecules 2004;5:1270-9. 
[107] Vreeland V, Waite JH, Epstein L. Minireview- Polyphenols and oxidases in substratum adhesion by marine algae and mussels. Journal of Phycology 1998;34:1-8.

[108] Bitton R, Bianco-Peled H. Novel biomimetic adhesives based on algae glue. Macromolecular Bioscience 2008;8:393-400.

[109] Ruibal R, Ernst V. The structure of the digital setae of lizards. J Morphol 1965;117:271-93.

[110] Geim AK, Dubonos SV, Grigorieva IV, Novoselov KS, Zhukov AA, Shapoval SY. Microfabricated adhesive mimicking gecko foot-hair. Nat Mater 2003;2:461-3.

[111] Lee H, Lee BP, Messersmith PB. A reversible wet/dry adhesive inspired by mussels and geckos. Nature 2007;448:338-41.

[112] Szomor ZL, Murrell GAC, Appleyard RC, Tyler MJ. Meniscal repair with a new biological glue: An ex vivo study. Techniques in Knee Surgery 2008;7:261-5.

[113] Zhang H, Bré LP, Zhao T, Zheng Y, Newland B, Wang W. Mussel-inspired hyperbranched poly(amino ester) polymer as strong wet tissue adhesive. Biomaterials 2014;35:711-9.

[114] Vote BJT, Elder MJ. Cyanoacrylate glue for corneal perforations: a description of a surgical technique and a review of the literature. Clinical and Experimental Ophthalmology 2000;28:437-42.

[115] Oelker AM, Grinstaff MW. Ophthalmic adhesives: a materials chemistry perspective. Journal of Materials Chemistry 2008;18:2521-36.

[116] Toriumi DM, Raslan WF, Friedman M, Tardy ME. Histotoxicity of cyanoacrylate tissue adhesives - A comparative study. Archives of Otolaryngology-Head \& Neck Surgery 1990;116:54650 .

[117] Leonard F, Kulkarni RK, Brandes G, Nelson J, Cameron JJ. Synthesis and degradation of poly (alkyl $\alpha$-cyanoacrylates). Journal of Applied Polymer Science 1966;10:259-72.

[118] Mizrahi B, Stefanescu CF, Yang C, Lawlor MW, Ko D, Langer R, et al. Elasticity and safety of alkoxyethyl cyanoacrylate tissue adhesives. Acta Biomaterialia 2011;7:3150-7.

[119] Rohm HW, Lurtz C, Wegmann J, Odermatt EK, Behrend D, Schmitz K-P, et al. Development of a biodegradable tissue adhesive based on functionalized 1,2-ethylene glycol bis(dilactic acid). II. Journal of Biomedical Materials Research Part B-Applied Biomaterials 2011;97B:66-73.

[120] Rajendra Pawar SS, Ravikumar Borade, Ashok Jadhav, Satish Dake, Abraham Domb. Cyano Acrylate Polymers in Medical Applications. Recent Patents on Material Science 2008;1:186-9.

[121] Ayan I, Colak M, Comelekoglu U, Milcan A, Ogenler O, Oztuna V, et al. Histoacryl glue in meniscal repairs (a biomechanical study). International Orthopaedics 2007;31:241-6.

[122] Reckers LJ, Fagundes DJ, Cohen M, Raymundo JLP, Moreira MB, Paiva VC. Medial meniscus transplantation using cyanoacrylate in rabbits. Acta cirurgica brasileira / Sociedade Brasileira para Desenvolvimento Pesquisa em Cirurgia 2006;21:92-6.

[123] Lim JI, Kim JH, Park H-K. The adhesive properties of prepolymerized allyl 2-cyanoacrylate/poly L-3,4-dihydroxyphenylalanine for use as bioglue. Materials Letters 2012;81:251-3.

[124] Lim JI, Kim JH. Enhanced biocompatibility and adhesive properties of modified allyl 2cyanoacrylate-based elastic bio-glues. Colloids and Surfaces B: Biointerfaces 2015;133:19-23.

[125] Weber SC, Chapman MW. Adhesives in Orthopaedic Surgery A Review of the Literature and In Vitro Bonding Strengths of Bone-bonding Agents. Clinical Orthopaedics and Related Research 1984;191:249-61. 
[126] Chivers RA, Wolowacz RG. The strength of adhesive-bonded tissue joints. International Journal of Adhesion and Adhesives 1997;17:127-32.

[127] Strehin I, Nahas Z, Arora K, Nguyen T, Elisseeff J. A versatile pH sensitive chondroitin sulfatePEG tissue adhesive and hydrogel. Biomaterials 2010;31:2788-97.

[128] Taguchi T, Saito H, Iwasashi M, Sakane M, Ochiai N. Biodegradable Adhesives Composed of Human Serum Albumin and Organic Acid-based Crosslinkers with Active Ester Groups. Journal of Bioactive and Compatible Polymers 2009;24:546-59.

[129] Inoue T, Taguchi T, Imade S, Kumahashi N, Uchio Y. Effectiveness and biocompatibility of a novel biological adhesive application for repair of meniscal tear on the avascular zone. Science and Technology of Advanced Materials 2012;13.

[130] R.T A. Survey of polyurethane adhesives. International Journal of Adhesion and Adhesives 1984;4:151-2.

[131] Han J, Chen B, Ye L, Zhang A-y, Zhang J, Feng Z-g. Synthesis and characterization of biodegradable polyurethane based on poly( $\varepsilon$-caprolactone) and L-lysine ethyl ester diisocyanate. Frontiers of Materials Science in China 2009;3:25-32.

[132] Guelcher SA. Biodegradable polyurethanes: Synthesis and applications in regenerative medicine. Tissue Engineering Part B-Reviews 2008;14:3-17.

[133] Kobayashi H, Hyon SH, Ikada Y. Water-curable and biodegradable prepolymers. Journal of Biomedical Materials Research 1991;25:1481-94.

[134] Hadba AR, Belcheva N, Jones F, Abuzaina F, Calabrese A, Kapiamba M, et al. Isocyanatefunctional adhesives for biomedical applications. Biocompatibility and feasibility study for vascular closure applications. Journal of Biomedical Materials Research Part B-Applied Biomaterials 2011;99B:27-35.

[135] Sternberg K, Rohm HW, Lurtz C, Wegmann J, Odermatt EK, Behrend D, et al. Development of a biodegradable tissue adhesive based on Functionalized 1,2-ethylene glycol bis(dilactic acid). I. Journal of Biomedical Materials Research Part B-Applied Biomaterials 2010;94B:318-26.

[136] Nayeb-Habib F, Salahshoor-Kordestani S, Afshar-Taromi F, Shariatinia Z. A Novel Topical Biocompatible Tissue Adhesive Based on Chitosan-modified Urethane Pre-polymer. Iranian Polymer Journal 2011;20:671-80.

[137] Field JR, Gunatillake P, Adhikari R, Ramshaw JAM, Werkmeister JA. Use of biodegradable urethane-based adhesives to appose meniscal defect edges in an ovine model: A preliminary study. Australian Veterinary Journal 2008;86:229-34.

[138] Lauto A, Mawad D, Foster LJR. Adhesive biomaterials for tissue reconstruction. Journal of Chemical Technology and Biotechnology 2008;83:464-72.

[139] Lang N, Pereira MJ, Lee Y, Friehs I, Vasilyev NV, Feins EN, et al. A Blood-Resistant Surgical Glue for Minimally Invasive Repair of Vessels and Heart Defects. Science Translational Medicine 2014;6:218ra6.

[140] Ishihara M, Nakanishi K, Ono K, Sato M, Kikuchi M, Saito Y, et al. Photocrosslinkable chitosan as a dressing for wound occlusion and accelerator in healing process. Biomaterials 2002;23:833-40. 
[141] Jeon EY, Hwang BH, Yang YJ, Kim BJ, Choi B-H, Jung GY, et al. Rapidly light-activated surgical protein glue inspired by mussel adhesion and insect structural crosslinking. Biomaterials 2015;67:11-9.

[142] Lando G, Cohn D. Introducing lactide-based biodegradable tissue adhesives. Journal of Materials Science-Materials in Medicine 2003;14:181-6.

[143] Cohn D, Lando G. Tailoring lactide/caprolactone co-oligomers as tissue adhesives. Biomaterials 2004;25:5875-84.

[144] Scotti C, Pozzi A, Mangiavini L, Vitari F, Boschetti F, Domeneghini C, et al. Healing of meniscal tissue by cellular fibrin glue: an in vivo study. Knee Surgery, Sports Traumatology, Arthroscopy 2009;17:645-51.

[145] Ferreira P, Coelho JFJ, Gil MH. Development of a new photocrosslinkable biodegradable bioadhesive. International Journal of Pharmaceutics 2008;352:172-81.

[146] Ferreira P, Silva AFM, Pinto MI, Gil MH. Development of a biodegradable bioadhesive containing urethane groups. Journal of Materials Science-Materials in Medicine 2008;19:111-20.

[147] Wang T, Nie J, Yang D. Dextran and gelatin based photocrosslinkable tissue adhesive. Carbohydrate Polymers 2012;90:1428-36. 


\section{Chapter 3}

\section{Development of Tissue Adhesives Based on Amphiphilic Isocyanate-Terminated Trimethylene Carbonate Block Copolymers}

Agnieszka I. Bochyńska ${ }^{1,2}$, Shahriar Sharifi ${ }^{1}$, Tony G. van Tienen ${ }^{2}$, Pieter Buma ${ }^{2}$, Dirk W. Grijpma ${ }^{1,3}$

${ }^{1}$ Department of Biomaterials Science and Technology, MIRA Institute, University of Twente, Enschede, the Netherlands

${ }^{2}$ Orthopaedic Research Laboratory, Department of Orthopaedics, Radboud Centre for Molecular Life Sciences, Radboud University Nijmegen Medical Centre, Nijmegen, the Netherlands

${ }^{3}$ University Medical Centre Groningen, University of Groningen, W.J. Kolff Institute, Department of Biomedical Engineering, Groningen, the Netherlands 


\section{Abstract}

In this study, novel three-armed star-shaped isocyanate-terminated block copolymers based on trimethylolpropane ethoxylate (TMPE) and trimethylene carbonate (TMC) varying in composition were designed and synthesized. By reaction with water, networks were formed. The characteristics of these networks were compared with those prepared from analogous linear structures based on polyethylene glycol (PEG) and TMC.

Tensile testing of the networks highlighted good mechanical properties. In lap shear adhesion tests to chamois leather, very good bonding strengths of up to $0.6 \mathrm{MPa}$ were obtained. These values compare favorably with those of Dermabond ${ }^{\circledR}$, which is currently one of the strongest clinically used tissue adhesives.

\section{Introduction}

Biodegradable tissue adhesives have great potential to be used in the biomedical field as replacement for sutures and staples. They allow easier and faster application and the procedure is less painful for the patient $[1,2]$.

In practice, only two types of adhesives are mainly applied in the clinic: fibrin glue and cyanoacrylates. Fibrin glues are natural materials that crosslink to form hydrogels via a mechanism that resembles the final stages of blood coagulation [3]. Fibrin is biocompatible and biodegradable, it rapidly degrades within 2 weeks. However, its bonding strength to tissue is too low to be used for load bearing applications and it can be a source of disease transmission $[4,5]$.

Secondly, cyanoacrylates are often applied. They have very good adhesive properties and cure quickly [6], however they are hard, rigid and brittle. These compounds are degradable, but since formaldehyde is a degradation product, their toxicity is an issue $[7,8]$. For this reason their application is limited to topical skin wound closure. Commercial products are Dermabond ${ }^{\circledR}$ and Histoacryl ${ }^{\circledR}$.

There is a clear need for a new tissue adhesive, with good mechanical- and adhesive properties that at the same time is biodegradable and non-toxic. It has been shown that isocyanate-functionalized polymers potentially can be used as tissue adhesives [9]. Our group reported that linear copolymers (oligomers) based on poly(ethylene glycol) (PEG) and trimethylene carbonate (TMC), which were end-functionalized 
with isocyanate groups have adhesive properties to intervertebral disc tissue [10]. PEG is a biocompatible hydrophilic polymer, while TMC is hydrophobic and flexible and provides enzymatic degradability [11]. Variation of the copolymer composition allows adjusting the hydrophilicity of the system and optimizing the wetting of the tissue surface [12]. The isocyanate groups allow chemical reactions with the amine, thiol and hydroxyl groups present in the tissue forming covalent bonds [13]. At the same time, reaction with water leads to the formation of amine end-groups which can react with isocyanate end-groups to form biuret bonds and network [14]. As carbon dioxide is formed during this reaction as well, these amphiphilic networks can be foamed.

In this study, we designed novel three-armed star oligomeric copolymers based on trimethylolpropane ethoxylate (TMPE), TMC and hexamethylene diisocyanate (HDI). Low molecular weight reactive copolymers with different contents of TMC were prepared, to assess the influence of the hydrophilic to hydrophobic ratio on the properties of the cured materials. The properties of the star-shaped copolymers and resultant networks were compared with those of analogous linear structures.

\section{Experimental Part}

\section{Materials}

Trimethylene carbonate (TMC) was purchased from Boehringer Ingelheim (Germany). Polyethylene glycol (PEG) $\left(\mathrm{M}_{\mathrm{n}}=400 \mathrm{~g} / \mathrm{mol}\right)$, trimethylolpropane ethoxylate (TMPE) $\left(\mathrm{M}_{\mathrm{n}}=450 \mathrm{~g} / \mathrm{mol}\right)$, acetic anhydride, stannous octoate (tin 2ethylhexanoate, $\left.\mathrm{SnOct}_{2}\right)$, chloroform-d $\left(\mathrm{CDCl}_{3}\right)$, fibrinogen and thrombin (both isolated from bovine plasma) were purchased from Sigma Aldrich (Netherlands). Hexamethylene diisocyanate (HDI) was purchased from Merck Schuchardt (Germany). Dermabond ${ }^{\circledR}$ (2-octyl cyanoacrylate) was purchased from Ethicon, Johnson \& Johnson (Netherlands). Phosphate buffered saline (PBS) was purchased from B Braun Melsungen AG (Germany). Diethyl ether was purchased from Biosolve (Netherlands) and dried over molecular sieves A4 prior to use. PEG and TMPE were dried at $140{ }^{\circ} \mathrm{C}$ under vacuum before use. All other products were used 
as received.

\section{Synthesis and characterization of oligomers and isocyanate-functionalized oligomers}

Oligomers were synthesized by ring opening polymerization of TMC using PEG or TMPE as the initiator. In a typical procedure, TMC was reacted with PEG or TMPE using $\mathrm{Sn}(\mathrm{Oct})_{2}(0.02 \mathrm{mmol} / \mathrm{mol}$ of monomer $)$ as a catalyst. The polymerization was conducted at $130{ }^{\circ} \mathrm{C}$ for 3 days under nitrogen atmosphere. Oligomers with TMC and PEG molar ratios of 2:1 and 4:1, and oligomers with TMC and TMPE with molar ratios of 3:1 and 6:1 were prepared. The used nomenclature for the synthesized oligomers is: PEG-(TMC $)_{2}$ or TMPE- $\left(\mathrm{TMC}_{\mathrm{m}}\right)_{3}$, where $\mathrm{m}$ is the number of TMC units per oligomer arm.

The oligomers were then reacted with HDI to obtain reactive molecules. In a typical procedure, a metered volume of HDI was placed in a flask under the flow of nitrogen. The oligomer was then added drop-wise to maintain an excess of the isocyanate compound. The final molar $\mathrm{OH} / \mathrm{NCO}$ ratios for the linear- and three-armed compounds were 2.08 and 3.12, respectively. The reaction was allowed to proceed at $75{ }^{\circ} \mathrm{C}$ for 8 hours. The excess of unreacted HDI was removed by precipitation in dry diethyl ether, the product was dried under vacuum overnight. The resulting products were labeled: PEG-(TMC $\left.\mathrm{m}_{\mathrm{m}} \mathrm{HDI}\right)_{2}$ or TMPE-(TMC $\mathrm{TMDI}_{3}$. Figure 1 shows the synthesis of the oligomers and their subsequent functionalization with HDI.

The chemical structure of the oligomers and functionalized oligomers was assessed using ${ }^{1} \mathrm{H}$ NMR spectroscopy (Bruker $400 \mathrm{MHz}$ NMR spectrometer) with $\mathrm{CDCl}_{3}$ as the solvent and FTIR spectroscopy using Perkin-Elmer Spectrum 1000 FTIR spectrometer. The accuracy of this method is $\pm 5 \%$. 
a)

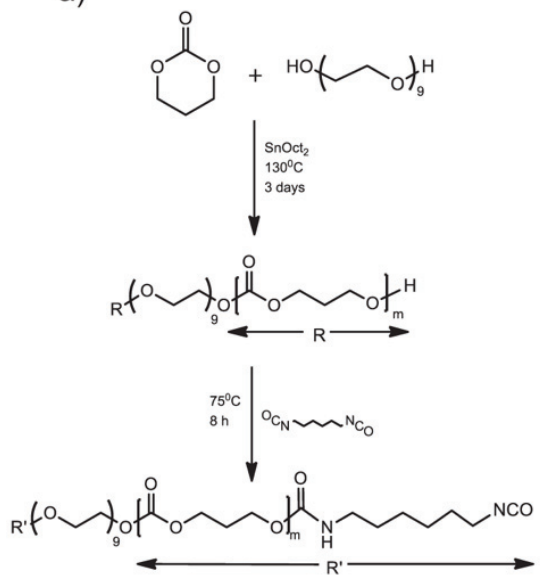

b)

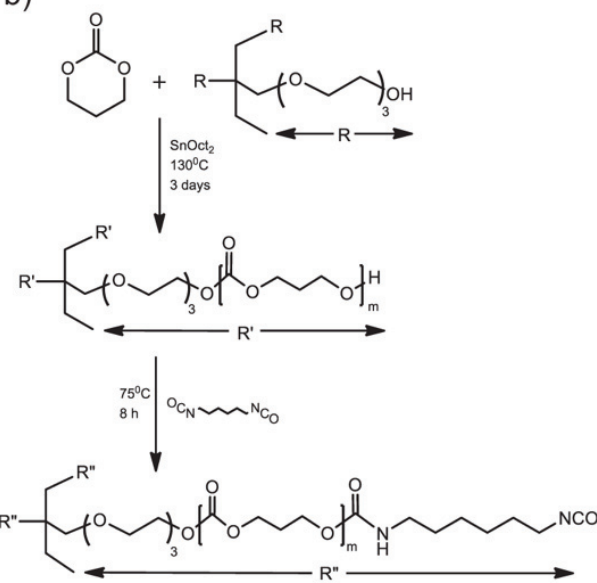

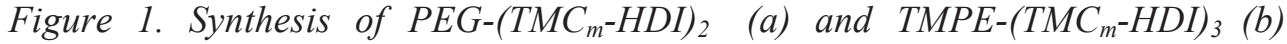
isocyanate-functionalized oligomeric copolymers. The value of $m$ is 1 or 2.

\section{Network formation and network characterization}

Network films were prepared by casting the isocyanate-functionalized oligomers on glass with a $0.3 \mathrm{~mm}$ thick casting knife and immersing in excess of water. The cast films were left overnight at room temperature (RT) to allow reaction with water and curing.

To evaluate the network characteristics, their gel content, degree of swelling in chloroform and water uptake were determined. The prepared networks were dried in a vacuum oven at $40{ }^{\circ} \mathrm{C}$ until constant weight, then their initial mass was determined $\left(\mathrm{m}_{\mathrm{i}}\right)$. The specimens were then placed in chloroform or water for 24 hours and their wet mass $\left(\mathrm{m}_{\mathrm{wc}}\right.$ and $\left.\mathrm{m}_{\mathrm{ww}}\right)$ was determined. Finally, the samples were re-dried in a vacuum oven at $40{ }^{\circ} \mathrm{C}$ until constant weight and their dry mass was determined $\left(\mathrm{m}_{\mathrm{d}}\right)$. The experiments were performed in triplicate.

The gel content (GC) in chloroform was calculated using:

$$
G C=\left(\frac{m_{d}}{m_{i}}\right) \cdot 100 \%
$$


The degree of swelling (DS) in chloroform was calculated using:

$$
D S=\left(\frac{m_{w c}}{m_{d}}\right) \cdot 100 \%
$$

The water uptake (WU) was calculated using:

$$
W U=\left(\frac{m_{w w}-m_{d}}{m_{d}}\right) \cdot 100 \%
$$

The thermal properties of the water-cured networks were determined by differential scanning calorimetry (DSC) using Perkin Elmer Pyris 1 before and after drying. The precision of this method for the temperature performance is $\pm 0.1{ }^{\circ} \mathrm{C}$. Samples of 5$10 \mathrm{mg}$ were heated from $-100{ }^{\circ} \mathrm{C}$ to $100{ }^{\circ} \mathrm{C}$ at $10{ }^{\circ} \mathrm{C} / \mathrm{min}$.

Dumbbell-shaped test specimens of the water-cured network films were prepared according to ISO 37:1994 (E), Type 3 and subjected to tensile testing using a Zwick Z020 universal tensile tester. The grip separation was $35 \mathrm{~mm}$ and the crosshead speed was $50 \mathrm{~mm} / \mathrm{min}$. The mechanical properties of the films were evaluated both in the wet and in the dry state after drying in a vacuum oven at $40{ }^{\circ} \mathrm{C}$ for 24 hours. All measurements were performed in triplicate.

\section{Application as tissue adhesive}

Chamois leather (dermal sheep collagen) was chosen as a model for tissue. Strips of approximately $0.5 \times 10 \times 30 \mathrm{~mm}$ were cut, immersed in water and blotted with tissue to remove excess water. The different isocyanate-functionalized compounds were applied onto the chamois leather to evaluate their adhesive properties. On each strip, the adhesive covered an area of approximately $100 \mathrm{~mm}^{2}$. Two of these strips were pressed together, immersed in water and left overnight at RT to allow curing and network formation.

To determine the adhesion strength, the wet specimens were subjected to a lap shear tensile test analogous to ASTM F2255-05 using a Zwick Z020 universal tensile tester. This is shown schematically in Figure 2. The grip to grip separation was 25 $\mathrm{mm}$ and the crosshead speed $50 \mathrm{~mm} / \mathrm{min}$. The shear adhesive bond strength expressed in MPa is the maximum shear force divided by the glued area. Each 
measurement was performed at least in triplicate.

Two currently applied tissue adhesives Dermabond ${ }^{\circledR}$ and fibrin glue were used as controls. Dermabond ${ }^{\circledR}$ was used as received, fibrin glue was prepared by dissolving fibrinogen and thrombin in PBS at concentrations of $100 \mathrm{mg} / \mathrm{mL}$ and $100 \mathrm{U} / \mathrm{mL}$, respectively. Subsequently, these two solutions were mixed in double syringe system with a static mixer and directly applied onto the wet chamois leather.

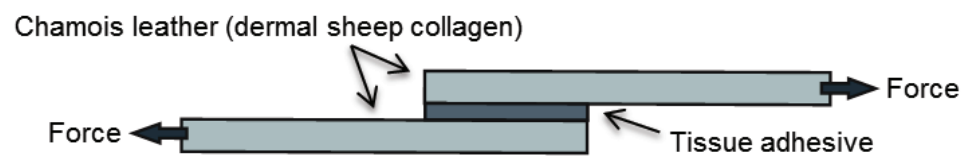

Figure 2. Testing of the lap shear adhesion strength after curing of the different tissue adhesives.

\section{Preliminary cytotoxicity evaluation}

The cytotoxicity of PEG-(TMC $\left.{ }_{1}-\mathrm{HDI}\right)_{2}$ was evaluated using primary human annulus fibrosus cells (ScienCell, USA) and corresponding media (ScienCell). The cells were incubated at $37{ }^{\circ} \mathrm{C}$ and $5 \% \mathrm{CO}_{2}$ for 3 d to reach $90 \%$ confluence. The PEG-(TMC ${ }_{1}$ $\mathrm{HDI})_{2}$ was added to the cell culture medium $(0.3 \mathrm{~g} / \mathrm{ml})$ and incubated overnight at $37{ }^{\circ} \mathrm{C}$. The extract was then filter-sterilized and added to the annulus fibrosus cells in culture at different concentrations varying from 1 to $20 \%(\mathrm{ml}$ extract per $\mathrm{ml}$ culture medium), 5 wells not containing the extract were used as control. The cells were then incubated for a further $24 \mathrm{~h}$ at $37{ }^{\circ} \mathrm{C}$ and $5 \% \mathrm{CO}_{2}$. At this time point, cell viability was assessed by basic light microscopical morphological investigation.

\section{Results and Discussion}

\section{Synthesis and characterization of oligomers and functionalized oligomers}

Several oligomers varying in composition were synthesized by ring opening polymerization of TMC using PEG or TMPE as initiator and subsequently reacted with HDI giving isocyanate-terminated reactive oligomers. NMR analysis showed that TMC conversion was higher than $98 \%$ in all cases.

The molecular weight of PEG was determined by NMR after functionalization with 
acetic anhydride, the molecular weight of TPME was confirmed by comparing the integral values of the methylene group at $0.9 \mathrm{ppm}$ with the repeating ethylene oxide units (-O- $\left.\mathrm{CH}_{2}-\mathrm{CH}_{2}-\right)$ at $3.5-3.75 \mathrm{ppm}$. The TMC content and the number average molecular weights $\left(\mathrm{M}_{\mathrm{n}}\right)$ of the non-functionalized oligomers were then determined by comparing the integral values of the TMC peak (-COO- $\left.\mathrm{CH}_{2}-\mathrm{CH}_{2}-\mathrm{CH}_{2}-\mathrm{O}-\right)$ at 4.1$4.3 \mathrm{ppm}$ or at $2.1 \mathrm{ppm}$ and the integral values of the PEG peak $\left(-\mathrm{O}-\mathrm{CH}_{2}-\mathrm{CH}_{2}-\right)$ at 3.5-3.7 ppm in the ${ }^{1} \mathrm{H}$ NMR spectra. In case of TMPE, the integral values of TMC were compared with those of the TMPE methylene group at $0.9 \mathrm{ppm}$.

A typical spectrum of a PEG- $\left(\mathrm{TMC}_{1}\right)_{2}$ oligomer is shown in Figure $3 \mathrm{a}$.

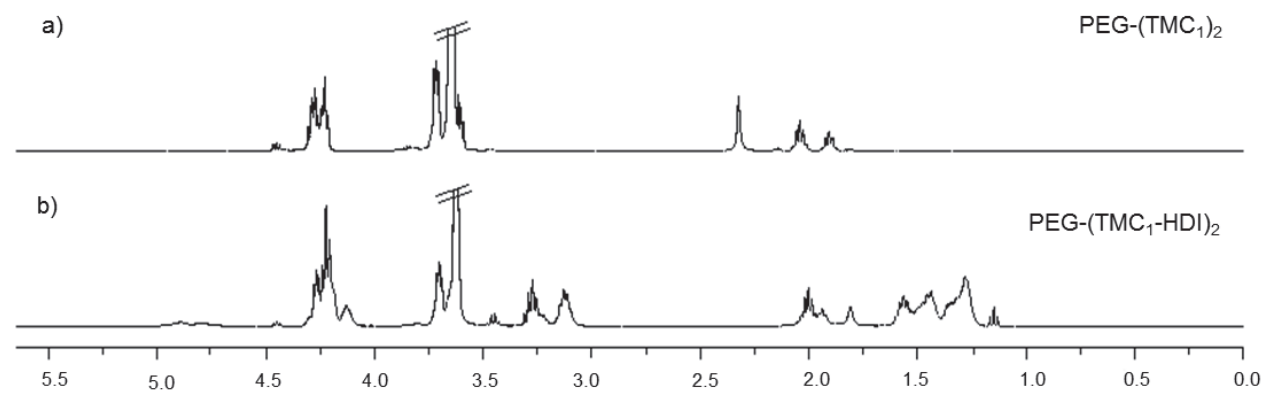

Figure 3. Characteristic ${ }^{1} H$ NMR spectra of (a) a PEG-(TMC $\left.)_{1}\right)_{2}$ oligomer and (b) a corresponding isocyanate-functionalized PEG-(TMC $\left.{ }_{1}-\mathrm{HDI}\right)_{2}$ oligomer.

Table 1 shows that the TMC contents and the determined number average molecular weights of PEG, TMPE and the synthesized block copolymeric oligomers are close to the expected values.

The extent of functionalization of the oligomers was also assessed by ${ }^{1} \mathrm{H}$ NMR spectroscopy, see Figure $3 \mathrm{~b}$ for a characteristic spectrum. The degree of functionalization was calculated by comparing the integral values of the TMC peaks at $2.1 \mathrm{ppm}$ with those of the methylene peaks of HDI (-OOCHN-CH${ }_{2}-\mathrm{CH}_{2}-\mathrm{CH}_{2}-$ $\mathrm{CH}_{2}-\mathrm{CH}_{2}-\mathrm{CH}_{2}-\mathrm{NCO}$ ) at $3.3 \mathrm{ppm}$ or at 1.44-1.6 ppm. As shown in Table 1, the degree of functionalization was high with values above $91 \%$ in all cases. In addition, FTIR spectroscopy showed the presence of both the unreacted free isocyanate end-groups 
at $2235-2300 \mathrm{~cm}^{-1}$ and the urethane bonds at $3250-3500 \mathrm{~cm}^{-1}$.

Table 1. Characteristics of the prepared oligomers. The TMC content, number average molecular weight $\left(M_{n}\right)$ as well as the degree of functionalization (DF) after subsequent reaction with $H D I$ were determined by ${ }^{1} H N M R$.

\begin{tabular}{lllll}
\hline Oligomer & $\begin{array}{l}\text { TMC content in } \\
\text { oligomer [mol\%] }\end{array}$ & $\begin{array}{l}\mathrm{M}_{\mathrm{n}}^{\mathrm{a}} \\
{[\mathrm{g} / \mathrm{mol}]}\end{array}$ & $\begin{array}{l}\mathrm{M}_{\mathrm{n}} \\
{[\mathrm{g} / \mathrm{mol}]}\end{array}$ & $\begin{array}{l}\text { DF after reaction } \\
\text { with HDI [\%] }\end{array}$ \\
\hline PEG & - & 400 & 398 & - \\
TMPE & - & 450 & 439 & - \\
PEG-(TMC $)_{2}$ & 66.5 & 604 & 601 & 94 \\
TMPE- $\left(\mathrm{TMC}_{1}\right)_{3}$ & 74.5 & 756 & 739 & 100 \\
PEG-(TMC $)_{3}$ & 80.0 & 809 & 806 & 99 \\
TMPE- $\left(\mathrm{TMC}_{2}\right)_{3}$ & 85.7 & 1062 & 1037 & 91 \\
\hline a) expected value & & & &
\end{tabular}

a) expected value

\section{Formation and characterization of networks}

To evaluate the physical properties of the polyurethane networks, networks in the form of films were formed by reaction of cast isocyanate-functionalized oligomers with water. In a series of reactions, the formation of biuret linkages leads to covalent crosslinking of the block copolymeric chains. Also carbon dioxide, which can lead to foaming, is formed. In our experiments, foaming was limited and films with thicknesses of 0.3-0.4 mm were obtained.

The network properties of these crosslinked amphiphilic films are presented in the Table 2. It can be noted that the gel content of the networks is high for all the compositions, confirming successful functionalization of the oligomers with HDI and crosslinking with water at room temperature. The degree of swelling of the networks in chloroform varied with architecture of the functionalized oligomers. Networks prepared from the linear functionalized oligomers based on PEG could be swollen 800 to $1000 \%$, while networks prepared from TMPE based functionalized oligomers could only be swollen up to approximately $300 \%$. This indicates that the latter networks are more densely crosslinked. The effect of composition seems to be minimal. (Note that the PEG-(TMC $2-\mathrm{HDI})_{2}$ network with the highest degree of swelling had the lowest gel content). 
Table 2 also shows that the water uptake of the networks depends on composition as well as on architecture of the functionalized oligomers used. For more or less comparable compositions, water uptake is significantly higher for networks based on PEG than for those based on TMPE as was the case for swelling in chloroform. The effect of TMC content is clear as well, especially for the networks prepared using linear structures. The highest water uptake is observed for PEG-(TMC $\left.{ }_{1}-\mathrm{HDI}\right)_{2}$, in which the weight content of the hydrophilic PEG component is $43.6 \%$. It was found that after uptake of water, the PEG-containing networks were opaque, while those based on TMPE remained transparent.

Table 2. Characteristics of the prepared networks. The gel content (GC), degree of swelling in chloroform (DS) and water uptake (WU) of the networks were determined in triplicate.

\begin{tabular}{|c|c|c|c|c|c|}
\hline Network & $\begin{array}{l}\mathrm{GC} \\
{[\%]}\end{array}$ & $\begin{array}{l}\text { DS } \\
{[\%]}\end{array}$ & $\begin{array}{l}\text { WU } \\
{[\%]}\end{array}$ & $\begin{array}{l}\text { TMC content } \\
{[\mathrm{wt} \%]}\end{array}$ & $\begin{array}{l}\text { PEG } \\
\text { content } \\
{[w t \%]}\end{array}$ \\
\hline PEG-(TMC $\left.{ }_{1}-\mathrm{HDI}\right)_{2}$ & $100 \pm 0$ & $813 \pm 73$ & $65 \pm 2$ & 21.8 & 43.6 \\
\hline TMPE-(TMC $\left.{ }_{1}-\mathrm{HDI}\right)_{3}$ & $99 \pm 1$ & $340 \pm 38$ & $11 \pm 1$ & 24.1 & 35.3 \\
\hline PEG-(TMC $\left.{ }_{2}-\mathrm{HDI}\right)_{2}$ & $86 \pm 5$ & $1019 \pm 59$ & $29 \pm 4$ & 35.4 & 35.2 \\
\hline TMPE-(TMC $\left.{ }_{2}-\mathrm{HDI}\right)_{3}$ & $99 \pm 1$ & $341 \pm 18$ & $9 \pm 1$ & 40.0 & 29.3 \\
\hline
\end{tabular}

The thermal properties of the networks were evaluated, results are shown in Table 3. In the wet state, only single glass transition temperatures $\left(\mathrm{T}_{\mathrm{g}}\right)$ can be observed. The networks prepared using PEG-containing functionalized oligomers had significantly lower glass transition temperatures than those prepared using TMPE. For both architectures an increase in TMC content leads to an increase in $\mathrm{T}_{\mathrm{g}}$. After drying the water-cured networks, melting points corresponding to the PEG or TMPE component in the soft segment ranging from approximately 35 to $48{ }^{\circ} \mathrm{C}$ were measured. Melting points at higher temperatures of approximately $80{ }^{\circ} \mathrm{C}$ that correspond to the urethane bonds in the hard segments could also be observed. 
Table 3. Thermal properties of the prepared networks in the water swollen state and in the dry state.

\begin{tabular}{|c|c|c|c|c|}
\hline \multirow[b]{2}{*}{ Network } & \multirow{2}{*}{$\begin{array}{c}\text { Wet } \\
\mathrm{T}_{\mathrm{g}}^{\mathrm{a})} \\
{\left[{ }^{\circ} \mathrm{C}\right]}\end{array}$} & \multicolumn{3}{|c|}{ Dry } \\
\hline & & $\begin{array}{c}\mathrm{T}_{\mathrm{g}}^{\mathrm{a})} \\
{\left[{ }^{\mathrm{o}} \mathrm{C}\right]}\end{array}$ & $\begin{array}{c}\mathrm{T}_{\mathrm{m}(\mathrm{soft})}{ }^{\mathrm{b})} \\
{\left[{ }^{\mathrm{O}} \mathrm{C}\right]}\end{array}$ & $\begin{array}{c}\mathrm{T}_{\mathrm{m}(\mathrm{hard})}{ }^{\mathrm{c})} \\
{\left[{ }^{\circ} \mathrm{C}\right]}\end{array}$ \\
\hline PEG-(TMC ${ }_{1}$-HDI $)_{2}$ & -52.5 & -40.2 & 38.4 & 80.0 \\
\hline TMPE-(TMC $\left.{ }_{1}-\mathrm{HDI}\right)_{3}$ & -35.9 & -13.6 & 48.7 & 80.0 \\
\hline PEG-(TMC $\left.{ }_{2}-\mathrm{HDI}\right)_{2}$ & -36.1 & -33.8 & 35.1 & 81.0 \\
\hline TMPE-(TMC $\left.{ }_{2}-\mathrm{HDI}\right)_{3}$ & -24.2 & -15.6 & 39.9 & 80.0 \\
\hline
\end{tabular}

\footnotetext{
a) glass transition temperature

b) melting temperature of PEG or TMPE in the soft segment

c) melting temperature of the urethane bond in the hard segment
}

In the dry state, $\mathrm{T}_{\mathrm{g}}$ of the networks is higher than in the hydrated state and varies from -40 to $-34^{\circ} \mathrm{C}$ for networks prepared from linear PEG-TMC structures and from -16 to $-14{ }^{\circ} \mathrm{C}$ for three-armed TMPE-TMC structures. In dry PEG-TMC networks, the glass transition temperature increases with increasing TMC contents, this effect is not evident in TMPE-TMC networks.

The tensile properties of the prepared networks were assessed in the wet and in the dry state, the data is presented in Table 4. Especially for the networks based on linear isocyanate-functionalized PEG-TMC oligomers, composition and water content (see Table 2) has a significant influence on the mechanical properties. The tensile strength (б), elasticity modulus (E) and elongation at break $(\varepsilon)$ of PEG-(TMC ${ }_{1}$ $\mathrm{HDI})_{2}$ networks that contain the lowest amounts of TMC are very much increased upon drying. For networks prepared from PEG-(TMC $\left.{ }_{2}-\mathrm{HDI}\right)_{2}$ this effect is not as pronounced. As networks based on TMPE-TMC do not take up as much water (Table 2), the difference in tensile properties in the dry state of these networks do not differ very much from those in the wet state. In all cases the tensile strength and the elasticity modulus of the networks increase with the TMC content. 
Table 4. Tensile properties of the prepared networks in the water-swollen state and in the dry state.

\begin{tabular}{llll|lll}
\hline \multirow{2}{*}{ Network } & \multicolumn{3}{c|}{ Wet } & \multicolumn{3}{c}{ Dry } \\
\cline { 2 - 7 } & $\sigma[\mathrm{MPa}]$ & $\mathrm{E}[\mathrm{MPa}]$ & $\varepsilon[\%]$ & $\sigma[\mathrm{MPa}]$ & $\mathrm{E}[\mathrm{MPa}]$ & $\varepsilon[\%]$ \\
\hline PEG-(TMC 1 -HDI) $)_{2}$ & $0.1 \pm 0.01$ & $1.2 \pm 0.2$ & $14.0 \pm 1.1$ & $2.6 \pm 0.3$ & $14.4 \pm 0.2$ & $52.6 \pm 14.3$ \\
TMPE-$\left(\mathrm{TMC}_{1}-\mathrm{HDI}\right)_{3}$ & $3.3 \pm 1.4$ & $34.5 \pm 4.8$ & $21.6 \pm 10.5$ & $3.8 \pm 0.2$ & $33.9 \pm 4.9$ & $26.4 \pm 4.7$ \\
PEG-(TMC $\left.{ }_{2}-\mathrm{HDI}\right)_{2}$ & $3.9 \pm 0.5$ & $21.5 \pm 5.0$ & $108.6 \pm 27.4$ & $3.5 \pm 0.1$ & $35.3 \pm 4.1$ & $48.0 \pm 0.7$ \\
TMPE-(TMC 2 -HDI) & $5.0 \pm 2.8$ & $45.1 \pm 11.6$ & $22.7 \pm 7.6$ & $4.4 \pm 0.5$ & $48.9 \pm 10.2$ & $21.7 \pm 1.3$ \\
\hline
\end{tabular}

\section{Application as tissue adhesives}

PEG-TMC and TMPE-TMC isocyanate-functionalized oligomers were applied as tissue adhesives using chamois leather (dermal sheep collagen) as a model for tissue. The reactive oligomers were spread onto the leather and allowed to cure overnight in a wet environment. Under these conditions the terminal isocyanate groups can react with amine- thiol- and hydroxyl groups present on the surface of the leather as well as with water to form the network.

The adhesive strength of the cured networks (the strength of the adhesive bond) was assessed in a lap shear test. Their strength in gluing chamois leather was compared with that of fibrin glue and Dermabond ${ }^{\mathbb{B}}$. The results are shown in Figure 4. The figure shows that not only the composition (and concomitant water-uptake) has an important effect on the adhesive bond strength, but that also the architecture of the used isocyanate-functionalized oligomers is of great importance. With increasing TMC content of networks prepared from linear isocyanate-functionalized PEGTMC oligomers the bond strength increased from 0.03 to $0.35 \mathrm{MPa}$. The bond strength of networks based on three-armed isocyanate-functionalized TMPE-TMC was even higher and increased from 0.56 to $0.68 \mathrm{MPa}$. In all cases, we observed cohesive failure of the glue, the interface between the cured adhesive and the leather remained intact. It is noteworthy that the TMPE-(TMC $\left.{ }_{1}-\mathrm{HDI}\right)_{3}$ and TMPE-(TMC $2_{2}^{-}$ $\mathrm{HDI})_{3}$ networks with the lowest water uptake had the highest adhesive bonding strengths to chamois leather. Apparently, in this system, it seems that further increasing hydrophilicity in order to enhance wetting of the leather surface is not necessary. 


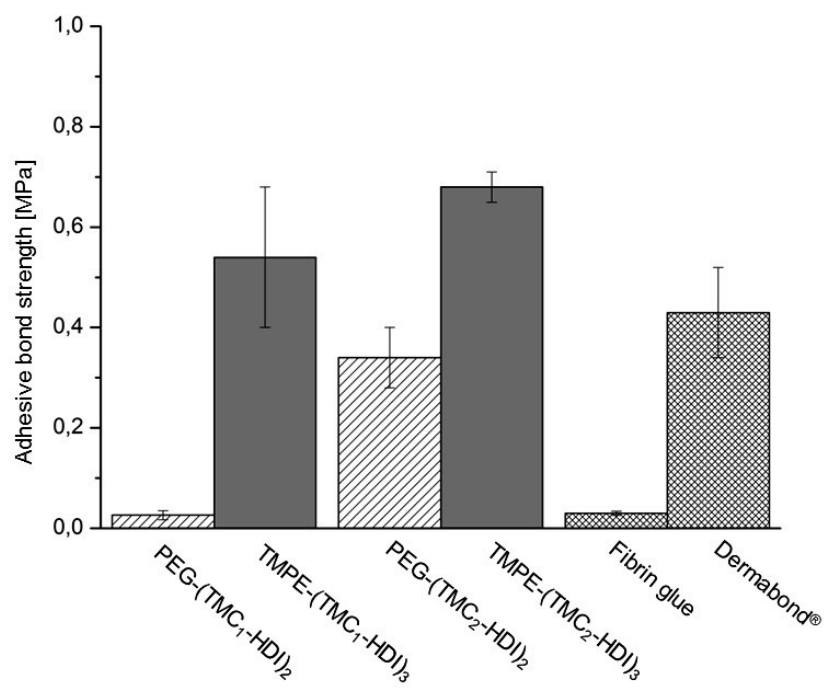

Figure 4. The adhesive bond strength in the wet state of glued chamois leather upon curing isocyanate-functionalized PEG-TMC and TMPE-TMC oligomers with water. Fibrin glue and Dermabond ${ }^{\circledR}$ were used as controls. Values are expressed as mean \pm standard deviation.

The adhesive bonding strength of fibrin glue was found to be very low, as is known from literature [15]. Dermabond ${ }^{\circledR}$ in contrast, is a much stronger adhesive [16], and in glueing chamois leather we found high adhesive strength values of approximately $0.4 \mathrm{MPa}$. The adhesive bond strength of the TMPE-TMC based networks was found to be even better than that of Dermabond ${ }^{\circledR}$.

\section{Cytotoxicity of isocyanate-functionalized oligomers}

As isocyanates can be toxic to cells, we conducted a first experiment to assess the cytotoxicity of PEG-(TMC $\left.{ }_{1}-\mathrm{HDI}\right)_{2}$ using human annulus fibrosus cells. The adhesive was placed in cell culture medium $(0.3 \mathrm{~g} / \mathrm{ml})$, the extract of this large quantity was then added to proliferating annulus fibrosus cells. It was found that the extract was not toxic to the cells at concentrations lower than $2 \%(\mathrm{ml}$ extract per $\mathrm{ml}$ cell culture medium) as cell viabilities remained equal to cell viabilities in cell culture medium only. With increasing concentration of extract in the culture 
medium, cell viabilities decreased: at 3, 5, 8, 10 and $20 \%$, the values of the cell viabilities were respectively $80,40,0,0,0 \%$ compared to the control. This indicates that cytotoxicity is strongly dependent on the amount of extract administered to the cells. At the lowest concentrations, cell viability is not much affected. Nevertheless, it will be important to conduct more extensive investigations of possible cytotoxicity.

\section{Conclusions}

We have designed and synthesized PEG-TMC and novel three-armed star-shaped copolymers based on TMPE and TMC, which were both end-functionalized with isocyanate groups for use as water-curing tissue adhesives. The mechanical properties and the bond strength to chamois leather of the three-armed star-shaped adhesives were significantly better than those of the linear structures and those of fibrin glue and Dermabond ${ }^{\circledR}$, which were used as controls. Although more extensive experiments are needed to confirm the compatibility of these adhesives with cells and tissues, the developed materials are promising for use as degradable and resorbable tissue adhesives.

\section{Acknowledgements}

This research is supported by Reumafonds, the Dutch Arthritis Foundation.

\section{References}

[1] Gross L, Hoffman R. Handbook of Adhesives. New York: Van Nostrand Reinhold; 1977.

[2] Bruns TB, Worthington JM. Using tissue adhesive for wound repair: A practical guide to Dermabond. American Family Physician 2000;61:1383-8.

[3] Spotnitz WD. Commercial fibrin sealants in surgical care. American Journal of Surgery 2001;182:8S-14S.

[4] Whitman DH, Berry RL, Green DM. Platelet gel: An autologous alternative to fibrin glue with applications in oral and maxillofacial surgery. Journal of Oral and Maxillofacial Surgery 1997;55:12949.

[5] Lauto A, Mawad D, Foster LJR. Adhesive biomaterials for tissue reconstruction. Journal of Chemical Technology and Biotechnology 2008;83:464-72.

[6] Chivers RA, Wolowacz RG. The strength of adhesive-bonded tissue joints. International Journal of Adhesion and Adhesives 1997;17:127-32.

60 
[7] Toriumi DM, Raslan WF, Friedman M, Tardy ME. Histotoxicity of cyanoacrylate tissue adhesives - A comparative study. Archives of Otolaryngology-Head \& Neck Surgery 1990;116:546-50.

[8] Mizrahi B, Stefanescu CF, Yang C, Lawlor MW, Ko D, Langer R, et al. Elasticity and safety of alkoxyethyl cyanoacrylate tissue adhesives. Acta Biomaterialia 2011;7:3150-7.

[9] Kobayashi H, Hyon SH, Ikada Y. Water-curable and biodegradable prepolymers. Journal of Biomedical Materials Research 1991;25:1481-94.

[10] Blanquer SBG, Sharifi S, Grijpma DW. Development of poly(trimethylene carbonate) network implants for annulus fibrosus tissue engineering. Journal of Applied Biomaterials and Functional Materials 2012;10:177-84.

[11] Bat E, Plantinga JA, Harmsen MC, van Luyn MJA, Zhang Z, Grijpma DW, et al. Trimethylene Carbonate and epsilon-Caprolactone Based (co)Polymer Networks: Mechanical Properties and Enzymatic Degradation. Biomacromolecules 2008;9:3208-15.

[12] Manuja N, Nagpal R, Pandit IK. Dental Adhesion: Mechanism, Techniques and Durability. Journal of Clinical Pediatric Dentistry 2012;36:223-34.

[13] Nayeb-Habib F, Salahshoor-Kordestani S, Afshar-Taromi F, Shariatinia Z. A Novel Topical Biocompatible Tissue Adhesive Based on Chitosan-modified Urethane Pre-polymer. Iranian Polymer Journal 2011;20:671-80.

[14] Dusek K. Theory of network formation by additional cross-linking of polyurethanes due to biuret and allophanate formation. Polymer Bulletin 1987;17:481-8.

[15] Sierra DH, Eberhardt AW, Lemons JE. Failure characteristics of multiple-component fibrin-based adhesives. Journal of Biomedical Materials Research 2002;59:1-11.

[16] Artzi N, Shazly T, Crespo C, Ramos AB, Chenault HK, Edelman ER. Characterization of Star Adhesive Sealants Based On PEG/Dextran Hydrogels. Macromolecular Bioscience 2009;9:754-65. 


\section{Chapter 4}

\section{Adhesion of Tissue Glues to Different Biological Substrates}

Agnieszka I. Bochyńska ${ }^{1,2}$, Gerjon Hannink ${ }^{2}$, Pieter Buma ${ }^{2}$, Dirk W. Grijpma ${ }^{1,3}$

${ }^{1}$ Department of Biomaterials Science and Technology, MIRA Institute, University of Twente, Enschede, the Netherlands

${ }^{2}$ Orthopaedic Research Laboratory, Department of Orthopaedics, Radboud Centre for

Molecular Life Sciences, Radboud University Nijmegen Medical Centre, Nijmegen, the Netherlands

${ }^{3}$ University Medical Centre Groningen, University of Groningen, W.J. Kolff Institute, Department of Biomedical Engineering, Groningen, the Netherlands 


\begin{abstract}
Tissue adhesives are attractive materials with potential to replace the use of sutures and staples in the repair of the injured tissues. The research field of tissue adhesives is dynamically growing, and different methods and tissue models are employed to evaluate the adhesive properties of newly developed materials. It is thus difficult to directly compare the properties of materials developed by researchers from different groups. Moreover, the extrapolation of results obtained using different tissue models to the targeted human tissues is often not possible.
\end{abstract}

Therefore, the purpose of the current study was to evaluate the adhesive properties of the three different tissues adhesives: the clinically used Dermabond ${ }^{\circledR}$ and fibrin glue, and the recently developed isocyanate-terminated three-armed adhesive block copolymer. Different biological substrates were used to assess their adhesion strengths: bovine Achilles tendon, meniscus tissue and skeletal muscle, chamois leather and collagen films. Comparisons of the adhesive properties of the glues to these substrates were made. The obtained results were analyzed in terms of the chemistry and the adhesion mechanisms of the glues, and the composition and properties of the substrates like their hydrophilicity and surface morphology.

We conclude that standardized procedures and models should be developed to allow direct comparison between the different (developed) tissue adhesives and to enable extrapolation of the results towards the targeted human tissues.

\title{
Introduction
}

Tissue adhesives are an attractive class of materials with the potential to be used as a replacement of other surgical techniques, such as sutures or staples. Tissue adhesives cause minimal tissue trauma, they are easy to apply and there is no need to remove them after the tissue has healed [1]. Therefore, much interest has recently been paid to the development of new adhesive materials which are aimed at the repair of different types of tissues. Adhesives are already used in clinical applications such as the repair of skin lacerations, pulmonary leaks, meniscus tears, abdominoplasty and cardiovascular vessels [2-4]. 
However, the availability of the human tissues for evaluating adhesive properties of newly developed adhesives is limited. Therefore, different materials have been employed in laboratory practice to serve as tissue models. Examples are polyamide films [5, 6], gelatin pieces [7-9], collagen membranes [10], animal tissues and even models using pieces of wood and pig skin [11]. However, the adhesion strength of the glues may significantly differ when tested using these tissue models instead of the targeted living tissues. Moreover, even though norms for testing adhesive materials exist, e.g. ASTM F2255-05, still the variability in the preparation of the substrates, the gluing procedures and the curing times can introduce large variations in the obtained results and direct comparison of the novel materials developed in different research groups is often not possible.

Therefore, the aim of this study was to evaluate and compare the adhesive strength of three different tissue glues to different biological substrates, using the clinically applied Dermabond ${ }^{\circledR}$ and fibrin glue, and a recently developed novel three-armed adhesive block copolymer. The differences in the observed adhesive strengths are discussed in terms of the hydrophilicity of the substrates, their surface morphology and the contact angle between applied glues and the surfaces. Recommendations towards choosing adequate substrates for evaluating adhesion strengths of newly developed glues are formulated.

\section{Materials and Methods}

\section{Tissue adhesives}

Three tissue adhesives were used in this study: Dermabond ${ }^{\circledR}$ (Ethicon, Johnson and Johnson, the Netherlands), fibrin glue (mixture of fibrinogen $(100 \mathrm{mg} / \mathrm{mL})$ and thrombin $(100 \mathrm{U} / \mathrm{mL})$ in PBS, both isolated from bovine plasma, Sigma Aldrich, the Netherlands) and a three-armed block copolymeric isocyanate-terminated adhesive, TMPE-(TMC $2-\mathrm{HDI})_{3}$, which was synthesized as described in detail previously [12]. The building blocks of the copolymer were trimethylolpropane ethoxylate (TMPE, $\mathrm{M}_{\mathrm{n}}=450 \mathrm{~g} / \mathrm{mol}$ ), trimethylene carbonate (TMC) and hexamethylene diisocyanate (HDI). 


\section{Preparation of the substrates for gluing experiments}

Bovine meniscus, bovine Achilles tendon and bovine skeletal muscle tissue were obtained from a local slaughterhouse. Meniscus tissue was cut with a cryotome (Microm $\mathrm{GmbH}$, Germany) in the direction along the alignment of the collagen fibers to obtain strips measuring approximately $0.5 \times 10 \times 25 \mathrm{~mm}$. Achilles tendons were cut lengthwise in the same manner. Skeletal muscle tissue was frozen and then cut with a scalpel to strips of approximately $2 \times 10 \times 25 \mathrm{~mm}$. Chamois leather (dermal sheep collagen) was cut in strips of 1x10x25 mm. Collagen films were prepared by swelling $1 \mathrm{w} / \mathrm{v} \%$ of type I insoluble collagen (from bovine Achilles tendon, Sigma Aldrich, Germany) in acetic acid $(0.05 \mathrm{M})$ overnight at $4{ }^{\circ} \mathrm{C}$. Subsequently, the mixture was shredded for $10 \mathrm{~min}$ at $9500 \mathrm{rpm}$ at $0{ }^{\circ} \mathrm{C}$ using a Braun MR $500 \mathrm{HC}$ blender (Braun, Germany). The resulting slurry was filtered through a nylon filter (average pore size $100 \mu \mathrm{m}$ ) and it was cast on a glass plate using a $3 \mathrm{~mm}$ thick casting knife and then left to dry under fume hood at room temperature (RT). After drying, collagen films of a thickness of approximately $100 \mu \mathrm{m}$ were obtained. Due to their weak mechanical properties, they were mounted on steel plates of a size $0.5 \times 10 \times 30$ $\mathrm{mm}$ with a cyanoacrylate glue prior to adhesion testing. All substrates were kept in water before use.

\section{Application of the tissue adhesives and evaluation of their bonding strength}

All tissues were thawed and together with chamois leather and collagen films were kept in demi water to prevent drying. The surfaces of the substrates were blotted dry and the different tissue adhesives were applied onto the strips. Dermabond ${ }^{\circledR}$ was used as received. Fibrin glue was prepared by mixing two solutions (fibrinogen and thrombin) in a double syringe equipped with a static mixer (Sulzer, Switzerland) and directly applied onto the substrates. The three-armed copolymeric adhesive was applied using a spatula. In all cases, the adhesives covered an area of approximately $100 \mathrm{~mm}^{2}$. Two of these strips were then pressed together, immersed in water and left overnight at RT to allow attachment of the adhesives to the substrates and curing.

To determine the strength of the adhesive bonding of the glues to the substrates after curing, the wet specimens were subjected to lap shear adhesion testing using a Zwick 
Z020 universal tensile machine according to ASTM F2255-05 standard ( $\mathrm{n}=5)$. The grip to grip separation was $22 \mathrm{~mm}$ and the crosshead speed was $50 \mathrm{~mm} / \mathrm{min}$. The shear adhesive bond strength $(\mathrm{S})$ was calculated as the maximum shear force divided by the glued area.

\section{Contact Angle Measurements}

Static Contact Angle (SCA) measurement between different tissue adhesives and substrates were measured using optical contact angle device (OCA15, Dataphysics, Germany). The drop of adhesive was deposited onto the surface of the wet substrates, after which the drop contour was fitted by the Young-Laplace method. Each measurement was performed in triplicate.

\section{Determination of the water content of the substrates}

All tissues were thawed and together with chamois leather and collagen films were kept in demi water to prevent drying. Subsequently, the substrates $(n=3)$ were blotted dry and their initial mass was determined $\left(\mathrm{m}_{\mathrm{i}}\right)$. The samples were frozen in liquid nitrogen, freeze-dried and their mass in the dry state was again determined $\left(\mathrm{m}_{\mathrm{d}}\right)$.

The water content of the substrates, expressed as a weight $\%$, was calculated as:

$$
W C=\frac{m_{i}-m_{d}}{m_{i}} \cdot 100 \%
$$

\section{Surface morphology of the substrates}

The surfaces of the substrates and the surfaces to which the glues were applied were visualized using scanning electron microscopy (SEM, $\mathrm{n}=1$ ). The adhesives were applied on strips of the different substrates, then kept in water overnight to let the adhesives attach and cure. Subsequently the samples were mounted on the SEM holders and were dried in an oven with convective air flow at $40{ }^{\circ} \mathrm{C}$. The surfaces of the samples were gold-sputtered for 60 seconds. The morphology was studied using Zeiss Gemini Sigma 300 SEM operating at $10 \mathrm{kV}$ electron beam. Cross-sections of chamois leather and meniscus tissue were also imaged after application of the threearmed adhesive. These samples were prepared as described above, but they were 
fractured in liquid nitrogen before drying. An FEI ESEM XL30 apparatus operating at $5 \mathrm{kV}$ electron beam was used in this case.

\section{Results}

The adhesive strength of the glues to the different substrates was determined in the lap shear adhesion tests. The observed failure mechanism was in all cases adhesive failure: the glues detached from the substrates. The values of the adhesive strengths of particular glues were highly dependent on the type of the glued substrate (Figure 1). The adhesion strength of Dermabond ${ }^{\circledR}$ varied from $19.9 \pm 5.7 \mathrm{kPa}$ up to $868.3 \pm 372.6 \mathrm{kPa}$ for muscle tissue and collagen films, respectively. Fibrin glue had adhesive strengths ranging from $1.9 \pm 0.8 \mathrm{kPa}$ to meniscus up to $53.8 \pm 35.0$ to collagen films. The three-armed block copolymeric glue had the highest adhesive strength to chamois leather $(719.4 \pm 225.0 \mathrm{kPa})$ and collagen films $(883.0 \pm 118.8 \mathrm{kPa})$ and the lowest to muscle tissue $(5.3 \pm 4.3 \mathrm{kPa})$.

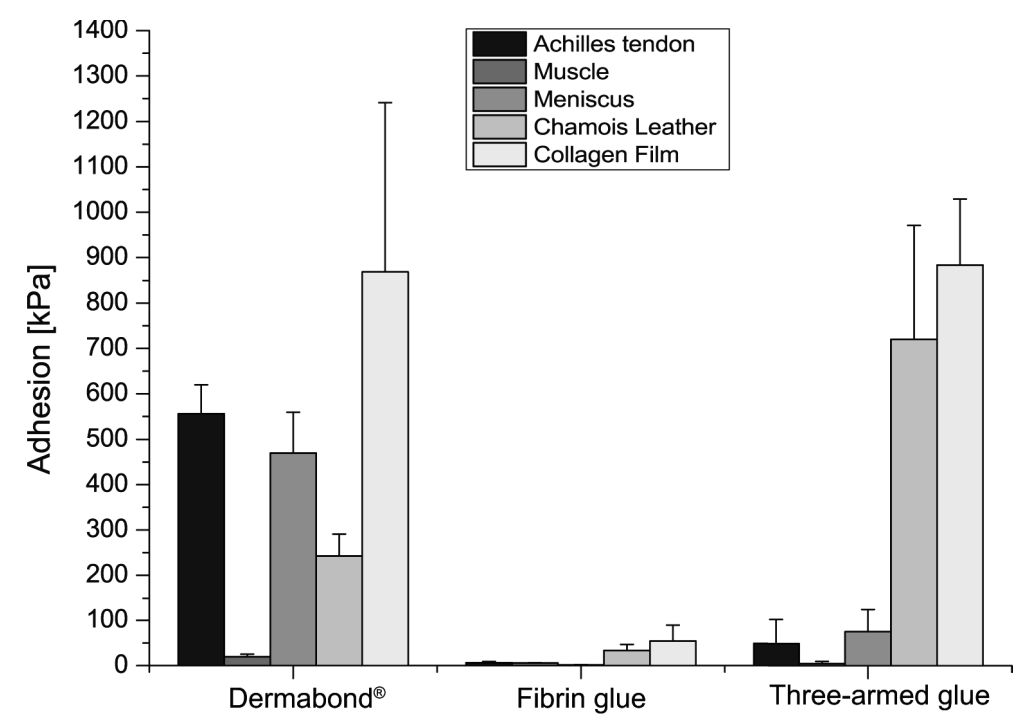

Figure 1. Adhesive strength of the different glues to different biological substrates determined in lap-shear testing. Data are presented as mean \pm standard deviations.

The static contact angles between drops of the glues and particular substrates are presented in Figure 2. Contact angles between Dermabond ${ }^{\circledR}$ and different substrates 
varied from $17.5 \pm 5.8^{\circ}$ to collagen films up to $35.8 \pm 2.1^{\circ}$ to muscle tissue. The contact angle between Dermabond ${ }^{\circledR}$ and chamois leather could not be determined, as drops of the glue were directly adsorbed into the surface of the substrate. The contact angle between fibrin glue and muscle tissue and chamois leather was relatively low; $11.1 \pm 2.1^{\circ}$ and $16.7 \pm 13.5^{\circ}$, respectively. For the other substrates it was slightly higher, ranging from $29.8 \pm 11.1^{\circ}$ for Achilles tendons up to $43.7 \pm 16.2^{\circ}$ for collagen films. The three-armed glue had similar contact angles to all the substrates, ranging from $43 \pm 3.3^{\circ}$ for collagen films to $54.3 \pm 2.6^{\circ}$ for chamois leather.

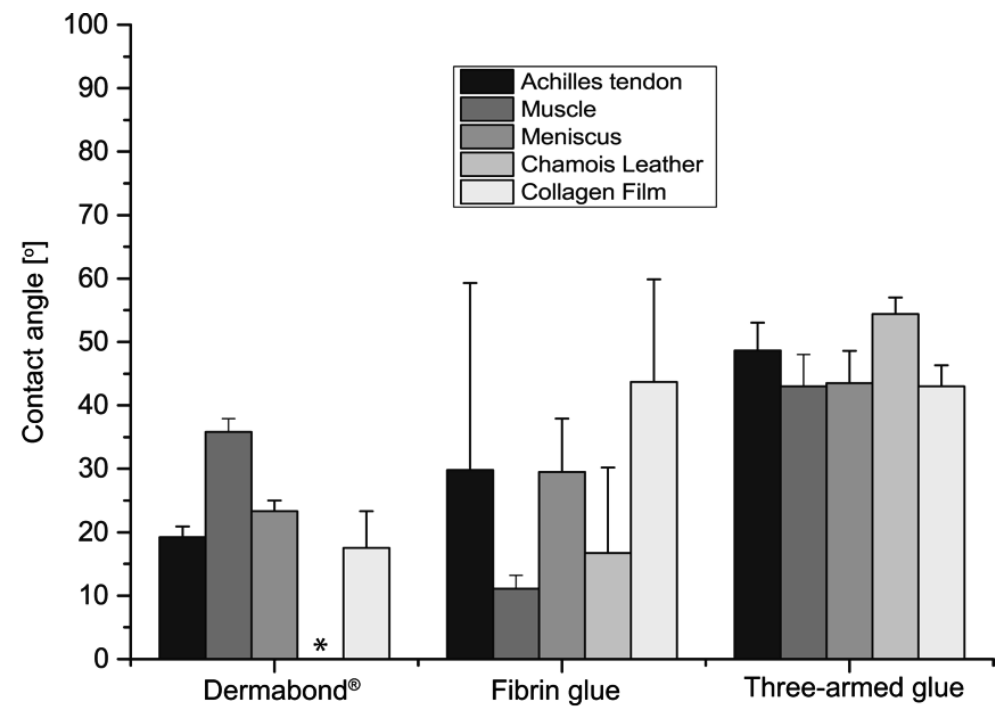

Figure 2. Static contact angles between glues and different hydrated substrates. Data are presented as mean \pm standard deviations. *Note that the contact angle between Dermabond ${ }^{\circledR}$ and chamois leather could not be determined due to immediate adsorption of the glue drop.

The water content of the substrates was between $63.3 \pm 1.8 \mathrm{wt} \%$ for Achilles tendon up to $77.5 \pm 1.5 \mathrm{wt} \%$ for muscle tissue (Figure 3 ). The collagen content of the human Achilles tendon is reported to be approximately $90 \%$ of the dry mass (mostly type I collagen). If we assume similar compositions of animal and human tissues, then taking the experimentally determined water content of $63.3 \mathrm{wt} \%$, the collagen content would constitute for approximately $24 \%$ of the wet mass. The 
experimentally measured meniscus water content of $68.9 \pm 0.8 \mathrm{wt} \%$ is very close to values reported in literature, which are found to be approximately $72 \mathrm{wt} \%$ for healthy human meniscus [13]. The collagen content of meniscus tissue is approximately 22 $\mathrm{wt} \%$, mostly type I and II. In muscle tissue, on the other hand, collagen constitutes only between 2 and $6 \%$ of the wet mass [14]. Assuming that both chamois leather and collagen films consist of only collagen, their collagen contents are approximately $26 \%$ of their wet mass.

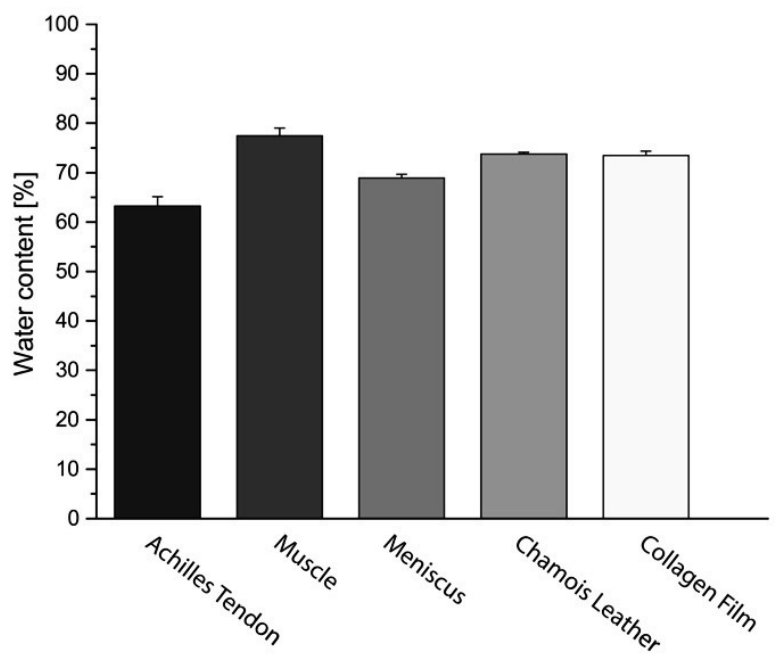

Figure 3. Water content of the investigated substrates. Data are presented as mean \pm standard deviations.

The SEM images of the surfaces of the substrates showed clear differences in their morphology (Figure 4). Chamois leather had numerous exposed fibers at the surface. The surface of the collagen film on the other hand, was smooth. The structure of the surfaces of the living tissue was relatively smooth with visible fibers aligned parallel to the surface. Dermabond ${ }^{\circledR}$ and the three-armed block copolymeric glue formed a smooth film on the surfaces of the substrates. Fibrin glue, on the other hand seemed to be partially absorbed by the substrates, which is especially pronounced on the chamois leather surface. This, however, might be the effect of the drying procedure of the samples. 


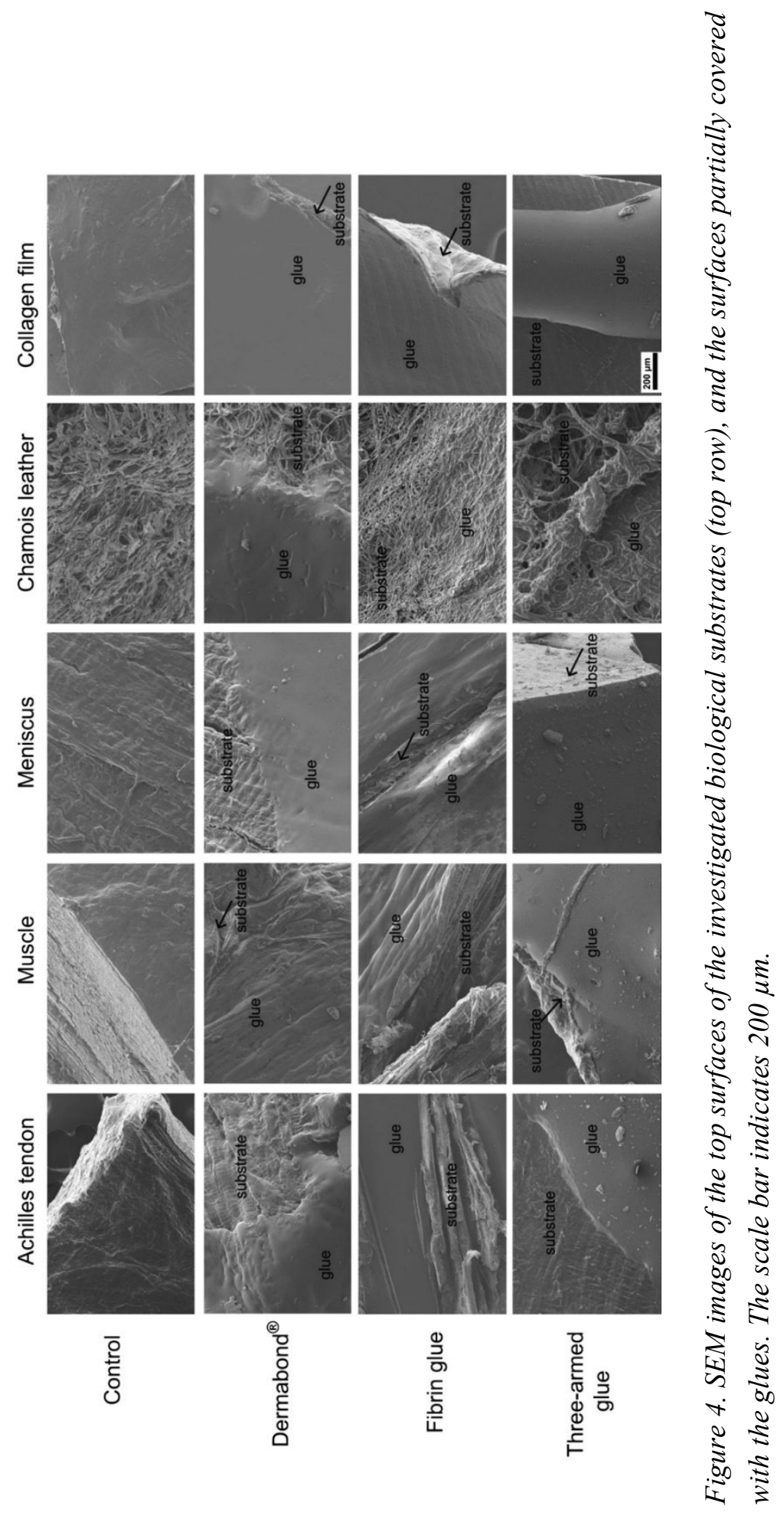


Additionally, images of cross-sections of the chamois leather and meniscus specimens after application of the three-armed adhesive, clearly showed that the glue had penetrated in-between the fibers of the chamois leather (Figure 5a). This was not the case with meniscus tissue, where the glue remained on the surface of the tissue (Figure 5b).
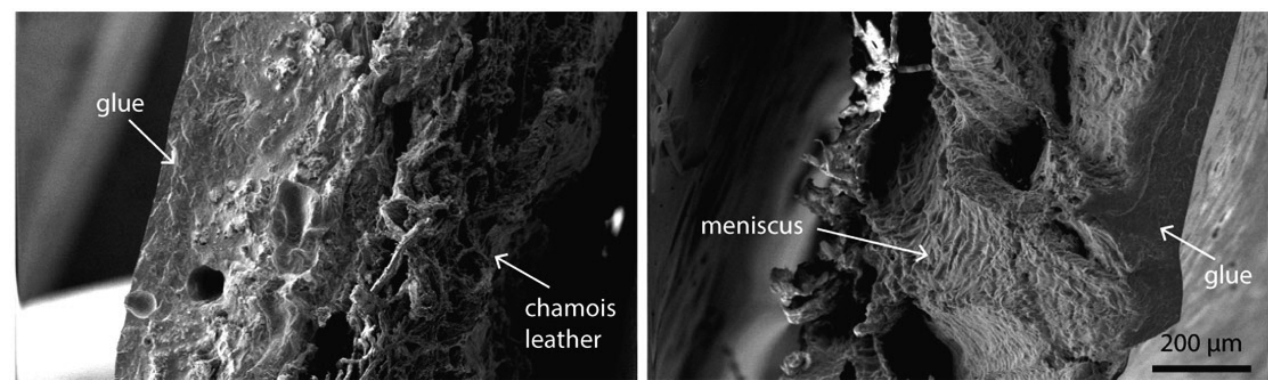

Figure 5. SEM images of the cross-sections of chamois leather (a) and meniscus tissue (b) after application of the three-armed adhesive on their surface.

\section{Discussion}

In order to understand the differences in adhesive strength of particular glues to various substrates, the gluing process must be analyzed. The gluing process consist of three main steps: (1) spreading of the liquid glue on the tissue surface (wetting), (2) attachment of the glue to the tissue and (3) curing of the glue (solidification). Steps (2) and (3) usually take place simultaneously. The attachment to the tissue can happen by means of chemical bonding, physical interactions (ionic interaction, van der Waals forces) or mechanical interlocking after solidification onto the surface of the substrate [15]. Therefore, both the chemistry and adhesive mechanisms of the glues and factors such as chemical composition and hydrophilicity of the substrates and their surface morphology are critical in achieving adhesive bond.

Dermabond ${ }^{\circledR}$ is based on 2-octyl cyanoacrylate, it polymerizes by reaction with trace amounts of water or upon contact with cell membranes and tissues [16]. The working mechanism of fibrin glue resembles the final stages of the blood coagulation process. It binds to the tissue by covalent bonding, and the formation of hydrogen- and electrostatic bonds [17]. The newly developed three-armed glue cures in the aqueous environment and attaches to the tissue via the formation of covalent bonds [12]. All 
glues additionally attach by mechanical interlocking onto the surface of the substrate.

Contact angle measurement gives information of how well the glue can spread and wet the surface of the substrate. The lower the contact angle between the glue and the substrate, the better the wetting of the surface is and the higher the adhesive strength is to be expected.

Dermabond ${ }^{\circledR}$ had similar contact angles to Achilles tendons, meniscus and collagen films, and its adhesive strength to these substrates was high. The somewhat higher contact angle between Dermabond ${ }^{\circledR}$ and muscle tissue and the fact that the glue was absorbed immediately by chamois leather are probably the reasons for the lower adhesive strength to these substrates. Fibrin glue had various contact angles with the different substrates. Its (poor) adhesive properties did not show clear dependence on these values. Also for the three-armed block copolymeric adhesive, no clear trend between adhesion strength and contact angle was established.

The collagen content and the hydrophilicity of the substrates are other factors determining the adhesive bond that can be achieved between glues and their surfaces. Muscle tissue had the lowest collagen content and the highest water percentage of all the substrates, and the adhesion strength of all three tested glues was relatively poor to muscle tissue when compared to other substrates. Moreover, both fibrin glue and the three-armed block copolymeric glue had higher adhesion strengths to chamois leather and collagen than to living tissues. It seems therefore, that the collagen content, which is higher for these two substrates than for the other substrates, is another critical factor determining the adhesion strength of these glues. Moreover, although the use of such synthetic substrates does not have the same clinical relevance as tests performed on living tissues, their production can be easily controlled thereby allowing to directly compare results obtained by different researchers. Furthermore, as their composition is well-defined, their use may increase the accuracy of the obtained adhesive results.

SEM images showed that chamois leather had numerous fibers exposed at the surface, possibly also allowing good mechanical interlocking of the glues. Indeed, the images of cross-sections of chamois leather and meniscus tissue after application 
of the three-armed adhesive clearly showed that the glue had penetrated in-between the fibers of the chamois leather. This explains the much higher adhesive strength of the three-armed glue to chamois leather $(719 \pm 225 \mathrm{kPa})$ than to meniscus tissue $(88.2 \pm 50.8 \mathrm{kPa})$. In addition, except for Dermabond ${ }^{\mathbb{B}}$ which due to its low viscosity was immediately absorbed, also the fibrin glue had better adhesion to chamois leather than to the other substrates. Furthermore, collagen films were a substrate that could readily be glued too by all three glues.

Based on the obtained results, it seems that collagen content, hydrophilicity and surface topography are critical factors for achieving good adhesive bonds. Employment of substrates that mimic the natural living tissues of interest, are the most promising materials with which to perform preliminary screening experiments in the development of novel adhesive materials. Nevertheless, in further evaluation of new materials, examination on the targeted animal- or human tissues should be performed in a well-controlled and standardized manner.

\section{Conclusions}

The results of adhesion strength determinations showed that not only the glues, but also the biological substrate had a significant influence on the adhesive strength of the bond. Therefore, there is a need for the development of unified tissue models and procedures to evaluate adhesive strengths in the development of novel tissue adhesives. Employing such a universal and standardized strategy would allow directly comparing the adhesive properties of different glues and extrapolating the results to the targeted human tissues.

\section{References}

[1] Gross L, Hoffman R. Handbook of Adhesives. New York: Van Nostrand Reinhold; 1977.

[2] Bruns TB, Worthington JM. Using tissue adhesive for wound repair: A practical guide to Dermabond. American Family Physician 2000;61:1383-8.

[3] Spotnitz WD. Commercial fibrin sealants in surgical care. American Journal of Surgery 2001;182:8S-14S.

[4] Gilbert TW, Badylak SF, Beckman EJ, Clower DM, Rubin JP. Prevention of seroma formation with TissuGlu ${ }^{\circledR}$ surgical adhesive in a canine abdominoplasty model: Long term clinical and histologic studies. Journal of Plastic, Reconstructive and Aesthetic Surgery 2013;66:414-22. 
[5] Cohn D, Lando G. Tailoring lactide/caprolactone co-oligomers as tissue adhesives. Biomaterials 2004;25:5875-84.

[6] Lando G, Cohn D. Introducing lactide-based biodegradable tissue adhesives. Journal of Materials Science-Materials in Medicine 2003;14:181-6.

[7] Ferreira P, Coelho JFJ, Gil MH. Development of a new photocrosslinkable biodegradable bioadhesive. International Journal of Pharmaceutics 2008;352:172-81.

[8] Ferreira P, Silva AFM, Pinto MI, Gil MH. Development of a biodegradable bioadhesive containing urethane groups. Journal of Materials Science-Materials in Medicine 2008;19:111-20.

[9] Wang T, Nie J, Yang D. Dextran and gelatin based photocrosslinkable tissue adhesive. Carbohydrate Polymers 2012;90:1428-36.

[10] $\mathrm{Hu} \mathrm{BH}$, Messersmith PB. Enzymatically cross-linked hydrogels and their adhesive strength to biosurfaces. Orthodontics \& craniofacial research 2005;8:145-9.

[11] Sheikh N, Mirzadeh H, Katbab AA, Salehian P, Daliri M, Amanpour S. Isocyanate-terminated urethane prepolymer as bioadhesive material: Evaluation of bioadhesion and biocompatibility, in vitro and in vivo assays. Journal of Biomaterials Science-Polymer Edition 2001;12:707-19.

[12] Bochyńska AI, Sharifi S, van Tienen TG, Buma P, Grijpma DW. Development of Tissue Adhesives Based on Amphiphilic Isocyanate-Terminated Trimethylene Carbonate Block Copolymers. Macromolecular Symposia 2013;334:40-8, Chapter 3 of this thesis.

[13] Herwig J, Egner E, Buddecke E. Chemical changes of human knee joint menisci in various stages of degeneration. Annals of the Rheumatic Diseases 1984;43:635-40.

[14] Sikorski ZE. Chemical and Functional Properties of Food Proteins: Boca Raton: CRC Press; (2001).

[15] Mehdizadeh M, Yang J. Design strategies and applications of tissue bioadhesives. Macromol Biosci 2013;13:271-88.

[16] Vote BJT, Elder MJ. Cyanoacrylate glue for corneal perforations: a description of a surgical technique and a review of the literature. Clinical and Experimental Ophthalmology 2000;28:437-42.

[17] Sierra DH. Fibrin Sealant Adhesive Systems: A Review of Their Chemistry, Material Properties and Clinical Applications. Journal of Biomaterials Applications 1993;7:309-52. 


\section{Chapter 5}

\section{Development of Biodegradable Hyper-Branched Tissue Adhesives for the Repair of Meniscus Tears}

Agnieszka I. Bochyńska ${ }^{1,2}$, Tony G. van Tienen ${ }^{2}$, Gerjon Hannink ${ }^{2}$, Pieter Buma ${ }^{2}$, Dirk W. Grijpma ${ }^{1,3}$

${ }^{1}$ Department of Biomaterials Science and Technology, MIRA Institute, University of Twente, Enschede, the Netherlands

${ }^{2}$ Orthopaedic Research Laboratory, Department of Orthopaedics, Radboud Centre for Molecular Life Sciences, Radboud University Nijmegen Medical Centre, Nijmegen, the Netherlands

${ }^{3}$ University Medical Centre Groningen, University of Groningen, W.J. Kolff Institute, Department of Biomedical Engineering, Groningen, the Netherlands 


\begin{abstract}
Meniscus tears are one of the most commonly occurring injuries of the knee joint. Current meniscus repair techniques are challenging and do not bring fully satisfactory results. Tissue adhesives are a promising alternative, since they are easy to apply and cause minimal tissue trauma.

In this study, a series of amphiphilic copolymers based on polyethylene glycol, trimethylene carbonate and citric acid were synthesized and subsequently endfunctionalized with hexamethylene diisocyanate to form reactive adhesive materials. The shear adhesive strength of the networks to bovine meniscus tissue measured in a lap-shear adhesion test ranged between $20-80 \mathrm{kPa}$, which was better than for fibrin glue $(10 \mathrm{kPa})$. The elastic modulus of the networks depended on composition and was in the same range as that of human meniscus. Cell compatibility was assessed using Alamar Blue staining after incubation of the bovine meniscus cells with different concentrations of the glues for 7 days. Cell viability was not affected after adding up to $3 \mathrm{mg}$ of the adhesive $/ \mathrm{mL}$ of medium.

The proposed materials are suitable candidates to be used as resorbable tissue adhesives for meniscus repair. They have excellent mechanical and adhesive properties that can be adjusted by varying the composition of the copolymers.
\end{abstract}

\title{
Introduction
}

Menisci are fibro-cartilaginous tissues present in duplicate in the knee joint. They play a crucial role in shock absorption and distribution of forces in the joint, as well as in lubrication and nutrition of articular cartilage [1]. Most injuries of the knee are associated with meniscus trauma; the meniscus tears which lead to pain, swelling and locking of the joint. Since menisci are only well-vascularized in the outer, peripheral zone, they have very limited capacity to self-repair $[2,3]$.

The preferred treatment strategy is to repair the meniscus using sutures or staples to restore the integrity of the tissue [4], or in case of tears in the avascular outer part, a partial meniscectomy is frequently performed. However, both solutions carry their drawbacks. Meniscectomy brings instant pain relief, but removal of only $15-34 \%$ of the meniscus will lead to a $350 \%$ increase in the contact stress in the joint and thus 
eventually will lead to development of degenerative changes and osteoarthritis [5]. Using sutures on the other hand, is mostly successful in the vascularized, peripheral zone of the meniscus, where cells have access to nutrients and growth factors $[6,7]$. The arthroscopic procedure using sutures is technically challenging, timeconsuming, the sutures are expensive and the success rate very much depends on the location and type of tear [8].

An attractive alternative for suturing would be use of biodegradable tissue adhesives [9]. Ideally, these materials provide stability by holding the torn tissue together during the period of healing, and gradually degrade to biocompatible products [10]. The application procedure could be faster, easier and cheaper than in the case of sutures. Tissue adhesives are already successfully used in other surgical applications, such as Dermabond ${ }^{\circledR}$ (2-octyl cyanoacrylate) for skin lacerations [11] or fibrin glue in hemostasis or pulmonary air leaks $[12,13]$. However, none of them is suitable for gluing the damaged meniscus. Cyanoacrylates are rigid and brittle materials, their elastic modulus $\left(\mathrm{E}_{\mathrm{mod}}\right)$ is approximately $500 \mathrm{MPa}$ [14], while the $\mathrm{E}_{\mathrm{mod}}$ of meniscus tissue (in circumferential direction) is only between 40-160 MPa [1, 15]. Moreover, formaldehyde is a degradation product, which limits their application within the body [16]. Fibrin glue is a natural biocompatible compound, but has poor mechanical and adhesive properties and a rapid degradation profile [17, 18]. Furthermore, it can be a source of disease transmission [19].

With these limitations in mind, we have been developing new polymeric tissue adhesives that are flexible and strong, and at the same time biocompatible and biodegradable. The adhesion process to the tissue consists of two steps: 1) wetting the surface of the tissue and 2) attachment to the tissue and curing of the material (network formation) [20]. Therefore, in order to provide optimal gluing of the meniscus, the glue must first spread well on the wet tissue surface. The material should therefore be sufficiently hydrophilic. At the same time, the polymeric network that is formed upon curing of the adhesive should be able to withstand the mechanical forces present at the site of application. For this, we envisaged the use of amphiphilic block-copolymers with hydrophilic blocks that ensure good spreading on the tissue surface and hydrophobic blocks that lead to networks with adequate mechanical properties. 
Previously, we reported on the synthesis and characterization of three-armed starshaped isocyanate-terminated block copolymers based on trimethylene carbonate (TMC) and trimethylolpropane ethoxylate (TMPE) [21]. These materials are capable to react with primary amines present in the proteins at the surface of the tissue and form stable covalent urea bonds with them [22]. At the same time they react with surrounding water forming a solid polyester-polyurethane network.

We showed that these three-armed copolymers had good adhesive potential and demonstrated better properties than analogous linear copolymers. Based on these results, we expect that by increasing degree of branching of the copolymers, and then the number of reactive groups which attach to the surface, it will be possible to enhance their adhesive properties.

In this paper, we report on the synthesis and characterization of novel hyperbranched amphiphilic, isocyanate-terminated copolymeric oligomers that vary in composition and in architecture and their possible application as a tissue adhesive for meniscus repair.

\section{Materials and Methods}

\section{Materials}

Poly(ethylene glycol) with number average molar mass (Mn) of $200 \mathrm{~g} / \mathrm{mol}_{\left(\mathrm{PEG}_{200}\right)}$ and $600 \mathrm{~g} / \mathrm{mol}\left(\mathrm{PEG}_{600}\right)$, citric acid $(\mathrm{CA})$, chloroform-d $\left(\mathrm{CDCl}_{3}\right)$, fibrinogen and thrombin (both isolated from bovine plasma), phosphate buffered saline (PBS), cholesterol esterase (from porcine pancreas, $35 \mathrm{U} / \mathrm{mL}$ ) (CE) were purchased from Sigma Aldrich (the Netherlands). Trimethylene carbonate (TMC) was obtained from ForYou (China). Hexamethylene diisocyanate (HDI) was purchased from Merck Schuchardt (Germany). Diethyl ether was purchased from Biosolve (the Netherlands). $\mathrm{PEG}_{200}$ and $\mathrm{PEG}_{600}$ were dried at $120{ }^{\circ} \mathrm{C}$ under vacuum, diethyl ether was dried over molecular sieves prior to use. All other chemicals were used as received. Dermabond ${ }^{\circledR}$ was obtained from Ethicon (Johnson \& Johnson, The Netherlands). Dulbecco's Modified Eagle's Medium (DMEM), fetal bovine serum (FBS) and Antibiotic-Antimycotic (PSF, contains 10,000 units/mL of penicillin, $10,000 \mu \mathrm{g} / \mathrm{mL}$ of streptomycin, and $25 \mu \mathrm{g} / \mathrm{mL}$ of Fungizone ${ }^{\circledR}$ ) were purchased from 
Gibco $^{\circledR}$ (UK). Collagenase type II was purchased from Worthington (USA). Bovine meniscus tissue was obtained from a local abattoir.

\section{Synthesis of oligomers and isocyanate-terminated hyper-branched oligomers}

A series of reactive isocyanate-terminated hyper-branched oligomers was prepared in a three step synthesis process, which is schematically depicted in the Figure 1. Ring opening polymerization of TMC using PEG as initiator was performed as previously described [21] (Figure 1a). TMC was reacted with $\mathrm{PEG}_{200}$ or $\mathrm{PEG}_{600}$ using $\mathrm{Sn}(\mathrm{Oct})_{2}(0.02 \mathrm{mmol} / \mathrm{mol}$ of monomer $)$ as a catalyst. The polymerization was conducted at $130{ }^{\circ} \mathrm{C}$ for 3 days under argon atmosphere. Linear oligomers with TMC to PEG molar ratios of 2:1 and 4:1 were prepared. The used nomenclature for these blockcopolymeric precursors is: $\mathrm{PEG}_{\mathrm{m}}-\left(\mathrm{TMC}_{\mathrm{n}}\right)_{2}$, where $\mathrm{m}$ is molar mass of PEG, $\mathrm{n}$ is the number of TMC units (in PTMC chain) per PEG chain end.

Then, the linear oligomers were reacted with $\mathrm{CA}$ in a polycondensation reaction at $120{ }^{\circ} \mathrm{C}$ for 1 day under vacuum (Figure $1 \mathrm{~b}$ ). In this manner hyper-branched oligomers were obtained with $\mathrm{PEG}_{\mathrm{m}}-\left(\mathrm{TMC}_{\mathrm{n}}\right)_{2}$ to $\mathrm{CA}$ molar ratios of 4:1, 7:1 and 10:1, respectively. The used nomenclature of these hyper-branched oligomers is: CA-xPEG $-\left(\mathrm{TMC}_{\mathrm{n}}\right)_{2}$, where $\mathrm{x}$ is 4,7 or 10 . To obtain reactive isocyanate-terminated molecules, these hyper-branched oligomers were subsequently reacted with excess of HDI at $75{ }^{\circ} \mathrm{C}$ for 1 day under argon atmosphere (Figure 1c). Drop-wise addition of the hyper-branched oligomer to HDI ensured that the molar excess of HDI was at least 1:3. Unreacted HDI was removed by washing in dry diethyl ether. The product was then dried under vacuum overnight. The resulting products were labelled: [CA$\left.\mathrm{xPEG}_{\mathrm{m}}-\left(\mathrm{TMC}_{\mathrm{n}}\right)_{2}\right]$-HDI.

An overview of prepared reactive isocyanate-terminated hyper-branched oligomers is given in Table 1. 

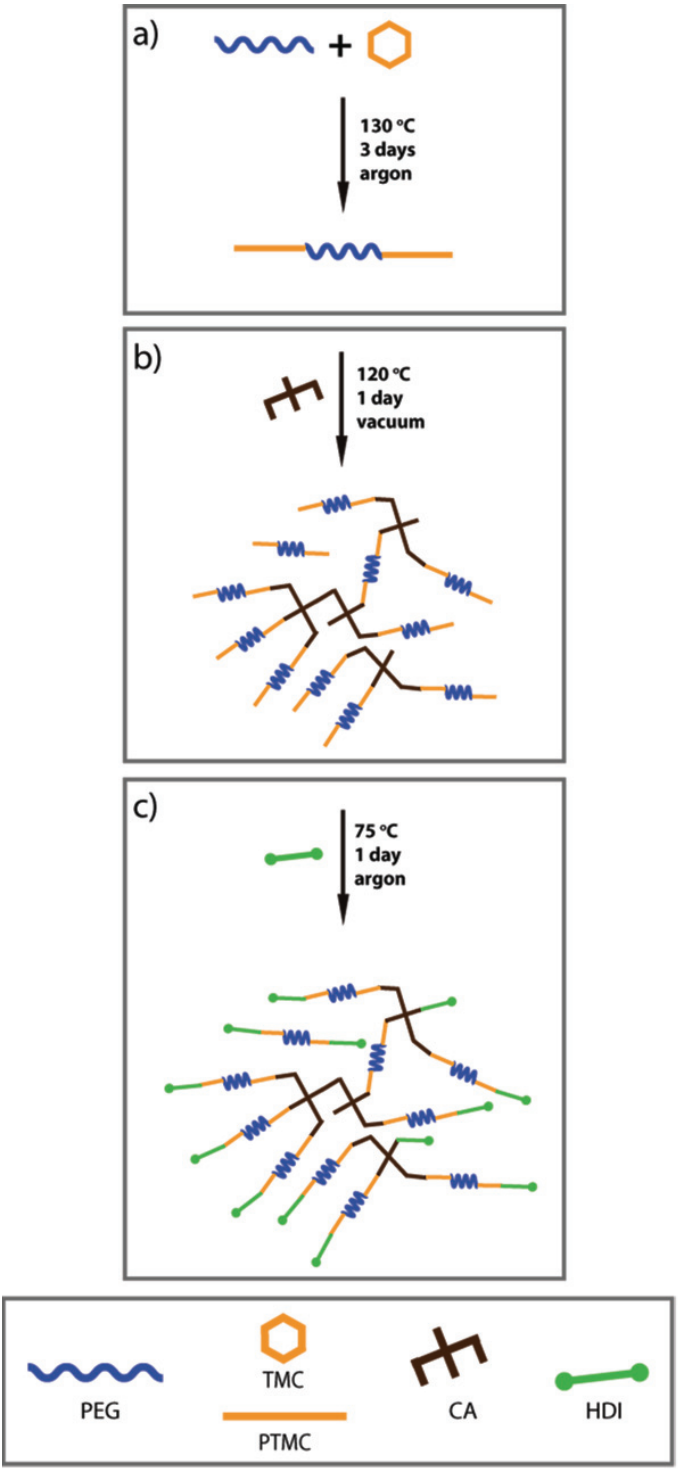

Figure 1. Scheme of the three-step synthesis of reactive isocyanate-terminated hyper-branched oligomers, a) Step 1: ring opening polymerization of TMC using PEG results in the formation of linear amphiphilic oligomers, b) Step 2: polycondensation of the linear amphiphilic oligomers and $C A$ resulting in hyperbranched structures, c) Step 3: reaction of the end groups of these hyper-branched structures with excess HDI resulting in the formation of reactive isocyanateterminated hyper-branched oligomers. 
Table 1. Overview of the prepared reactive isocyanate-terminated hyper-branched oligomers.

\begin{tabular}{|c|c|c|}
\hline & $1 \mathrm{TMC}$ unit per PEG chain end & 2 TMC units per PEG chain end \\
\hline \multirow{3}{*}{ 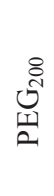 } & {$\left[\mathrm{CA}-4 \mathrm{PEG}_{200}-\left(\mathrm{TMC}_{1}\right)_{2}\right]-\mathrm{HDI}$} & {$\left[\mathrm{CA}-4 \mathrm{PEG}_{200}-\left(\mathrm{TMC}_{2}\right)_{2}\right]-\mathrm{HDI}$} \\
\hline & {$\left[\mathrm{CA}-7 \mathrm{PEG}_{200}-\left(\mathrm{TMC}_{1}\right)_{2}\right]-\mathrm{HDI}$} & {$\left[\mathrm{CA}-7 \mathrm{PEG}_{200}-\left(\mathrm{TMC}_{2}\right)_{2}\right]-\mathrm{HDI}$} \\
\hline & {$\left[\mathrm{CA}-10 \mathrm{PEG}_{200}-\left(\mathrm{TMC}_{1}\right)_{2}\right]-\mathrm{HDI}$} & {$\left[\mathrm{CA}-10 \mathrm{PEG}_{200}-\left(\mathrm{TMC}_{2}\right)_{2}\right]-\mathrm{HDI}$} \\
\hline \multirow{3}{*}{$\begin{array}{l}8 \\
0 \\
0 \\
\text { III } \\
2\end{array}$} & {$\left[\mathrm{CA}-4 \mathrm{PEG}_{600}-\left(\mathrm{TMC}_{1}\right)_{2}\right]-\mathrm{HDI}$} & {$\left[\mathrm{CA}-4 \mathrm{PEG}_{600}-\left(\mathrm{TMC}_{2}\right)_{2}\right]-\mathrm{HDI}$} \\
\hline & {$\left[\mathrm{CA}-7 \mathrm{PEG}_{600}-\left(\mathrm{TMC}_{1}\right)_{2}\right]-\mathrm{HDI}$} & {$\left[\mathrm{CA}-7 \mathrm{PEG}_{600}-\left(\mathrm{TMC}_{2}\right)_{2}\right]-\mathrm{HDI}$} \\
\hline & {$\left[\mathrm{CA}-10 \mathrm{PEG}_{600}-\left(\mathrm{TMC}_{1}\right)_{2}\right]-\mathrm{HDI}$} & {$\left[\mathrm{CA}-10 \mathrm{PEG}_{600}-\left(\mathrm{TMC}_{2}\right)_{2}\right]-\mathrm{HDI}$} \\
\hline
\end{tabular}

The composition and chemical structure of the intermediate linear- and hyperbranched oligomers, and of the isocyanate functionalized end-products was evaluated using ${ }^{1} \mathrm{H}$ NMR spectroscopy (Bruker 400MHz NMR spectrometer) using $\mathrm{CDCl}_{3}$ as the solvent. The $-\mathrm{NCO}$ content of the reactive hyper-branched oligomers was determined by back-titration of the isocyanate groups according to the ASTM D2572 standard.

\section{Characterization of the networks obtained after curing the isocyanate- terminated hyper-branched oligomers}

Cross-linked polyurethane networks were obtained by casting $0.3 \mathrm{~mm}$ thick films of the isocyanate-terminated hyper-branched oligomers on glass plates, subsequent overnight immersion in water at room temperature (RT) allowed the curing reaction to take place.

In order to determine the physical characteristics of the obtained water-cured network films, they were dried in vacuum at $40{ }^{\circ} \mathrm{C}$ until constant weight and their initial mass was determined $\left(\mathrm{m}_{\mathrm{i}}\right)$. To assess the process of network formation, the gel content of the networks was determined after vacuum-drying. The specimens were incubated in chloroform, which was determined to be a good swelling agent and a suitable solvent to extract the sol fraction of the network, for 24 hours and dried in vacuum until constant weight $\left(\mathrm{m}_{\mathrm{dc}}\right)$. 
The gel content (GC) was calculated according to:

$$
G C=\left(\frac{m_{d c}}{m_{i}}\right) \cdot 100 \%
$$

To assess their swelling behavior, the obtained water-cured network films were also placed in water for 24 hours, and their wet mass $\left(\mathrm{m}_{\mathrm{w}}\right)$ was determined. The samples were then re-dried (in vacuum at $40{ }^{\circ} \mathrm{C}$ ) until constant weight, and their dry mass was determined $\left(\mathrm{m}_{\mathrm{dw}}\right)$.

The water uptake (WU) was calculated using:

$$
W U=\left(\frac{m_{w}-m_{d w}}{m_{d w}}\right) \cdot 100 \%
$$

Of each network, three different specimens were evaluated.

The thermal properties of the water-cured networks in their wet as-prepared state were determined by differential scanning calorimetry (DSC) using a Perkin Elmer Pyris 1 . Samples weighing $5-10 \mathrm{mg}$ were heated from $-100{ }^{\circ} \mathrm{C}$ to $100{ }^{\circ} \mathrm{C}$ at $10{ }^{\circ} \mathrm{C} / \mathrm{min}$.

Dumbbell-shaped test specimens of the water-cured network films were prepared as described above. The wet as-prepared samples were subjected to tensile testing at room temperature in triplicate according to ISO 37:1994 (E), Type 3 using a Zwick Z020 universal tensile tester. The grip to grip separation was $35 \mathrm{~mm}$ and the crosshead speed was $50 \mathrm{~mm} / \mathrm{min}$.

\section{In vitro degradation of water-cured polyurethane networks}

The in vitro degradation of the water-cured networks was assessed in PBS solutions ( $\mathrm{pH}=7.4$, containing $0.02 \mathrm{wt} \%$ of sodium azide as bactericide) at $37^{\circ} \mathrm{C}$. Disc-shaped specimens (10 $\mathrm{mm}$ in diameter and thicknesses varying between 100 and $500 \mu \mathrm{m})$ were punched out from the network films and placed in 48 well-plates containing 1 $\mathrm{mL}$ of PBS and let to degrade. The medium was changed twice a week. At predetermined time points, the specimens were recovered and their mass and thickness were determined in the wet state and after drying in vacuum until constant weight. Of each network triplicate specimens were evaluated. 
Additionally, enzymatic degradation experiments were conducted in the same manner using CE solution in PBS ( $20 \mu \mathrm{g} / \mathrm{mL}, 0.02 \mathrm{wt} \%$ of sodium azide). The results of these experiments are presented in the Supplementary Material.

\section{Application of the reactive isocyanate-terminated hyper-branched oligomers as tissue adhesives}

The reactive isocyanate-terminated hyper-branched oligomers were used as an adhesive to glue bovine meniscus tissue. The bovine menisci were cut in circumferential direction to obtain strips measuring approximately $2 \times 10 \times 25 \mathrm{~mm}$. The strips of tissue were kept hydrated until the gluing experiment. The surfaces of the tissue strips were blotted dry and the different isocyanate-functionalized oligomers, which are viscous liquids, were applied to the strips of tissue using a spatula. They were then pressed together and immersed in water overnight. The adhesive covered an area of approximately $100 \mathrm{~mm}^{2}$. Two of these strips were then pressed together and immersed in water and left overnight at RT to allow attachment of the adhesive to the substrate, curing and network formation. This environment is a simplification of the wet synovial fluid-containing knee joint, but it allows us to investigate the curing characteristics of the different networks and their adhesive strengths to the tissue. Figure $2 \mathrm{a}$ and $2 \mathrm{~b}$ illustrate this process.

To determine the strength of the adhesive bond after curing, the wet specimens were subjected to lap shear adhesion testing (Figure 2c) using a Zwick Z020 universal tensile tester in analogy to ASTM F2255-05. The grip to grip separation was $25 \mathrm{~mm}$ and the crosshead speed was $50 \mathrm{~mm} / \mathrm{min}$. The shear adhesive bond strength (S) expressed in $\mathrm{kPa}$ is the maximum shear force divided by the glued area. For each adhesive, the experiments were conducted in triplicate.

Additionally, the performance of two commercially available tissue adhesives, fibrin glue and Dermabond ${ }^{\circledR}$, was evaluated. Fibrin glue was prepared by dissolving fibrinogen and thrombin in PBS at concentrations of $100 \mathrm{mg} / \mathrm{mL}$ and $100 \mathrm{U} / \mathrm{mL}$, respectively. These two solutions were mixed in a double barrel syringe equipped with a static mixer and directly applied onto the strips of bovine meniscus tissue. Dermabond ${ }^{\circledR}$ was used as received and also directly applied onto the meniscus strips. 
In these cases the lap shear adhesion tests were conducted directly after applying the adhesives, as theses adhesives cure within a few seconds.

\section{Cell culturing in the presence of reactive isocyanate-terminated hyper- branched oligomers}

Meniscus cells were isolated from bovine meniscus tissue (cut to pieces of approximately $1 \mathrm{~mm}^{3}$ ) after digestion in collagenase solution for 2 days at $37^{\circ} \mathrm{C}$ and $5 \% \mathrm{CO}_{2}$. The solution contained collagenase type II ( $3 \mathrm{mg} / \mathrm{mL}$ of medium), DMEM, $10 \%$ FBS and $1 \%$ PSF. The cells were isolated from remaining extracellular matrix using a $70 \mu \mathrm{m}$ cell bag.

The bovine meniscus cells were cultured for 5 days in DMEM medium containing $10 \%$ FBS and $1 \%$ of PSF using 24 well-plates in standard culture conditions $\left(37^{\circ} \mathrm{C}\right.$, $5 \% \mathrm{CO}_{2}, 95 \%$ humidity). The cell concentration was 25,000 cells/well, the wells contained $1 \mathrm{~mL}$ of medium. On day 5 the cells were stained using the Alamar Blue ${ }^{\circledR}$ (Bio-Rad, AbD Serotec ${ }^{\circledR}$, UK) cell metabolic activity assay and counted. The cells were then further cultured in the presence of varying amounts of isocyanateterminated hyper-branched oligomeric adhesives. Amounts of 0.5 to $30 \mathrm{mg}$ of these reactive hyper-branched oligomers were placed on permeable Transwell ${ }^{\circledR}$ membranes, which were subsequently immersed in the medium. Cell viability was again assessed after 1, 3 and 7 days upon contacting the medium with the isocyanateterminated hyper-branched oligomeric adhesives (this corresponds to day 5, 8 and 12 of overall culture time). The experiments were conducted at least in triplicate.

In addition, the Live/Dead ${ }^{\circledR}$ assay (Molecular Probes, the Netherlands) in which calcein $\mathrm{AM}(2 \mu \mathrm{M}$ solution) stains living cells green and ethidium homodimer-1 ( $4 \mu \mathrm{M}$ solution) stains dead cells red, was used to visualize the viable and non-viable cells. 
a)

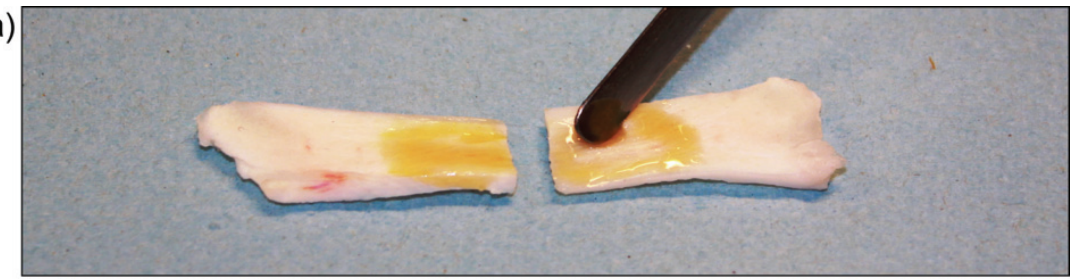

b)

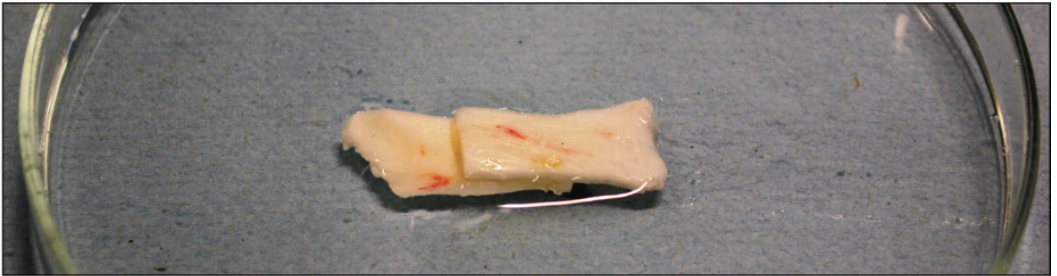

c)

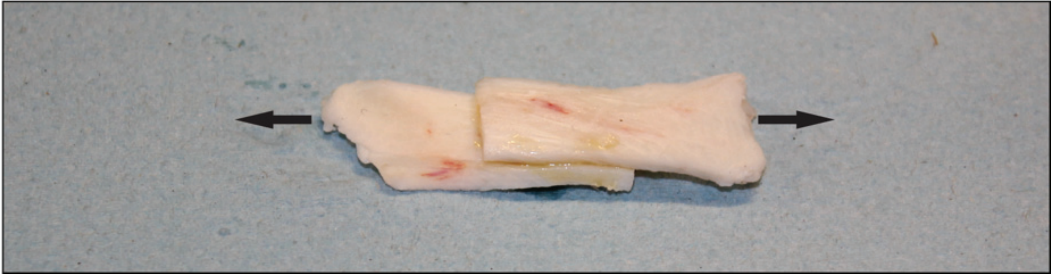

Figure 2. a) Application of the reactive isocyanate-terminated hyper-branched oligomer (adhesive) on strips of meniscus tissue (the covered area is approximately $1 \mathrm{~cm}^{2}$, b) Two strips of tissue are glued, pressed together and kept immersed in water overnight, c) The glued specimens are then subjected to lap shear testing.

\section{Statistical analysis}

Descriptive statistics were used to summarize the data. Data were expressed as mean values \pm standard deviations. For the adhesion tests, all compositions of the tissue adhesives were compared with fibrin glue using one-way ANOVA followed by Fisher's LSD post-hoc test. For the degradation study, the main effects of mass loss in time between networks containing $\mathrm{PEG}_{200}$ and $\mathrm{PEG}_{600}$ were determined using twoway ANOVA. P-values $<0.05$ were considered statistically significant. Statistical analyses were performed using SPSS (IBM, version 21). 


\section{Results and Discussion}

\section{Synthesis and characterization of reactive isocyanate-terminated hyper- branched oligomers}

A series of hyper-branched isocyanate-terminated reactive oligomers was synthesized in a three-step procedure. First linear amphiphilic copolymers containing $\mathrm{PEG}_{200}$ or $\mathrm{PEG}_{600}$ and $\mathrm{TMC}\left(\mathrm{PEG}_{\mathrm{m}}-\left(\mathrm{TMC}_{\mathrm{n}}\right)_{2}\right)$ were prepared. Then the linear copolymers were reacted with $\mathrm{CA}$ in a polycondensation reaction. As the functionality of CA is higher than 2, this would lead to the formation of branched structures [23]. To obtain oligomers with different degrees of branching, the ratio of $\mathrm{PEG}_{\mathrm{m}}-\left(\mathrm{TMC}_{\mathrm{n}}\right)$ to $\mathrm{CA}$ was varied. Oligomers with $\mathrm{PEG}_{\mathrm{m}}-\left(\mathrm{TMC}_{\mathrm{n}}\right)$ to CA ratios of 4:1, 7:1 or 10:1 were prepared. In these molecules the ratio of the hydroxyl-to carboxyl groups was $3: 1,5: 1$ and 7:1, respectively. As the linear $\mathrm{PEG}_{\mathrm{m}}-\left(\mathrm{TMC}_{\mathrm{n}}\right)_{2}$ component was always used in excess, gelation during the polycondensation reaction was avoided and hyper-branched polyesters with unreacted terminal hydroxyl groups were obtained. The hyper-branched polyesters were then end-functionalized by reaction with excess with HDI and removal of the unreacted HDI by washing.

In the different steps of the reaction, NMR was used to follow the synthesis process. The successful synthesis of linear $\mathrm{PEG}_{\mathrm{m}}-\left(\mathrm{TMC}_{\mathrm{n}}\right)_{2}$ oligomers was confirmed by the presence of peaks corresponding to PEG repeating units at $3.5 \mathrm{ppm}$ and to peaks corresponding to TMC at 4.2 and $2.1 \mathrm{ppm}$. After reacting the linear $\mathrm{PEG}_{\mathrm{m}}-\left(\mathrm{TMC}_{\mathrm{n}}\right)_{2}$ copolymers with $\mathrm{CA}$, additional peaks corresponding to $\mathrm{CA}$ at $2.75 \mathrm{ppm}$ could be detected. After end-functionalization of the hyper-branched oligomers with the diisocyanate, peaks in the NMR spectra at 3.3 and 1.3-1.7 ppm that correspond to HDI could be discerned. All synthesized oligomers were viscous liquids at RT and at $37{ }^{\circ} \mathrm{C}$.

Comparison of the areas of the different peaks in the NMR spectra allowed the determination of the composition of the synthesized reactive isocyanate-terminated hyper-branched oligomers. Table 2 gives an overview of the composition of the adhesives. 
Table 2. Content of PEG, TMC and HDI (in wt \%), and of free isocyanate groups (-NCO) in the reactive hyper-branched oligomers.

\begin{tabular}{|c|c|c|c|c|}
\hline $\begin{array}{l}\text { Hyper-branched reactive } \\
\text { oligomer }\end{array}$ & $\begin{array}{l}\text { PEG content } \\
\text { in the } \\
\text { isocyanate- } \\
\text { terminated } \\
\text { oligomer } \\
{[\mathrm{wt} \%]^{\text {a) }}}\end{array}$ & $\begin{array}{l}\text { TMC content } \\
\text { in the } \\
\text { isocyanate- } \\
\text { terminated } \\
\text { oligomer } \\
{[\mathrm{wt} \%]^{\text {a) }}}\end{array}$ & $\begin{array}{l}\text { HDI content } \\
\text { in the } \\
\text { isocyanate- } \\
\text { terminated } \\
\text { oligomer } \\
{[\mathrm{wt} \%]^{\mathrm{a})}}\end{array}$ & $\begin{array}{l}\text { Free - } \\
\text { NCO } \\
\text { groups } \\
{[\%]^{\text {b) }}}\end{array}$ \\
\hline$\left[\mathrm{CA}-4 \mathrm{PEG}_{200}-\left(\mathrm{TMC}_{1}\right)_{2}\right]-\mathrm{HDI}$ & 27.1 & 26.5 & 32.7 & $11.8(1.5)$ \\
\hline$\left[\mathrm{CA}-7 \mathrm{PEG}_{200}-\left(\mathrm{TMC}_{1}\right)_{2}\right]-\mathrm{HDI}$ & 21.5 & 24.7 & 47.7 & $11.7(0.2)$ \\
\hline$\left[\mathrm{CA}-10 \mathrm{PEG}_{200}-\left(\mathrm{TMC}_{1}\right)_{2}\right]-\mathrm{HDI}$ & 19.1 & 22.8 & 38.1 & $14.7(2.0)$ \\
\hline$\left[\mathrm{CA}-4 \mathrm{PEG}_{200}-\left(\mathrm{TMC}_{2}\right)_{2}\right]-\mathrm{HDI}$ & 15.1 & 35.1 & 41.5 & $13.1(0.7)$ \\
\hline$\left[\mathrm{CA}-7 \mathrm{PEG}_{200}-\left(\mathrm{TMC}_{2}\right)_{2}\right]-\mathrm{HDI}$ & 13.4 & 31.5 & 37.9 & $9.5(0.9)$ \\
\hline$\left[\mathrm{CA}-10 \mathrm{PEG}_{200}-\left(\mathrm{TMC}_{2}\right)_{2}\right]-\mathrm{HDI}$ & 15.1 & 32.8 & 43.7 & $12.1(0.7)$ \\
\hline$\left[\mathrm{CA}-4 \mathrm{PEG}_{600}-\left(\mathrm{TMC}_{1}\right)_{2}\right]-\mathrm{HDI}$ & 41.8 & 14.7 & 37.6 & $10.9(0.7)$ \\
\hline$\left[\mathrm{CA}-7 \mathrm{PEG}_{600}-\left(\mathrm{TMC}_{1}\right)_{2}\right]-\mathrm{HDI}$ & 48.3 & 14.4 & 27.7 & $13.5(1.6)$ \\
\hline$\left[\mathrm{CA}-10 \mathrm{PEG}_{600}-\left(\mathrm{TMC}_{1}\right)_{2}\right]$-HDI & 51.4 & 12.6 & 33.6 & $6.9(1.2)$ \\
\hline$\left[\mathrm{CA}-4 \mathrm{PEG}_{600}-\left(\mathrm{TMC}_{2}\right)_{2}\right]-\mathrm{HDI}$ & 36.5 & 25.6 & 30.5 & $10.8(0.2)$ \\
\hline$\left[\mathrm{CA}-7 \mathrm{PEG}_{600}-\left(\mathrm{TMC}_{2}\right)_{2}\right]-\mathrm{HDI}$ & 37.1 & 26.7 & 31.4 & $7.1(1.9)$ \\
\hline$\left[\mathrm{CA}-10 \mathrm{PEG}_{600}-\left(\mathrm{TMC}_{2}\right)_{2}\right]-\mathrm{HDI}$ & 33.0 & 21.6 & 40.0 & $5.8 \quad(0.3)$ \\
\hline etermined by ${ }^{1} \mathrm{H}-\mathrm{NMR}$ in $\sin$ & xperiments & & & \\
\hline
\end{tabular}

The table shows that no clear influence of the extent of branching, indicated by the different $\mathrm{CA}$ to $\mathrm{PEG}_{\mathrm{m}}-\left(\mathrm{TMC}_{\mathrm{n}}\right)_{2}$ ratios, can be seen. This holds for compositions based on $\mathrm{PEG}_{200}$ as well as for compositions based on $\mathrm{PEG}_{600}$.

The number of free isocyanate groups of the reactive oligomers based on $\mathrm{PEG}_{200}$, which according to the testing standard is expressed as a mass percentage, is in the 
range of $10-15 \%$. There does not seem to be a clear effect of composition or degree of branching on the number of free isocyanate groups. For $\mathrm{PEG}_{600}$-based oligomers, the number of free reactive isocyanate groups seems to decrease from approximately 11 to approximately $7 \%$ with increasing $\mathrm{CA} / \mathrm{PEG}_{600}-\left(\mathrm{TMC}_{\mathrm{n}}\right)_{2}$ ratio. This implies that with an increasing extent of branching the number of available reactive isocyanate groups does not increase. It seems therefore not beneficial to further increase the $\mathrm{CA} / \mathrm{PEG}_{600}-\left(\mathrm{TMC}_{\mathrm{n}}\right)_{2}$ ratio to increase the number of reactive end-groups per molecule.

In these reactive hyper-branched oligomers, no apparent relationship between the HDI content and the number of free isocyanate groups can be seen either. It is thus likely that during the synthesis, purification or drying process, the (highly) reactive terminal isocyanate groups have reacted prematurely for example with traces of moisture present in the air or in the used solvents. The result of this is that these materials are not as well-defined as would be desired. Nevertheless, as shown later, these materials do have good adhesive properties.

\section{Physical properties of the water-cured polyurethane networks}

When an isocyanate-terminated tissue adhesive is applied to tissue, it not only forms covalent bonds with functional groups present on the tissue surface $\left(-\mathrm{NH}_{2},-\mathrm{COOH}\right.$, - $\mathrm{SH},-\mathrm{OH})$, it simultaneously also cures to form a network by reaction with water in the surrounding fluids [22]. It is therefore of great importance to evaluate the physical and mechanical properties of such networks and how these depend on the chemical composition of their precursors.

Polyurethane network films with a thickness of 100-500 $\mu \mathrm{m}$ were prepared by casting the reactive hyper-branched oligomers onto a glass plate, and cross-linking by reaction with water. An overview of the physical properties of the obtained networks is presented in Table 3. It can be seen in the table that in general networks with very high gel contents are obtained, especially for networks based on $\mathrm{PEG}_{200}$, where gel contents range from 93 to $100 \%$. For networks based on $\mathrm{PEG}_{600}$ gel contents are also high, although somewhat lower (61 to $99 \%$ ). This indicates that the cross-linking process is more efficient for hyper-branched oligomers based on $\mathrm{PEG}_{200}$. 
The water uptake of the networks is mainly related to the content of the hydrophilic PEG component in the network and was significantly higher for networks containing $\mathrm{PEG}_{600}$. In these networks the weight percentage of the PEG component was higher, rendering the networks more hydrophilic. In addition, longer PEG chains increase the mesh size of the networks, allowing them also to take up more water. Water uptake is influenced by the content of hydrophobic TMC as well: with increasing TMC content, water uptake decreases. This is especially pronounced for the networks based $\mathrm{PEG}_{600}$.

An overview of the mechanical properties of the networks in the wet state as determined in tensile testing experiments is also given in Table 3. Both their tensile strength $(\sigma)$ and elastic modulus (E) were found to be strongly dependent on the composition of the hyper-branched reactive oligomers used in network formation.

In the wet state, the tensile strength of networks based on $\mathrm{PEG}_{200}(6-9 \mathrm{MPa})$ was higher than the tensile strength of the ones based on $\mathrm{PEG}_{600}$ (approximately $1 \mathrm{MPa}$ ). The elastic modulus of the $\mathrm{PEG}_{200}$ networks was also higher than that of the $\mathrm{PEG}_{600}$, networks, with elastic modulus values of respectively 50-150 MPa and 1.5-6 $\mathrm{MPa}$ (see Table 3). These differences were the result of the differences in hydrophilicity of the networks; networks containing $\mathrm{PEG}_{200}$ were less hydrophilic and took up less water. Importantly, the elastic moduli of hydrated networks based on $\mathrm{PEG}_{200}$ were in the same range as the elastic modulus of human menisci measured in the circumferential direction (40-160 MPa) $[1,15,24]$. The elongation at break of the networks ranged from 30-100\%, no clear influence of composition could be observed.

Thermal analysis of the polyurethane networks after their preparation was done by DSC. It was shown that in the wet state the networks were essentially amorphous with only a minor melting endotherm corresponding to the urethane bonds at approximately $80{ }^{\circ} \mathrm{C}$. For all networks a clear glass transition lower than $37{ }^{\circ} \mathrm{C}$ was observed, their flexible rubber-like mechanical characteristics at physiological conditions. For networks containing $\mathrm{PEG}_{200}$ the glass transition temperature $\left(\mathrm{T}_{\mathrm{g}}\right)$ was significantly higher than for those containing $\mathrm{PEG}_{600}$. The $T_{\mathrm{g}}$ of the former networks ranged between -10 and $-17^{\circ} \mathrm{C}$, while $\mathrm{T}_{\mathrm{g}}$ of the latter networks varied between -38 and $-52{ }^{\circ} \mathrm{C}$. In both cases $\mathrm{T}_{\mathrm{g}}$ decreased with increasing TMC content. 
Table 3. Overview of the physical and mechanical properties of the prepared networks in the wet state. Values are expressed as mean values with standard deviations in brackets.

\begin{tabular}{|c|c|c|c|c|c|c|}
\hline $\begin{array}{l}\text { Hyper-branched reactive } \\
\text { oligomer }\end{array}$ & $\begin{array}{l}\text { PEG } \\
\text { content in } \\
\text { the } \\
\text { reactive } \\
\text { oligomer }^{\mathrm{a})} \\
{[\mathrm{wt} \%]}\end{array}$ & $\begin{array}{l}\text { Gel } \\
\text { Content } \\
{[\%]}\end{array}$ & $\begin{array}{l}\text { Water } \\
\text { uptake } \\
{[\%]}\end{array}$ & $\begin{array}{l}\text { Tensile } \\
\text { strength } \\
{[\mathrm{MPa}]}\end{array}$ & $\begin{array}{l}\mathrm{E}_{\text {mod }} \\
{[\mathrm{MPa}]}\end{array}$ & $\begin{array}{l}\text { Elongation } \\
\text { at break [\%] }\end{array}$ \\
\hline$\left[\mathrm{CA}-4 \mathrm{PEG}_{200}-\left(\mathrm{TMC}_{1}\right)_{2}\right]-\mathrm{HDI}$ & 27.1 & $\begin{array}{l}97.6 \\
(0.7)\end{array}$ & $\begin{array}{l}35.5 \\
(4.2)\end{array}$ & $\begin{array}{l}3.4 \\
(1.2)\end{array}$ & $\begin{array}{l}52.8 \\
(16.7)\end{array}$ & $\begin{array}{l}14.2 \\
(10.4)\end{array}$ \\
\hline$\left[\mathrm{CA}-7 \mathrm{PEG}_{200}-\left(\mathrm{TMC}_{1}\right)_{2}\right]-\mathrm{HDI}$ & 21.5 & $\begin{array}{l}92.3 \\
(0.6)\end{array}$ & $\begin{array}{l}19.6 \\
(0.7)\end{array}$ & $\begin{array}{l}6.2 \\
(1.6)\end{array}$ & $\begin{array}{l}74.4 \\
(7.6)\end{array}$ & $\begin{array}{l}41.4 \\
(36.2)\end{array}$ \\
\hline$\left[\mathrm{CA}-10 \mathrm{PEG}_{200}-\left(\mathrm{TMC}_{1}\right)_{2}\right]-\mathrm{HDI}$ & 19.1 & $\begin{array}{l}100.0 \\
(1.8)\end{array}$ & $\begin{array}{l}10.9 \\
(1.5)\end{array}$ & $\begin{array}{l}7.6 \\
(1.3)\end{array}$ & $\begin{array}{l}67.8 \\
(5.4)\end{array}$ & $\begin{array}{l}57.8 \\
(21.2)\end{array}$ \\
\hline$\left[\mathrm{CA}-4 \mathrm{PEG}_{200}-\left(\mathrm{TMC}_{2}\right)_{2}\right]-\mathrm{HDI}$ & 15.1 & $\begin{array}{l}100.0 \\
(2.1)\end{array}$ & $\begin{array}{l}42.8 \\
(2.8)\end{array}$ & $\begin{array}{l}14.4 \\
(1.5)\end{array}$ & $\begin{array}{l}151.0 \\
(7.1)\end{array}$ & $\begin{array}{l}48.2 \\
(16.0)\end{array}$ \\
\hline$\left[\mathrm{CA}-7 \mathrm{PEG}_{200}-\left(\mathrm{TMC}_{2}\right)_{2}\right]-\mathrm{HDI}$ & 13.4 & $\begin{array}{l}96.7 \\
(0.4)\end{array}$ & $\begin{array}{l}14.6 \\
(0.9)\end{array}$ & $\begin{array}{l}4.9 \\
(3.1)\end{array}$ & $\begin{array}{l}62.5 \\
(11.4)\end{array}$ & $\begin{array}{l}28.6 \\
(28.1)\end{array}$ \\
\hline$\left[\mathrm{CA}-10 \mathrm{PEG}_{200}-\left(\mathrm{TMC}_{2}\right)_{2}\right]-\mathrm{HDI}$ & 15.1 & $\begin{array}{l}97.4 \\
(1.8)\end{array}$ & $\begin{array}{l}18.1 \\
(2.8)\end{array}$ & $\begin{array}{l}7.8 \\
(2.1)\end{array}$ & $\begin{array}{l}85.4 \\
(15.8)\end{array}$ & $\begin{array}{l}56.6 \\
(33.1)\end{array}$ \\
\hline$\left[\mathrm{CA}-4 \mathrm{PEG}_{600}-\left(\mathrm{TMC}_{1}\right)_{2}\right]-\mathrm{HDI}$ & 41.8 & $\begin{array}{l}97.3 \\
(4.6)\end{array}$ & $\begin{array}{l}80.3 \\
(5.6)\end{array}$ & $\begin{array}{l}1.2 \\
(0.2)\end{array}$ & $\begin{array}{l}6.5 \\
(2.2)\end{array}$ & $\begin{array}{l}35.0 \\
(12.2)\end{array}$ \\
\hline$\left[\mathrm{CA}^{-7 \mathrm{PEG}_{600}}-\left(\mathrm{TMC}_{1}\right)_{2}\right]-\mathrm{HDI}$ & 48.3 & $\begin{array}{l}87.9 \\
(5.9)\end{array}$ & $\begin{array}{l}149.4 \\
(8.3)\end{array}$ & $\begin{array}{l}1.0 \\
(0.3)\end{array}$ & $\begin{array}{l}2.05 \\
(0.6)\end{array}$ & $\begin{array}{l}83.7 \\
(26.0)\end{array}$ \\
\hline$\left[\mathrm{CA}-10 \mathrm{PEG}_{600}-\left(\mathrm{TMC}_{1}\right)_{2}\right]-\mathrm{HDI}$ & 51.4 & $\begin{array}{l}79.8 \\
(40)\end{array}$ & $\begin{array}{l}164.8 \\
(19.6)\end{array}$ & $\begin{array}{l}0.6 \\
(0.1)\end{array}$ & $\begin{array}{l}1.5 \\
(0.4)\end{array}$ & $\begin{array}{l}75.5 \\
(29.4)\end{array}$ \\
\hline$\left[\mathrm{CA}-4 \mathrm{PEG}_{600}-\left(\mathrm{TMC}_{2}\right)_{2}\right]-\mathrm{HDI}$ & 36.5 & $\begin{array}{l}98.9 \\
(2.2)\end{array}$ & $\begin{array}{l}86.7 \\
(0.6)\end{array}$ & $\begin{array}{l}0.4 \\
(0.1)\end{array}$ & $\begin{array}{l}0.85 \\
(0.2)\end{array}$ & $\begin{array}{l}43.8 \\
(19.3)\end{array}$ \\
\hline$\left[\mathrm{CA}-7 \mathrm{PEG}_{600}-\left(\mathrm{TMC}_{2}\right)_{2}\right]-\mathrm{HDI}$ & 37.1 & $\begin{array}{l}77.4 \\
(16.3)\end{array}$ & $\begin{array}{l}92.1 \\
(12.3)\end{array}$ & $\begin{array}{l}1.0 \\
(0.2)\end{array}$ & $\begin{array}{l}4.3 \\
(0.9)\end{array}$ & $\begin{array}{l}30.8 \\
(5.9)\end{array}$ \\
\hline$\left[\mathrm{CA}-10 \mathrm{PEG}_{600}-\left(\mathrm{TMC}_{2}\right)_{2}\right]-\mathrm{HDI}$ & 33.0 & $\begin{array}{l}60.7 \\
(10.4)\end{array}$ & $\begin{array}{l}115.5 \\
(3.8)\end{array}$ & $\begin{array}{l}0.3 \\
(0.0)\end{array}$ & $\begin{array}{l}3.0 \\
(0.6)\end{array}$ & $\begin{array}{l}9.9 \\
(3.6)\end{array}$ \\
\hline
\end{tabular}

${ }^{a}$ determined by ${ }^{1} \mathrm{H}-\mathrm{NMR}$ 


\section{In vitro degradation of the water-cured polyurethane networks}

The in vitro degradation of the polyurethane networks formed upon curing of the adhesives by reaction with water, was evaluated during incubation in PBS over a period of 26 weeks. At predetermined time points changes in mass and thickness of the specimens were determined after drying. The remaining mass of the networks is depicted in the top part of Figure 3. The figure shows that the mass loss of networks containing PEG $_{600}$ was significantly faster than that of networks containing PEG $_{200}$ $(p<0.05)$. After a meniscus tear repair procedure with sutures, it can take 2-4 months before evidence of healing can be seen [25]. It would therefore be desired that the adhesive, which can be applied as a series of drops on the surfaces of the tear, holds the meniscus together during this period enabling its healing before fully degrading. The degradation profile of networks containing $\mathrm{PEG}_{200}$ and of some networks containing $\mathrm{PEG}_{600}$ seem suitable for this application, since they gradually degrade and start losing mass after 4-8 weeks. After 26 weeks networks containing PEG $_{600}$ had lost $30 \%$ to almost $100 \%$ of their mass (they were fragmented), while networks containing $\mathrm{PEG}_{200}$ had lost 5-40\%). Networks containing $\mathrm{PEG}_{600}$ were more hydrophilic than networks containing $\mathrm{PEG}_{200}$ (see Table 3) and therefore more prone to hydrolytic degradation. The networks with the highest water uptake: [CA$\left.7 \mathrm{PEG}_{600}-\left(\mathrm{TMC}_{1}\right)_{2}\right]$-HDI and $\left[\mathrm{CA}-10 \mathrm{PEG}_{600}-\left(\mathrm{TMC}_{1}\right)_{2}\right]-\mathrm{HDI}$ showed the most rapid loss of mass during degradation. While the degree of branching did not seem to have an effect on the rate of mass loss, it is apparent the networks with higher contents of hydrophobic TMC degraded at a lower rate. This is especially obvious for networks containing $\mathrm{PEG}_{600}$. 
a)

$$
\begin{aligned}
& -\square-\left[C A-4 \mathrm{PEG}_{200}-\left(\mathrm{TMC}_{1}\right)_{2}\right]-\mathrm{HDI} \\
& -\mathrm{O}-\left[\mathrm{CA}-7 \mathrm{PEG}_{200}-\left(\mathrm{TMC}_{1}\right)_{2}\right]-\mathrm{HDI} \\
& -\nabla-\left[\mathrm{CA}-10 \mathrm{PEG}_{200}-\left(\mathrm{TMC}_{1}\right)_{2}\right]-\mathrm{HDI} \\
& \rightarrow-\left[C A-4 P E G_{200}-\left(\mathrm{TMC}_{2}\right)_{2}\right]-\mathrm{HDI} \\
& \text { - }\left[\mathrm{CA}-7 \mathrm{PEG}_{200}-\left(\mathrm{TMC}_{2}\right)_{2}\right]-\mathrm{HDI} \\
& \text { - }\left[\mathrm{CA}-10 \mathrm{PEG} \mathrm{F}_{200}-\left(\mathrm{TMC}_{2}\right)_{2}\right]-\mathrm{HDI}
\end{aligned}
$$
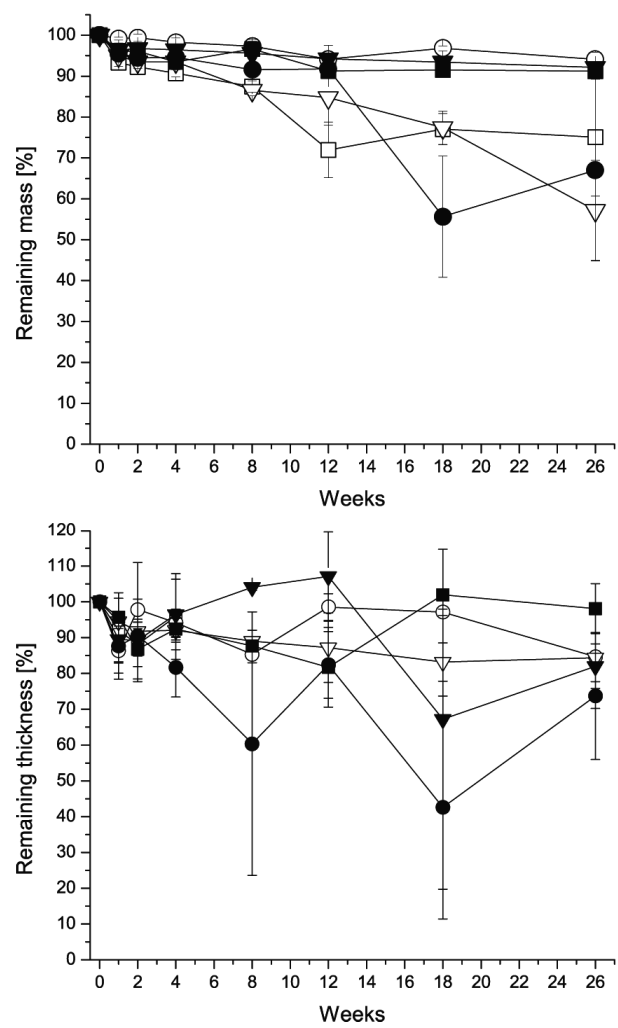

b) $\quad-\square-\left[\mathrm{CA}^{\left.-4 P E \mathrm{G}_{600}-\left(\mathrm{TMC}_{1}\right)\right]-\mathrm{HDI}}\right.$ $-\mathrm{O}-\left[\mathrm{CA}-\mathrm{TPEG} \mathrm{G00}_{600}-\left(\mathrm{TMC}_{1}\right)_{2}\right]-\mathrm{HDI}$ $\rightarrow-\left[C A-10 P E G_{600}-\left(T_{M C}\right)_{2}\right)-H D I$ $=-\left[\mathrm{CA}-4 \mathrm{PEG}_{600}-\left(\mathrm{TMC}_{2}\right)_{2}\right]-\mathrm{HDI}$ $-\left[\mathrm{CA}-7 \mathrm{PEG}_{600}-\left(\mathrm{TMC}_{2}\right)_{2}\right]-\mathrm{HDI}$ $\boldsymbol{\nabla}\left[\mathrm{CA}-10 \mathrm{PEG}_{600}-\left(\mathrm{TMC}_{2}\right)_{2}\right]-\mathrm{HDI}$
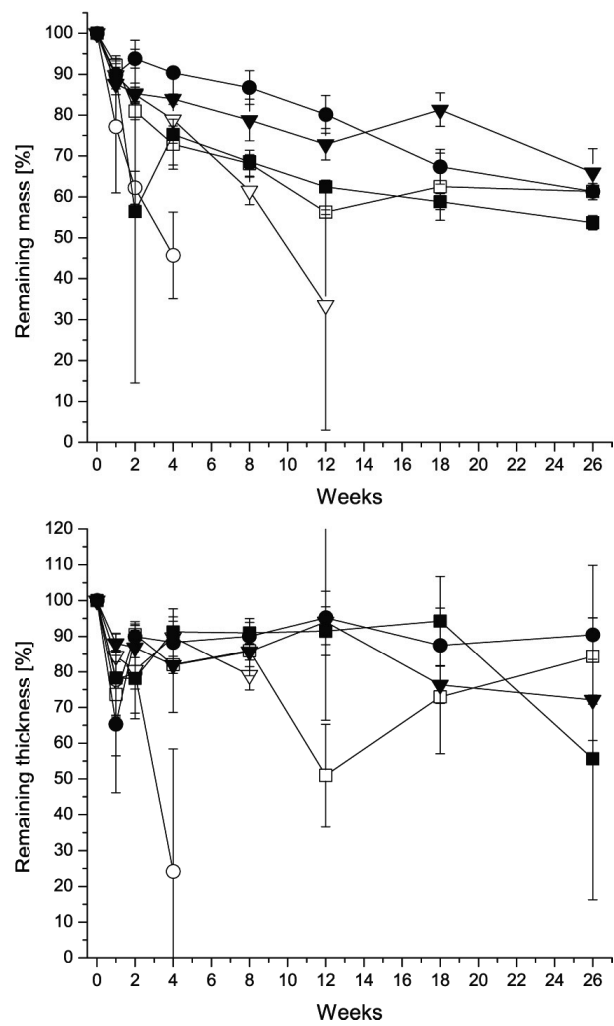

Figure 3. Remaining mass (top) and thickness (bottom) of networks in the dry state after in vitro incubation in $P B S$. a) networks based on $P E G_{200}$ and b) networks based on $P E G_{600}$. Mass loss of networks containing $P E G_{600}$ was significantly faster than that of networks containing $P E G_{200}(p<0.05) .{ }^{*}$ Note that after 4 weeks the thickness of CA 4PEG $G_{200}-\left(T M C_{1}\right)_{2}-H D I$ network specimens was very irregular and could not be determined accurately; after 4 weeks the thickness and the mass of CA-7PEG $600^{-}$ $\left(T M C_{1}\right)_{2}$-HDI network specimens could not be determined due to loss of integrity of these samples; after 8 weeks the thickness of CA-10PEG $G_{600}-\left(T M C_{1}\right)_{2}-H D I$ network specimen could not be determined due to loss of integrity of these samples. After 12 weeks their mass could not be determined either. 
Changes in the thickness of the network specimens was also monitored during incubation in PBS (see bottom part of the Figure 3). It is shown that the networks based on $\mathrm{PEG}_{200}$ exhibited only minor changes in specimen thickness of discs height during degradation. In contrast, the thickness of all specimens based on PEG $_{600}$ gradually decreased in time. These materials also became fragile during the degradation experiment. Plotting the thickness of the specimens as a function of their mass loss (not shown), indicated that these materials degraded by a bulk erosion process. As linear high molecular weight PTMC degrades due to activity of enzymes [24], degradation experiments were also conducted in CE solutions (see Supplementary Material). Similar degradation profiles were observed and changes in mass loss and thickness incubated in CE and PBS were not significant. This means that the major mechanism of degradation in vitro is non-enzymatic hydrolysis. Upon hydrolysis of the network, the network will ultimately degrade into PEG, CA, 1,3propane diol, $\mathrm{CO}_{2}$, water and 1,6-hexanediamine. These water soluble compounds can be metabolized or excreted by the kidneys.

\section{Adhesion strength}

The adhesive properties of the reactive isocyanate-terminated hyper-branched oligomers were determined in lap shear adhesion tests with bovine meniscus tissue as the substrate. The adhesives were applied to strips of tissue, which were pressed together and immersed in water overnight. Figure 4 shows that the adhesion strength varied between approximately 20 to $80 \mathrm{kPa}$, this is the case for $\mathrm{PEG}_{200}$-based compositions as well as for $\mathrm{PEG}_{600}$-based compositions. These adhesive strengths should be sufficient to hold a torn meniscus together; using a human cadaver knee model it was determined that on average the distraction forces on sutured menisci did not exceed $5 \mathrm{~N}$ when the applied load was $300 \mathrm{~N}$ [26, 27]. In another study, where the forces were assessed indirectly, the distraction forces in a bucket-handle lesion were determined to be less than $10 \mathrm{~N}$ [28]. For a $1 \mathrm{~cm}^{2}$ tear, this corresponds to a required adhesive strength in the order of 50 to $100 \mathrm{kPa}$. During the non-weight bearing recovery period of the patient, the required adhesive strengths would be even lower. Although the differences in adhesion strength of the prepared adhesives were low and the standard deviations of the means of the measurements high, it seemed that the adhesive strength of reactive oligomers is somewhat higher for the 
compositions with the higher TMC contents. No clear effect of the content of free isocyanate end-groups can be discerned (see the results presented in Table 2).

In all cases the observed mode of failure of the adhesive bond was adhesive failure: the network detached from the surface of the tissue, while the cured network itself remained undamaged. The smooth surface of the meniscus tissue used in the experiment did not result in deep penetration of the adhesive into the tissue and therefore in adequate mechanical interlocking of the cured network of the tissue. Roughening the meniscus surface before gluing by rasping could improve the adhesive strength of the oligomers due to increased area of contact, exposure of collagen fibers and the chemical groups capable of reacting with the isocyanate glues. This technique is already used in clinical practice to improve the meniscus healing potential $[2,29]$.

The adhesive strengths of the reactive hyper-branched oligomers were compared with those of fibrin glue and Dermabond ${ }^{\circledR}$, which are currently used in the clinic. Dermabond ${ }^{\circledR}$ is only approved for topical use as a skin adhesive, but as it has a high bonding strength to tissue it was used as a positive control in our study. The adhesive strengths to bovine meniscus tissue were respectively $10 \mathrm{kPa}$ and $650 \mathrm{kPa}$ for fibrin glue and Dermabond ${ }^{\circledR}$. Although the adhesive strength of our hyper-branched adhesives was lower than that of Dermabond ${ }^{\circledR}$, they were significantly higher (seven times stronger) than the adhesive strength of fibrin glue $(\mathrm{p}<0.05)$. Even though the performed statistical tests showed significant differences between particular compositions of our adhesives and fibrin glue, it should be kept in mind that the sample size was relatively low. Therefore, the main trends are more important than the differences between the different tissue adhesives. The properties of the adhesives will need to be assessed in more detail under physiological conditions using synovial fluid, biomechanical- and cadaveric models and animal experiments. It should also be noted that, as mentioned before, Dermabond ${ }^{\circledR}$ is a very rigid, nondegradable material and therefore not suited for our intended application. 


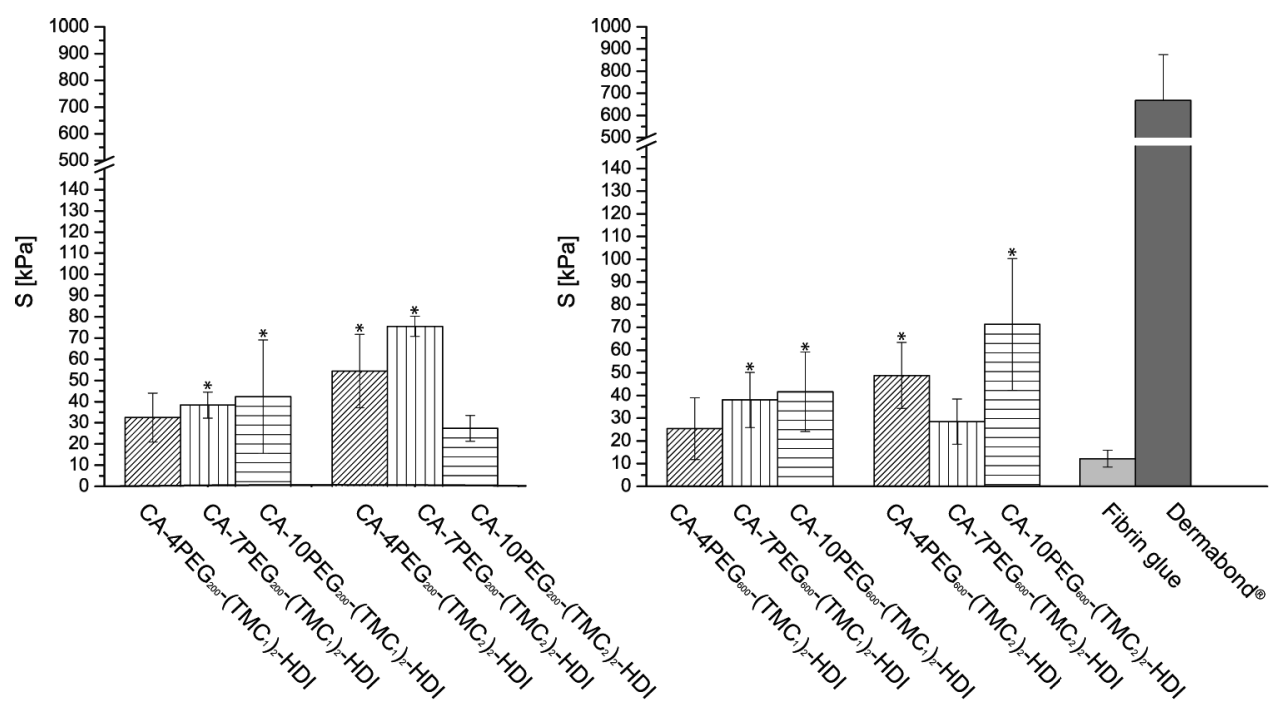

Figure 4. Lap shear adhesion strength of the different reactive hyper-branched adhesives and fibrin glue and Dermabond ${ }^{\circledR}$ controls to bovine meniscus tissue. Values are expressed as mean values \pm standard deviation. Asterisks indicate statistically significant differences between a particular adhesive and fibrin glue $(p<0.05)$. Adhesion strength values of Dermabond ${ }^{\circledR}$ were not included in the statistical comparisons.

\section{Compatibility of the reactive hyper-branched oligomers with meniscus cells}

To assess the potential cytoxicity of the reactive hyper-branched isocyanateterminated oligomers, different amounts of the adhesives were brought in indirect contact with bovine meniscus cells in culture. As could be concluded from the experimental results described above, the main factor that determines the physical properties of the reactive oligomers and cured networks is the molar mass of the PEG component in the reactive hyper-branched precursor. To assess the compatibility of the adhesives with meniscus cells, two compositions of the reactive hyper-branched oligomers were chosen: $\mathrm{CA}-7 \mathrm{PEG}_{200}-\left(\mathrm{TMC}_{2}\right)_{2}$-HDI and CA$4 \mathrm{PEG}_{600}-\left(\mathrm{TMC}_{2}\right)_{2}-\mathrm{HDI}$. Both these materials spreads well on the surface of the tissue and had satisfactory adhesion strengths to meniscus tissue.

After culturing the meniscus cells for 5 days, amounts of 0.5 to $30 \mathrm{mg}$ of CA$7 \mathrm{PEG}_{200}-\left(\mathrm{TMC}_{2}\right)_{2}-\mathrm{HDI}$ and $\mathrm{CA}-4 \mathrm{PEG}_{600}-\left(\mathrm{TMC}_{2}\right)_{2}-\mathrm{HDI}$ were brought into contact 
with the cell culture medium using permeable Transwell ${ }^{\circledR}$ membranes. The volume of cell culture medium in the wells containing the cells was $1 \mathrm{~mL}$.

a)

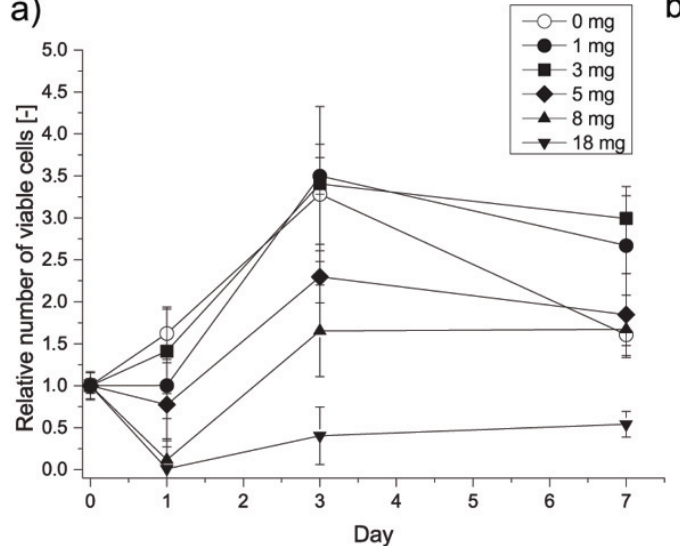

b)

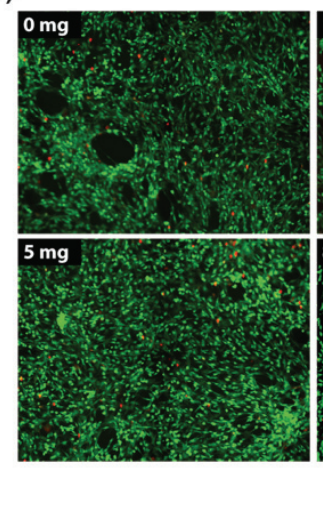

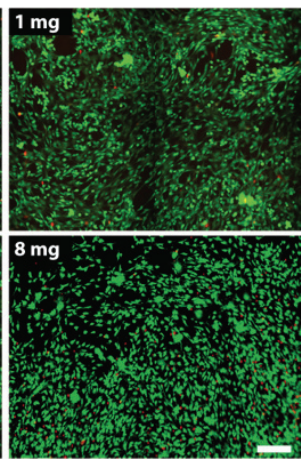

Figure 5. a) Viability of bovine meniscus cells after contacting $1 \mathrm{~mL}$ of medium with different amounts of $C A-4 P E G_{600}-\left(T M C_{2}\right)_{2}-H D I$ adhesive during culture expressed as the relative number of living cells prior to the addition of the adhesives to the medium, data is presented as mean \pm standard deviation b) Microscopic images of the cells in culture after Live/Dead staining at day 7 after the indicated amounts of the adhesive were brought into contact with the medium. The scale bar indicates 200 $\mu m$.

The viability of the bovine meniscus cells in time after contacting the medium with the reactive hyper-branched $\mathrm{CA}-4 \mathrm{PEG}_{600}\left(\mathrm{TMC}_{2}\right)_{2}$ - $\mathrm{HDI}$ adhesive is presented in Figure 5a. When no adhesive was added, the cells continued to proliferate until confluency was reached and number of cells was reduced. When the hyper-branched adhesive (which contains reactive isocyanate endgroups) was added to the medium, cell viability initially decreased. This in vitro decrease in viability at day 1 after adding the adhesives strongly depended on the amount of adhesive placed in the culture medium. In all cases, nevertheless, cell viability then increased and the cells continued to proliferate until confluency was reached. This was even the case for high amounts of 18 and $30 \mathrm{mg}$ adhesive per $\mathrm{ml}$ of cell culture medium. However in these cases the viability of cells initially decreased dramatically and after 7 days of culture only approximately $50 \%$ of the initial number of cells was reached. When the lower amounts of hyper-branched adhesive were added, the viability of the cells 
was not significantly affected when compared to the control experiment and no toxic effects were observed when the amounts were $3 \mathrm{mg} / \mathrm{mL}$ medium or less. The results of the Live-Dead assays presented in Figure $5 \mathrm{~b}$ confirm that 7 days after adding the reactive adhesives up to concentrations of $8 \mathrm{mg}$ per $\mathrm{ml}$ of medium, a confluent layer of living cells is present.

Similar results were obtained for the $\mathrm{CA}-7 \mathrm{PEG}_{200}-\left(\mathrm{TMC}_{2}\right)_{2}-\mathrm{HDI}$ adhesive (Supplementary Material).

These results imply that, although the non-cured adhesives did affect cell viability, once the hyper-branched adhesive cured in the medium, a toxic effect was not observed anymore. We assume that for repair of the meniscus lesion six drops of adhesive would be needed. Given that the mass of such drop is $3 \mathrm{mg}$, a total of 18 $\mathrm{mg}$ would be required. As the volume of synovial fluid present in the knee joint is $6.7+/-2.3 \mathrm{ml}$ (and even higher in an arthritic joint [30] ), the amount of adhesive per $\mathrm{mL}$ of fluid would be even lower than the safe limit of $3 \mathrm{mg} / \mathrm{mL}$, which we determined in this experiment. Therefore, no severe tissue reactions would be observed. Currently, subcutaneous implantations of these adhesive materials in small animals are being conducted to confirm their biocompatibility in vivo.

\section{Conclusions}

We have shown that hyper-branched isocyanate-terminated oligomers based on citric acid, poly (ethylene glycol) and trimethylene carbonate are favourable candidates for use as biocompatible resorbable tissue adhesives for gluing meniscus tears. These reactive oligomers are viscous liquids that can easily be applied in an arthroscopic procedure using a syringe. The mechanical properties are suitable after curing, they can be varied by changing the composition and architectural design of the oligomeric precursors. Particularly of interest are networks based on $\mathrm{PEG}_{200}$, which had mechanical properties close to those of human meniscus tissue. For the different compositions, the lap shear adhesion strengths to bovine meniscus tissue did not significantly differ. In vitro degradation studies showed that networks based on $\mathrm{PEG}_{600}$ degraded much faster than networks based on $\mathrm{PEG}_{200}$. Cell culturing experiments using meniscus cells demonstrated that an adverse tissue response is not to be expected in the presence of suitable amounts of the reactive adhesives. 
For application in the clinic, the adhesive should not only have good adhesion to the tissue, suitable degradation characteristics and minimal toxicity, it should also be rapidly curing. Ongoing work is aimed at optimizing the composition and architecture of these reactive oligomers.

\section{Acknowledgements}

This research is supported by Reumafonds, the Dutch Arthritis Foundation.

\section{References}

[1] Fithian DC, Kelly MA, Mow VC. Material properties and structure-function-relationships in the menisci. Clinical Orthopaedics and Related Research 1990:19-31.

[2] Henning CE, Lynch MA, Clark JR. Vascularity for healing of meniscus repairs. Arthroscopy: The Journal of Arthroscopic \& Related Surgery 1987;3:13-8.

[3] Starke C, Kopf S, Petersen W, Becker R. Meniscal Repair. Arthroscopy-the Journal of Arthroscopic and Related Surgery 2009;25:1033-44.

[4] Rath E, Richmond JC. The menisci: basic science and advances in treatment. British Journal of Sports Medicine 2000;34:252-7.

[5] Krause WR, Pope MH, Johnson RJ, Wilder DG. Mechanical changes in knee after meniscectomy. Journal of Bone and Joint Surgery-American Volume 1976;58:599-604.

[6] Scotti C, Pozzi A, Mangiavini L, Vitari F, Boschetti F, Domeneghini C, et al. Healing of meniscal tissue by cellular fibrin glue: an in vivo study. Knee Surgery, Sports Traumatology, Arthroscopy 2009;17:645-51.

[7] Makris EA, Hadidi P, Athanasiou KA. The knee meniscus: Structure-function, pathophysiology, current repair techniques, and prospects for regeneration. Biomaterials 2011;32:7411-31.

[8] DeHaven KE. Meniscus Repair. The American Journal of Sports Medicine 1999;27:242-50.

[9] Bouten PJM, Zonjee M, Bender J, Yauw STK, van Goor H, van Hest JCM, et al. The chemistry of tissue adhesive materials. Progress in Polymer Science 2014;39:1375-405.

[10] Sheikh N, Katbab AA, Mirzadeh H. Isocyanate-terminated urethane prepolymer as bioadhesive base material: synthesis and characterization. International Journal of Adhesion and Adhesives 2000;20:299-304.

[11] Bruns TB, Worthington JM. Using tissue adhesive for wound repair: A practical guide to Dermabond. American Family Physician 2000;61:1383-8.

[12] Spotnitz WD. Commercial fibrin sealants in surgical care. American Journal of Surgery 2001;182:8S-14S.

[13] Matar AF, Hill JG, Duncan W, Orfanakis N, Law I. Use of biological glue to control pulmonary air leaks. Thorax 1990;45:670-4.

[14] Mizrahi B, Stefanescu CF, Yang C, Lawlor MW, Ko D, Langer R, et al. Elasticity and safety of alkoxyethyl cyanoacrylate tissue adhesives. Acta Biomaterialia 2011;7:3150-7. 
[15] Tissakht M, Ahmed AM. Tensile stress-strain characteristics of the human meniscal material. Journal of Biomechanics 1995;28:411-22.

[16] Leggat PA, Smith DR, Kedjarune U. Surgical applications of cyanoacrylates adhesives: A review of toxicity. ANZ Journal of Surgery 2007;77:209-13.

[17] Sierra DH. Fibrin Sealant Adhesive Systems: A Review of Their Chemistry, Material Properties and Clinical Applications. Journal of Biomaterials Applications 1993;7:309-52.

[18] Shao XX, Hutmacher DW, Ho ST, Goh JCH, Lee EH. Evaluation of a hybrid scaffold/cell construct in repair of high-load-bearing osteochondral defects in rabbits. Biomaterials 2006;27:107180.

[19] Gibble JW, Ness PM. Fibrin glue: the perfect operative sealant? Transfusion 1990;30:741-7.

[20] Oelker AM, Grinstaff MW. Ophthalmic adhesives: a materials chemistry perspective. Journal of Materials Chemistry 2008;18:2521-36.

[21] Bochyńska AI, Sharifi S, van Tienen TG, Buma P, Grijpma DW. Development of Tissue Adhesives Based on Amphiphilic Isocyanate-Terminated Trimethylene Carbonate Block Copolymers. Macromolecular Symposia 2013;334:40-8, Chapter 3 of this thesis.

[22] Nayeb-Habib F, Salahshoor-Kordestani S, Afshar-Taromi F, Shariatinia Z. A Novel Topical Biocompatible Tissue Adhesive Based on Chitosan-modified Urethane Pre-polymer. Iranian Polymer Journal 2011;20:671-80.

[23] Gao C, Yan D. Hyperbranched polymers: from synthesis to applications. Progress in Polymer Science 2004;29:183-275.

[24] Lechner K, Hull M, Howell S. Is the circumferential tensile modulus within a human medial meniscus affected by the test sample location and cross-sectional area? Journal of Orthopaedic Research 2000;18:945-51.

[25] Morgan CD, Wojtys EM, Casscells CD, Casscells SW. Arthroscopic meniscal repair evaluated by second-look arthroscopy. The American Journal of Sports Medicine 1991;19:632-8.

[26] Becker R, Brettschneider O, Gröbel KH, Von Versen R, Stärke C. Distraction forces on repaired bucket-handle lesions in the medial meniscus. American Journal of Sports Medicine 2006;34:1941-7.

[27] Staerke C, Brettschneider O, Gröbel KH, Becker R. Tensile forces on sutures in the human lateral knee meniscus. Knee Surgery, Sports Traumatology, Arthroscopy 2009;17:1354-9.

[28] Dürselen L, Hebisch A, Claes LE, Bauer G. Gapping phenomenon of longitudinal meniscal tears. Clinical Biomechanics 2003;18:505-10.

[29] Okuda K, Ochi M, Shu N, Uchio Y. Meniscal Rasping for Repair of Meniscal Tear in the Avascular Zone. Arthroscopy: The Journal of Arthroscopic \& Related Surgery 1999;15:281-6.

[30] Heilmann HH, Lindenhayn K, Walther HU. Synovial volume of healthy and arthrotic human knee joints. Z Orthop Ihre Grenzgeb 1996;134:144-8. 


\section{Supplementary Material}

a)

$$
\begin{aligned}
& -\square-\left[\text { CA-4PEG } 200-\left(\text { TMC }_{1}\right)_{2}\right]-\mathrm{HDI} \\
& -\mathrm{O}-\left[\mathrm{CA}-7 \mathrm{PEG}_{200}-\left(\mathrm{TMC}_{1}\right)_{2}\right]-\mathrm{HDI} \\
& -\nabla-\left[\mathrm{CA}-10 \mathrm{PEG}_{200}-\left(\mathrm{TMC}_{1}\right)_{2}\right]-\mathrm{HDI} \\
& -\left[\mathrm{CA}-4 \mathrm{PEG}_{200}-\left(\mathrm{TMC}_{2}\right)_{2}\right]-\mathrm{HDI} \\
& \text { - }\left[\mathrm{CA}-7 \mathrm{PEG}_{200}-\left(\mathrm{TMC}_{2}\right)_{2}\right]-\mathrm{HD} \\
& \boldsymbol{\nabla}-\left[\mathrm{CA}-10 \mathrm{PEG}_{200}-\left(\mathrm{TMC}_{2}\right)_{2}\right]-\mathrm{HDI}
\end{aligned}
$$
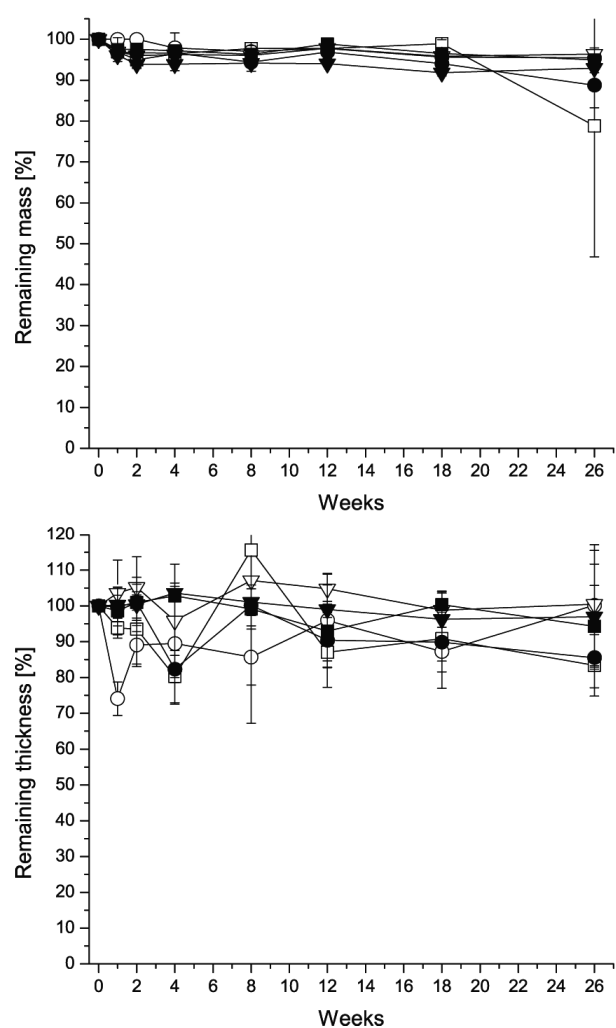
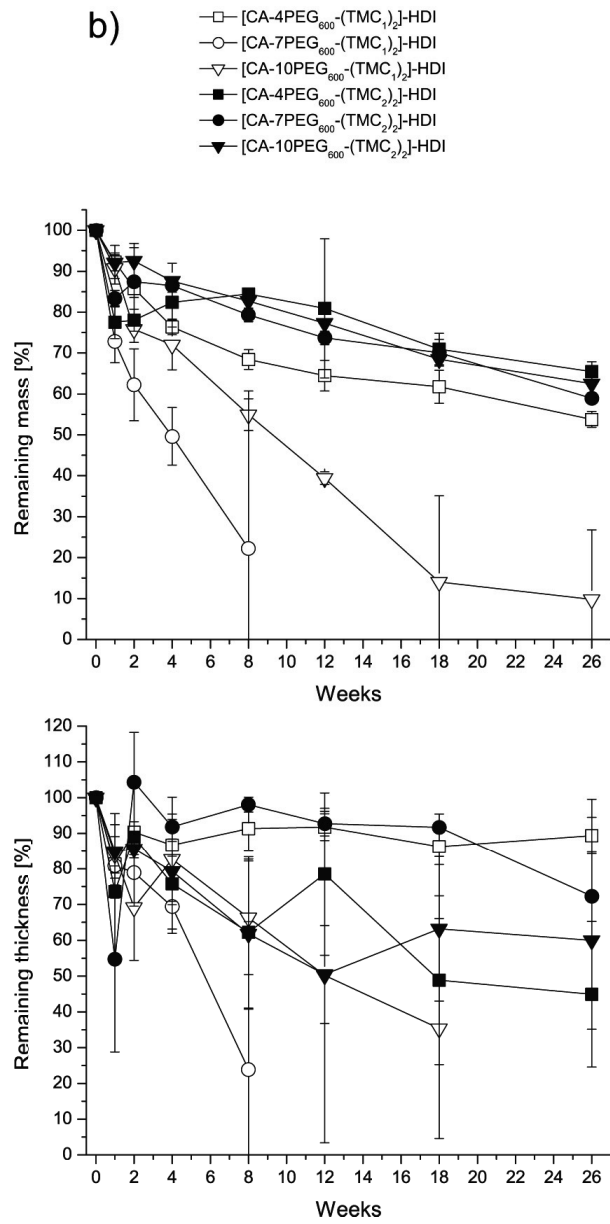

Figure SI 1. Remaining mass (top) and thickness (bottom) of networks in the dry state after in vitro incubation in CE solution. a) networks based on $P E G_{200}$ and b) networks based on $P E G_{600}$. Mass loss of networks containing $P E G_{600}$ was significantly faster than that of networks containing $P E G_{200}(p<0.05)$. *Note that after 12 weeks the thickness and mass of CA-7PEG $G_{600}-\left(T M C_{1}\right)_{2}-H D I$ network specimens and after 18 weeks the thickness of CA-10PEG $G_{600}-\left(T M C_{1}\right)_{2}-H D I$ network specimen could not be determined due to loss of mechanical integrity of these samples. 


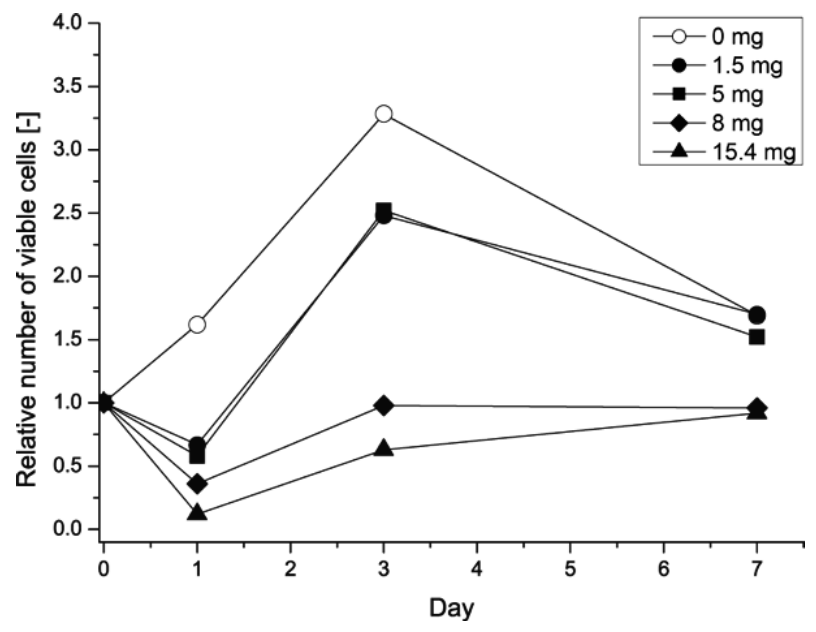

Figure SI 2. Viability of bovine meniscus cells after contacting $1 \mathrm{~mL}$ of medium with different amounts of $C A-7 P E G_{200}\left(T M C_{2}\right)_{2}-H D I$ adhesive during culture in vitro (expressed as a relative number to the amount of living cells before adding the reactive hyper-branched adhesive to the medium), data is presented as mean \pm standard deviation. 


\section{Chapter 6}

\section{Evaluation of Novel Biodegradable Three-Armed- and Hyper-Branched Tissue Adhesives in a Meniscus Explant Model}

Agnieszka I. Bochyńska ${ }^{1,2}$, Gerjon Hannink ${ }^{1}$, Renate Verhoeven ${ }^{1}$, Dirk W. Grijpma $^{2,3}$, Pieter Buma ${ }^{1}$

${ }^{1}$ Orthopaedic Research Laboratory, Department of Orthopaedics, Radboud Centre for Molecular Life Sciences, Radboud University Nijmegen Medical Centre, Nijmegen, the Netherlands

${ }^{2}$ Department of Biomaterials Science and Technology, MIRA Institute, University of Twente, Enschede, the Netherlands

${ }^{3}$ University Medical Centre Groningen, University of Groningen, W.J. Kolff Institute, Department of Biomedical Engineering, Groningen, the Netherlands 


\begin{abstract}
Current treatment methods to repair meniscal tears do not bring fully satisfactory results. Tissue adhesives are considered promising alternatives, since they are easy to apply and cause minimal tissue trauma.
\end{abstract}

The first aim of this study was to analyze the adhesive properties of and tissue response to two recently developed biodegradable block copolymeric three-armedand hyper-branched tissue adhesives. The second aim was to investigate if tissue surface modification with collagenase improves the attachment of the adhesives and increases the healing potential of the tissue.

Cylindrical explants were harvested from bovine menisci. The central core of the explants was removed and glued back into the defect, with or without incubation in collagenase solution prior to gluing, using one of the novel glues, Dermabond ${ }^{\circledR}$ or fibrin glue. The repair constructs were cultured in vitro for 1 and 28 days. Adhesion tests and histology were performed to analyze the effects of the glue in combination with the additional treatment.

The adhesive strength of the novel glues was 40-50 kPa, which was significantly higher than that of fibrin glue $(15 \mathrm{kPa})$. Cells were present in direct contact with the glues, and the tissue remained vital during the whole culture period. Increased cellularity around the tear in the collagenase treated explants was observed after 1 day.

The two newly developed tissue adhesives are attractive materials to be used for repair of meniscal tears. The beneficial influence of collagenase treatment in treating meniscal tears with glues still needs to be confirmed in more clinical relevant studies.

\title{
Introduction
}

Meniscus tears are one of the most commonly occurring injuries of the knee joint. Unfortunately, most tears do not heal spontaneously, since meniscus tissue has a very limited capacity for self-repair [1]. This is mainly due to its limited vascular supply, which is only present in the outer part of the tissue [2]. Moreover, the high density of the extracellular matrix (ECM) of the meniscus limits the mobility of the 
relatively low number of cells populating the tissue $[3,4]$. In addition, the meniscus is constantly loaded and prone to being displaced continuously. This is a critical factor, as wound sites need to be kept in close proximity to each other to allow healing.

Current treatment methods consist of either suturing of the torn meniscus or partial meniscectomy [5-7]. However, neither of them brings fully satisfactory results. Partial meniscectomy leads to increased contact stresses acting on articular cartilage ultimately leading to its degeneration [8]. On the other hand, the success rate of repair with sutures strongly depends on the location and type of the tear. Treatment outcomes of tears located in highly loaded, avascular part of the meniscus are particularly poor $[9,10]$. In order to improve treatment results, techniques aiming at inducing vascular supply, such as trephination and rasping have been employed [11, 12]. Nevertheless, it has been reported that up to $75 \%$ of repaired tears in the avascular zone failed to heal completely, and a further $20 \%$ required a secondary surgical intervention [13].

Therefore, there is an increasing interest in the development of alternative methods to both induce meniscus self-repair and provide mechanical stability to the tears. It has been shown that chemical modification of the meniscus tissue surface with collagenase in vitro resulted in decreased densities of ECM and increased numbers of cells in a close proximity to the tear edge [14]. Furthermore, tissue adhesives (glues) have been recognized as a promising alternative treatment to sutures, based on their ease of application, moldability, and possibility to deliver in situ biological compounds and degradability $[15,16]$. However, the current clinically used adhesives are not suitable for this particular application, due to either their poor mechanical properties or their cytoxicity $[17,18]$.

We recently developed two new tissue adhesives as potential materials for meniscus tear repair: biodegradable three-armed and hyper-branched block copolymeric structures $[19,20]$. These adhesives attach to the tissue via covalent bonding of reactive isocyanate-end groups to proteins present on the surface of the tissue.

The first aim of the current study was to analyze the adhesive properties of the glues and the tissue response after application of the glues in an in vitro culture of meniscus 
explants. The second aim was to investigate if modification of the tissue surface with collagenase improves the mechanical attachment of the glues to the tissue and increases the healing potential of the tissue itself.

\section{Materials and Methods}

\section{Adhesive block copolymers}

The isocyanate-terminated reactive three-armed- and hyper-branched adhesive block copolymers were synthesized as previously described in detail [19, 20]. The building blocks of the copolymers were either trimethylolpropane ethoxylate (TMPE, $\mathrm{M}_{\mathrm{n}}=450 \mathrm{~g} / \mathrm{mol}$ ), trimethylene carbonate (TMC) and hexamethylene diisocyanate (HDI), or polyethylene glycol ( $P E G, M_{n}=400 \mathrm{~g} / \mathrm{mol}$ ), TMC, citric acid (CA) and HDI. The resulting products were labeled: TMPE-(TMC $2-\mathrm{HDI})_{3}$ (threearmed) and CA-4PEG-( $\left.\mathrm{TMC}_{2}\right)_{2}$-HDI (hyper-branched), respectively. The adhesives were sterilized with gamma irradiation prior to use ( $25 \mathrm{kGy}$, SynergyHealth BV, The Netherlands). To ensure that the chemical structure of the copolymers was not affected by sterilization procedure, their ${ }^{1} \mathrm{H}$ NMR (Bruker $400 \mathrm{MHz}$ NMR spectrometer) and FTIR (Perkin Elmer) spectra were recorded and compared before and after sterilization.

\section{Preparation of meniscal explants}

Knees from 12-18 months old cows were obtained from the local slaughterhouse. The medial menisci were removed from the joints under sterile conditions. Five cylindrical explants were harvested from the central part of each meniscus using an $8 \mathrm{~mm}$ biopsy punch as described by Hennerbichler et al. [21, 22]. The height of the explants was trimmed to $4 \mathrm{~mm}$. Thereafter, to simulate a full-thickness meniscal tear, the explants were centrically cored with a $4 \mathrm{~mm}$ biopsy punch. The explants were randomly assigned to different experimental groups ( $\mathrm{n}=6$ per group). The cores were removed from the outer annulus and the explants were further processed and cultured in vitro as described in detail below. 


\section{Evaluation of the adhesive strength and biocompatibility of the glues}

The repair constructs were created by gluing back the inner cylinder into the outer annulus of the explants using three-armed- or hyper-branched adhesive block copolymers, fibrin glue (mixture of fibrinogen $(100 \mathrm{mg} / \mathrm{mL})$ and thrombin $(100$ $\mathrm{U} / \mathrm{mL}$ ) in PBS, both isolated from bovine plasma, Sigma Aldrich, the Netherlands) or Dermabond $^{\circledR}$ (Ethicon, Johnson\&Johnson, the Netherlands) (Figure 1a). Repair constructs without applying glue were used as control. The repair constructs were cultured in vitro for 1 and 28 days in basal medium composed of Dulbecco's Modified Eagle's Medium (DMEM, Gibco ${ }^{\circledR}$, UK) supplemented with $10 \%$ fetal bovine serum (FBS, Gibco ${ }^{\circledR}, \mathrm{UK}$ ), 1\% penicillin/streptomycin/fungizone (PSF, Gibco $^{\circledR}$, USA) and L-ascorbic acid (Merck, Darmstadt, Germany) at a concentration of $25 \mu \mathrm{g} / \mathrm{mL}$ of medium.

At both time points, the adhesive strength of the glues to meniscal tissue ( $\mathrm{n}=5$ per group) was measured using a push out test on a BOSE ${ }^{\circledR}$ Electroforce ${ }^{\circledR}$ setup equipped with either a 20 or $200 \mathrm{~N}$ load cell (BOSE Bose Corp. ElectroForce Systems Group, MN, USA). The setup was equipped with a metal rod, which was used to push out the inner cylinder of the explants. The inner cylinder (core) was displaced at a rate of $5 \mathrm{~mm} / \mathrm{min}$ until it was completely separated from the outer annulus. In order to determine exact sizes of the constructs, pictures of explants were taken and their height and diameter were analyzed after each test. The adhesive strength was calculated by dividing the maximum peak force recorded during the adhesion test by the outer surface area $P$ of the inner cylinder covered with the adhesive $(P=\pi$. $d \cdot h$, where $d$ is the diameter of the inner cylinder and $h$ its height).

At the predetermined time points, repair constructs ( $\mathrm{n}=1$ per group) were fixated in $10 \%$ formalin, embedded in poly(methyl methacrylate) (PMMA), sectioned to $8 \mu \mathrm{m}$ slides and stained with hematoxylin and eosin (H\&E) to visualize cells and ECM. Sections were scored for the number of cells present inside and at the edge of the gap between the inner cylinder and outer annulus of the explants ( 3 random locations per explant using 200x field magnification). 


\section{Effect of tissue surface modification on adhesion strength and tissue response}

In order to assess the influence of tissue surface pretreatment with collagenase, the explants (both annulus and the inner core) were incubated in basal medium containing $0.05 \mathrm{mg} / \mathrm{mL}$ collagenase (type IV from Clostridium histolyticum, $\geq 125$ collagenase digestion units/mg solid, Sigma Aldrich) for 3 hours at $37{ }^{\circ} \mathrm{C}$ according to the protocol described by Qu et al. [23] (Figure 1b). Subsequently, the explants were washed 3 times with PBS and the repair constructs were prepared following the same protocol as described above. Constructs were cultured for 1 and 28 days in basal medium. Then, the constructs were subjected to the mechanical push out test $(n=5)$ following the same protocol as described above. For histological analysis, samples ( $n=1$ per group) were fixated in $10 \%$ formalin, embedded in poly(methyl methacrylate) (PMMA), sectioned to $8 \mu \mathrm{m}$ slides and stained with $\mathrm{H} \& \mathrm{E}$, and Picrosirius Red (PR) to visualize changes in structure of collagen fibers after incubation in collagenase. Sections were scored for the number of cells in the same way as reported in the section above.

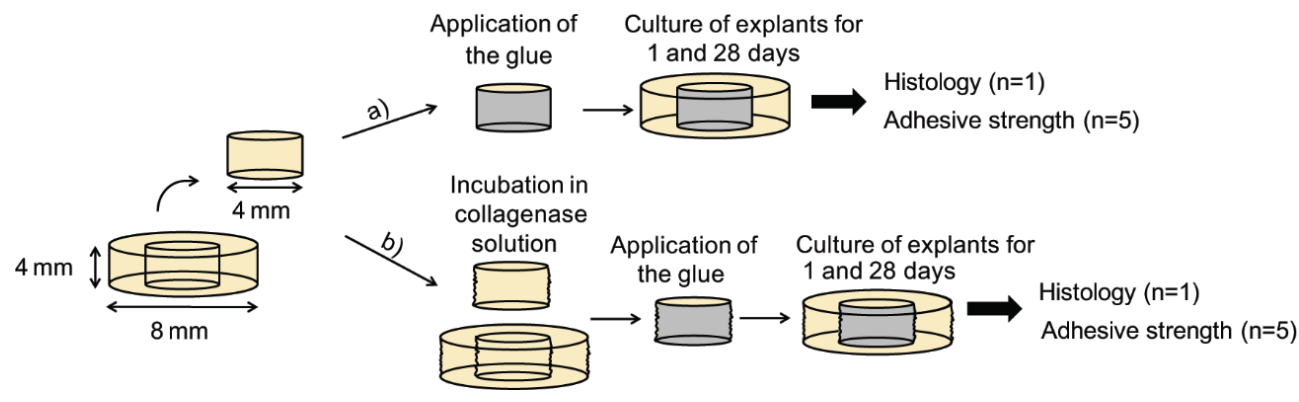

Figure 1. Overview of the experimental design. a) Setup used to assess the adhesive strength of and the tissue response to the glues; b) Setup used to evaluate the influence of collagenase pre-treatment of the explants on adhesion of the glues and tissue condition.

\section{Statistical analysis}

The adhesive strengths of the glues and differences in the number of cells in the gap between the groups were compared using a three-way ANOVA with Fischer's LSD post-hoc test. Data are presented as a mean \pm standard deviation. P values $<0.05$ 
were considered as significant. All statistical analyses were performed using SPSS (version 20, IBM Corporation).

\section{Results}

The two block copolymeric tissue adhesives were successfully synthesized, which was confirmed by analysis of their ${ }^{1} \mathrm{H}$ NMR spectra as described previously in detail $[19,20]$. Moreover, both ${ }^{1} \mathrm{H}$ NMR and FTIR measurements recorded before and after gamma sterilization showed nearly identical spectra indicating that their chemical structure was not changed due to the sterilization process.

\section{Adhesive strength and biocompatibility of the glues}

The glues were applied on the side surface area of the inner cylinder of the explants and reinserted into the annulus. Some of the glue, which leaked out due to the limited space between the gap edges, was removed before placing the repair constructs in the culture medium. The results of the adhesion tests showed that the adhesive strengths of the newly developed block copolymeric glues (mean of the adhesive strength after day 1 and day $28: 49.9 \pm 31.7 \mathrm{kPa}$ and $49.1 \pm 37.8 \mathrm{kPa}$ for three-armed and hyper-branched glue, respectively) were significantly higher than that of fibrin glue $(8.4 \pm 7.5 \mathrm{kPa})$ and of the control group without glue $(7.1 \pm 8.3 \mathrm{kPa})(\mathrm{p}<0.05$; Figure 2). At the same time, there was no significant difference in adhesive strength between three-armed- and hyper-branched glues. Moreover, there were no significant differences in adhesive strength on day 1 and 28 within all experimental groups. Since Dermabond ${ }^{\mathbb{B}}$ had a much higher adhesive strength $(471.1 \pm 108.6 \mathrm{kPa})$ than the other glues, it was not included in the statistical analyses. 


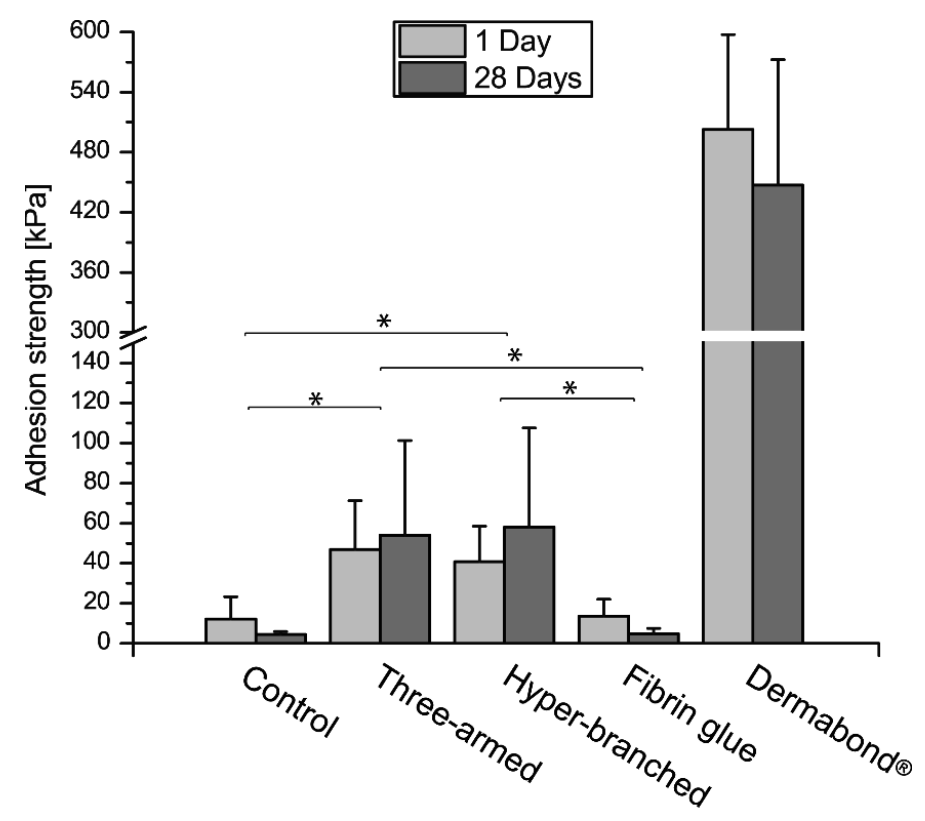

Figure 2. Adhesive strength of the glues to bovine meniscus tissue measured in a push-out test. Data are expressed as mean \pm standard deviations. Asterisks indicate significant differences between means $(p<0.05)$. Dermabond ${ }^{\mathbb{B}}$ was not included in the statistical analysis.

The repair constructs were stained with H\&E to visualize cells and ECM at day 1 and 28 of culture (Figure 3). Both the three-armed and the hyper-branched glues were present in the gap of the repair constructs after 1 and 28 days. After 1 day of explant culture, meniscus fibroblasts were seen in close proximity to the gap in the HE stained sections of all experimental groups (Figure 3). There were no differences in the number of cells between the different groups. After 28 days of culture similar results were observed and meniscus fibroblasts were detected in the gap and in close proximity to its edges in all groups except the Dermabond ${ }^{\circledR}$ group. An increased number of cells present in the gap was observed in explants glued with fibrin glue and in the control group. 


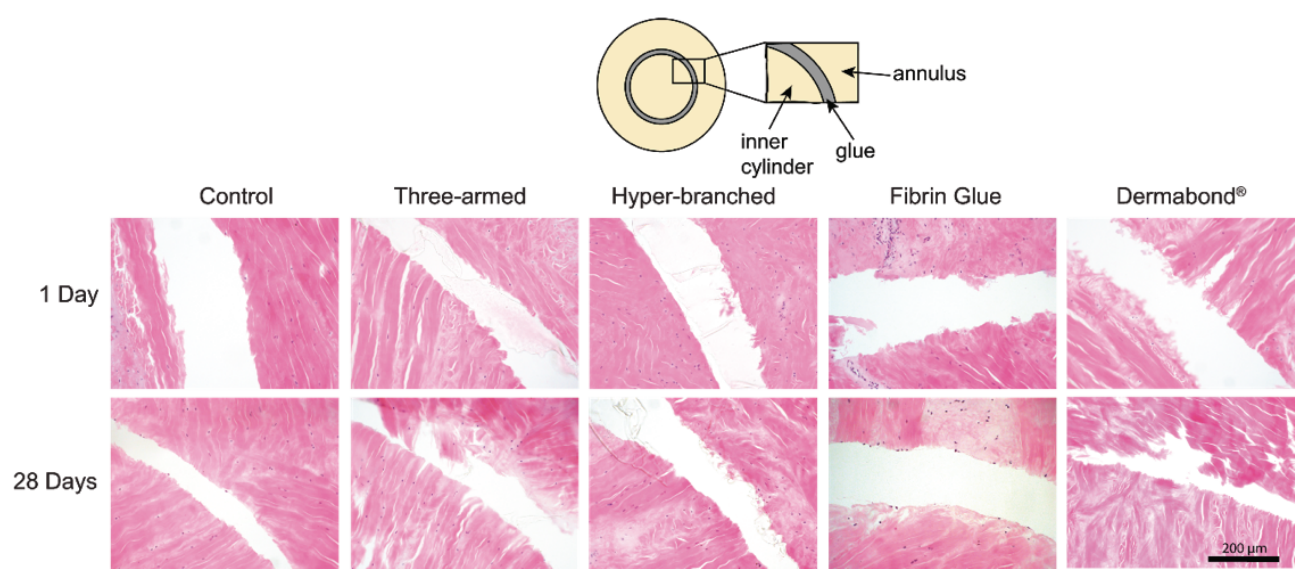

Figure 3. H\&E staining of the glued cylindrical explants cultured in vitro for 1 and 28 days. View on the gap between the inner cylinder and the annulus of the repair constructs.

\section{Effect of tissue surface pre-treatment with collagenase on adhesion strength and tissue response}

Incubating the meniscus explants in a collagenase solution resulted in a visible decrease in matrix density in PR stained sections and an increased number of cells after H\&E staining in the area close to the gap between the annulus and inner cylinder of the explants (Figure 4). 

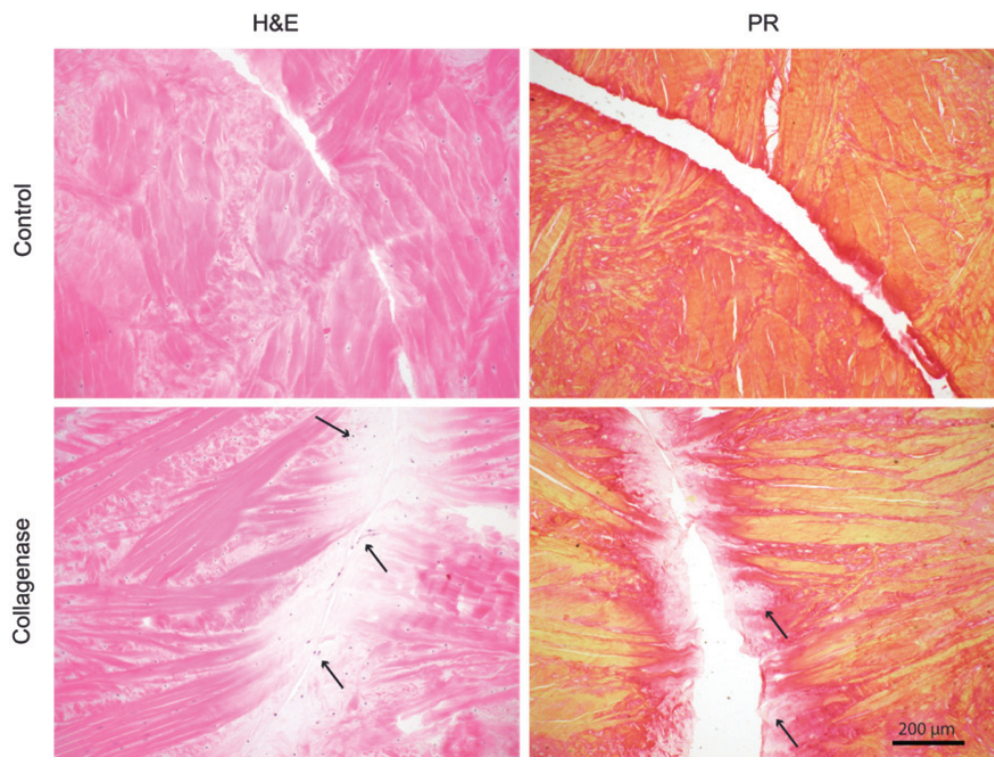

Figure 4. H\&E and PR staining of meniscus explants incubated in a collagenase solution for 3 hours (bottom) and a control (top). The arrows indicate cells present close to the gap edge (slides stained with $H \& E$ ) and decreased density of collagen fibers at the gap edge (slides stained with PR). View on the gap between inner cylinder and annulus of the explants.

In the collagenase-treated explants the mean adhesive strengths after 1 and 28 days of the three-armed and hyper-branched glues $(39.8 \pm 28.4 \mathrm{kPa}$ and $41.3 \pm 25.0 \mathrm{kPa}$, respectively) were better than that of fibrin glue $(14.2 \pm 6.7 \mathrm{kPa})$ and the control group with no glue $(6.8 \pm 4.4 \mathrm{kPa})(\mathrm{p}<0.05)$ (Figure 5). There were no significant differences in adhesive strength between the three-armed and hyper-branched adhesives and no differences in adhesive strength between day 1 and 28. Only in the group glued with Dermabond $^{\circledR}$, differences in adhesive strength between day 1 and day 28 were observed. Adhesive strength of Dermabond ${ }^{\circledR}(397 \pm 109.2 \mathrm{kPa})$ was not included in the statistical test. 


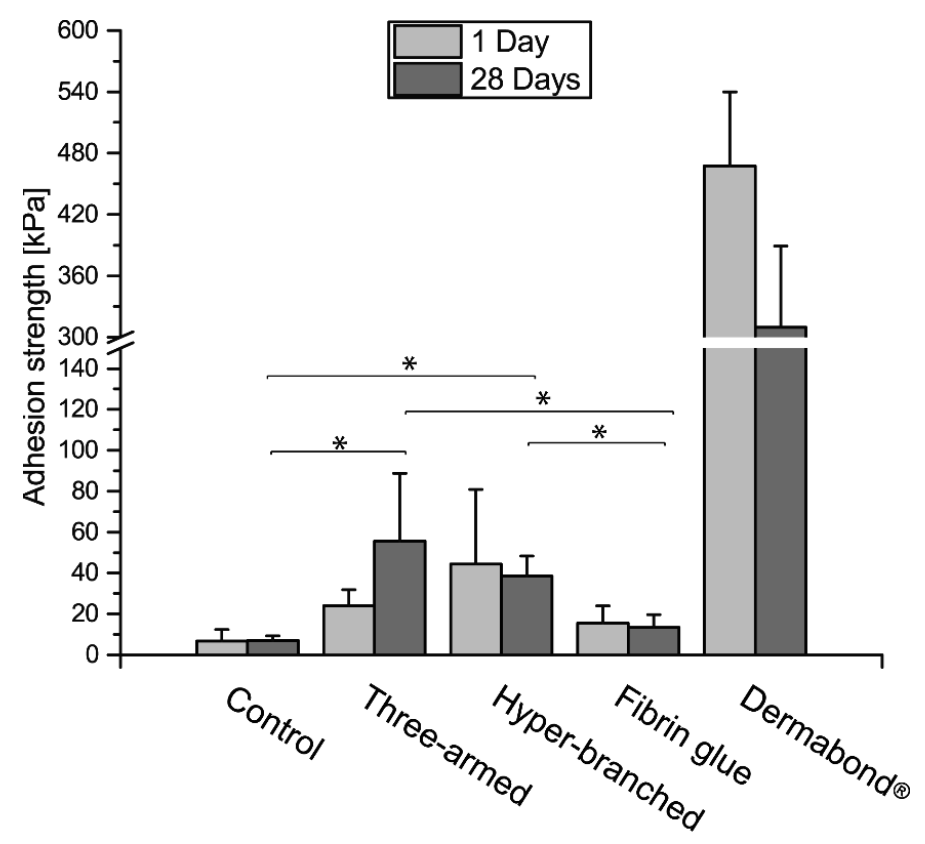

Figure 5. Adhesive strength of the glues to bovine meniscus tissue determined in a push-out test on explants incubated in a collagenase solution prior to the in vitro culture. Data are expressed as mean \pm standard deviation. Asterisks indicate significant differences between means $(p<0.05)$. Dermabond ${ }^{\circledR}$ was not included in the statistical analysis.

All repair constructs were stained with $\mathrm{H} \& \mathrm{E}$ to visualize cells and ECM at day 1 and 28 of culture (Figure 6). Both the three-armed and hyper-branched glues could be seen in the gap of the repair constructs after 1 and 28 days. On the day 1 , in all groups except Dermabond ${ }^{\circledR}$, a slightly increased number of cells in close proximity to the gap was observed when compared to the previous experiment where explants were not incubated in collagenase prior to culture. However, at day 28 , these differences in numbers of cells were not present anymore. Within the groups treated with collagenase, there were no differences in the number of cells between control, threearmed and hyper-branched glues groups, and a slightly increased number of cells in the fibrin glue group was observed. In the Dermabond ${ }^{\circledR}$ group no H\&E stained cells could be detected. 


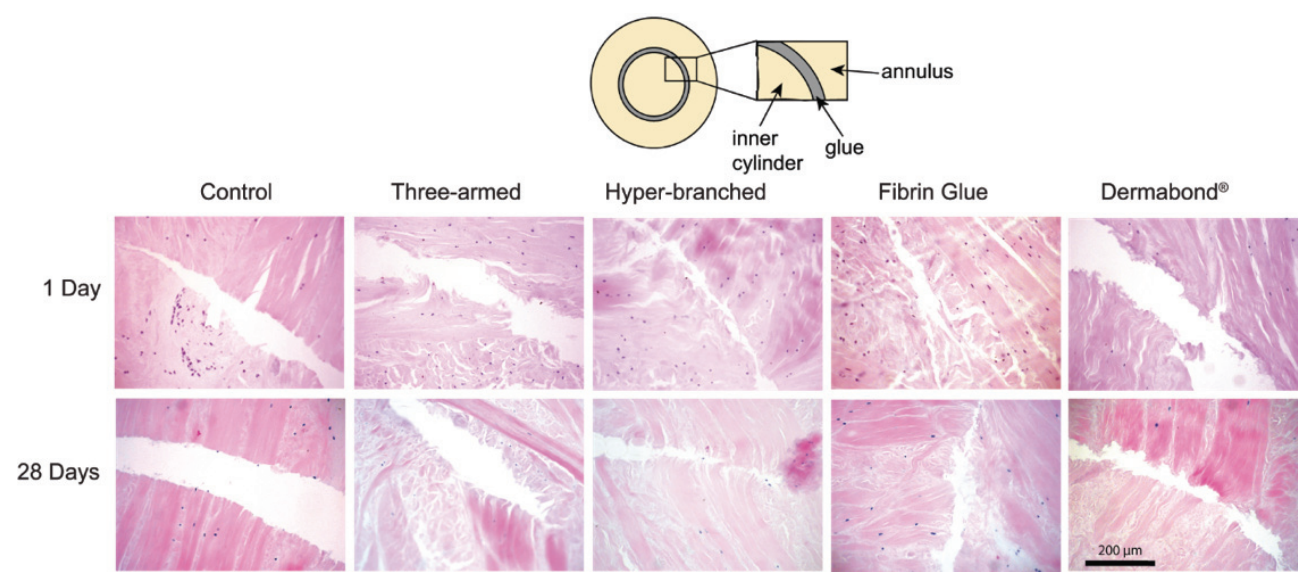

Figure 6. H\&E staining of the explants incubated in a collagenase solution prior to gluing and culturing in vitro for 1 and 28 days. View on the gap between inner cylinder and the annulus.

\section{Discussion}

The first aim of this study was to assess and compare the adhesive strength of two recently developed block copolymeric glues and to evaluate the tissue response after application of the glues in an in vitro meniscus explant culture. We employed a welldescribed meniscus explant model, which mimics full-thickness meniscal tears [21, 22, 24-26].

Both newly developed glues had a good adhesive strength to meniscus tissue (40-50 $\mathrm{kPa}$ ), which was significantly higher than that of fibrin glue (approximately $11 \mathrm{kPa}$ ) and that of the control groups (approximately $7 \mathrm{kPa}$ ). The adhesion mechanism of the developed glues is the covalent attachment of reactive isocyanate end-groups to collagen fibers of meniscus tissue. However, as both the three-armed- and the hyperbranched glue had similar adhesion strengths, it seems that a further increase of the degree of branching of the copolymers will not improve on their adhesive properties. The decision which of the two compositions should be used in a future clinical application should be based on further mechanical studies and on currently ongoing in vivo biocompatibility evaluations of the glues.

Even though the adhesive strengths of our glues were lower than those of Dermabond $^{\circledR}$, they do have clinical relevance. It has been shown that distraction 
forces acting on a torn meniscus in a cadaver knee model did not exceed 5-10 N when a load of $300 \mathrm{~N}$ was applied [27, 28]. This means that the stress was not more than $50-100 \mathrm{kPa}$, during the recovery period after surgery the load on the knee might be even lower. Moreover, the glues stayed in place during the whole culture period and did not lose their bonding strength. This follows from the constant values of the adhesive strength observed after 1 and 28 days of culture for each particular composition. Histological staining of the slides revealed that our novel glues did not exhibit any toxicity, as fibroblast cells were seen after 28 days of culture in vitro in close proximity to the gap and tissue remained vital during the whole culture period. On the contrary, in the Dermabond ${ }^{\circledR}$ group, there were no cells present after 28 days, and the tissue started losing its integrity.

The meniscus is mostly an avascular tissue. Due to its limited cellularity and dense ECM, it has a very low capacity for self-repair [1]. Therefore, in clinical practice, surgeons use techniques such as mechanical rasping, trephination and the creation of access channels to stimulate neo-vascularization to the wound site, expose collagen fibers, refresh the wound and allow cells to enter the tear and stimulate healing $[11,29]$. Moreover, roughening the surface of the tear and exposing the collagen fibers could potentially have a beneficial influence on the adhesive strength of the glues as well. As the available surface area is larger, the covalent interactions between the tissue and the glue will increase. Also the mechanical interlocking of the cured glue to the tissue would be enhanced.

Therefore, the second aim of this study was to assess the influence of surface modification on the adhesive strength of the glues to the tissue and the cellularity around the gap edges. The strategy we employed was analogous to the one described by Qu et al. [14], where the authors managed to re-program the wound environment to a more juvenile-like meniscus tissue with increased cellularity by incubating adult meniscus explants in collagenase solution. In our experiments, we incubated the explants in collagenase solution, after which the explants were glued and cultured in vitro. The results of the mechanical adhesion tests showed that the mean adhesive strength of all tested glues was slightly lower than those determined in the earlier experiments where no collagenase was used. However, the standard deviations were high and the differences were not statistically significant. This could be due to the non-homogenous distribution of the glues in the gap of the explants. Moreover, the 
explants were from different donors and different locations of the meniscus. Such a design allowed excluding possible bias associated with differences in tissue structure and cellularity, but resulted in high standard deviations within the experimental groups. Nevertheless, it seems that treatment with collagenase did not improve the adhesive strength of the glues. Histological staining after 1 day of culture revealed that there was an increased number of cells in close proximity to the gap edge in all groups (except those glued with Dermabond ${ }^{\circledR}$ ) when compared to the explants, which were not incubated in collagenase prior to culture. However, after 28 days the cellularity of the glued implants was comparable for both conditions. This could be due to the fact that the glues, which filled the whole gap between the inner cylinder and the outer annulus of the repair constructs, acted as a barrier for the cells and hindered them entering the tear gap. Moreover, the glue present in the gap might have blocked the access to nutrients present in the culture medium. Therefore, in future in vivo experiments and clinical application, only a few drops of the glue may be applied locally.

\section{Conclusions}

The two newly developed block copolymeric tissue adhesives are attractive materials to be used in repairing meniscal tears. An adhesive strength of $40-50 \mathrm{kPa}$ should be sufficient to hold edges of meniscal tears together during the healing period. As there was no difference in adhesive strength between the two adhesive compositions, a decision on the most suitable adhesive to be used in future clinical application, should be made after investigating their mechanical properties, biodegradability and biocompatibility in an in vivo model in more detail. Incubation of the tissue explants in collagenase solution might improve tissue capacity for selfrepair.

\section{Acknowledgements}

This research is supported by Reumafonds, the Dutch Arthritis Foundation.

\section{References}

[1] Starke C, Kopf S, Petersen W, Becker R. Meniscal Repair. Arthroscopy-the Journal of Arthroscopic and Related Surgery 2009;25:1033-44. 
[2] Henning CE, Lynch MA, Clark JR. Vascularity for healing of meniscus repairs. Arthroscopy: The Journal of Arthroscopic \& Related Surgery 1987;3:13-8.

[3] Qu F, Pintauro MP, Haughan JE, Henning EA, Esterhai JL, Schaer TP, et al. Repair of dense connective tissues via biomaterial-mediated matrix reprogramming of the wound interface. Biomaterials 2015;39:85-94.

[4] Forriol F. Growth factors in cartilage and meniscus repair. Injury 2009;40:70005-1.

[5] Abrams GD, Frank RM, Gupta AK, Harris JD, McCormick FM, Cole BJ. Trends in meniscus repair and meniscectomy in the United States, 2005-2011. American Journal of Sports Medicine 2013;41:2333-9.

[6] Lozano J, Ma CB, Cannon WD. All-inside Meniscus Repair: A Systematic Review. Clinical Orthopaedics and Related Research 2007;455:134-41.

[7] Barber FA, Herbert MA. Meniscal repair devices. Arthroscopy: The Journal of Arthroscopic \& Related Surgery 2000;16:613-8.

[8] Krause WR, Pope MH, Johnson RJ, Wilder DG. Mechanical changes in knee after meniscectomy. Journal of Bone and Joint Surgery-American Volume 1976;58:599-604.

[9] Longo UG, Campi S, Romeo G, Spiezia F, Maffulli N, Denaro V. Biological Strategies to Enhance Healing of the Avascular Area of the Meniscus. Stem Cells International 2012;2012:528359.

[10] Krych AJ, McIntosh AL, Voll AE, Stuart MJ, Dahm DL. Arthroscopic repair of isolated meniscal tears in patients 18 years and younger. American Journal of Sports Medicine 2008;36:1283-9.

[11] Okuda K, Ochi M, Shu N, Uchio Y. Meniscal rasping for repair of meniscal tear in the avascular zone. Arthroscopy 1999;15:281-6.

[12] Uchio Y, Ochi M, Adachi N, Kawasaki K, Iwasa J. Results of rasping of meniscal tears with and without anterior cruciate ligament injury as evaluated by second-look arthroscopy. Arthroscopy 2003;19:463-9.

[13] Rubman MH, Noyes FR, Barber-Westin SD. Arthroscopic repair of meniscal tears that extend into the avascular zone. A review of 198 single and complex tears. American Journal of Sports Medicine 1998;26:87-95.

[14] Qu F, Lin J-MG, Esterhai JL, Fisher MB, Mauck RL. Biomaterial-mediated delivery of degradative enzymes to improve meniscus integration and repair. Acta Biomaterialia 2013;9:6393-402.

[15] Simson JA, Strehin IA, Allen BW, Elisseeff JH. Bonding and fusion of meniscus fibrocartilage using a novel chondroitin sulfate bone marrow tissue adhesive. Tissue Engineering - Part A 2013;19:1843-51.

[16] Chih-Chang Chu HPG, J. Anthony von Fraunhofer. Wound Closure Biomaterials and Devices. 1 ed: CRC-Press; February 1, 1997

[17] Leggat PA, Smith DR, Kedjarune U. Surgical applications of cyanoacrylates adhesives: A review of toxicity. ANZ Journal of Surgery 2007;77:209-13.

[18] Sierra DH. Fibrin Sealant Adhesive Systems: A Review of Their Chemistry, Material Properties and Clinical Applications. Journal of Biomaterials Applications 1993;7:309-52.

[19] Bochyńska AI, Van Tienen TG, Hannink G, Buma P, Grijpma DW. Development of biodegradable hyper-branched tissue adhesives for the repair of meniscus tears. Acta Biomaterialia 2016;32:1-9, Chapter 5 of this thesis. 
[20] Bochyńska AI, Sharifi S, van Tienen TG, Buma P, Grijpma DW. Development of Tissue Adhesives Based on Amphiphilic Isocyanate-Terminated Trimethylene Carbonate Block Copolymers. Macromolecular Symposia 2013;334:40-8, Chapter 3 of this thesis.

[21] Hennerbichler A, Moutos FT, Hennerbichler D, Weinberg JB, Guilak F. Interleukin-1 and tumor necrosis factor alpha inhibit repair of the porcine meniscus in vitro. Osteoarthritis and Cartilage 2007;15:1053-60.

[22] Hennerbichler A, Moutos FT, Hennerbichler D, Weinberg JB, Guilak F. Repair response of the inner and outer regions of the porcine meniscus in vitro. American Journal of Sports Medicine 2007;35:754-62.

[23] Qu F, Pintauro MP, Haughan JE, Henning EA, Esterhai JL, Schaer TP, et al. Repair of dense connective tissues via biomaterial-mediated matrix reprogramming of the wound interface. Biomaterials 2015;39:85-94.

[24] McNulty AL, Moutos FT, Weinberg JB, Guilak F. Enhanced integrative repair of the porcine meniscus in vitro by inhibition of interleukin-1 or tumor necrosis factor alpha. Arthritis Rheum 2007;56:3033-42.

[25] McNulty AL, Moutos FT, Wilusz RE, Weinberg JB, Guilak F. The effects of pro-inflammatory cytokines on functional repair of the meniscus. MCB Molecular and Cellular Biomechanics 2006;3:197-8.

[26] Ionescu LC, Lee GC, Huang KL, Mauck RL. Growth factor supplementation improves native and engineered meniscus repair in vitro. Acta Biomaterialia 2012;8:3687-94.

[27] Becker R, Brettschneider O, Gröbel KH, Von Versen R, Stärke C. Distraction forces on repaired bucket-handle lesions in the medial meniscus. American Journal of Sports Medicine 2006;34:1941-7. [28] Staerke C, Brettschneider O, Gröbel KH, Becker R. Tensile forces on sutures in the human lateral knee meniscus. Knee Surgery, Sports Traumatology, Arthroscopy 2009;17:1354-9.

[29] Zhang Z, Arnold JA, Williams T, McCann B. Repairs by trephination and suturing of longitudinal injuries in the avascular area of the meniscus in goats. American Journal of Sports Medicine $1995 ; 23: 35-41$. 


\section{Chapter 7}

\section{The Effect of Tissue Surface Modification with Collagenase and Addition of TGF- $\beta 3$ on the Healing Potential of Meniscal Tears Repaired with Tissue Glues In Vitro}

Agnieszka I. Bochyńska ${ }^{1,2}$, Gerjon Hannink ${ }^{1}$, Renate Verhoeven ${ }^{1}$, Dirk W. Grijpma $^{2,3}$, Pieter Buma ${ }^{1}$

${ }^{1}$ Orthopaedic Research Laboratory, Department of Orthopaedics, Radboud Centre for Molecular Life Sciences, Radboud University Nijmegen Medical Centre, Nijmegen, the Netherlands

${ }^{2}$ Department of Biomaterials Science and Technology, MIRA Institute, University of Twente, Enschede, the Netherlands

${ }^{3}$ University Medical Centre Groningen, University of Groningen, W.J. Kolff Institute, Department of Biomedical Engineering, Groningen, the Netherlands 


\begin{abstract}
The aim of the current in vitro study was to investigate if tissue surface modification with collagenase and addition of the TGF- $\beta 3$ can increase the number of cells present in meniscus tears repaired with the use of newly developed tissue adhesives based on isocyanate-terminated block copolymers.

Cylindrical explants were harvested from the inner part of bovine menisci. To simulate a full-thickness tear, the central core of the explants was removed and glued back into the defect, with or without incubation in collagenase solution prior to gluing. The repair constructs were then cultured with or without addition of TGF$\beta 3$, and assessed for their histological appearance.
\end{abstract}

The histological staining of the constructs confirmed that both developed adhesives were not cytotoxic. After 28 days, meniscus cells were present in direct contact with the glues. The addition of TGF- $\beta 3$ to the culture medium resulted in the presence of cells that formed a sheath inside the simulated tear and in increased cell numbers at the edges of annulus of the explants. In the group in which the tissue was incubated in collagenase and cultured in medium containing TGF- $\beta 3$, thicker layers of cells were observed.

These results suggest that repairing the torn meniscus with tissue adhesives after pretreatment of the tissue with collagenase and stimulation with a TGF- $\beta 3$ is a very promising treatment method, especially when treating the inner avascular part of the meniscus. Nevertheless, longer-term in vitro and in vivo studies are needed to confirm the beneficial effects of this combination therapy.

\title{
Introduction
}

Biodegradable tissue adhesives are an attractive class of materials with potential to be used in the repair of meniscus tears [1-3]. They are easy to apply, keep the torn parts of the tissue together during the period of healing, and degrade into harmless compounds that are then metabolized or excreted from the body.

However, meniscus tissue is largely avascular and its dense extracellular matrix (ECM) restricts the already relatively low number of cells in their mobility and 
proliferation potential $[4,5]$. Hence, the capacity of the meniscus for self-repair is very limited and tears, especially those located in the avascular zone, do not heal spontaneously. In clinical practice, rasping of the tissue and trephination to create access channels to stimulate neo-vascularization and new tissue ingrowth is an oftenperformed procedure [6-9]. Still, the success rate of repairing tears in the avascular zone is disappointing. The study of Rubman et al. showed that out of the 91 meniscal repairs evaluated arthroscopically, $23(25 \%)$ were classified as healed, $35(38 \%)$ as partially healed, and $33(36 \%)$ as failed [10]. 20\% of treated patients reported on in this study required a second intervention [10]. Therefore, there is a rapidly growing interest in the use of biological factors that could induce meniscus repair [11]. Qu et $a l$. showed that partial digestion of adult meniscal explants with collagenase prior to culture in vitro resulted in a less dense ECM at the edges of the explants and in an increased cellularity [12]. A later in vivo experiment using ovine menisci confirmed that partial digestion of the tissue enhances repair by creating a more compliant and porous microenvironment that facilitates migration of cells to the tear margin and their proliferation [13]. Another approach to stimulate cellular migration and proliferation is the local delivery of growth factors [14-16]. Particularly, transforming growth factor TGF- $\beta 3$, which is an anabolic factor for meniscus fibroblasts, was shown to increase the integration strength in both adult and juvenile menisci in vitro [15].

We recently reported on the development of reactive three-armed and hyperbranched block copolymeric tissue adhesives that can attach to the tissue via covalent bonding $[17,18]$. In a following study, meniscus explants were glued with these adhesives and cultured in vitro. It was shown that both developed materials have satisfactory bonding strengths to the tissue and did not exhibit toxicity to the cells, and therefore have the potential to be used in the treatment meniscal tears [19]. However, the continuous glue layer present in the repaired meniscal tear might limit cell migration and the transport of nutrients and waste products.

The aim of the current study was twofold. First, to evaluate if partial gluing of the repaired tissue allows cells to migrate into the simulated tear (gap). Second, to investigate if modification of the tissue surface with collagenase and the addition of TGF- $\beta 3$ can increase the number of cells present in the repaired meniscus tear and 
thereby enhance healing of the tissue. We hypothesized that the optimal treatment for meniscus tissue repair would be a degradable glue to hold the edges of meniscal tear in close proximity to each other, in combination with additional biological factors to enhance the capacity of the meniscus for self-repair.

\section{Materials and Methods}

\section{Tissue glues}

Two different reactive isocyanate-terminated adhesive block copolymers were prepared: a three-armed TMPE-(TMC $\left.{ }_{2}-\mathrm{HDI}\right)_{3}$ adhesive and a hyper-branched CA4PEG-( $\left.\mathrm{TMC}_{2}\right)_{2}$-HDI adhesive. Their synthesis has been described in detail before $[17,18]$. These adhesives were respectively prepared from trimethylolpropane ethoxylate (TMPE, $\mathrm{M}_{\mathrm{n}}=450 \mathrm{~g} / \mathrm{mol}$ ), trimethylene carbonate (TMC) and hexamethylene diisocyanate (HDI), and from polyethylene glycol (PEG, $\mathrm{M}_{\mathrm{n}}=400 \mathrm{~g} / \mathrm{mol}$ ), $\mathrm{TMC}$, citric acid (CA) and HDI. Prior to use, the adhesives were sterilized by gamma irradiation ( $25 \mathrm{kGy}$, SynergyHealth BV, The Netherlands). The materials were characterized by ${ }^{1} \mathrm{H}-\mathrm{NMR}$ (Bruker 400MHz NMR spectrometer) and FTIR (Perkin Elmer) before and after sterilization.

\section{Preparation of meniscus explants}

Meniscus explants were prepared in an analogous way as described by Hennerbichler et al. [20,21]. Briefly, fresh knees from 12-18 months old cows were purchased from a local slaughterhouse. The medial menisci were removed from the joint under sterile conditions. Five cylindrical explants $(8 \mathrm{~mm}$-diameters $)$ were obtained from the central part of each meniscus with a biopsy punch and randomly assigned to different experimental groups. Subsequently, their height was trimmed to $4 \mathrm{~mm}$ and an inner cylinder of $4 \mathrm{~mm}$ in diameter was centrically cored from each explant.

\section{The influence of surface modification with collagenase and TGF- $\beta 3$ addition on cellular migration in glued meniscus tissue constructs}

Explants (both outer annulus and inner cylinder) were incubated in basal medium containing 0 (control) or $0.05 \mathrm{mg} / \mathrm{mL}$ collagenase (type IV from Clostridium 
histolyticum, $\geq 125$ collagenase digestion units/mg solid, Sigma Aldrich) for 3 hours at $37{ }^{\circ} \mathrm{C}$ according to the protocol described by Qu et al. [13]. Basal medium was composed of Dulbecco's Modified Eagle's Medium (DMEM, Gibco ${ }^{\circledR}$, UK) with $10 \%$ fetal bovine serum (FBS, Gibco $\left.{ }^{\circledR}, \mathrm{UK}\right), 1 \%$ penicillin/streptomycin/fungizone (PSF, Gibco ${ }^{\circledR}$, USA) and L-ascorbic acid (Merck, Darmstadt, Germany) at a concentration of $25 \mu \mathrm{g} / \mathrm{mL}$ of medium. Repair constructs were created by applying three lines of glue (approximately 5-10 $\mu \mathrm{L}$ per line) onto the sides of the inner cylinder using a syringe equipped with a $23 \mathrm{G}$ needle and gently reinserting the inner cylinder into the outer annulus (Figure 1a). This gluing procedure allowed parts of the tissue from inner cylinder and the outer annulus to remain in direct contact (Figure 1b). Repair constructs were created using the three-armed adhesive and the hyper-branched one; constructs without any glue were used as controls.

a)

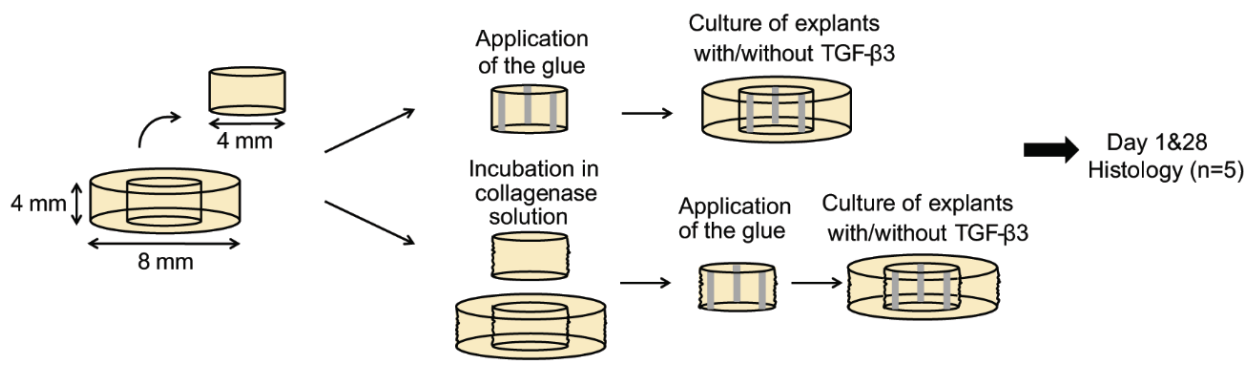

Figure 1. a) An overview of the experimental design, b) Top view on the meniscal repair construct glued with the strips of the glue.

Constructs were cultured for 1 and 28 days in basal medium containing 0 (control) or $10 \mathrm{ng} / \mathrm{mL}$ of TGF- $\beta 3$. In total, four different culture conditions were employed (Table 1). After 1 and 28 days, the repair constructs ( $n=5$ per group) were fixated in $10 \%$ formalin, embedded in poly(methyl methacrylate) (PMMA), sectioned into 8 $\mu \mathrm{m}$ thick coupes and stained with hematoxylin and eosin (H\&E) and picrosirius red (PR) to visualize cells, ECM and collagen fibers. For each group, H\&E-stained sections were scored for the number of cells present inside and at the edge of the 
simulated meniscal tear, which was defined as a gap between inner cylinder and outer annulus of the explants. Moreover, the number of cells and the thickness of the cell layers at the outer edge of the annulus of the explants (no cells, single cell layer or multiple cell layers) were assessed. Digestion of collagen fibers was visually assessed on the PR stained sections. For the scoring, 5 explants per group at 3 random locations of each explant were analyzed by light microscopy (200x field magnification).

Table 1. Conditions used in the in vitro culturing of glued meniscus tissue constructs.

\begin{tabular}{ccccc}
\hline Conditions & I & II & III & IV \\
\hline Incubation in collagenase prior to gluing & no & yes & no & yes \\
Addition of TGF- $\beta 3$ to the culture medium & no & no & yes & yes \\
\hline
\end{tabular}

\section{Statistical analysis}

Differences in the number of cells in the different experimental groups were evaluated using a three-way ANOVA followed by Fischer's LSD post-hoc test. Data are presented as a mean value \pm standard deviation. $P$ values $<0.05$ were considered as significant. All statistical analyses were done using SPSS (version 20, IBM Corporation).

\section{Results}

The reactive three-armed TMPE-(TMC $2-\mathrm{HDI})_{3}$ and hyper-branched CA-4PEG$\left(\mathrm{TMC}_{2}\right)_{2}$-HDI adhesives were successfully synthesized as confirmed by ${ }^{1} \mathrm{H}-\mathrm{NMR}$ and FTIR analysis. No differences were observed before and after the sterilization procedure by gamma irradiation.

The H\&E staining showed that the glues did not induce any toxic reaction to the tissue, the tissue remained vital during the whole culturing period. After 1 day of explant culture, vital meniscus fibroblasts were seen in close proximity to the gap in the H\&E stained sections of all experimental groups. After 28 days cells could also be observed within the gap in all experimental groups. Within the same culturing conditions, there were no significant differences in cell numbers between the threearmed glue, the hyper-branched glue and the control group (Figure 2). There was also no difference in the number of cells between conditions I and II, indicating that 
modification of the tissue surface by incubation in collagenase solution prior to culture did not have any beneficial influence on migration of the cells into the gap. However, there were differences between conditions IV, where explants were incubated in collagenase and TGF- $\beta 3$ was added to the culture medium, and the other culturing conditions. Although the differences in the number of cells were not statistically significant between these different culturing conditions (after 28 days respectively $3.6 \pm 1.6,3.7 \pm 1.9$ and $4.1 \pm 1.7$ for the three-armed glue, the hyperbranched glue and the control), it could clearly be seen that when culturing under conditions IV the cells populating the gap between the inner cylinder and the outer annulus start to form sheaths in the spaces between the lines of glue. This was never observed when culturing under the other conditions.

At the outer edges of the annuli of the repair constructs there were no differences in cells numbers between the three-armed glue, the hyper-branched glue and the control group when cultured under the same conditions after 28 days (Figure 3). However, the influence of incubation in collagenase solution and the addition of growth factor TGF- $\beta 3$ was clearly visible (Figure 3 ). When non-treated explants were cultured in medium containing TGF- $\beta 3$ (III), single or double layers of cells aligned in an organized circumpherential manner could be seen. When explants were incubated in collagenase and cultured in medium supplemented with TGF- $\beta 3$ (IV), even thicker multi-layered cell sheets were formed. This was not observed in explants cultured in the absence of growth factor (I and II), here only few cells at the outer edge of the repair constructs could be observed. 

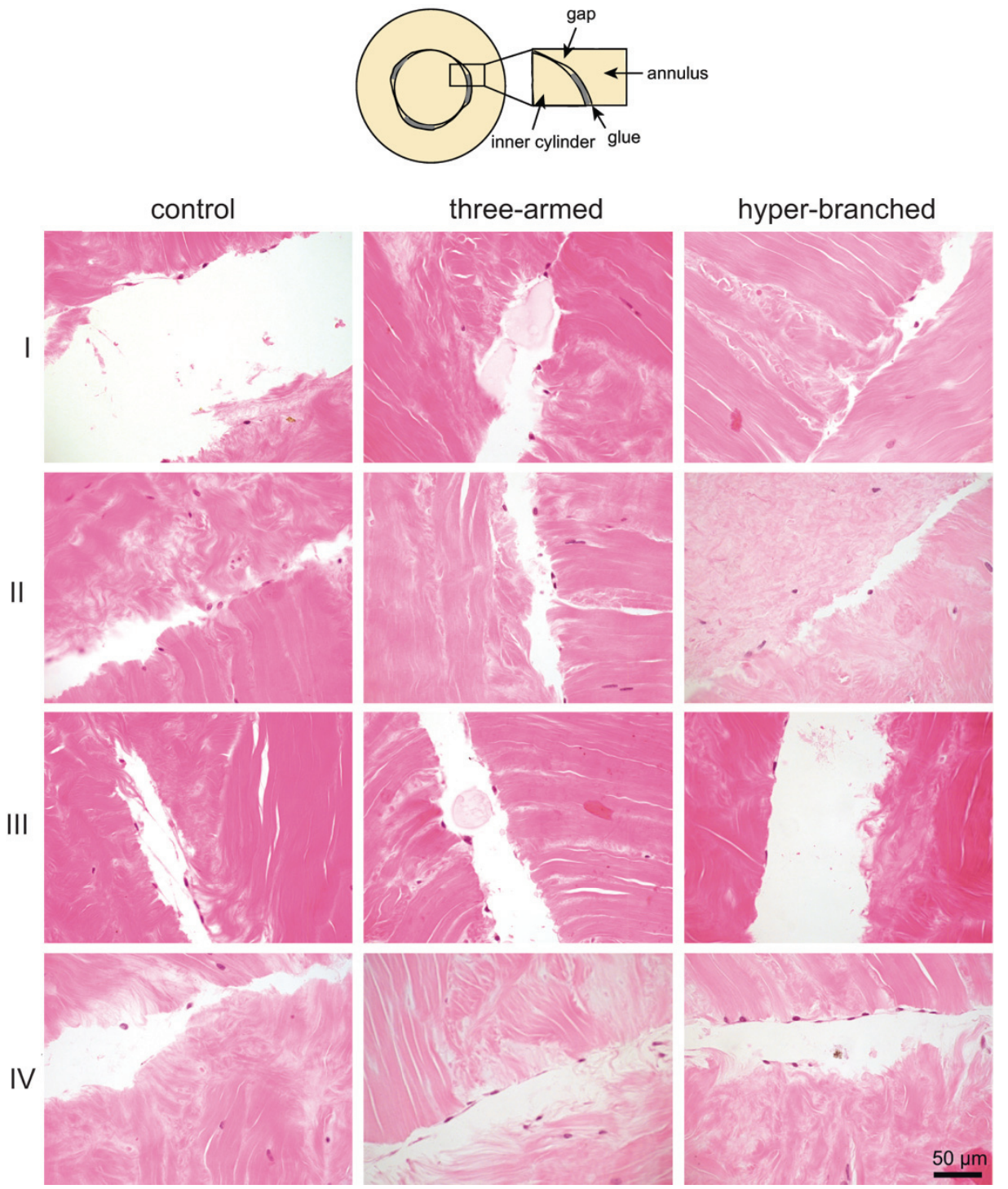

Figure 2. Representative light microscopy images of $H \& E$ stained meniscus tissue repair constructs cultured in vitro for 28 days under the different conditions (I-IV) described in Table 1. View on the partial gap between the inner cylinder and the annulus. 


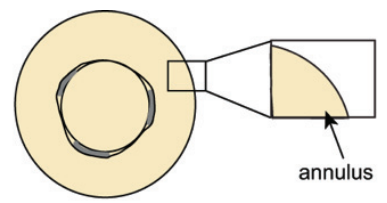

I

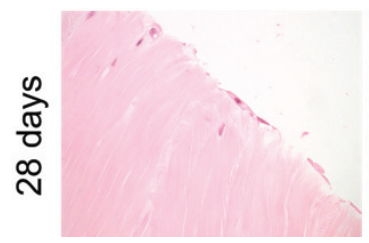

II

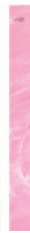

III

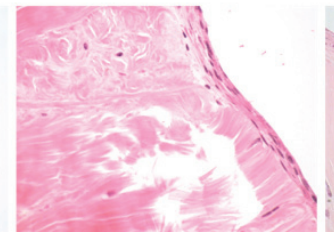

IV

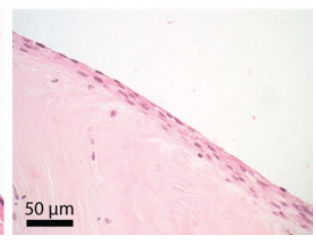

Figure 3. Typical images of the outer edge of the annulus of the repair constructs (H\&E staining) cultured for 28 days under different conditions (I-IV) as described in Table 1. The figure shows images of the experimental three-armed glue group. In the other experimental groups (the hyper-branched glue and control groups), similar results were observed.

Visualization of the collagen fibers at the outer edges of the repair constructs after 1 day of culturing (after PR staining) revealed that in the groups incubated in collagenase (II and IV) the constructs were partially digested (Figure 4). After 28 days of culture, the influence of incubation in collagenase solution was even more pronounced. In the groups where TGF- $\beta 3$ was added to the culture medium (III and IV) circumferentially oriented collagen fibers were detected. This was not observed in experimental groups I and II. In the experimental group where the explants were incubated in collagenase and the medium contained TGF- $\beta 3$ (IV), the cellular layer and the collagen layer were thicker than in the group that only contained the growth factor (III). 

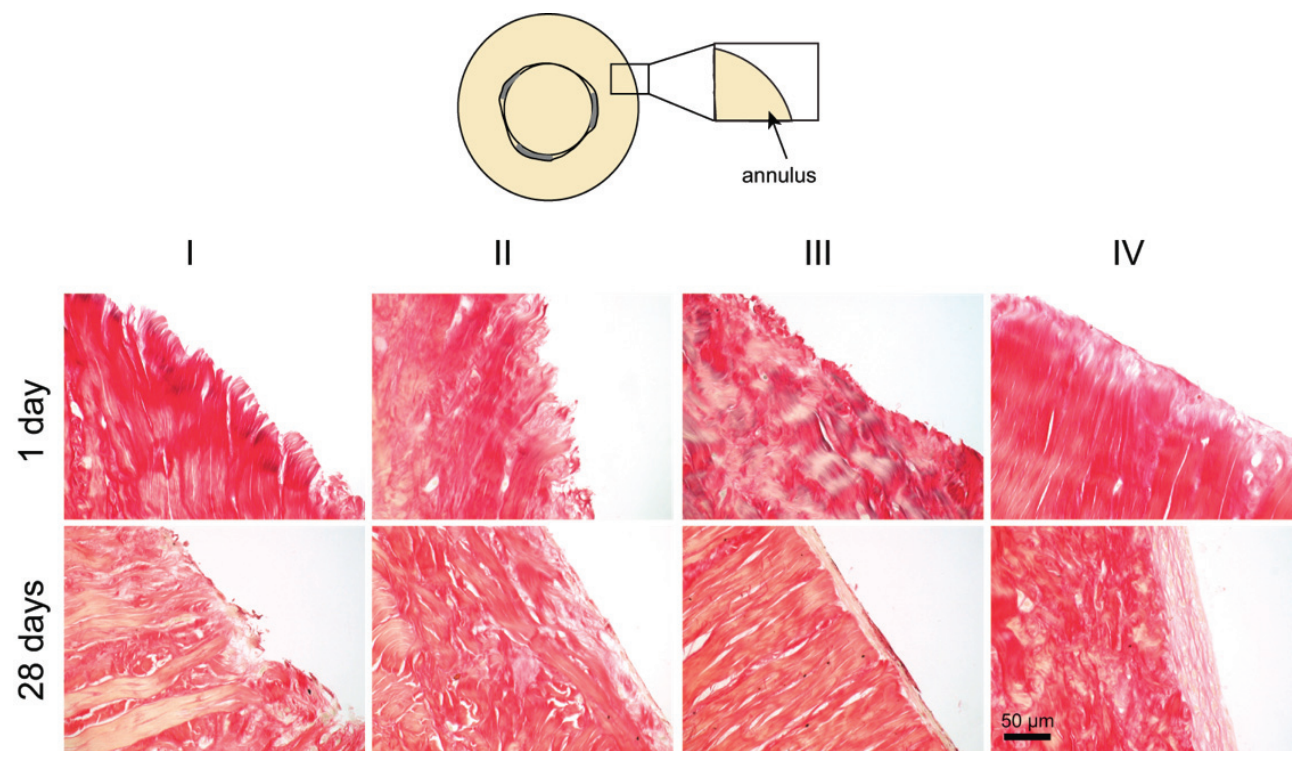

Figure 4. Typical images showing the alignment of collagen fibers (PR staining) at the outer edge of the annulus of the repair constructs after 1 and 28 days of culture under the different conditions (I-IV) described in Table 1. Images of repair constructs prepared using the three-armed glue are shown. In the other experimental groups (the hyper-branched glue and the control group), similar results were observed.

\section{Discussion}

The two recently developed tissue adhesives appeared to be promising materials for meniscus tears treatment [19]. However, if the entire tear gap between the inner core and outer annulus of the explants is filled with glue, it could potentially limit cell migration. Therefore, in this study only partial gluing of the explants was performed. Such design will probably also be closer to a future clinical application, where only a few drops of glue would be applied to repair the tear [18]. In the present study, thin lines of the glues were applied to the tissue, and great care was taken to gently reinsert the inner cylinder into the outer annulus of the explants without spreading the glue over a larger surface area. As the glues could be seen in the histological slides after 1 and 28 days, partial gluing of the tissue, which stayed in place during the whole culture period, could be confirmed. 
Histological evaluation of the gaps between the glued tissues in the repair constructs after 1 and 28 days showed the presence of fibroblasts in all experimental groups. Within 28 days of culture, cells were able to populate the gaps in between the lines of glue. There were no differences in cell numbers within the same culturing conditions, confirming the cell compatibility of the three-armed adhesive as well as that of the hyper-branched one.

The incubation of explants in collagenase and further addition of the TGF- $\beta 3$ to the culture medium resulted in a presence of sheets of cells in the gap of the repair constructs. Indeed, TGF- $\beta 3$ is known to be an anabolic chemotactic and mitogenic agent which attract cells and stimulates their replication [22]. Our findings are in accordance with data previously shown in literature that reprogramming the torn region of cartilaginous tissues such as the meniscus $[12,13,15]$ and the articular cartilage $[23,24]$ with the use of enzymes e.g. collagenase or hyaluronidase increases the density of cells at the wound edges and promotes repair.

Although sheets of cells were formed in the gap and the cells were found to deposit new ECM, complete bridging of the tear gap was never observed. The reason for this could be that the growth factor was immediately absorbed in the peripheral part of the tissue. As this part was in a direct contact with the medium, the influence of the growth factor on the inner part of the repair constructs might not have been as pronounced. After longer culturing times of the explants (e.g. 6 or 8 weeks), the cell layers in the gap could possibly be more extensive [15]. Moreover, even though only partial gluing of explants was performed, the two edges of the tear stayed in very close proximity to each other, probably limiting the amount of nutrient containing medium that is available for the cells present in the gap. Furthermore, meniscus tissue is a tissue with very limited numbers of cells, especially in the inner region from where the explants used in this study were obtained. This might also be a reason for the low cell numbers in the gap and the limited differences between the various culture conditions.

Investigation of the outer edge of annulus of the explants, where the cells likely had better access to TGF- $\beta$ and nutrients in the culture medium, confirmed the positive influence of incubation in collagenase solution and the addition of TGF- $\beta 3$ to the medium. Multi-layer cell sheets were present when the explants were both incubated in collagenase and cultured in medium containing growth factor. Slightly thinner 
layers were seen when only TGF- $\beta 3$ was added to the medium. As the influence of both treatments was more pronounced at the outer edge of the annulus of the explants, it seems that the restricted access of medium to the gap is a limiting factor in our experimental setup. In clinical application, however, the glue will be applied as drops. Also, due to mechanical loading and fluid flow within the joint, the accessibility of nutrients to the cells is expected to be better.

\section{Conclusions}

Modification of the surface of meniscus tissue by incubation in collagenase and the presence of growth factor TGF- $\beta 3$ were shown to have a positive influence on the number of cells present in the gap of a meniscus repair construct glued with novel reactive isocyanate-terminated three-armed- and hyper-branched glues. The healing potential of a torn meniscus can possibly be enhanced by using a combined therapy which makes use of collagenase tear surface treatment, biodegradable glues and the presence of growth factors. Further longer-term in vitro and in vivo studies are needed to validate these findings.

\section{Acknowledgements}

This research is supported by Reumafonds, the Dutch Arthritis Foundation.

\section{References}

[1] Simson JA, Strehin IA, Allen BW, Elisseeff JH. Bonding and fusion of meniscus fibrocartilage using a novel chondroitin sulfate bone marrow tissue adhesive. Tissue Engineering - Part A 2013;19:1843-51.

[2] Ishimura M, Ohgushi H, Habata T, Tamai S, Fujisawa Y. Arthroscopic meniscal repair using fibrin glue .2. Clinical applications. Arthroscopy-the Journal of Arthroscopic and Related Surgery 1997;13:558-63.

[3] Scotti C, Pozzi A, Mangiavini L, Vitari F, Boschetti F, Domeneghini C, et al. Healing of meniscal tissue by cellular fibrin glue: an in vivo study. Knee Surgery, Sports Traumatology, Arthroscopy 2009; 17:645-51.

[4] Chevrier A, Nelea M, Hurtig MB, Hoemann CD, Buschmann MD. Meniscus structure in human, sheep, and rabbit for animal models of meniscus repair. Journal of Orthopaedic Research 2009;27:1197-203.

[5] Arnoczky SP, Warren RF. Microvasculature of the human meniscus. American Journal of Sports Medicine 1982;10:90-5. 
[6] Okuda K, Ochi M, Shu N, Uchio Y. Meniscal rasping for repair of meniscal tear in the avascular zone. Arthroscopy 1999;15:281-6.

[7] Uchio Y, Ochi M, Adachi N, Kawasaki K, Iwasa J. Results of rasping of meniscal tears with and without anterior cruciate ligament injury as evaluated by second-look arthroscopy. Arthroscopy 2003;19:463-9.

[8] Fox JM, Rintz KG, Ferkel RD. Trephination of incomplete meniscal tears. Arthroscopy 1993;9:4515.

[9] Zhang Z, Arnold JA, Williams T, McCann B. Repairs by trephination and suturing of longitudinal injuries in the avascular area of the meniscus in goats. American Journal of Sports Medicine 1995;23:35-41.

[10] Rubman MH, Noyes FR, Barber-Westin SD. Arthroscopic repair of meniscal tears that extend into the avascular zone. A review of 198 single and complex tears. American Journal of Sports Medicine 1998;26:87-95.

[11] Longo UG, Campi S, Romeo G, Spiezia F, Maffulli N, Denaro V. Biological Strategies to Enhance Healing of the Avascular Area of the Meniscus. Stem Cells International 2012;2012:528359.

[12] Qu F, Lin J-MG, Esterhai JL, Fisher MB, Mauck RL. Biomaterial-mediated delivery of degradative enzymes to improve meniscus integration and repair. Acta Biomaterialia 2013;9:6393-402.

[13] Qu F, Pintauro MP, Haughan JE, Henning EA, Esterhai JL, Schaer TP, et al. Repair of dense connective tissues via biomaterial-mediated matrix reprogramming of the wound interface. Biomaterials 2015;39:85-94.

[14] Petersen W, Pufe T, Stärke C, Fuchs T, Kopf S, Neumann W, et al. The effect of locally applied vascular endothelial growth factor on meniscus healing: Gross and histological findings. Archives of Orthopaedic and Trauma Surgery 2007;127:235-40.

[15] Ionescu LC, Lee GC, Huang KL, Mauck RL. Growth factor supplementation improves native and engineered meniscus repair in vitro. Acta Biomaterialia 2012;8:3687-94.

[16] Cucchiarini M, Schmidt K, Frisch J, Kohn D, Madry H. Overexpression of TGF- $\beta$ via rAAVMediated Gene Transfer Promotes the Healing of Human Meniscal Lesions Ex Vivo on Explanted Menisci. American Journal of Sports Medicine 2015;43:1197-205.

[17] Bochyńska AI, Sharifi S, van Tienen TG, Buma P, Grijpma DW. Development of Tissue Adhesives Based on Amphiphilic Isocyanate-Terminated Trimethylene Carbonate Block Copolymers. Macromolecular Symposia 2013;334:40-8, Chapter 3 of this thesis.

[18] Bochyńska AI, Van Tienen TG, Hannink G, Buma P, Grijpma DW. Development of biodegradable hyper-branched tissue adhesives for the repair of meniscus tears. Acta Biomaterialia 2016;32:1-9, Chapter 5 of this thesis.

[19] Bochyńska AI, Hannink G, Verhoeven R, Grijpma DW, Buma P. Evaluation of novel biodegradable three-armed- and hyper-branched tissue adhesives in a meniscus explant model. Manuscript submitted to Journal of Biomedical Materials Research Part A, Chapter 6 of this thesis.

[20] Hennerbichler A, Moutos FT, Hennerbichler D, Weinberg JB, Guilak F. Interleukin-1 and tumor necrosis factor alpha inhibit repair of the porcine meniscus in vitro. Osteoarthritis and Cartilage 2007;15:1053-60. 
[21] Hennerbichler A, Moutos FT, Hennerbichler D, Weinberg JB, Guilak F. Repair response of the inner and outer regions of the porcine meniscus in vitro. American Journal of Sports Medicine 2007;35:754-62.

[22] Sporn M, Roberts A, Wakefield L, Assoian R. Transforming growth factor-beta: biological function and chemical structure. Science 1986;233:532-4.

[23] van de Breevaart Bravenboer J, In der Maur CD, Bos PK, Feenstra L, Verhaar JA, Weinans H, et al. Improved cartilage integration and interfacial strength after enzymatic treatment in a cartilage transplantation model. Arthritis Research and Therapy 2004;6:6.

[24] Janssen LM, In der Maur CD, Bos PK, Hardillo JA, van Osch GJ. Short-duration enzymatic treatment promotes integration of a cartilage graft in a defect. Ann Otol Rhinol Laryngol 2006;115:4618 . 


\section{Chapter 8}

\section{In Vitro and In Vivo Characterization of Biodegradable Reactive Isocyanate-Terminated Three-Armed- and Hyper- Branched Block Copolymeric Tissue Adhesives}

Agnieszka I. Bochyńska ${ }^{1,2}$, Gerjon Hannink ${ }^{1}$, Jan J. Rongen ${ }^{1}$, Dirk W. Grijpma ${ }^{2,3}$, Pieter Buma ${ }^{1}$

${ }^{1}$ Orthopaedic Research Laboratory, Department of Orthopaedics, Radboud Centre for Molecular Life Sciences, Radboud University Nijmegen Medical Centre, Nijmegen, the Netherlands

${ }^{2}$ Department of Biomaterials Science and Technology, MIRA Institute, University of Twente, Enschede, the Netherlands

${ }^{3}$ University Medical Centre Groningen, University of Groningen, W.J. Kolff Institute, Department of Biomedical Engineering, Groningen, the Netherlands 


\begin{abstract}
Meniscus tears are common injuries of the knee joint. Currently a few treatment modalities are available, but these are not successful in all conditions. Tissue adhesives are an attractive class of biomaterials as they are easy to apply and cause minimal tissue trauma, their use could serve as an alternative treatment. We recently developed biodegradable reactive isocyanate-terminated three-armed- and hyperbranched block copolymeric adhesives (glues) that can potentially be used for the treatment of meniscal tears.

The aim of the current study was to evaluate the physicochemical- and adhesive properties of these novel glues, to study their degradation profile after curing both in vitro and in vivo, and to assess the tissue reaction after subcutaneous injection in rats.

The developed glues had sufficient adhesive strength to meniscus tissue after curing (66-88 $\mathrm{kPa}$ ). After curing, networks based on the three-armed adhesive had tensile properties that were in the same range as those of human meniscus tissue. The networks degraded by hydrolysis. After 26 weeks networks based on the hyperbranched adhesive showed a faster mass loss $(25.4 \%)$ compared to networks prepared from the three-armed glues $(5.5 \%)$. Both glues induced an inflammatory reaction involving macrophages and PMN cells. However, no necrosis and only initial toxic effects on peripheral tissues were observed.

The proposed materials might be suitable candidates for the use as resorbable tissue adhesives for meniscus repair. Nevertheless, further studies in a biomechanically relevant animal model should still be performed.
\end{abstract}

\title{
Introduction
}

The meniscus is a frequently injured tissue with limited potential for self-repair [1, 2]. Current clinical repair techniques mostly make use of sutures or staples, but are not successful in all conditions $[3,4]$. Surgical tissue adhesives (i.e. glues) are an attractive class of biomaterials that have the potential to be used for the treatment of meniscal tears [5]. They are easy to apply via a minimally invasive procedure [6], and their structure can be designed to degrade after the tissue is healed. Several tissue adhesives are already used in clinical practice. Fibrin glue is used in the treatment of 
pulmonary leaks, Dermabond ${ }^{\circledR}$ for skin lacerations and the recently FDA-approved TissuGlu ${ }^{\circledR}$ for abdominoplasty [7-10]. However, none of these adhesives is suited for the treatment of meniscus tears due to inadequate mechanical properties or cytotoxic characteristics [11].

We have recently reported on the development of two novel biodegradable isocyanate-terminated three-armed and hyper-branched block copolymeric tissue adhesives with the potential to be used for the repair of meniscus tears $[12,13]$. These materials have adequate adhesive strengths to the meniscus after curing. Moreover, previous in vitro experiments have shown that when using relevant amounts of these adhesives they are essentially non-toxic to meniscus cells [12]. The three-armed oligomeric adhesive has a well-defined and controlled molecular structure, in which the three isocyanate end-groups react to form a cured polyurethane network. The molecular structure of the hyper-branched adhesive is less well-defined. It has more reactive end-groups per molecule that can covalently attach to the tissue and cures to form a polyester-polyurethane network. [12].

The purpose of the current study was to evaluate the physicochemical- and adhesive properties of these three-armed and hyper-branched copolymeric tissue adhesives, to study their degradation profile after curing both in vitro and in vivo, and to assess the tissue reaction after subcutaneous injection in rats.

\section{Materials and Methods}

\section{Materials}

The isocyanate-terminated reactive three-armed- and hyper-branched adhesive oligomers (glues) were prepared as previously described [12, 13]. The building blocks of the three-armed block copolymeric adhesives were trimethylolpropane ethoxylate (TMPE, $\left.\mathrm{M}_{\mathrm{n}}=450 \mathrm{~g} / \mathrm{mol}\right)$, trimethylene carbonate (TMC) and hexamethylene diisocyanate (HDI). The building blocks of the hyper-branched adhesive were polyethylene glycol (PEG, $\left.\mathrm{M}_{\mathrm{n}}=400 \mathrm{~g} / \mathrm{mol}\right), \mathrm{TMC}$, citric acid (CA) and HDI. The prepared reactive adhesives oligomers are designated as: TMPE-(TMC $2_{2}$ $\mathrm{HDI})_{3}$ (three-armed adhesive) and CA-4PEG-(TMC $)_{2}$-HDI (hyper-branched adhesive). 
The adhesives were sterilized by gamma irradiation in a nitrogen atmosphere prior to use (25 kGy, SynergyHealth BV, The Netherlands). Their ${ }^{1} \mathrm{H}-\mathrm{NMR}$ (Bruker $400 \mathrm{MHz}$ NMR spectrometer) and FTIR (Spectrum Two, Perkin Elmer) spectra were recorded before and after sterilization and compared.

\section{Preparation and characterization of water-cured networks}

Polyurethane networks films were obtained by casting the viscous isocyanateterminated three-armed and hyper-branched copolymers with a $0.3 \mathrm{~mm}$ casting knife on glass plates, and subsequent curing in water as described previously [13]. To determine the gel content of the water-cured networks, they were dried in vacuum at $40{ }^{\circ} \mathrm{C}$ and their initial mass was determined $\left(\mathrm{m}_{\mathrm{i}}\right)$. The specimens $(\mathrm{n}=3)$ were then swollen in chloroform for 24 hours to extract the sol fraction, and dried in vacuum until constant weight $\left(\mathrm{m}_{\mathrm{dc}}\right)$. To assess their water uptake $(\mathrm{n}=3)$, they were placed in water for 24 hours and their wet mass $\left(\mathrm{m}_{\mathrm{w}}\right)$ was determined. The networks were then re-dried until constant weight, and their dry mass was determined $\left(\mathrm{m}_{\mathrm{dw}}\right)$.

The gel content (GC) was determined using:

$$
G C=\left(\frac{m_{d c}}{m_{i}}\right) \cdot 100 \%
$$

The water uptake (WU) was determined using:

$$
W U=\left(\frac{m_{w}-m_{d w}}{m_{d w}}\right) \cdot 100 \%
$$

The thermal properties of the networks in the wet state were assessed by differential scanning calorimetry (DSC, Perkin Elmer Pyris 1). Specimens weighing 5-10 mg were heated from $-100{ }^{\circ} \mathrm{C}$ to $100{ }^{\circ} \mathrm{C}$ at $10{ }^{\circ} \mathrm{C} / \mathrm{min}$.

\section{Adhesion of the reactive isocyanate-terminated block copolymers to bovine meniscus tissue}

The reactive isocyanate-terminated oligomers were applied $(n=5)$ onto strips of bovine meniscus tissue with sizes of approximately $0.5 \times 10 \times 25 \mathrm{~mm}$. (The tissue strips had been kept hydrated in water and excess water was blotted from the surface 
just before application of the adhesives). The adhesives were applied with a spatula and covered an area of approximately $1 \mathrm{~cm}^{2}$. Subsequently, two strips were pressed together, immersed in water at room temperature and left to cure. The adhesive bonding strength to the tissue was assessed after 1, 4, 8 and 24 hours of curing in a lap shear adhesion experiment analogous to ASTM F2255-05. A Zwick Z020 universal tensile tester was used, the grip to grip separation was $25 \mathrm{~mm}$ and the crosshead speed was $50 \mathrm{~mm} / \mathrm{min}$. The shear adhesive bond strength (S) was calculated as the maximum shear force divided by the glued area.

\section{In vitro degradation of water-cured networks}

The in vitro degradation of the water-cured networks (disc-shaped specimens with a diameter of $10 \mathrm{~mm}$ punched out from films with a thickness of 350-500 $\mu \mathrm{m}$ ) was assessed in triplicate in phosphate buffer saline (PBS) solution $(\mathrm{pH}=7.4)$ and cholesterol esterase solution (CE, from porcine pancreas, $35 \mathrm{U} / \mathrm{mL}$, Sigma Aldrich, The Netherlands) at $37{ }^{\circ} \mathrm{C}$. Both solutions contained $0.02 \mathrm{wt} \%$ of sodium azide as bactericide. The samples were placed in 48 well-plates containing $1 \mathrm{~mL}$ of PBS or $\mathrm{CE}$ solution and let to degrade. The medium was changed twice per week. The specimens were recovered and their mass, thickness and the liquid uptake were determined in the wet state at predetermined time points and after drying in vacuum until constant weight.

\section{In vivo biocompatibility of the reactive isocyanate-terminated block copolymers and in vivo degradation of water-cured networks}

To evaluate the biocompatibility of the isocyanate-terminated adhesive block copolymers in vivo, the reactive adhesives were subcutaneously injected in rats. Also, the degradation of the water-cured network films implanted subcutaneously was assessed. All procedures were approved by the Animal Ethics Committee of the Radboud University. In total 40 Sprague-Dawley rats weighing 200-250 g were operated in 5 groups based on time to sacrifice (4 male and 4 female per group). The animals were housed in a humidity- and temperature-controlled room with 12 hours light/dark cycle. The rats received water and pelleted diet ad libitum. The animals were operated under general anesthesia, which was induced using isoflurane. After shaving and disinfection, two subcutaneous pockets were made to the right and two 
pockets to the left of midline incisions on the back of the rats. In two of these pockets $0.1 \mathrm{~mL}$ of the three-armed- or the hyper-branched isocyanate-terminated adhesive block copolymers were injected using a syringe, in the other two pockets films of water-cured networks based on the three-armed- and hyper-branched adhesives (20x10x0.3-0.6 mm) were implanted. The network films were decontaminated by washing in $70 \%$ ethanol (15 minutes), drying (30 minutes) and washing three times in PBS (5 minutes). This procedure was repeated three times. The implants (reactive adhesive or water-cured network film) were randomized among the pockets. Caregivers structurally monitored animal welfare during the first 7 postoperative days. After 1 day, $1,4,12$ and 26 weeks, the rats were euthanized by $\mathrm{CO}_{2}$ asphyxiation.

\section{Histological evaluation of the tissue reaction towards the reactive adhesives}

After subcutaneous injection of the adhesives, the in situ cured specimens together with the surrounding tissue were retrieved from the pockets. Additionally, two control samples (a piece of skin tissue without the cured glue from a female rat and a piece from a male rat) per time point were taken for analysis. Samples were fixated in formalin (10\% solution in PBS), embedded in poly(methyl methacrylate) (PMMA), sectioned to $8 \mu \mathrm{m}$ and stained with hematoxylin and eosin (H\&E) to visualize the cells and the extracellular matrix (ECM). To visualize macrophages, immunohistochemical staining was performed as well. The samples were deplasticized (using choloroform/xylene 1:1) and cut to $5 \mu \mathrm{m}$ thick sections. Endogenous peroxidase was then blocked by incubation in $3 \% \mathrm{H}_{2} \mathrm{O}_{2}$ in methanol for $30 \mathrm{~min}$ and aspecific reaction sites were blocked by incubation in $10 \%$ normal horse serum for $30 \mathrm{~min}$. Afterwards, the sections were incubated overnight at $4^{\circ} \mathrm{C}$ with mouse monoclonal anti-rat ED1 antibody (AbD Serotec ${ }^{\circledR}$, 1:200 dilution in PBS, $\mathrm{pH}=7.4$, with $1 \%$ bovine serum albumin (BSA)) and in biotinylated horse antimouse antibody (dilution 1:400 in $\mathrm{PBS}, \mathrm{pH}=7.4$ ) for 45 minutes at room temperature. Afterwards sections were incubated in Avidin Biotin Complex for 60 min at room temperature. Before, between and after each incubation step, the sections were washed 3 times with 3 minutes changes of PBS. The macrophages were visualized using dimethylaminoazobenzene and counterstaining with hematoxylin. 
The histological slides were scored to assess the inflammatory reaction (cell type/response and tissue response) following a custom protocol based on ISO 109936 and the protocol described by Link et al [14] using a 200x microscope magnification field (Table 1). The histology scoring results are reported as median values with the observed range in parentheses.

\section{In vivo degradation of water-cured networks}

The water-cured network films were explanted from the subcutaneous pockets, weighed in the swollen state, rinsed with water to remove any remaining debris or tissue and dried at $40{ }^{\circ} \mathrm{C}$ until constant weight. Their determined mass and thickness ( $m_{d}$ and $d_{d}$, respectively) were then compared with their initial mass and thickness $\left(\mathrm{m}_{\mathrm{i}}\right.$ and $\left.\mathrm{d}_{\mathrm{i}}\right)$ to assess the extent of degradation. The liquid uptake of the degrading networks was also determined. To observe changes in mechanical properties during implantation, explanted specimens of each material $(n=6)$ were subjected to tensile testing in the wet state at room temperature (RT) according to ASTM D882. A Zwick Z020 universal tensile tester was used, the grip-to-grip separation was $11 \mathrm{~mm}$ and the crosshead speed was $50 \mathrm{~mm} / \mathrm{min}$. The properties of hydrated network films ( $\mathrm{n}=6$ ) which were not implanted were also determined.

At each time point, changes in the surface morphology of the different network films during in vivo degradation $(\mathrm{n}=1)$ were observed by Scanning Electron Microscope imaging (SEM, Zeiss Gemini Sigma 300).

\section{Statistical analysis}

To compare differences in mass loss, remaining height and degree of swelling of the in vitro and in vivo degrading water-cured networks in time, three-way ANOVA with Fischer's LSD post-hoc test was used. To evaluate differences in adhesive strength between the glues in time, a two-way ANOVA was used, followed by Fischer's LSD post-hoc test. P- values $<0.05$ were considered statistically significant. Data is presented as mean \pm standard deviation (SD), unless indicated otherwise. Statistical analyses were performed using SPSS Statistics (version 20, IBM Corporation). 


\section{Table 1. Scoring criteria of the histological slide based on ISO 10993-6 standard} and the protocol described by Link et al [13].

\begin{tabular}{|c|c|c|}
\hline Evaluation (H\&E) & Response & Score \\
\hline \multirow[t]{5}{*}{ Capsule quantitatively } & Not applicable & 0 \\
\hline & 1-4 fibroblasts & 1 \\
\hline & 5-9 fibroblasts & 2 \\
\hline & 10-30 fibroblasts & 3 \\
\hline & $>30$ fibroblasts & 4 \\
\hline \multirow[t]{5}{*}{ Capsule qualitatively } & $\begin{array}{l}\text { Cannot be evaluated because of infection or other } \\
\text { factors not necessarily related to the material }\end{array}$ & 0 \\
\hline & $\begin{array}{l}\text { Capsule is fibrous, mature, not dense, resembling } \\
\text { connective or fat tissue in the non-injured region }\end{array}$ & 1 \\
\hline & $\begin{array}{l}\text { Capsule tissue is fibrous but immature, showing } \\
\text { fibroblasts and little collagen }\end{array}$ & 2 \\
\hline & $\begin{array}{l}\text { Capsule tissue is granulous and dense, containing both } \\
\text { fibroblasts and many inflammatory cells }\end{array}$ & 3 \\
\hline & $\begin{array}{l}\text { Capsule consists of masses of inflammatory cells with } \\
\text { little or no signs of connective tissue organization }\end{array}$ & 4 \\
\hline \multirow[t]{6}{*}{ Interface qualitatively } & $\begin{array}{l}\text { Cannot be evaluated because of infection or other } \\
\text { factors not necessarily related to the material }\end{array}$ & 0 \\
\hline & $\begin{array}{l}\text { Fibroblasts contact the implant surface without the } \\
\text { presence of macrophages or leucocytes }\end{array}$ & 1 \\
\hline & Scattered foci of macrophages and leucocytes are & 2 \\
\hline & present & 3 \\
\hline & One layer of macrophages and leucocytes are present & 4 \\
\hline & Multiple layers of macrophages and leucocytes present & \\
\hline \multirow[t]{4}{*}{ Thickness of reactive layer } & Narrow band & 1 \\
\hline & Moderately thick band & 2 \\
\hline & Thick band & 3 \\
\hline & Extensive band & 4 \\
\hline \multirow[t]{5}{*}{ Neovascularization } & None & 0 \\
\hline & Minimal capillary proliferation, focal, $1-3$ buds & 1 \\
\hline & $\begin{array}{l}\text { Groups of 4-7 capillaries with supporting fibroblastic } \\
\text { structures }\end{array}$ & 2 \\
\hline & Broad band of capillaries with supporting structures & 3 \\
\hline & $\begin{array}{l}\text { Extensive band of capillaries with supporting } \\
\text { fibroblastic structures }\end{array}$ & 4 \\
\hline \multirow[t]{5}{*}{ Necrosis } & None & 0 \\
\hline & Minimal & 1 \\
\hline & Mild & 2 \\
\hline & Moderate & 3 \\
\hline & Severe & 4 \\
\hline \multirow{2}{*}{$\begin{array}{l}\text { Cytotoxic effect on the peripheral } \\
\text { tissue }\end{array}$} & No & 0 \\
\hline & Yes (e.g. giant cells attacking muscle cells) & 3 \\
\hline $\begin{array}{l}\text { Evaluation } \\
\text { (Immunohistochemistry) }\end{array}$ & Response & Score \\
\hline \multirow[t]{5}{*}{ Macrophages } & None & 0 \\
\hline & Rare, $1-5 /$ per high field & 1 \\
\hline & 5-10/per high field & 2 \\
\hline & Heavy infiltrate & 3 \\
\hline & Packed & 4 \\
\hline Total maximum score & & 31 \\
\hline
\end{tabular}




\section{Results}

\section{Isocyanate-terminated three-armed- and hyper-branched block copolymeric tissue adhesives}

Isocyanate-terminated three-armed- and hyper-branched block copolymers were successfully synthesized. Comparison of the areas under the peaks that correspond to PEG (3.5-3.7 ppm) or TMPE (3.5-3.75 ppm) with TMC (2.1 and 4.1-4.3 ppm) in the ${ }^{1} \mathrm{H}-\mathrm{NMR}$ spectra of non-functionalized oligomers, showed that the conversion of TMC was $94 \%$ and $92 \%$ for the three-armed- and the hyper-branched oligomers, respectively. Analysis of the areas under the peaks that correspond to PEG or TMPE and HDI (3.1-3.35 ppm and 1.25-1.65 ppm) in the spectra of the oligomers functionalized with HDI confirmed that for both the three-armed- and the hyperbranched oligomers the degree of functionalization was $100 \%$.

Comparison of the ${ }^{1} \mathrm{H}-\mathrm{NMR}$ and FTIR spectra before and after gamma irradiation of the functionalized oligomers showed nearly identical spectra, indicating that their chemical structure was not affected by the sterilization process.

\section{Characteristics of water-cured networks prepared from isocyanate-terminated three-armed- and hyper-branched block copolymers}

The chemical composition and the physical properties of the water-cured networks prepared from the reactive adhesives are given in Table 2. Assuming complete incorporation in the networks, the mass ratio of the hydrophilic PEG or TMPE component to the hydrophobic TMC component in the functionalized block copolymeric oligomers was 0.73 and 0.98 for three-armed- and the hyper-branched reactive network precursor, respectively. The gel content of the cured networks was $98.7 \pm 0.3$ and $91.7 \pm 6.7$ after water-curing of the three-armed- and the hyperbranched adhesive, respectively. The water uptake of $25.3 \pm 8.7 \%$ of networks based on the hyper-branched adhesives was significantly higher than that of the ones based on the three-armed adhesives, which was only $5.7 \pm 1.4 \%$. In the hydrated state, the glass transition temperature $\left(\mathrm{T}_{\mathrm{g}}\right)$ of both networks was below $37{ }^{\circ} \mathrm{C}$. 
Table 2. Composition and physical properties of networks prepared by curing the three-armed-and hyper-branched adhesives in water.

\begin{tabular}{lll}
\hline & $\begin{array}{l}\text { Three-armed adhesive-based } \\
\text { network }\end{array}$ & $\begin{array}{l}\text { Hyper-branched adhesive- } \\
\text { based network }\end{array}$ \\
\hline TMPE or PEG content ${ }^{\mathrm{a})}\left[\mathrm{wt}^{\mathrm{o}} \%\right]$ & 28.7 & 36.1 \\
$\mathrm{TMC} \mathrm{content}^{\mathrm{a})}[\mathrm{wt} \%]$ & 39.1 & 36.8 \\
$\mathrm{Gel} \mathrm{Content}[\%]$ & $98.7(0.3)$ & $91.7(6.7)$ \\
Water Uptake [\%] & $5.7(1.4)$ & $25.3(8.7)$ \\
$\mathrm{T}_{\mathrm{g}}{ }^{\mathrm{b}}\left[{ }^{\circ} \mathrm{C}\right]$ & -27.2 & -40.5 \\
\hline a) Assuming the reactive oligomers are fully incorporated in the network \\
b) Determined in the wet state
\end{tabular}

\section{Adhesion of the reactive isocyanate-terminated block copolymers to bovine meniscus tissue}

For both compositions, the adhesive strength of the glues to bovine meniscus tissue determined in lap-shear testing significantly increased with curing time in water (Figure 1) $(\mathrm{p}<0.05)$. The mean adhesion of the hyper-branched adhesive was already $62 \pm 56 \mathrm{kPa}$ after 8 hours, which was close to the maximum value of $66 \pm 5 \mathrm{kPa}$ which was reached after 24 hours. The three-armed glue reached an adhesive strength of $65 \pm 17$ and $88 \pm 51 \mathrm{kPa}$ after 8 and 24 hours, respectively. There were no statistically significant differences in adhesive strength between the two glues. 


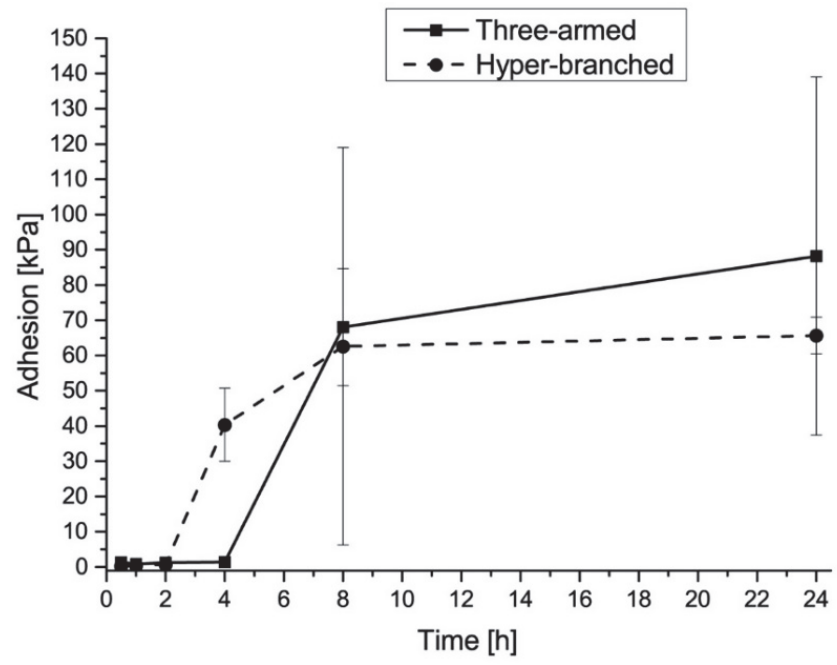

Figure 1. The adhesive strength of reactive three-armed-and hyper-branched adhesives to bovine meniscus tissue determined in lap shear testing at different curing times.

\section{In vitro and in vivo degradation of water-cured networks}

The mass loss and the liquid uptake of water-cured network films prepared from the reactive three-armed- and the hyper-branched block copolymers were determined after degradation in vitro in PBS and CE solutions, and in vivo after subcutaneous implantation. There were no behavioural changes or signs of physical impairment observed in the animals upon implantation of the water-cured network films. The remaining mass of the networks at the predetermined time points is depicted in the Figure 2. In all cases, networks prepared from the hyper-branched block copolymers degraded significantly faster than those prepared from the three-armed block copolymers $(\mathrm{p}<0.001)$. The mass loss after 26 weeks of networks based on the threearmed adhesives was $5.5 \pm 3.2 \%$, while that of networks prepared from the hyperbranched adhesives was $25.4 \pm 7.8 \%$. The latter network films had lost their mechanical integrity after 26 weeks. Degradation in the different degradation environments, i.e. in CE, PBS or in vivo, did not lead to statistically significant differences in remaining mass. 
a)

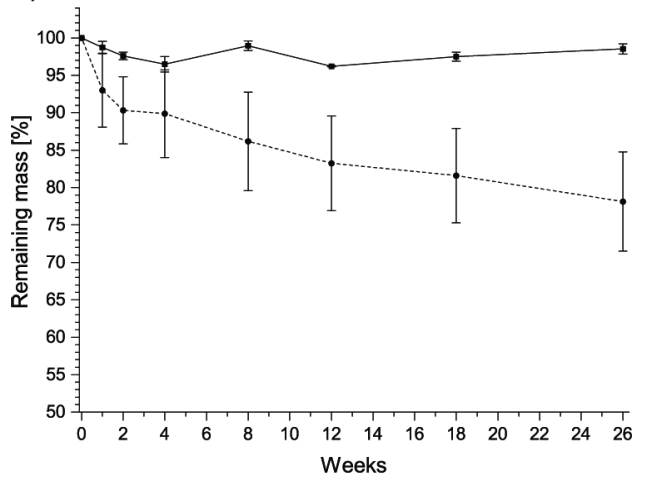

b)

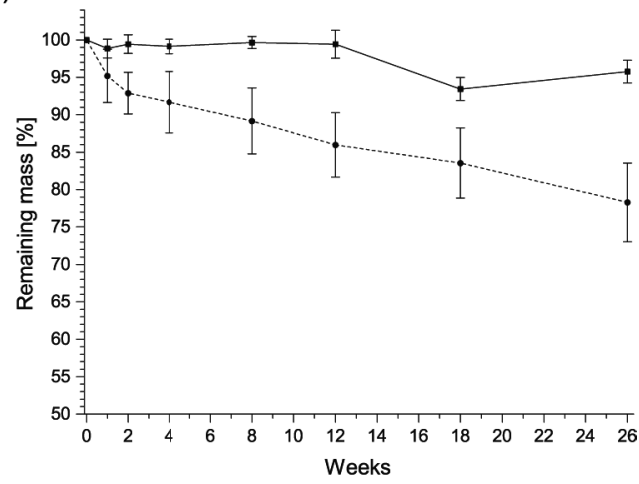

c)

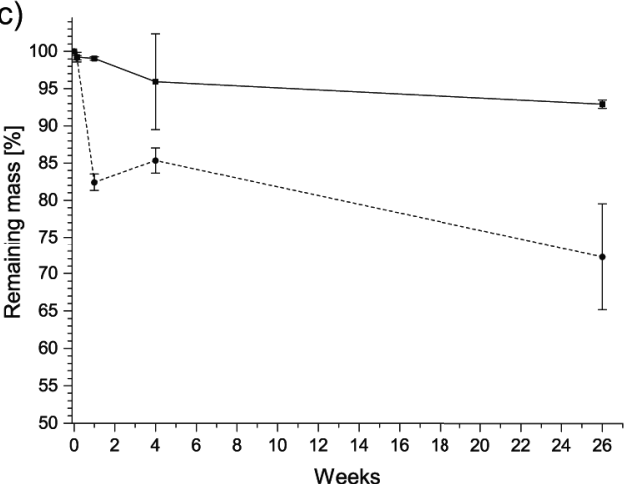

Figure 2. The remaining mass (in the dry state) of networks prepared from reactive isocyanate-terminated three-armed-and hyper-branched block copolymers at different time points during a) in vitro incubation in $C E$, b) in vitro incubation in $P B S, c)$ in vivo subcutaneous implantation in rats.

At all time points, the liquid uptake of networks prepared from the hyper-branched adhesives was significantly higher than that of networks prepared from the threearmed adhesives during incubation in the different environments $(p<0.05)$ (Supplementary Material, Figure S1). Moreover, there were no differences in the uptake of body liquids of a particular network in the different in vitro or in vivo degradation environments. Only after 26 weeks, the networks based on the hyperbranched adhesive degrading in vivo had a liquid uptake of $54.2 \pm 4.9 \%$ that was significantly higher than that of the same networks degrading in vitro $(30.1 \pm 7.9 \%$ and $29.1 \pm 8.3 \%$ in PBS and CE, respectively). 
For both networks, the thickness of the degrading films did not change significantly during the incubation in the different environments. The remaining thickness of the films in time is presented in the Supplementary Material, Figure S2.

The tensile properties of hydrated network films before and upon subcutaneous implantation were determined. The elastic modulus $\left(\mathrm{E}_{\mathrm{mod}}\right)$ and the maximum tensile strength $\left(\sigma_{\max }\right)$ were considerably higher for networks prepared from the three-armed adhesives than for those prepared from the hyper-branched precursors (Table 3 ). The values of elastic modulus and tensile strength of networks based on the three-armed precursors did not change significantly during in vivo degradation. On the contrary, the properties of networks based on the hyper-branched adhesives did change considerably. The tensile strength decreased from $3.5 \pm 2.1$ to $1.3 \pm 0.2 \mathrm{MPa}$, and the elastic modulus from $15.6 \pm 11.7$ to $3.8 \pm 0.5$ after 26 weeks in vivo. For both networks, the elongation at break decreased by nearly a factor two. 
Table 3. Tensile properties of hydrated network films prepared from isocyanateterminated three-armed- and hyper-branched block copolymers during subcutaneous implantation in rats.

Note that after 26 weeks the tensile properties of the networks prepared from the hyper-branched adhesives could not be determined due to loss of integrity of the specimens.

\begin{tabular}{llll|lll}
\hline \multirow{2}{*}{$\begin{array}{l}\text { Time } \\
\text { point }\end{array}$} & \multicolumn{3}{c|}{ Three-armed } & \multicolumn{3}{c}{ Hyper-branched } \\
\cline { 2 - 7 } & $\mathrm{E}[\mathrm{MPa}]$ & $\sigma_{\max }[\mathrm{MPa}]$ & $\varepsilon_{\max }[\%]$ & $\mathrm{E}[\mathrm{MPa}]$ & $\sigma_{\max }[\mathrm{MPa}]$ & $\varepsilon_{\max }[\%]$ \\
\hline Control & $102.2 \pm 9.6$ & $10.4 \pm 3.3$ & $71.7 \pm 53.2$ & $15.6 \pm 11.7$ & $3.5 \pm 2.1$ & $87.0 \pm 46.9$ \\
1 day & $113.1 \pm 18.8$ & $11.2 \pm 3.0$ & $52.2 \pm 23.7$ & $19.0 \pm 1.7$ & $2.7 \pm 0.5$ & $27.4 \pm 7.0$ \\
1 week & $76.0 \pm 14.1$ & $10.6 \pm 3.3$ & $83.0 \pm 41.6$ & $5.1 \pm 0.6$ & $1.4 \pm 0.6$ & $45.7 \pm 15.7$ \\
4 weeks & $73.7 \pm 13.0$ & $6.4 \pm 2.4$ & $28.5 \pm 22.0$ & $5.8 \pm 0.7$ & $1.6 \pm 0.4$ & $38.7 \pm 7.4$ \\
12 weeks & $81.5 \pm 22.0$ & $8.5 \pm 3.5$ & $45.3 \pm 30.0$ & $3.8 \pm 0.5$ & $1.3 \pm 0.2$ & $49.5 \pm 13.6$ \\
26 weeks & $131.3 \pm 8.8$ & $12.4 \pm 1.2$ & $44.5 \pm 18.0$ & - & - & - \\
\hline
\end{tabular}

The SEM images of the surfaces of the in vivo degrading network films showed changes in the surface morphology in time. Upon implantation, the initially smooth surfaces of the water-cured network films gradually became rough and irregular (Figure 3). This was especially evident in the case of network films prepared from the hyper-branched adhesive. Here it can be seen that already after 1 week the surface becomes rough, after 26 weeks the roughness was quite pronounced. 


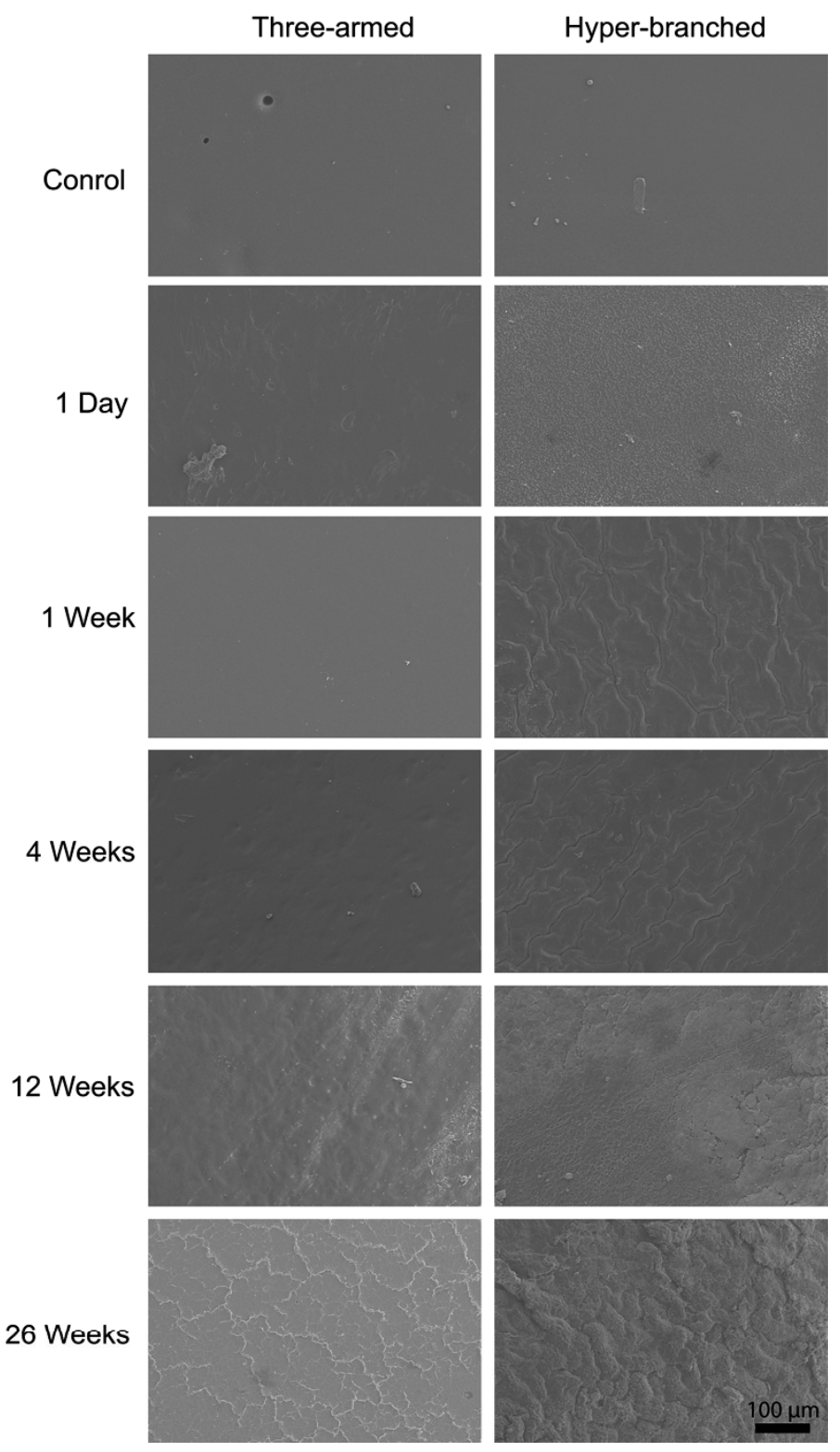

Figure 3. SEM images of the surfaces of network films prepared from isocyanate-terminated three-armed- and hyper-branched block copolymers degrading in vivo during subcutaneous implantation in rats. 


\section{Biocompatibility of the glues in vivo}

Subcutaneous injection of the reactive adhesives resulted in the in situ curing and formation of the irregular-shaped polyurethane networks. During the process of network formation carbon dioxide was released, resulting in porous structured networks.

No behavioural changes or signs of physical impairment were observed in the animals during the course of the study.

A few rats had a rash appearing on the skin close to the injection pockets up to 1 week post implantation. However, the animals did not show any signs of discomfort and the rash disappeared spontaneously. The scoring results of the H\&E-stained slides of the tissue samples into which the adhesives were subcutaneously injected are presented in Figure 4 and Figure 5. The median total scores of the histological slides at the different time points are given in Table 4. The total score of the control samples was 8 (6-10). The scoring results of each category at different time points are presented in Supplementary Material (Table S1 and Table S2 for the three-armed adhesive and hyper-branched adhesive, respectively).

There were no visible differences in the tissue reaction to the injected glues between female and male rats. There was, however, a large rat-specific variation in the tissue response to the adhesives: while in some of the rats a mild tissue reaction was observed, a more severe reaction to the adhesives was seen at the same time points in other rats.

At 1 day post injection, a tissue reaction with an immature, hydrated and slightly swollen fibrous interfacial tissue with low numbers of fibroblasts and immune cells was observed for both adhesives (Figure $4 \mathrm{a}$ and Figure 5a). The total histology score was 16 (3-23) and 15 (4-24) for the three-armed- and the hyper-branched adhesive, respectively. After 1 week the interface around the injected adhesive was much thicker, and more fibrous in nature with groups of sprouting vessels and larger numbers of immune cells present. Immunohistochemical staining (Figure $4 \mathrm{~b}$ and Figure 5b, and Figure 6) indicate that these include macrophages and polymorphonuclear (PMN) cells. No differences between the two adhesives were 
seen, the total histology scores were quite similar, 19.5 (7-29) and 20.5 (9-25) for the three-armed- and the hyper-branched adhesive, respectively. After 4 weeks post implantation, the number of PMN cells had decreased compared to the numbers at 1 week. For both glues, giant cells and clusters of macrophages could be seen in the interface (Figure 4c,d, Figure 5c,d and Figure 6b). After 4 weeks, the total score of the hyper-branched adhesive of 17 (6-21) was lower than that for the three-armed adhesive which was 20.5 (6-26). After 12 and 26 weeks there were pronounced differences in tissue response to the adhesives between individual rats (Figure 4e-h and Figure 5e-h). After 12 and 26 weeks, the total score of the hyper-branched glue (18 (3-23) and 17.5 (4-24), respectively) was similar that of the three-armed adhesive (16.5 (6-23) and 22 (13-23), respectively). There was a relatively mild response in some individual rats, while in other rats an increased number of PMN cells surrounding the degrading adhesives could be observed. Macrophages were seen only rarely (Figure 6c), and regarding neovascularization mainly small groups of capillaries with supporting fibroblastic structures were observed.

Table 4. Total histological evaluation scores of rat skin tissue samples after subcutaneous injection of the reactive isocyanate-terminated three-armed-and hyper-branched block copolymeric tissue adhesives. The data are presented as median values with the observed range in parentheses.

\begin{tabular}{llllll}
\hline & 1 day & 1 week & 4 weeks & 12 weeks & 26 weeks \\
\hline Three-armed & $16(3-23)$ & $19.5(7-29)$ & $20.5(6-26)$ & $16.5(6-23)$ & $22(13-23)$ \\
Hyper-branched & $15(4-24)$ & $20.5(9-25)$ & $17(6-21)$ & $18(3-23)$ & $17.5(4-24)$ \\
\hline
\end{tabular}



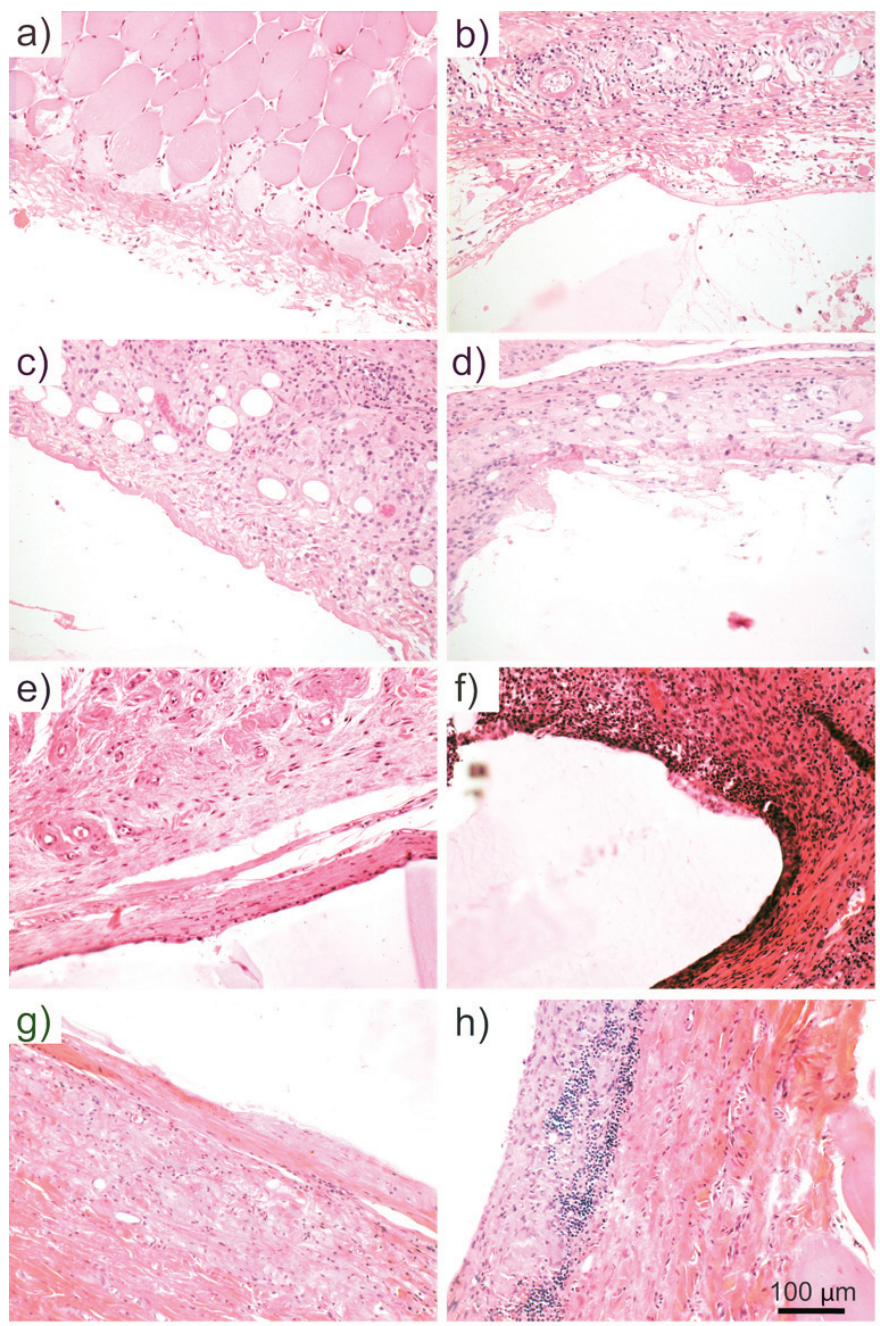

Figure 4. Typical microscopy images of the rat subcutaneous tissue response (H\&E stained) to the injected reactive three-armed adhesives after a) 1 day, b) 1 week, $c$, d) 4 weeks (mild and more severe response to the same glue in different rats), e, f) 12 weeks (mild and more severe response to the same glue in different rats), $g, h$ ) 26 weeks (mild and more severe response to the same glue in different rats). 

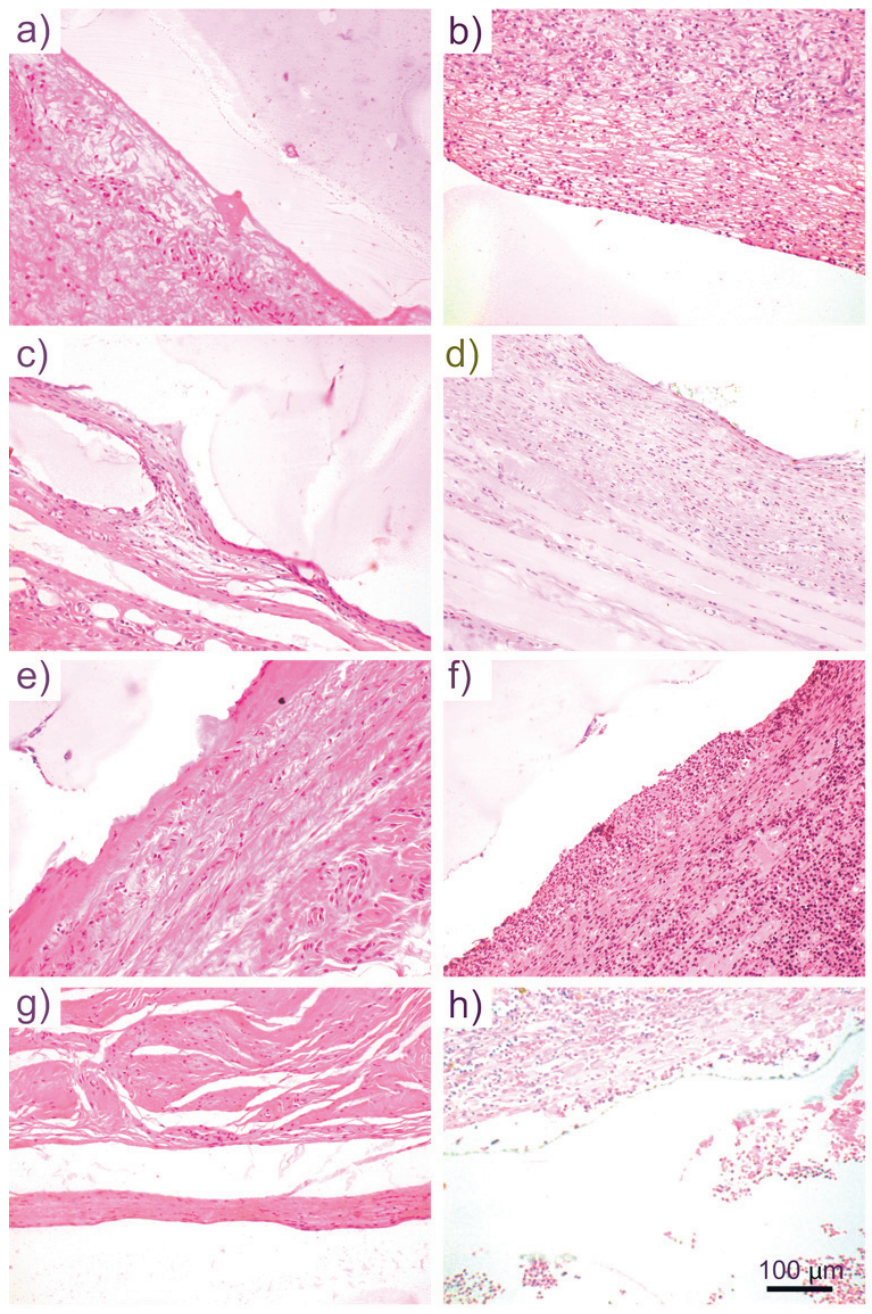

Figure 5. Typical microscopy images of the rat subcutaneous tissue response (H\&E stained) to the injected reactive hyper-branched adhesive after a) 1 day, b) 1 week, $c, d) 4$ weeks (mild and more severe response to the same glue in different rats), $e$, f) 12 weeks (mild and more severe response to the same glue in different rats), $g, h$ ) 26 weeks (mild and more severe response to the same glue in different rats). 
a)

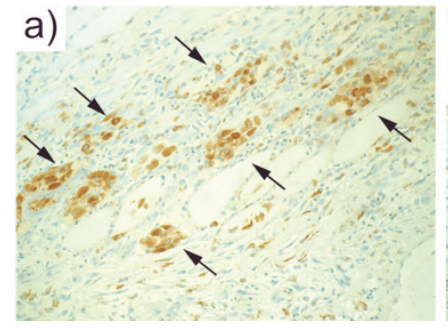

b)

)

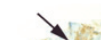

c)

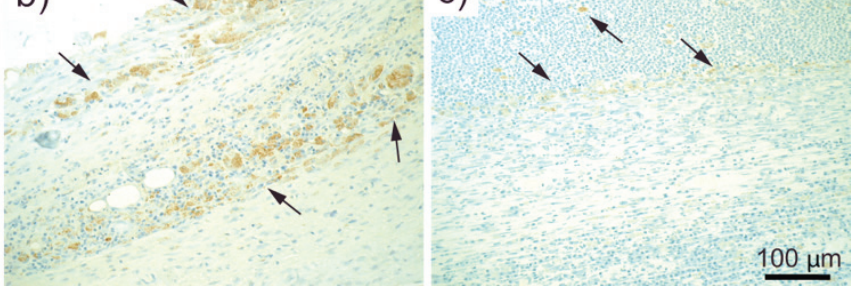

Figure 6. Typical microscopy images of the rat subcutaneous tissue response (immunohistochemistry, macrophages are stained in brown colour and are indicated by arrows) to the injected reactive hyper-branched adhesive a) after 1 week clusters of macrophages were observed, b) after 4 weeks the number of macrophages had decreased and giant cells could be observed, c) after 26 weeks clusters of macrophages were only rarely seen.

\section{Discussion}

The successful synthesis of reactive isocyanate-terminated three-armed- and hyperbranched block copolymeric adhesives was confirmed by ${ }^{1} \mathrm{H}-\mathrm{NMR}$ analysis. Moreover, gamma irradiation under nitrogen atmosphere appears to be a suitable sterilization method for these isocyanate-terminated glues as their NMR and FTIR spectra before and after gamma irradiation were almost identical. This is in agreement with reports in literature regarding the use of gamma irradiation for the sterilization of polyurethane precursors $[15,16]$.

Water-cured networks prepared from the reactive hyper-branched adhesives had a higher ratio of hydrophilic PEG components to hydrophobic TMC components and consequently higher water uptakes than networks prepared from the three-armed adhesives. The higher water uptake of networks prepared from the hyper-branched adhesives could also indicate that their cross-linking density was lower than that of networks prepared from the three-armed copolymers. For both networks, the high gel content values (above 90\%) indicated successful curing upon reaction of the reactive oligomers with water. The gel contents of networks prepared from the threearmed adhesive were slightly higher than that of networks prepared from the hyperbranched adhesives. This could be due to the higher hydrophilicity of the hyper- 
branched adhesives and networks which could lead to dissolution of the reacting block copolymeric oligomers before their incorporation into the (swollen) network.

The glass transition temperature of both networks in the wet state was below the physiological temperature of $37{ }^{\circ} \mathrm{C}$. This implies that in the intended application conditions, the cured adhesives will be flexible and rubber-like in nature.

The shear adhesion strength to meniscus tissue of both the three-armed- and the hyper-branched glues increased with curing time, respectively reaching maximum values of $88 \mathrm{kPa}$ and $66 \mathrm{kPa}$ after 24 hours. These adhesive strengths should be sufficient for application in repairing meniscal tears, as it was reported in literature that distraction forces acting on a sutured meniscus did not exceed $5 \mathrm{~N}$ when a load of $300 \mathrm{~N}$ was applied to human cadaver knees $[17,18]$. These values correspond to stresses of approximately $50 \mathrm{kPa}$. In recovery/rehabilitation period after surgery, the loads applied to the knee may even be lower.

The curing rate of the hyper-branched adhesive appeared to be faster than that of the three-armed adhesive, as bonding strengths close to maximum values were reached after 8 hours and 24 hours, respectively. The differences in curing rate might be due to the different numbers of reactive isocyanate end-groups per molecule in the different adhesive compounds. It is expected that these numbers are higher in the case of the hyper-branched adhesives [12]. The hyper-branched adhesive was also more hydrophilic, and may have attracted more water leading to faster curing. Its adhesive strength was not significantly higher than that of the three-armed adhesive. This can be due to partial dissolution of the adhesive in water before curing, also the higher water uptake of the formed network might have limited the extent of covalent bonding to the tissue.

The degradation of the water-cured networks in vivo could be due to the activity of macrophages which excrete degradative enzymes, or by plain hydrolysis. Therefore, in vitro degradation experiments in PBS (to assess the extent of plain hydrolysis) and in CE solution (which is an enzyme excreted by macrophages that is known to degrade polyurethanes and poly(trimethylene carbonate) [19-22]) were also performed. 
The rate of mass loss of networks prepared from the three-armed adhesives was significantly lower than that of networks based on the isocyanate-terminated hyperbranched oligomers in all degradative environments. These differences are due to the different hydrophilicities of the materials, as it is known that degradable hydrophilic polymeric materials hydrolyse faster [23]. The networks resulting from the hyper-branched adhesive absorb significantly more degradation medium. Furthermore, the ester linkages that are present in these networks are more susceptible to hydrolysis than urethane bonds [24].

As there were no statistically significant differences in rate of mass loss of the degrading networks in the different in vitro and in vivo degradation environments, it can be concluded that plain hydrolysis is the main mode of degradation. Enzymatic degradation of PTMC apparently does not play a role. The thickness of the degrading network films in the different environments did not change significantly in time (Supplementary Material, Figure S2). Thus, as the mechanical properties of the networks decreased with the loss of mass in time (some networks had disintegrated at 26 weeks), it can be concluded the networks degrade via a bulk erosion process. The values of the elastic modulus (E) and the maximum tensile stress $\left(\sigma_{\max }\right)$ of networks prepared from the three-armed adhesives did not change significantly during in vivo degradation and were in the same range as those of the human meniscus ( $\sigma=10-19 \mathrm{MPa}, \mathrm{E}=60-150 \mathrm{MPa})[25,26]$. The somewhat low values of $\mathrm{E}$ and $\sigma$ determined at 1, 4 and 12 weeks may be due to irregularities, defects or air bubbles in the prepared network films. In contrast, the elastic modulus and maximum tensile stress values of networks based on the hyper-branched adhesives were significantly much more affected by the degradation process. The networks had become brittle in time and were fragmented at 26 weeks.

SEM images of the surfaces of network films degraded in vivo, showed that the surface of network films prepared from the hyper-branched adhesives already became rough and irregular after 1 week of implantation. This roughness was even more pronounced after 26 weeks. Changes of the surface topographies of networks prepared from the three-armed adhesives were visible only after 12 weeks of degradation, and only after 26 weeks their surface had become somewhat rougher. This is in line with the observations of mass loss of the networks during degradation, which was significantly faster for networks based on the hyper-branched adhesives. 
Subcutaneous injection of the glues resulted in the presence of inflammatory reaction. The three-armed adhesives showed a slightly more severe tissue reaction than the hyper-branched ones. Inflammation involving infiltration of macrophages was observed, however there was no necrosis, and inflammation was seen only in tissue in direct contact with the glue. The cytotoxic reaction of the peripheral tissue was observed only in few rats after 1 day and 1 week post injection. At the later time points this was not seen anymore. This initial inflammatory reaction can be due to the isocyanate groups, these are known to be skin irritants [27]. A different application site, e.g. in intramuscular-, bone- or meniscus tissue, could possibly result in a less extensive reaction [16]. The observation that the hyper-branched adhesives showed a less severe tissue reaction may be due to their faster curing times compared to the three-armed compositions, the tissue may be exposed to the unreacted isocyanate groups for shorter times. At the same time, the wide variations in the histological scoring results after injection of these adhesives can be the result of the fact that part of the material had not been entirely incorporated into the network. As described, the gel content of networks prepared from hyper-branched adhesives, was slightly lower than that of those prepared from the three-armed adhesives.

The inflammatory reaction, which could still be observed at the later time points post injection, was probably a reaction to the presence of degradation products of the in situ cured adhesives. Networks based on the three-armed adhesives ultimately degrade into water-soluble TMPE, 1,3-propane diol, $\mathrm{CO}_{2}$, water and 1,6hexanediamine. Networks based on the hyper-branched adhesives degrade into PEG, 1,3-propane diol, $\mathrm{CO}_{2}$, water,1,6-hexanediamine and $\mathrm{CA}$. These water-soluble compounds can be metabolized or excreted by the kidneys. However, these compounds can also lead to changes in local $\mathrm{pH}$ which can be the cause of the inflammation.

The porous degrading networks formed after subcutaneous injection of the adhesives attracted many PMN cells, these are normal host defense mechanisms and inflammatory reactions to both the surgical procedure and the presence of implanted porous and degrading materials $[28,29]$. The erosion rate, and the size and shape of implanted materials can influence the intensity of the tissue response to degradable 
polymers [30-32]. In cases where the injected adhesives had cured forming porous spheres, many PMN cells were observed in the histological slides. In other cases, where the adhesives had formed more elongated and flat porous films, considerably less PMNs were seen. There were large variations in tissue response observed after injecting the adhesives. These were found to be rat-specific and not much dependent on the follow-up period. Analysis of the histological slides showed that while the same rats showed more severe responses to both of the injected glues, other individuals showed a very mild inflammatory response towards the glue. This could due to the fact that isocyanates can induce contact sensitivity [33]. In our case, probably not all animals had become sensitized, explaining the variability in the results.

In our experiments, we injected $100 \mu \mathrm{L}$ of the adhesives subcutaneously, as this amount allowed to easily detect the glues under the skin of rats. However, in clinical application this amount would be significantly lower (only a few 5-10 $\mu \mathrm{L}$ drops). As the target application of our glues is repairing the torn meniscus, which is mostly an avascular tissue, the inflammatory reaction is expected to be much less extensive. Furthermore, a mild inflammatory reaction would be desired as this could induce healing of the meniscus tissue.

\section{Conclusions}

The two newly developed isocyanate-functionalized three-armed- and hyperbranched tissue adhesives are promising materials for the repair of meniscal tears. They reach satisfactory adhesive strengths to meniscus tissue after curing. Their degradation profiles depend significantly on their chemistry, particularly on the presence of ester linkages in their network structure as these are prone to hydrolytic degradation. Histological analysis revealed that the glues caused an inflammatory reaction upon subcutaneous injection. This reaction is expected to be less prominent when the adhesives are applied in lower amounts to avascular meniscal tissue. To minimize tissue exposure times to free isocyanate groups, current studies are aimed at minimizing curing times of the adhesives.

\section{Acknowledgements}

This research is supported by Reumafonds, the Dutch Arthritis Foundation. 


\section{References}

[1] Henning CE, Lynch MA, Clark JR. Vascularity for healing of meniscus repairs. Arthroscopy: The Journal of Arthroscopic \& Related Surgery 1987;3:13-8.

[2] Starke C, Kopf S, Petersen W, Becker R. Meniscal Repair. Arthroscopy-the Journal of Arthroscopic and Related Surgery 2009;25:1033-44.

[3] Lozano J, Ma CB, Cannon WD. All-inside Meniscus Repair: A Systematic Review. Clinical Orthopaedics and Related Research 2007;455:134-41.

[4] van Trommel MF, Simonian PT, Potter HG, Wickiewicz TL. Different Regional Healing Rates with the Outside-In Technique for Meniscal Repair. The American Journal of Sports Medicine 1998;26:44652.

[5] Simson JA, Strehin IA, Allen BW, Elisseeff JH. Bonding and fusion of meniscus fibrocartilage using a novel chondroitin sulfate bone marrow tissue adhesive. Tissue Engineering - Part A 2013;19:1843-51.

[6] Burdick JA, Anseth KS. Photoencapsulation of osteoblasts in injectable RGD-modified PEG hydrogels for bone tissue engineering. Biomaterials 2002;23:4315-23.

[7] Gilbert TW, Badylak SF, Beckman EJ, Clower DM, Rubin JP. Prevention of seroma formation with TissuGlu ${ }^{\circledR}$ surgical adhesive in a canine abdominoplasty model: Long term clinical and histologic studies. Journal of Plastic, Reconstructive and Aesthetic Surgery 2013;66:414-22.

[8] Fabian T, Federico JA, Ponn RB. Fibrin glue in pulmonary resection: a prospective, randomized, blinded study. The Annals of Thoracic Surgery 2003;75:1587-92.

[9] Singer AJ, Quinn JV, Hollander JE. The cyanoacrylate topical skin adhesives. The American Journal of Emergency Medicine 2008;26:490-6.

[10] Spotnitz WD. Commercial fibrin sealants in surgical care. American Journal of Surgery 2001;182:8S-14S.

[11] Bochyńska AI, Hannink G, Grijpma DW, Buma P. Tissue adhesives for meniscus tear repair: an overview of current advances and prospects for future clinical solutions. Journal of Materials Science: Materials in Medicine 2016;27:1-18, Chapter 2 of this thesis.

[12] Bochyńska AI, Van Tienen TG, Hannink G, Buma P, Grijpma DW. Development of biodegradable hyper-branched tissue adhesives for the repair of meniscus tears. Acta Biomaterialia 2016;32:1-9, Chapter 5 of this thesis.

[13] Bochyńska AI, Sharifi S, van Tienen TG, Buma P, Grijpma DW. Development of Tissue Adhesives Based on Amphiphilic Isocyanate-Terminated Trimethylene Carbonate Block Copolymers. Macromolecular Symposia 2013;334:40-8, Chapter 3 of this thesis.

[14] Link DP, van den Dolder J, van den Beucken JJ, Cuijpers VM, Wolke JG, Mikos AG, et al. Evaluation of the biocompatibility of calcium phosphate cement/PLGA microparticle composites. J Biomed Mater Res A 2008;87:760-9.

[15] Sheikh N, Mirzadeh H, Katbab AA, Salehian P, Daliri M, Amanpour S. Isocyanate-terminated urethane prepolymer as bioadhesive material: Evaluation of bioadhesion and biocompatibility, in vitro and in vivo assays. Journal of Biomaterials Science-Polymer Edition 2001;12:707-19. 
[16] Rohm HW, Lurtz C, Wegmann J, Odermatt EK, Behrend D, Schmitz K-P, et al. Development of a biodegradable tissue adhesive based on functionalized 1,2-ethylene glycol bis(dilactic acid). II. Journal of Biomedical Materials Research Part B-Applied Biomaterials 2011;97B:66-73.

[17] Becker R, Brettschneider O, Gröbel KH, Von Versen R, Stärke C. Distraction forces on repaired bucket-handle lesions in the medial meniscus. American Journal of Sports Medicine 2006;34:1941-7. [18] Staerke C, Brettschneider O, Gröbel KH, Becker R. Tensile forces on sutures in the human lateral knee meniscus. Knee Surgery, Sports Traumatology, Arthroscopy 2009;17:1354-9.

[19] Tsutsumi C, Nakagawa K, Shirahama H, Yasuda H. Enzymatic degradations of copolymers of Llactide with cyclic carbonates. Macromolecular Bioscience 2002;2:223-32.

[20] Bat E, van Kooten TG, Feijen J, Grijpma DW. Macrophage-mediated erosion of gamma irradiated poly(trimethylene carbonate) films. Biomaterials 2009;30:3652-61.

[21] Bat E, Feijen J, Grijpma DW. Biodegradable elastomeric networks: highly efficient cross-linking of poly(trimethylene carbonate) by gamma irradiation in the presence of pentaerythritol triacrylate. Biomacromolecules 2010;11:2692-9.

[22] Labow RS, Meek E, Santerre JP. Hydrolytic degradation of poly(carbonate)-urethanes by monocyte-derived macrophages. Biomaterials 2001;22:3025-33.

[23] Göpferich A. Mechanisms of polymer degradation and erosion. Biomaterials 1996;17:103-14.

[24] Szycher M. Szycher's Handbook of Polyurethanes, Second Edition: CRC Press; 2012.

[25] Fithian DC, Kelly MA, Mow VC. Material properties and structure-function-relationships in the menisci. Clinical Orthopaedics and Related Research 1990:19-31.

[26] Lechner K, Hull M, Howell S. Is the circumferential tensile modulus within a human medial meniscus affected by the test sample location and cross-sectional area? Journal of Orthopaedic Research 2000;18:945-51.

[27] Baur X, Dewair M, Fruhmann G. Detection of immunologically sensitized isocyanate workers by RAST and intracutaneous skin tests. Journal of Allergy and Clinical Immunology 1984;73:610-8.

[28] van Tienen TG, Heijkants RGJC, Buma P, de Groot JH, Pennings AJ, Veth RPH. Tissue ingrowth and degradation of two biodegradable porous polymers with different porosities and pore sizes. Biomaterials 2002;23:1731-8.

[29] Ramrattan NN, Heijkants RG, van Tienen TG, Schouten AJ, Veth RP, Buma P. Assessment of tissue ingrowth rates in polyurethane scaffolds for tissue engineering. Tissue Eng 2005;11:1212-23.

[30] Bat E, Plantinga JA, Harmsen MC, Van Luyn MJA, Feijen J, Grijpma DW. In vivo behavior of trimethylene carbonate and $\varepsilon$-caprolactone-based (co)polymer networks: Degradation and tissue response. Journal of Biomedical Materials Research - Part A 2010;95:940-9.

[31] Wood NK, Kaminski EJ, Oglesby RJ. The significance of implant shape in experimental testing of biological materials: disc vs. rod. Journal of Biomedical Materials Research 1970;4:1-12.

[32] Ibim SM, Uhrich KE, Bronson R, El-Amin SF, Langer RS, Laurencin CT. Poly(anhydride-coimides): In vivo biocompatibility in a rat model. Biomaterials 1998;19:941-51.

[33] Thorne PS, Hillebrand JA, Lewis GR, Karol MH. Contact sensitivity by diisocyanates: Potencies and cross-reactivities. Toxicology and Applied Pharmacology 1987;87:155-65. 


\section{Supplementary Material}

- Three-armed

-... Hyper-branched
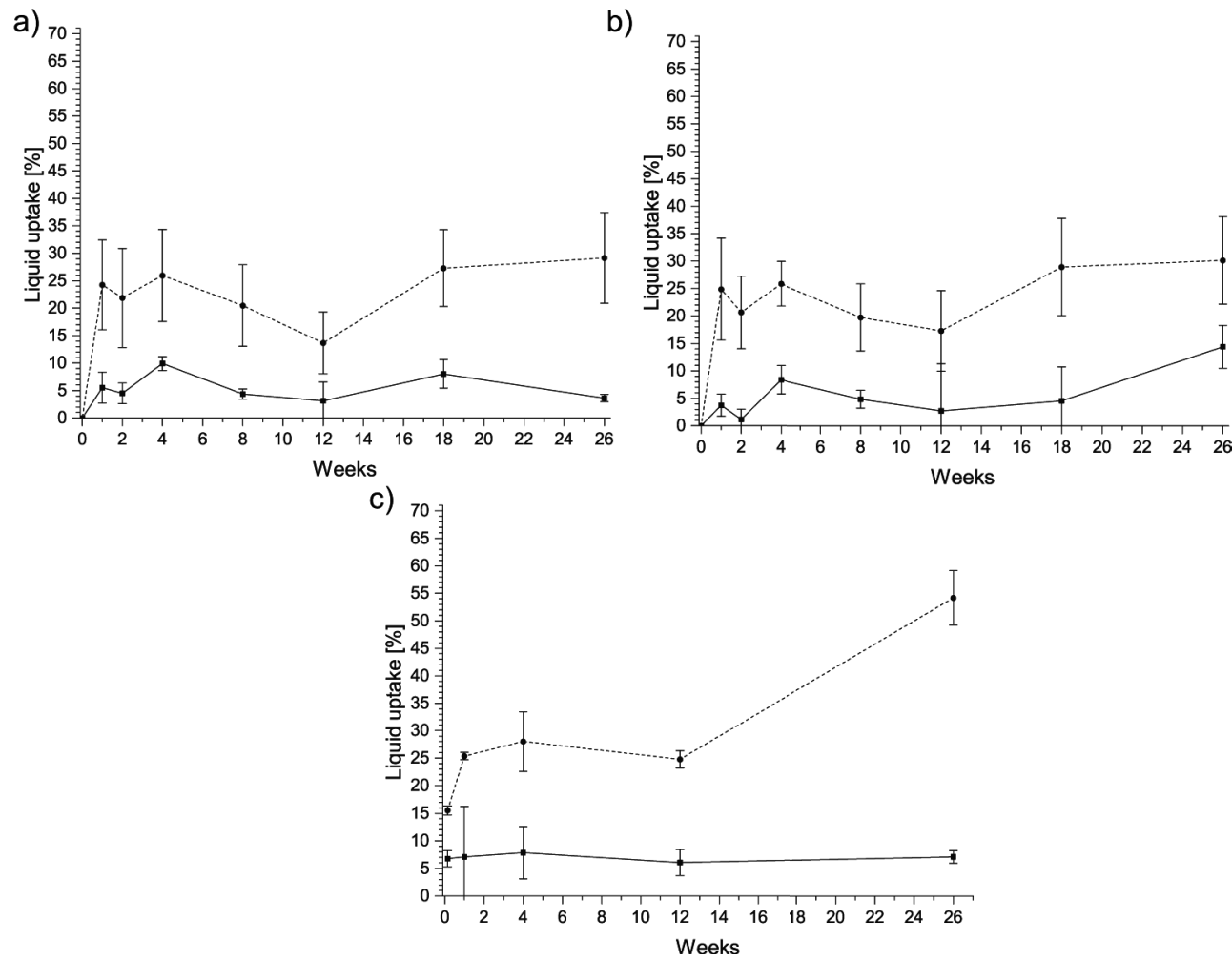

Figure S1. Uptake of liquids by network films prepared from reactive isocyanateterminated three-armed- and hyper-branched block copolymers at different time points during a) in vitro in $C E$, b) in vitro in $P B S$, c) in vivo subcutaneous implantation in rats. In all degradation environments, the liquid uptake was significantly higher for networks prepared from hyper-branched adhesives than from three-armed $(p<0.05)$. 
- Three-armed

Hyper-branched

a)

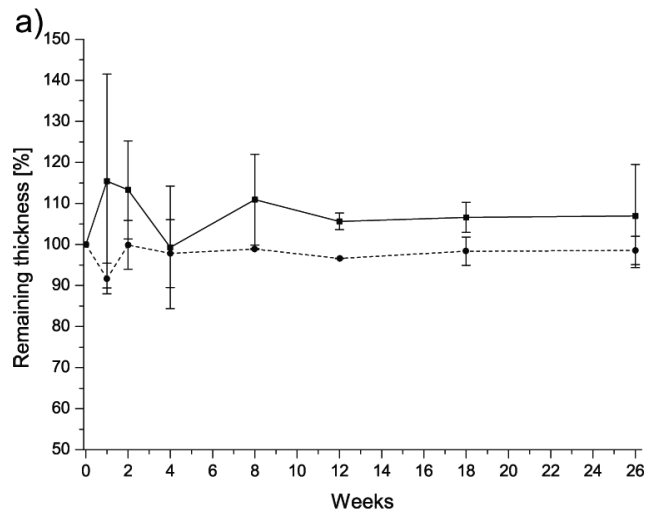

c) b)

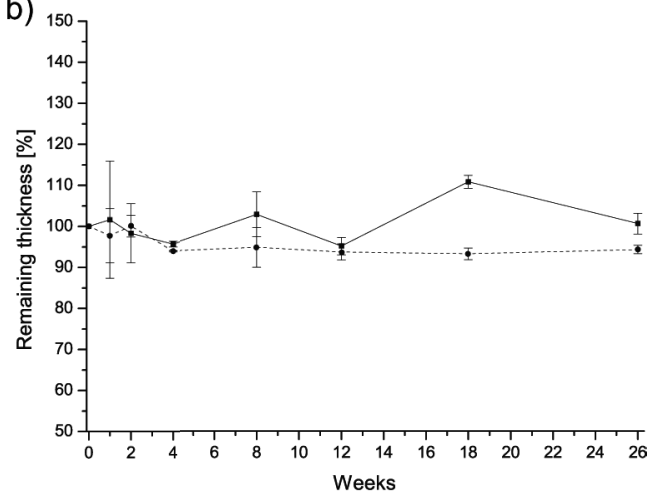

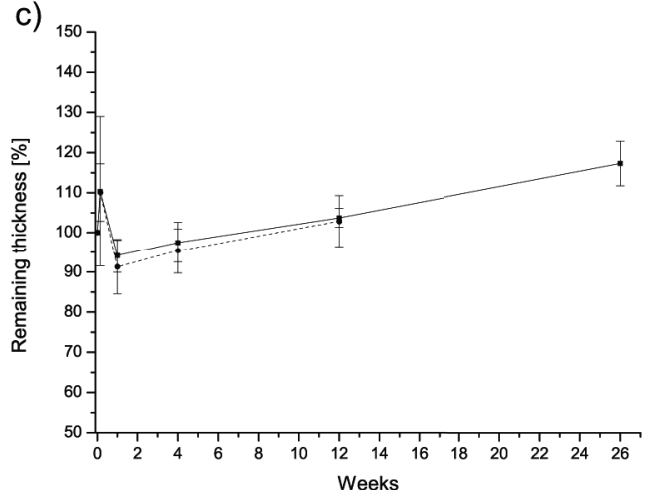

Figure S2. Thickness of network films prepared from reactive isocyanate-terminated three-armed-and hyper-branched block copolymers at different time points during a) in vitro in $C E$, b) in vitro in $P B S, c)$ in vivo subcutaneous implantation in rats. There were no significant differences in thickness between the degrading networks in time.

Note that after 26 weeks it was not possible to determine the thickness of network films prepared from isocyanate-terminated hyper-branched block copolymers degrading in vivo due to loss of integrity of the specimens. 


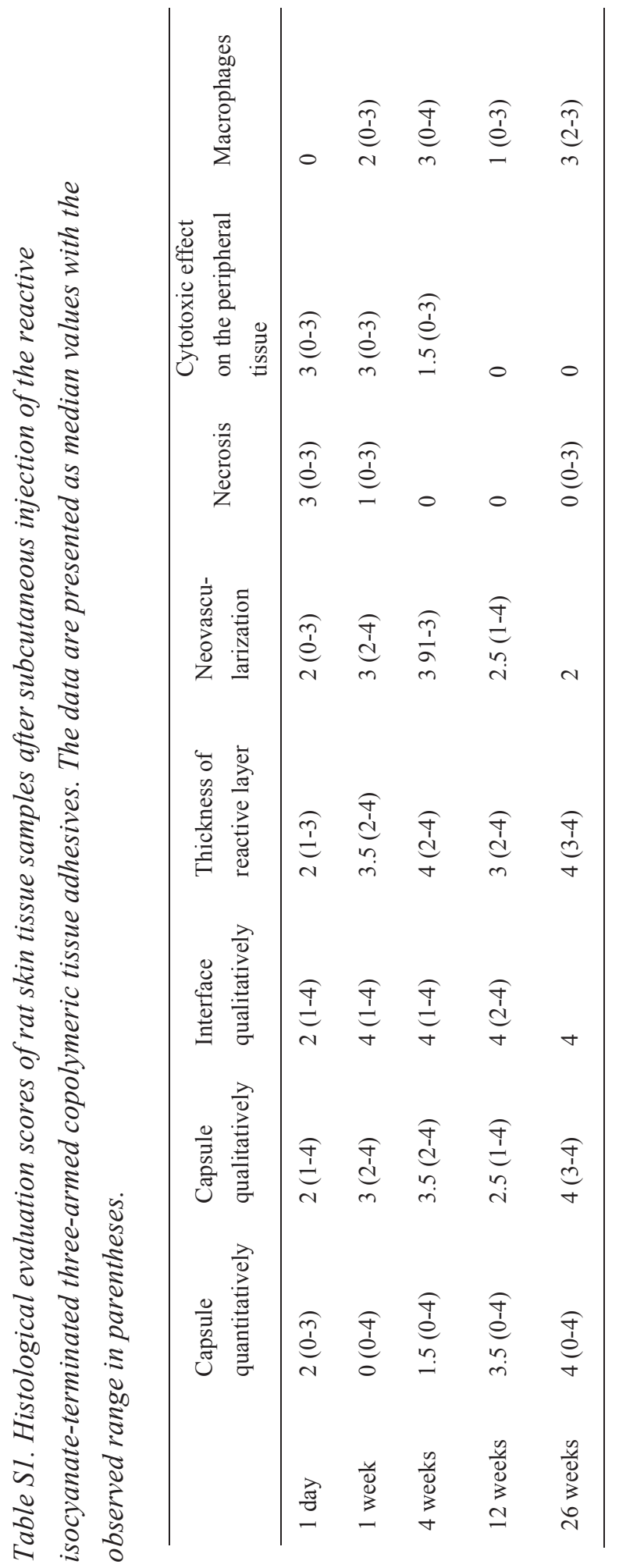




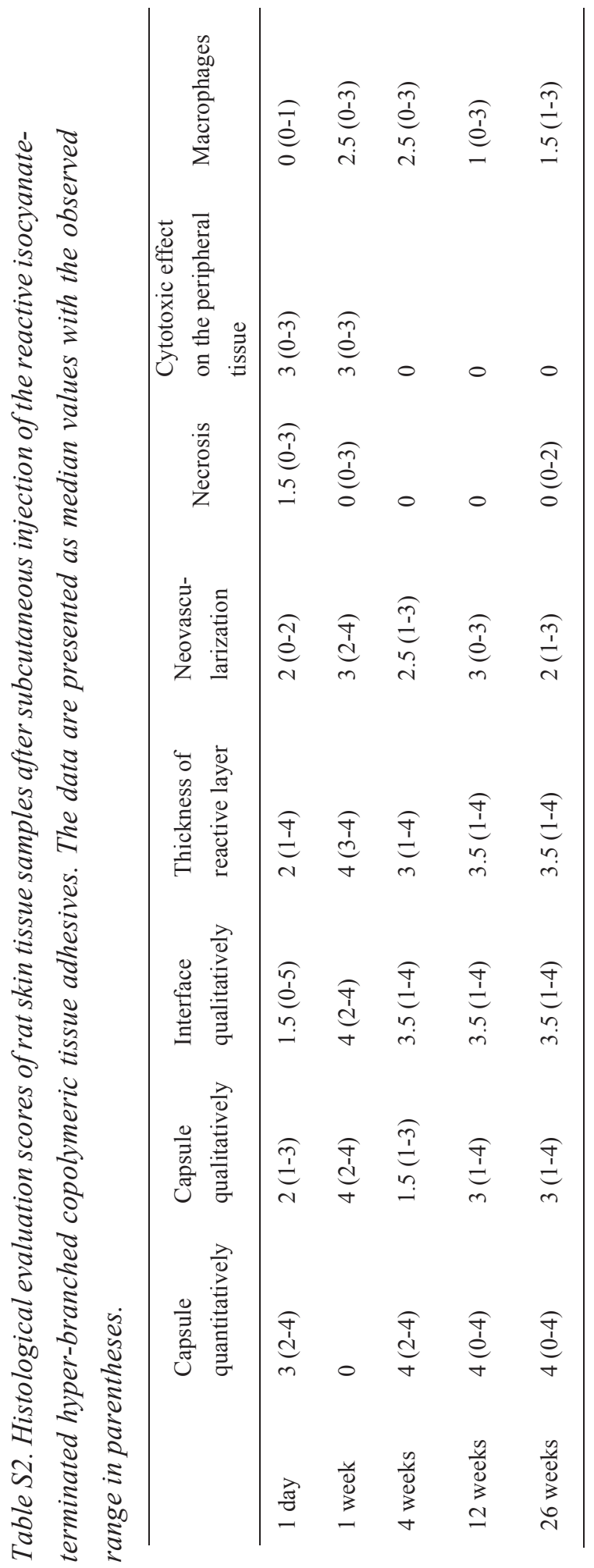




\section{Chapter 9}

\section{Development of a Fast Curing Tissue Adhesive for Meniscus Tear Repair}

Agnieszka I. Bochyńska ${ }^{1,2}$, Gerjon Hannink ${ }^{2}$, Dennis Janssen², Pieter Buma ${ }^{2}$, Dirk W. Grijpma ${ }^{1,3}$

${ }^{1}$ Department of Biomaterials Science and Technology, MIRA Institute, University of Twente, Enschede, the Netherlands

${ }^{2}$ Orthopaedic Research Laboratory, Department of Orthopaedics, Radboud Centre for Molecular Life Sciences, Radboud University Nijmegen Medical Centre, Nijmegen, the Netherlands

${ }^{3}$ University Medical Centre Groningen, University of Groningen, W.J. Kolff Institute, Department of Biomedical Engineering, Groningen, the Netherlands 


\begin{abstract}
Isocyanate-terminated adhesive amphiphilic block copolymers are attractive materials to treat meniscus tears due to their tuneable mechanical properties and good adhesive characteristics. However, a drawback of this class of materials is their relatively long curing time. In this study we evaluate the use of an amine cross-linker and addition of catalysts as two strategies to accelerate the curing rates of a recently developed biodegradable reactive isocyanate-terminated hyper-branched adhesive block copolymer prepared from polyethylene glycol (PEG), trimethylene carbonate, citric acid and hexamethylene diisocyanate.
\end{abstract}

The curing kinetics of the hyper-branched adhesive alone and in combination with different concentrations of spermidine solutions, and after addition of 2,2dimorpholinodiethylether (DMDEE) or 1,4-diazabicyclo [2.2.2] octane (DABCO) were determined using FTIR. Additionally, lap-shear adhesion tests using all compositions at various time points were performed. The two most promising compositions of the fast curing adhesives were evaluated in a meniscus bucket handle lesion model and their performance was compared with that of fibrin glue. The results showed that addition of both spermidine and catalysts to the adhesive copolymer can accelerate the curing rate and that firm adhesion can already be achieved after 2 hours. The adhesive strength to meniscus tissue of 3.2-3.7 $\mathrm{N}$ was considerably higher for the newly developed compositions than for fibrin glue ( 0.3 $\mathrm{N})$.

The proposed combination of an adhesive component and a cross-linking component or catalyst is a promising way to accelerate curing rates of isocyanate-terminated tissue adhesives.

\title{
Introduction
}

Traumatic meniscal tears are common injuries of the knee. They result in pain, swelling and locking of the knee joint, and may eventually result in the development of osteoarthritis [1]. Bucket handle tears are among the most frequently occurring types of tears resulting from the injury $[2,3]$. These are extended, longitudinal tears 
that are not likely to heal spontaneously due to the displacement of part of the torn tissue.

Tissue adhesives are attractive biomaterials to be used for treating meniscus tears [4]. They are already employed in clinical practice for various applications. Cyanoacrylates are used clinically for gluing skin lacerations, fibrin glue for pulmonary leaks and repair of cardiovascular defects, and TissueGlu ${ }^{\circ}$ for abdominoplasty [5-7]. However, these materials are not suitable for the repair of meniscal tears either due to their cytoxicity or their insufficient mechanical- and adhesive properties. Therefore, there is a growing interest in the development of new tissue adhesives, which are strong, non-toxic, biodegradable and fast-curing.

Isocyanate-terminated polymers are of particular interest, since they have easily tuneable mechanical properties, they attach to the tissue via formation of strong covalent bonds and degrade to non-toxic products [4]. However, a drawback of this class of materials is the relatively long curing time: it can take up to several hours before the adhesive reaches maximum bonding strength. Few strategies have been employed to speed up the curing rates of isocyanate-terminated polymers. Sternberg et al. engaged the use of polymers such as hyaluronic acid, gelatin, chitosan acetate, and chitosan chloride, which were mixed with the isocyanate-terminated adhesive component prior to its application $[8,9]$. Another strategy was chosen by Beckman et al. and Smith et al. who added catalysts such as 2,2-dimorpholinodiethylether (DMDEE) and 1,4-diazabicyclo [2.2.2] octane (DABCO) to isocyanate-terminated adhesive compounds $[10,11]$. They reported that attachment to the tissue can already be achieved after several minutes.

We have recently developed a series of isocyanate-terminated amphiphilic block copolymers for the repair of meniscal tears $[12,13]$. These adhesive materials have satisfactory adhesion strengths to meniscus tissue, adequate mechanical properties of the networks after curing, in addition they are biodegradable and compatible with meniscus cells and tissue when used in physiological amounts. However, it takes between 8 to 24 hours for these materials to completely cure. This may cause leakage into surrounding tissues and limit their potential clinical application. 
The aim of the current study was to develop a fast curing tissue adhesive (glue) based on a previously developed hyper-branched adhesive block copolymer [13, 14]. We describe two ways of accelerating the curing rate of this isocyanate-terminated copolymeric glue. One strategy was to employ spermidine, a polyamine that acts as a cross-linker. The other strategy was based on the addition of a catalyst to the isocyanate-terminated copolymer, which will accelerate the curing process in the presence of surrounding body fluids. The resulting adhesive compositions were evaluated in terms of their curing rates, and their adhesion strengths to meniscus tissue.

\section{Materials and Methods}

\section{Adhesive components}

The reactive isocyanate-terminated hyper-branched adhesive block copolymer was synthesized as previously reported in detail [13]. The adhesive was prepared from polyethylene glycol $\left(\mathrm{PEG}, \mathrm{M}_{\mathrm{n}}=400 \mathrm{~g} / \mathrm{mol}\right.$ ), trimethylene carbonate $(\mathrm{TMC})$, citric acid (CA) and hexamethylene diisocyanate (HDI). The final product was labeled CA-4PEG-(TMC $\left.)_{2}\right)_{2}$-HDI. After each synthesis step, the chemical structures of the intermediate reaction products were confirmed by ${ }^{1} \mathrm{H}$ NMR spectroscopy (Bruker $400 \mathrm{MHz}$ NMR spectrometer) using $\mathrm{CDCl}_{3}$ as the solvent.

\section{Two-component adhesive with cross-linkers}

The two-component adhesive (glue) was composed of the reactive isocyanateterminated hyper-branched block copolymer (adhesive component) and a crosslinking component. The cross-linking component was a mixture of spermidine (Sigma Aldrich, the Netherlands) and a linear copolymer $\mathrm{HO}-\mathrm{TMC}_{2}-\mathrm{PEG}_{400^{-}} \mathrm{TMC}_{2}-$ $\mathrm{OH}$, which was prepared as described previously [12]. The glue was applied to the tissue with a double-chamber syringe (Sulzer, Switzerland) in which the volume ratio of the adhesive component to the crosslinking component was 4:1 (see Fig. 1a). The amount of spermidine in the cross-linking solution was adjusted so that the ratio of the isocyanate groups of the adhesive component to the amine groups in the crosslinking component was 5:1 (spermidine 5:1) or 10:1 (spermidine 10:1) (assuming that the degree of functionalization of the hyper-branched block copolymer with 
HDI was $100 \%$ ). The molar ratio of $\mathrm{HO}-\mathrm{TMC}_{2}-\mathrm{PEG}_{400}-\mathrm{TMC}_{2}-\mathrm{OH}$ to spermidine in the cross-linking component was 2.14 for spermidine $5: 1$, and 4.65 for spermidine $10: 1$.

\section{Catalysed single-component adhesive}

The effect of adding a catalyst to the adhesive component on the curing and the adhesive properties of the cured network was evaluated. The adhesive component (which is a viscous liquid) was placed in a round bottom flask at room temperature (RT) and kept under argon. Subsequently, 2,2-dimorpholinodiethylether (DMDEE, Sigma Aldrich, the Netherlands) or 1,4-diazabicyclo [2.2.2] octane (DABCO, Sigma Aldrich, the Netherlands) was added and the mixture was stirred for 2 hours to activate the terminal isocyanate groups of the adhesive component. The amount of added DMDEE was $0.1 \mathrm{wt} \%$ of the adhesive component, while the amount of $\mathrm{DABCO}$ was equal to 0.034 of the number of isocyanate groups of the adhesive component (assuming 100\% degree of functionalization with HDI). The mixtures of the adhesive component and the catalysts were applied using a conventional $2 \mathrm{~mL}$ syringe equipped with a $23 \mathrm{G}$ needle (Fig. 1b).

a)

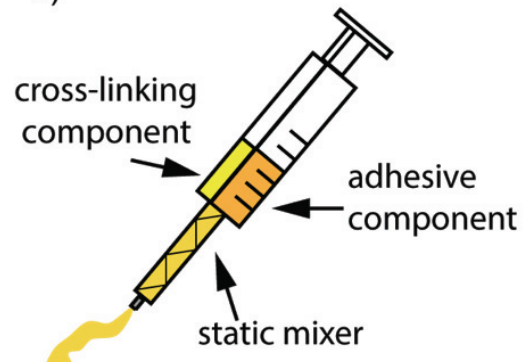

b)

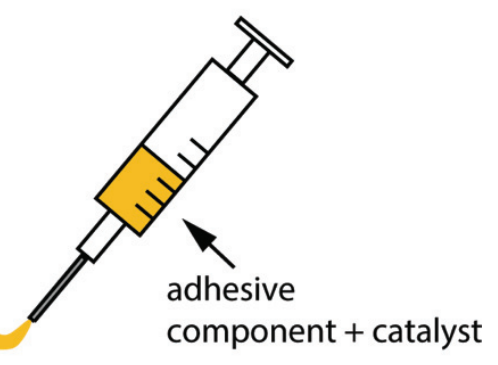

Figure 1. Schematic drawing of the syringe systems used to apply the fast curing adhesives. a) Double-chamber syringe equipped with a static mixer where the adhesive component and the cross-linking component are mixed during their application, b) Conventional syringe used to apply a mixture of the adhesive component and a catalyst. 


\section{Curing kinetics of the adhesives}

The curing kinetics of the hyper-branched adhesive component and after mixing with a cross-linking component or a catalyst were determined by FTIR using a Perkin Elmer Spectrum Two Spectrometer. As the free isocyanate groups react to form a network, the peaks at $2255 \mathrm{~cm}^{-1}$ disappear. A drop of the adhesive composition $(\mathrm{n}=1)$ was placed on the prism and covered with demineralized water, the spectra were recorded after $0,5,15$ and 30 minutes, and after 1, 2, 4, 8 and 24 hours. The conversion of isocyanate groups was calculated from the areas of the peaks relative to the peak area at $\mathrm{t}=0$.

\section{Lap-shear adhesion strength of the adhesive compositions to meniscus tissue}

Lap-shear adhesion testing of the adhesives to meniscus tissue was also performed at different curing times. Bovine lateral menisci from a local slaughterhouse were frozen and cut with a cryotome (Microm GmbH, Germany) into strips measuring approximately $0.5 \times 10 \times 25 \mathrm{~mm}$ parallel to the direction of alignment of the circumpherential collagen fibers. The tissue strips were thawed to RT and kept hydrated in water until the gluing experiment. The surfaces of the tissue strips were blotted dry, and the different adhesives were applied to the strips of tissue. The adhesives covered an area of approximately $100 \mathrm{~mm}^{2}$. The strips of tissue were then pressed together and immersed in water. The strength of the adhesive bond was measured in a lap shear adhesion test using a Zwick Z020 universal tensile tester in analogy to ASTM F2255-05. The grip to grip separation was $22 \mathrm{~mm}$ and the crosshead speed was $50 \mathrm{~mm} / \mathrm{min}$. The measurement was performed after 30 minutes and after 1, 2, 4, 8 and 24 hours of applying the glues $(n=3)$. The shear adhesive bond strength ( $\mathrm{S}$, expressed in $\mathrm{kPa}$ ) was determined from the maximum shear force divided by the glued area.

Evaluation of the adhesive strength of the adhesives in a meniscus buckethandle tear model

The adhesive strength of the glues was evaluated in a simulated meniscus buckethandle tear. Fresh frozen bovine menisci were thawed in water and the outlines of the bucket-handle tears were drawn along the central part of the menisci ending 1 
$\mathrm{cm}$ from posterior and anterior horns. Subsequently, the menisci were mounted in a custom-made clamp using needles (see Fig. 2a) and placed in a BOSE ${ }^{\circledR}$ Electroforce ${ }^{\circledR}$ setup equipped with a 200N load cell (BOSE Bose Corp. ElectroForce Systems Group, MN, USA). The outer part of the meniscus was fixed using three needles and the inner part was fixed with a single needle. Then, bucket-handle tears were cut along the drawn outline with a scalpel. The inner part of the meniscus was pulled down at a rate of $5 \mathrm{~mm} / \mathrm{min}$ to pre-condition the tissue (10 repetitions). The maximum displacement that could be applied with this setup was $6 \mathrm{~mm}$.

The two outer needles fixing the upper (outer) part of the meniscus were removed, the meniscus was now fixated with only one needle holding the upper (outer) part and one needle holding the bottom (inner) part (Fig. 2b). The tissue was then again pre-conditioned by opening and closing the tear ( 5 repetitions). The meniscal tear was opened again and the tear surface was rasped using a surgical rasp (diamond rasp $45^{\circ}$, Acufex, Smith \& Nephew). The different adhesive compositions $(100 \mu \mathrm{L})$ were applied to the surface of the tears using the syringe systems pictured in Fig. 1. In this setup, the performance of the hyper-branched adhesive, the hyper-branched adhesive mixed with spermidine 5:1 and the hyper-branched adhesive containing DABCO was evaluated $(n=5)$. As a control, the performance of fibrin glue (a mixture of fibrinogen $(100 \mathrm{mg} / \mathrm{mL})$ and thrombin $(100 \mathrm{U} / \mathrm{mL})$ in PBS $(\mathrm{pH}=7.4)$, both isolated from bovine plasma, Sigma Aldrich, the Netherlands) was also evaluated $(n=3)$. An experiment in which no adhesive was applied was also performed $(n=1)$. After application of the adhesives, the tear was closed and the meniscus was wrapped with a moist tissue and left to cure at $37{ }^{\circ} \mathrm{C}$.

After approximately 18 hours (overnight), bucket-handle tear of the meniscus was opened to evaluate the adhesive strength of the glues. The hyper-branched adhesive component needed longer curing time than other compositions, therefore to have the same protocol during the experiments, the adhesion of all adhesives was tested after overnight curing. Force-displacement curves at $5 \mathrm{~mm} / \mathrm{min}$ were recorded. After the glue failed, a second force-displacement curve was determined. This curve was used as a baseline for the non-glued meniscus $(n=5)$. The force-displacement curve for a cut meniscus to which no glue was applied $(n=1)$ was also obtained. 
The maximum adhesive strength of the glues (the maximum force before failure of the adhesive bond) and corresponding displacement were determined. Additionally, the energy required to open the glued meniscus tears was determined from the area under the force-displacement curve up to the force at failure and the corresponding displacement. The energy to rupture the adhesive bond between the glue and the tissue was calculated as the difference between the energy required to open the glued tear and the area under the baseline curve up to the force at failure and the corresponding displacement (Matlab, The MathWorks, USA).

\section{Results}

Analysis by ${ }^{1} \mathrm{H}-\mathrm{NMR}$ after each synthesis step and FTIR confirmed that the adhesive hyper-branched block copolymers were successfully synthesized $[12,13]$.

\section{Curing kinetics of the adhesive compositions}

The curing kinetics of the hyper-branched adhesive component and those of the hyper-branched adhesive component after mixing with a cross-linking component and a catalyst were determined by FTIR spectroscopy. The disappearance of the peak corresponding to free $\mathrm{NCO}$ groups was followed in time, and the conversion of free isocyanate groups upon curing with water was determined (see Fig. 3).

In the hyper-branched adhesive component, $76.3 \%$ and $23.3 \%$ unreacted isocyanate groups remained after 4 and 8 hours reaction with water, respectively. After 24 hours, all isocyanate groups had reacted. By mixing the hyper-branched adhesive with the cross-linking compositions, the rate of curing accelerated significantly: after 4 hours the remaining unreacted isocyanate groups were $32.5 \%$ and $20.1 \%$ for the compositions with spermidine 1:10 and spermidine 1:5, respectively. After 8 hours these values were $3.5 \%$ and $6.7 \%$, respectively. For all compositions, all isocyanate groups had reacted after 24 hours. 


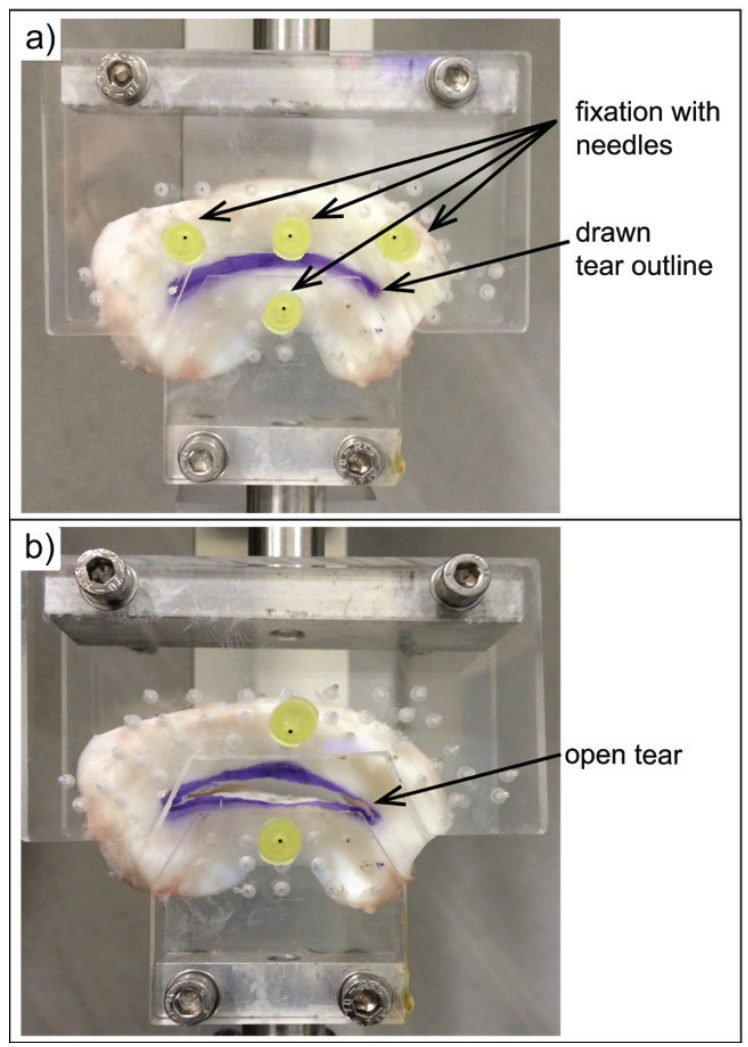

Figure 2. Fixation of a bovine lateral meniscus tissue in a custom-made clamp. a) Meniscus with a drawn bucket-handle tear outline mounted in the clamp using 4 needles, b) The two outer needles holding the upper (outer) part of the meniscus were removed, and the bucket-handle tear was opened to allow application of the glues.

When the DMDEE catalyst was added to the hyper-branched adhesive component, its curing rate was similar to that after adding the cross-linking composition. The remaining unreacted isocyanate groups were $20.6 \%$ and $0.4 \%$ after 4 and 8 hours, respectively. Addition of $\mathrm{DABCO}$ to the hyper-branched adhesive component resulted in a much faster curing rate. Already after 2 hours the amount of remaining isocyanate groups was only $5.5 \%$, while after 8 hours all isocyanate groups had reacted. 
a)

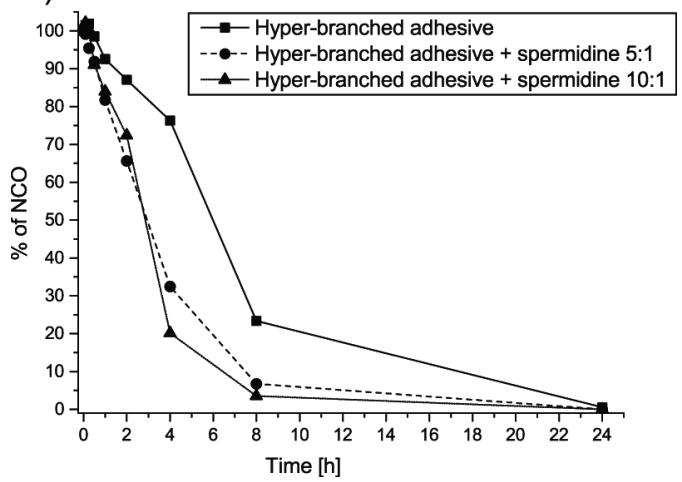

b)

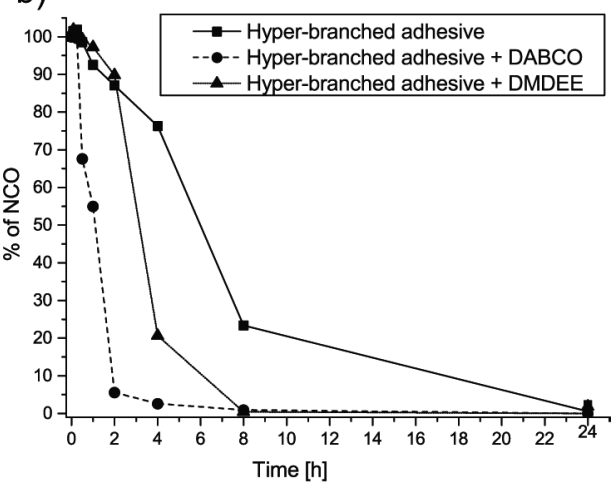

Figure 3. Changes in the amount of unreacted isocyanate groups determined by FTIR during curing by reaction with water of a) the hyper-branched adhesive component to which cross-linking compositions were added and b) the hyperbranched adhesive component to which catalysts were added.

\section{Lap-shear adhesion strength of the adhesive compositions to meniscus tissue}

The shear adhesion strength of the hyper-branched adhesive component and that of the hyper-branched adhesive component after addition of the cross-linking component and the catalysts was determined at different curing times (Fig. 4). The adhesive strength of the hyper-branched adhesive was already close to its maximum value after 8 hours $(62.6 \pm 56.4 \mathrm{kPa})$ and reached $65.7 \pm 5.2 \mathrm{kPa}$ after 24 hours. After mixing the hyper-branched adhesive component with spermidine $5: 1$, the determined adhesive strength was $48.7 \pm 23.2 \mathrm{kPa}$ and $99.9 \pm 57.7 \mathrm{kPa}$ after 8 and 24 hours, respectively. The addition of the spermidine 10:1 resulted in a lower ultimate adhesive strength of $15.3 \pm 9.3 \mathrm{kPa}$ after 24 hours.

When the DMDEE catalyst was added to the hyper-branched adhesive, the adhesive strength was relatively low initially; after 4 and 8 hours values of $10.9 \pm 2.3 \mathrm{kPa}$ and $11.5 \pm 12.8 \mathrm{kPa}$, respectively, were determined. However, after 24 hours, the adhesive strength reached $61.5 \pm 46.9 \mathrm{kPa}$. Addition of the DABCO catalyst to the reactive hyper-branched oligomer resulted in already reaching relatively high adhesive strengths after 2 hours of application $(50.5 \pm 14.9 \mathrm{kPa})$, ultimately reaching $64.4 \pm 14.3$ $\mathrm{kPa}$ after 24 hours. 
a)

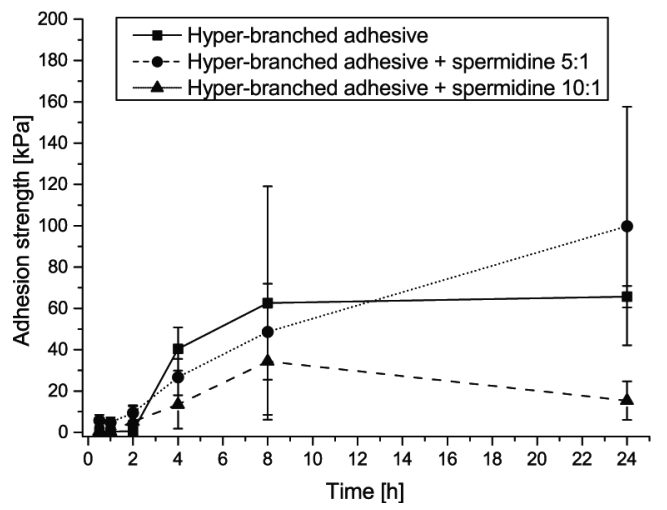

b)

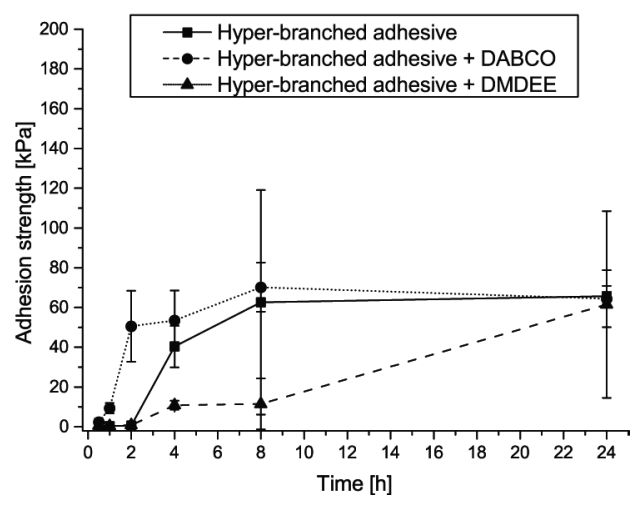

Figure 4. Evolution of the shear-adhesion strength of the different adhesive compositions to meniscus tissue during curing by reaction with water of a) the hyper-branched adhesive component to which cross-linking components were added and b) the hyper-branched adhesive component to which catalysts were added. The data is presented as mean \pm standard deviations.

\section{Adhesion in a bucket-handle meniscal tear model}

The adhesive properties of the hyper-branched adhesive component, and the composition after mixing with spermidine 5:1 and DABCO were evaluated in a meniscal bucket-handle tear model. The average length of the tear was $45.0 \pm 3.8 \mathrm{~mm}$ and the average tear surface area was $353.4 \pm 53.3 \mathrm{~mm}^{2}$. A characteristic example of the recorded force-displacement curves is shown in Fig. 5.

The maximum adhesive strength of the adhesive component and that of the adhesive to which cross-linking composition and a catalyst were added was between $3.2 \pm 0.47$ $\mathrm{N}$ for the composition with DABCO, and up to $3.7 \pm 0.96 \mathrm{~N}$ and $3.7 \pm 1.5 \mathrm{~N}$, respectively, for the hyper-branched adhesive component alone and the hyperbranched adhesive component to which spermidine 5:1 was added (Table 1). The displacement at which the maximum force was reached was between 1.6 $\pm 0.4 \mathrm{~N}$ for the composition with spermidine $5: 1$, and up to $2.8 \pm 0.6 \mathrm{~mm}$ for the composition with DABCO. It was not possible to determine a maximum adhesive strength of the fibrin glue, as its force-displacement curve was similar to that of a non-glued torn meniscus and it did not show a clear maximum. Thus the highest force recorded during 
opening the bucket-handle tear glued with fibrin glue was the force of $0.3 \pm 0.04 \mathrm{~N}$ reached at the maximum displacement of $6 \mathrm{~mm}$. A single meniscus with a simulated tear, but without application of glue was tested as well. It was found that the forcedisplacement curve was very similar to the baselines determined after failure of the glues in the glued menisci.

The energy necessary to open a glued meniscus tear was determined from the area under the force-displacement curves of the glued menisci. The highest values were determined for the hyper-branched adhesive component $(11.0 \pm 5.2 \mathrm{~mJ})$. The energies calculated for compositions with spermidine 5:1 and DABCO were slightly lower: $5.5 \pm 3.7 \mathrm{~mJ}$ and $10.3 \pm 2.1 \mathrm{~mJ}$, respectively. For all compositions, the required energy to open the glued tear was pointedly higher than that for the fibrin glue and the nonglued control.

By subtracting the areas under the force-displacement curves of the baseline curves from the force-displacement curves of the glued tears, the energy required to break the adhesive bond between the glue and meniscus could be determined (Fig. 5). The highest values were determined for the hyper-branched adhesive component $(6.1 \pm 3.5 \mathrm{~mJ})$, followed by the values for the composition with DABCO $(4.8 \pm 1.1 \mathrm{~mJ})$ and spermidine $5: 1(3.2 \pm 2.1 \mathrm{~mJ})$. For the fibrin glue this energy was determined to be 0 , as its force-displacement curve overlapped the baseline curve. 


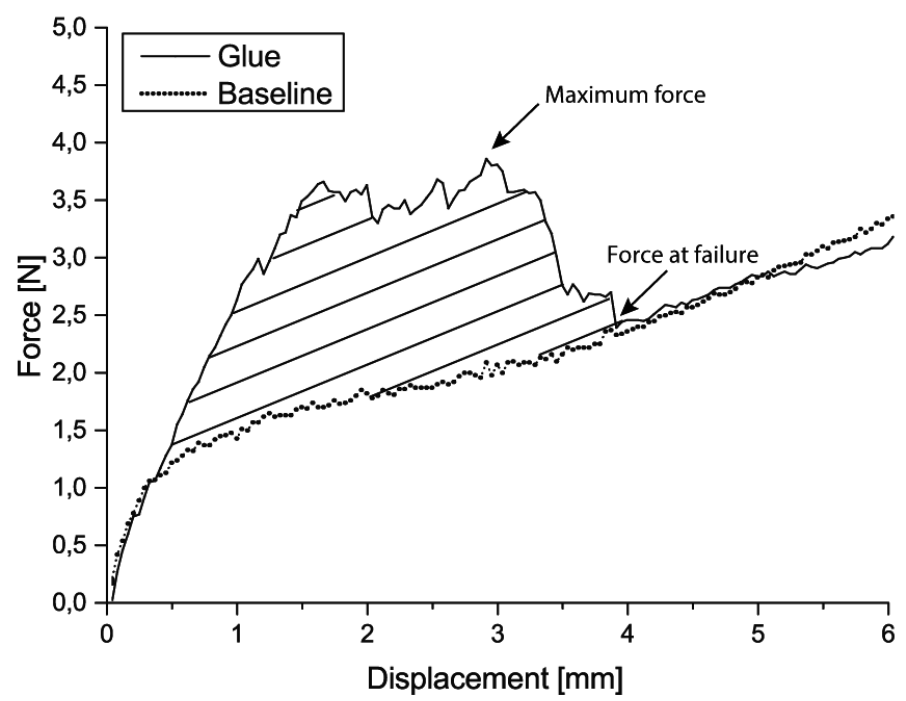

Figure 5. Characteristic force-displacement curves obtained during evaluation of the adhesive strength of the adhesives in a bucket-handle meniscus tear model. The figure shows the behaviour of the reactive hyper-branched adhesive component during opening of the glued tear and that of the reference baseline curve obtained after the adhesive failed.

\section{Discussion}

Two methods to accelerate the curing rates of isocyanate-terminated hyper-branched copolymers were evaluated. In one of the employed strategies a two-component adhesive formulation consisting of a hyper-branched adhesive component and a cross-linking mixture with an amine group-containing compound was used. It is known that amine groups have up to 50 times higher reactivity towards isocyanategroups than hydroxyl groups, and using such composition will allow the glue to cure within significantly shorter times $[8,9,15]$. The adhesive was applied using a double-chamber syringe equipped with a static mixer. In this way, the two components can be mixed immediately before application on the tissue. For this to occur efficiently, similar viscosities of the components are required. As it is also necessary to maintain the correct (excess) stoichiometric balance between isocyanate groups and amine groups, the spermidine cross-linker was diluted with a 
low molecular weight hydroxyl group-terminated $\mathrm{HO}-\mathrm{TMC}_{2}-\mathrm{PEG}_{400}-\mathrm{TMC}_{2}-\mathrm{OH}$ block copolymer. In this manner correct viscosities and ratios of isocyanate groups to amine groups were obtained.

Table 1. Adhesion testing of different compositions of the reactive isocyanateterminated hyper-branched adhesives using a bucket-handle meniscus tear model.

\begin{tabular}{|c|c|c|c|c|}
\hline Glue & $\begin{array}{l}\text { Maximum } \\
\text { adhesive } \\
\text { force }[\mathrm{N}]\end{array}$ & $\begin{array}{l}\text { Displacement } \\
\text { at maximum } \\
\text { force }[\mathrm{mm}]\end{array}$ & $\begin{array}{l}\text { Energy required to } \\
\text { open glued tear }[\mathrm{mJ}]\end{array}$ & $\begin{array}{l}\text { Energy required to } \\
\text { detach adhesive } \\
{[\mathrm{mJ}]}\end{array}$ \\
\hline $\begin{array}{l}\text { Hyper-branched } \\
\text { adhesive }\end{array}$ & $3.7 \pm 0.97$ & $2.4 \pm 0.96$ & $11.0 \pm 5.2$ & $6.1 \pm 3.5$ \\
\hline $\begin{array}{l}\text { Hyper-branched } \\
\text { adhesive }+ \\
\text { spermidine } 5: 1\end{array}$ & $3.7 \pm 1.5$ & $1.6 \pm 0.4$ & $5.5 \pm 3.7$ & $3.2 \pm 2.1$ \\
\hline $\begin{array}{l}\text { Hyper-branched } \\
\text { adhesive }+ \\
\text { DABCO }\end{array}$ & $3.2 \pm 0.47$ & $2.8 \pm 0.6$ & $10.3 \pm 2.1$ & $4.8 \pm 1.1$ \\
\hline Fibrin glue & $0.3 \pm 0.04 *$ & $6.0^{*}$ & $1.6 \pm 0.1 * *$ & 0 \\
\hline
\end{tabular}

A second strategy to accelerate the curing rate of the adhesive component was the use of catalysts DMDEE or DABCO. These catalysts have been shown to significantly increase the curing rates of isocyanate-terminated adhesives $[10,11]$.

Both the addition of a cross-linking component and catalysts accelerated the curing rates of the hyper-branched adhesive component (Fig. 3). The curing rate was most increased when DABCO was added to the hyper-branched adhesive, after only 2 hours nearly $95 \%$ of the isocyanate groups had already reacted to form a polyurethane network. Formulating the reactive hyper-branched adhesive with a cross-linking component resulted in slightly lower curing rates. However, the extruded reacting mixture could be precisely placed on the tissue as a result of its high viscosity. Once placed, it did not flow and would probably not leak into the surrounding tissues when used in a clinical application. 
The values of the adhesive strength of the adhesive component and those of the mixture of the adhesive component with spermidine 5:1 determined in lap shear tests were similar. However, when the reactive hyper-branched adhesive was mixed with spermidine 10:1, the resulting ultimate adhesive strength was lower. It seems that in the latter case the diluent concentration was too high and hampered the adhesion process. When catalysts were added to the adhesive component, the ultimate tensile strengths of the different cured compositions were similar. This indicates that the faster network formation did not hinder the attachment of the adhesives to the tissue, and that the number of remaining unreacted isocyanate groups available was sufficient to allow adhesion of the curing glues to the tissue.

The adhesive composition to which spermidine 5:1 had been added, and the adhesive component mixed with DABCO showed the most promising results in lap-shear adhesion testing and their curing times were considerably shorter than for the adhesive component alone. Thus, these two compositions were further evaluated as adhesive formulations in the bucket-handle meniscus tear model, as bucket handle tears are among the most commonly occurring types of traumatic meniscus injuries. They are of great clinical relevance, since they result in locking of the knee joint [3]. The performance of the two new adhesive compositions was compared with that of the hyper-branched adhesive component only and fibrin glue. The torn meniscus was preconditioned, glued, kept moist and left overnight to allow the glues cure, after which the adhesive test was performed.

It was observed that during the several hours the meniscus was mounted in the clamp, its mechanical properties had changed and the force needed to open the tear decreased (data not shown). This was probably due to relaxation, which is wellknown to occur in biological tissues [16-18]. Also, even though the tissue was wrapped with a moist fabric, it could have been not sufficiently hydrated [19, 20]. Therefore, to be able to assess the effect of gluing the meniscus tears with the different adhesive compositions, comparisons were made with 'baseline' forcedisplacement curves obtained directly after testing the glued menisci to failure. We showed in a single experiment that a meniscus in which a tear was cut (but not glued) and evaluated under the same conditions, displayed similar mechanical properties as 
those that had been glued and tested to failure. This implies that application of the glues did not affect the mechanical characteristics of the meniscus tissue.

The force necessary to rupture the adhesive bond between the glue and the meniscus and open the bucket-handle tear for the isocyanate-terminated hyper-branched component alone was similar to that after mixing with spermidine 5:1 or DABCO. The determined forces were considerably higher than when fibrin glue was employed. Apparently, mixing-in of a cross-linking composition and catalyst to the adhesive do not substantially hamper the adhesive strength of the cured network.

The adhesive strength of the adhesive compositions (3.2-3.7 N) should be sufficient to hold the torn meniscus together during the period of healing, as it has been reported that in a cadaver knee model the distraction forces acting on a torn meniscus do not exceed 5-10 N when a load of $300 \mathrm{~N}$ is applied [21, 22]. During the recovery period after surgery, the load on the knee would be even lower. From this it follows that the developed adhesive compositions should be able to perform adequately in the clinic. The simulated lesion was made with a scalpel and even though a mechanical rasp was used to refresh the wound and expose collagen fibers as done in clinical practice $[23,24]$, a meniscus tear that occurs spontaneously will be much rougher and more fibrillated. In gluing such a tear, better attachment of the adhesive due to larger surface areas and more extensive mechanical interlocking can be expected [25].

The energy required to open the glued meniscus tears was pointedly higher for the developed adhesive formulations than for fibrin glue and the control. The forcedisplacement curves indicated that these adhesives did not fail immediately when forces close to the maximum values were reached, but were able to maintain an adhesive bond for several more millimeters of applied displacement. The forcedisplacement curve of the meniscus tear model in which fibrin glue was used was identical to that of the baseline, indicating that fibrin glue had no effect in keeping the edges of meniscus tears together. 


\section{Conclusions}

New, rapidly curing adhesive systems composed of a reactive isocyanate-terminated hyper-branched adhesive component and a cross-linking composition or catalyst are promising biomaterials for the repair of meniscal tears. The addition of a crosslinking composition or a catalyst to the hyper-branched adhesive component resulted in considerably accelerated curing rates, without notably compromising the adhesive properties to the tissue. The adhesive strengths evaluated in a meniscus buckethandle lesion model were found to be much higher than that of fibrin glue. Further studies are needed to confirm the biocompatibility of these systems with cells and tissues in vitro and in vivo.

\section{Acknowledgements}

This research is supported by Reumafonds, the Dutch Arthritis Foundation.

\section{References}

[1] Berthiaume M-J, Raynauld J-P, Martel-Pelletier J, Labonté F, Beaudoin G, Bloch DA, et al. Meniscal tear and extrusion are strongly associated with progression of symptomatic knee osteoarthritis as assessed by quantitative magnetic resonance imaging. Annals of the Rheumatic Diseases 2005;64:556-63.

[2] Lykissas MG, Mataliotakis GI, Paschos N, Panovrakos C, Beris AE, Papageorgiou CD. Simultaneous bicompartmental bucket-handle meniscal tears with intact anterior cruciate ligament: a case report. Journal of Medical Case Reports 2010;4:34-.

[3] Shakespeare D, Rigby H. The bucket-handle tear of the meniscus. A clinical and arthrographic study. Bone \& Joint Journal 1983;65-B:383-7.

[4] Bochyńska AI, Hannink G, Grijpma DW, Buma P. Tissue adhesives for meniscus tear repair: an overview of current advances and prospects for future clinical solutions. Journal of Materials Science: Materials in Medicine 2016;27:1-18, Chapter 2 of this thesis.

[5] Bruns TB, Worthington JM. Using tissue adhesive for wound repair: A practical guide to Dermabond. American Family Physician 2000;61:1383-8.

[6] Spotnitz WD. Commercial fibrin sealants in surgical care. American Journal of Surgery 2001;182:8S-14S.

[7] Gilbert TW, Badylak SF, Beckman EJ, Clower DM, Rubin JP. Prevention of seroma formation with TissuGlu ${ }^{\circledR}$ surgical adhesive in a canine abdominoplasty model: Long term clinical and histologic studies. Journal of Plastic, Reconstructive and Aesthetic Surgery 2013;66:414-22. 
[8] Rohm HW, Lurtz C, Wegmann J, Odermatt EK, Behrend D, Schmitz K-P, et al. Development of a biodegradable tissue adhesive based on functionalized 1,2-ethylene glycol bis(dilactic acid). II. Journal of Biomedical Materials Research Part B-Applied Biomaterials 2011;97B:66-73.

[9] Sternberg K, Rohm HW, Lurtz C, Wegmann J, Odermatt EK, Behrend D, et al. Development of a biodegradable tissue adhesive based on Functionalized 1,2-ethylene glycol bis(dilactic acid). I. Journal of Biomedical Materials Research Part B-Applied Biomaterials 2010;94B:318-26.

[10] Eric J. Beckman, Jianying Zhang. Medical Adhesive and Methods of Tissue Adhesion, US Patent: US20040170597 A1. In: Publication USPA, editor. United States of America2007.

[11] Smith J., Beckman EJ. Hydrophilic biodegradable adhesives, US Patent 13/440,074. In: Patent US, editor. United States of America: Cohera Medicals Inc; 2012.

[12] Bochyńska AI, Sharifi S, van Tienen TG, Buma P, Grijpma DW. Development of Tissue Adhesives Based on Amphiphilic Isocyanate-Terminated Trimethylene Carbonate Block Copolymers. Macromolecular Symposia 2013;334:40-8, Chapter 3 of this thesis.

[13] Bochyńska AI, Van Tienen TG, Hannink G, Buma P, Grijpma DW. Development of biodegradable hyper-branched tissue adhesives for the repair of meniscus tears. Acta Biomaterialia 2016;32:1-9, Chapter 5 of this thesis.

[14] Bochyńska AI, Hannink G, Verhoeven R, Grijpma DW, Buma P. Evaluation of novel biodegradable three-armed- and hyper-branched tissue adhesives in a meniscus explant model. Manuscript submitted to Journal of Biomedical Materials Research Part A, Chapter 6 of this thesis.

[15] Szycher M. Szycher's Handbook of Polyurethanes, Second Edition: CRC Press; 2012.

[16] Liu Z., K Y. The Preconditioning and Stress Relaxation of Skin Tissue Journal of Biomedical \& Pharmaceutical Engineering 2008;2:22-8

[17] Toms SR, Dakin GJ, Lemons JE, Eberhardt AW. Quasi-linear viscoelastic behavior of the human periodontal ligament. J Biomech 2002;35:1411-5.

[18] Scapino RP, Canham PB, Finlay HM, Mills DK. The behaviour of collagen fibres in stress relaxation and stress distribution in the jawjoint disc of rabbits. Archives of Oral Biology 1996;41:1039-52.

[19] Viidik A. Biomechanics of Tendons and Other Soft Connective Tissues. Testing Methods and Structure-Function Interdependence. In: Bergmann G, Kölbel R, Rohlmann A, editors. Biomechanics: Basic and Applied Research: Selected Proceedings of the Fifth Meeting of the European Society of Biomechanics, September 8-10, 1986, Berlin, FRG. Dordrecht: Springer Netherlands; 1987. p. 59-72. [20] Chimich D, Shrive N, Frank C, Marchuk L, Bray R. Water content alters viscoelastic behaviour of the normal adolescent rabbit medial collateral ligament. J Biomech 1992;25:831-7.

[21] Becker R, Brettschneider O, Gröbel KH, Von Versen R, Stärke C. Distraction forces on repaired bucket-handle lesions in the medial meniscus. American Journal of Sports Medicine 2006;34:1941-7. [22] Staerke C, Brettschneider O, Gröbel KH, Becker R. Tensile forces on sutures in the human lateral knee meniscus. Knee Surgery, Sports Traumatology, Arthroscopy 2009;17:1354-9.

[23] Okuda K, Ochi M, Shu N, Uchio Y. Meniscal rasping for repair of meniscal tear in the avascular zone. Arthroscopy 1999;15:281-6. 
[24] Uchio Y, Ochi M, Adachi N, Kawasaki K, Iwasa J. Results of rasping of meniscal tears with and without anterior cruciate ligament injury as evaluated by second-look arthroscopy. Arthroscopy 2003;19:463-9.

[25] Lakshmi S. Nair. Injectable Hydrogels for Regenerative Engineering: Imperial College Press; 2016. 
Summary 
The aim of the work described in this thesis was to develop biocompatible and biodegradable tissue adhesives for the repair of meniscus tears. The chosen strategy was to use isocyanate-terminated three-armed and hyper-branched block copolymers. The building blocks of these reactive copolymers were trimethylolpropane ethoxylate (TMPE), trimethylene carbonate (TMC) and hexamethylene diisocyanate (HDI), and polyethylene glycol (PEG), TMC, citric acid (CA) and HDI, respectively.

The aim and general structure of the thesis were described in Chapter 1

In Chapter 2 the anatomy, physiology and biomechanics of the meniscus were discussed. Current repair techniques were reviewed and requirements for tissue adhesive materials were formulated. The ideal candidate for a tissue adhesive has to fulfil several general requirements, i.e. it has to be biocompatible, allow easy application and has to be biodegradable. Moreover, the tissue adhesive material should have specific properties, such as an adequate tensile strength, elastic modulus and degradation rate, in accordance with the tissue of interest. In Chapter $\mathbf{2}$ it was defined that the ideal adhesive for meniscus repair has to withstand stresses in the knee of at least $50 \mathrm{kPa}$. It also should have tensile properties close to those of the human meniscus in circumpherential direction, as this is the direction in which the majority of the meniscus tears occur. The material should hold the torn tissue together during the period of healing, and then degrade into non-toxic low molecular weight products that can be excreted by the kidneys. Polymer-based materials have been found to be promising candidates to be used as tissue adhesives, as the properties of these well-defined materials are easily tuneable.

In Chapter 3 a first study on the development of amphiphilic block copolymeric adhesives was described. Three-armed star-shaped isocyanate-terminated block copolymers based on TMPE and TMC varying in composition were designed and synthesized. The characteristics of these networks were compared with those prepared from analogous linear structures based on PEG and TMC. Tensile testing showed very good mechanical properties of the cured copolymers. These properties were found to depend on the length of the PTMC chains in the structure. In lap-shear adhesion tests, very good bonding strengths to chamois leather, which was used as 
a tissue model, of up to $600 \mathrm{kPa}$ were obtained. These strengths were much higher than those of analogous linear structures. The obtained results indicate that branching can enhance both the mechanical and the adhesive properties of these glues.

Chapter $\mathbf{4}$ addressed the problem of choosing right tissue models when performing adhesion experiments using newly developed tissue adhesives. The adhesive properties of three different tissue adhesives, namely Dermabond ${ }^{\circledR}$, fibrin glue, and the newly developed three-armed isocyanate-terminated adhesive, were evaluated using five different biological substrates: bovine Achilles tendon, meniscus tissue, skeletal muscle, chamois leather and collagen films. It was found that the strength of the adhesive bond depends both on the used glue as well as on the surface roughness of the substrates, their hydrophilicity and biochemical composition. It was concluded that standardized procedures and models should be developed to allow direct comparison between different tissue adhesives, and to enable extrapolation of the results towards the specific targeted human tissues.

Chapter 5 presented a series of amphiphilic hyper-branched copolymers based on PEG (molecular mass $\mathrm{M}_{\mathrm{n}}=200 \mathrm{~g} / \mathrm{mol}$ or $\mathrm{M}_{\mathrm{n}}=600 \mathrm{~g} / \mathrm{mol}$ ), TMC, CA and endfunctionalized with HDI. The adhesive strength of the networks to bovine meniscus tissue determined in a lap-shear adhesion test ranged between $20-80 \mathrm{kPa}$, which was significantly higher than the adhesion strength of fibrin glue. The mechanical properties of the copolymeric networks were found to be highly dependent on the molecular mass of PEG in the molecule. The elastic modulus of the networks containing $\mathrm{PEG}_{200}$ was determined to be in the same range as that of the human meniscus in circumpherential direction. The degradation rate of the networks was also dependent on the molecular mass of PEG, and was found to be significantly faster for the networks based on $\mathrm{PEG}_{600}$. After incubation with different amounts of the glues for 7 days, the viability of bovine meniscus cells was not affected when physiologically relevant amounts of the adhesives were added to the medium.

The networks based on the $\mathrm{PEG}_{200}$ had mechanical properties close to the values of human meniscus, but their degradation rate was low. The networks based on PEG $_{600}$ had inferior mechanical properties, but faster degradation rates. For further experiments, networks based on $\mathrm{PEG}_{400}$ were chosen. 
In Chapter 6 the adhesive properties of- and the tissue response to three-armed- and hyper-branched tissue adhesives were assessed and compared in a meniscus explant model. Additionally, the surface of the tissue was modified using collagenase to assess if it improved the attachment of the adhesives and increased the healing rate of the tissue. Cylindrical explants were glued with the three-armed or hyperbranched adhesives and cultured in vitro for 28 days. Their performance was compared with that of fibrin glue and Dermabond ${ }^{\circledR}$. The adhesive strength of the three-armed- and hyper-branched glues was 40-50 kPa, which was significantly higher than that of fibrin glue. Additionally, according to the requirements stated in Chapter 2, this adhesive strength was sufficient to be used in the treatment of meniscus tears. The adhesion strength to explants treated with and without collagenase was similar, therefore it was concluded that collagenase treatment did not enhance adhesion. Cells were observed to be in direct contact with the glues, and the tissue remained vital during the whole culture period. Increased cellularity around the tear in the collagenase-treated explants was observed after the first day. However, at day 28 , the cellularity around the tear was similar to the group that was not incubated in collagenase. By filling the whole tear gap, the glues might have acted as a barrier and blocked access to the nutrients present in the medium thereby limiting the migration of cells to the tear.

Due to these limitations, it was proposed in Chapter 7 to use a modified experimental setup which introduced only partial gluing of the explants. The focus of this study was to investigate if tissue surface modification with collagenase and the addition of TGF- $\beta 3$ to the culture medium can increase the number of cells present in meniscus tears glued with the three-armed-and hyper-branched adhesives. Histological staining of the repair constructs confirmed that both developed adhesives were not cytotoxic and that meniscus cells were present in direct contact with the glues. The addition of TGF- $\beta 3$ to the culture medium resulted in the presence of cells that formed a sheath within the simulated tear. Based on these results, it was concluded that the healing potential of a torn meniscus can possibly be enhanced by using a combined therapy which makes use of tear surface treatment using collagenase, biodegradable glues and the addition of growth factors. 
In Chapter 8 a more detailed characterization of the three-armed- and hyperbranched adhesives in vitro and in vivo was performed. Their physicochemical and adhesive properties, the degradation profile of the water-cured network films and the tissue reaction after subcutaneous injection of the adhesives in rats were tested. Both developed glues showed to have sufficient adhesive strengths (80-100 $\mathrm{kPa})$ to meniscus tissue after curing. The main mechanism of degradation was found to be hydrolysis and after 26 weeks the networks based on hyper-branched adhesives showed a faster mass loss (approximately $25.5 \%$ ) compared to the networks prepared from three-armed glues (approximately 5.5\%). Both glues induced a mild to moderate inflammatory reaction involving macrophages and PMN cells. However, no necrosis or toxic effects on peripheral tissues were observed. As the intended application is treatment of damaged meniscus tissue, it is expected that the application of only a few drops of adhesive will result in a minimal tissue reaction.

Acceleration of the curing rates of the adhesives is desired, as it takes up to 24 hours for the materials to fully cure. This could potentially limit their clinical application. In Chapter 9 it was proposed to employ an amine cross-linker and to add a catalyst to the adhesive components to increase their curing rate. The curing kinetics of the hyper-branched adhesive alone, the adhesive in combination with different concentrations of spermidine solutions, and after addition of 2,2dimorpholinodiethylether (DMDEE) or 1,4-diazabicyclo [2.2.2] octane (DABCO) to the adhesive, were determined using FTIR. Additionally, lap-shear adhesion tests were performed after application of the adhesives onto strips of bovine meniscus tissue and to simulated bucket-handle lesions in the bovine meniscus. It was found that addition of both spermidine and catalysts accelerated the curing rate of the adhesive copolymer, resulting in firm adhesion already after 2 hours after application of the glue. The adhesion strength to meniscus tissue determined in a bucket handle tear model (3.2-3.7 N), was considerably higher for the newly developed compositions than for fibrin glue $(0.3 \mathrm{~N})$.

The work presented in this thesis describes the development of novel tissue adhesives for the repair of meniscus tears. The developed materials have satisfactory adhesive strengths to meniscus tissue. They attach to the tissue surface via formation of covalent bonds and simultaneously cure in the presence of body fluids. Their 
tensile strength, elastic modulus and degradation profile can be tuned by varying the PEG molecular weight, PTMC chain length and the ratio between the particular components in the adhesives. These adhesive materials showed good biocompatibility with meniscus cells and tissue in vitro, and a mild to moderate tissue reaction after subcutaneous injection in vivo. The obtained results pave the way for further in vivo studies in larger animal models to assess the efficacy of these glues in treating meniscal tears. 
Samenvatting 
Dit proefschrift beschrijft de ontwikkeling van biocompatibele en biodegradeerbare weefsellijmen om meniscusscheuren te repareren. Hierbij werd gekozen voor het gebruik van drie-armige en vertakte copolymeren. De bouwstenen van deze reactieve co-polymeren waren respectievelijk trimethylolpropaan ethoxylaat (TMPE), trimethyleen carbonaat (TMC) en hexamethyleen diisocyanaat (HDI) en polyethyleen glycol (PEG), TMC, citroenzuur (CZ) en HDI.

Het doel en de algemene structuur van dit proefschrift zijn beschreven in Hoofdstuk 1 .

Hoofdstuk 2 beschrijft de anatomie, fysiologie en biomechanica van de meniscus. Er werd een overzicht gegeven van de huidige reparatietechnieken en de eisen voor weefsellijmen werden geformuleerd. De ideale weefsellijm heeft een aantal algemene eigenschappen. Het moet bijvoorbeeld biocampatibel en biodegradeerbaar zijn en het moet gemakkelijk toe te passen zijn. Bovendien moet de weefsellijm specifieke eigenschappen hebben welke overeenkomen met het weefsel waarin het toegepast wordt zoals adequate treksterkte, elasticiteitsmodulus en degradatiesnelheid. In Hoofdstuk 2 werd vastgesteld dat de ideale lijm voor meniscusreparatie mechanische spanningen van minstens $50 \mathrm{kPa}$ aan moet kunnen. Daarnaast moet de lijm een treksterkte hebben die overeenkomt met de circumferentiele treksterkte van een menseliijke meniscus, omdat de meeste meniscus scheuren zich in die richting bevinden. Het materiaal zou het gescheurde weefsel bij elkaar moeten houden gedurende de herstelperiode om vervolgens af te breken in gifvrije producten met een laag moleculair gewicht die uitgescheiden kunnen worden door de nieren. Materialen gebasseerd op polymeren worden gezien als veelbelovende kandidaten voor weefsel lijmen, omdat de eigenschappen van deze materialen gemakkelijk aan te passen zijn.

Hoofdstuk 3 beschijft een eerste studie met betrekking tot de ontwikkeling van amfifiele blokcopolymerische lijmen. Drie-armige, ster-vormige isocyanaat getermineerde blokcopolymeren gebasseerd op TMPE en TMC met verschillende composities werden ontworpen en gesynthetiseerd. De eigenschappen van deze materialen zijn vergeleken met gelijksoortige lineaire structuren gebasseerd op PEG 
en TMC. Uit de trekproeven bleek dat de copolymeren zeer goede mechanische eigenschappen bezaten. Deze eigenschappen waren afhankelijk van de lengte van de PTMC ketens in de structuren. De overlapsafschuivings experimenten lieten zien dat de materialen zeer goed hechtten aan zeemleer met spanningen tot $600 \mathrm{kPa}$. Zeemleer werd gebruik als weefselmodel. Deze spanningen waren veel hoger dan die van de gelijksoortige lineaire structuren. De resultaten geven een indicatie dat vertakking zowel de mechanische eigenschappen als ook de hecht eigenschappen van deze strcuturen kan verbeteren.

Hoofdstuk 4 behandelt de problemen bij de keuze voor de juiste weefselmodellen bij het testen van de ontwikkelde weefsellijmen. De lijmeigenschappen van Dermabond $^{\circledR}$, fibrinelijm en de nieuw ontwikkelde drie-armige isocyanaat getermineerde lijm werden geevalueerd op vijf verschillende weefsels: achillespeesweefsel van een koe, meniscusweefsel, skeletspieren, zeemleer en collagene films. De sterkte van de binding hing af van zowel het type lijm als de ruwheid, hydrophiliciteit en biochemische samenstelling van het substraat. Hieruit is geconcludeerd dat er gestandaardiseerde procedures en modellen ontwikkeld dienen te worden zodat er een directe vergelijking tussen de verschillende lijmen gemaakt kan worden en extrapolatie van de resultaten naar specifieke humane weefsels mogelijk wordt.

Hoofdstuk 5 presenteerde een serie van amfifiele vertakte copolymeren gebasseerd op PEG (moleculaire massa $\mathrm{M}_{\mathrm{n}}=200 \mathrm{~g} / \mathrm{mol}$ of $\mathrm{M}_{\mathrm{n}}=600 \mathrm{~g} / \mathrm{mol}$ ), TMC, CZ en gefunctionaliseerd met HDI. De lijmsterkte van de netwerken op menicusweefsel van koeien was tussen de $20-80 \mathrm{kPA}$ en werd bepaald met behulp van overlapsafschuivings experimenten. Dit was significant hoger dan de lijmsterkte van fibrinelijm. De mechanische eigenschappen van de copolymeer netwerken bleken zeer afhankelijk van de moleculaire massa van de PEG in het molecuul. De elasticiteitsmodulus van de netwerken met $\mathrm{PEG}_{200}$ bleek vergelijkbaar met die van de humane meniscus in circumferentiele richting. Ook de degradatiesnelheid bleek afhankelijk van de moleculaire massa van PEG waarbij de netwerken met PEG $_{600}$ significant sneller degradeerden. In de aanwezigheid van verschillende hoeveelheden lijm, gedurende 7 dagen, bleek dat de levensvatbaarheid van rund 
meniscus cellen niet beinvloed werd door fysiologische hoeveelheden lijm in het medium.

The netwerken gebasseerd op $\mathrm{PEG}_{200}$ hadden mechanische eigenschappen die dicht in de buurt zaten van die van de humane meniscus, maar ze degradeerden langzaam. Netwerken gebasseerd op $\mathrm{PEG}_{600}$ hadden slechtere mechanische eigenschappen, maar degradeerden sneller. Voor toekomstige experimenten werd daarom gekozen voor netwerken gebasseerd op $\mathrm{PEG}_{400}$.

Hoofdstuk 6 beschrijft het onderzoek naar de lijmeigenschappen van de drie-armige en vertakte weefsellijmen en de weefselreactie daarop. Deze werden vergeleken met een model van een meniscus explantaat. Daarnaast was het oppervlak van de weefsels behandeld met collagenase om te bekijken of dit de hechting van de lijmen en de snelheid van weefselgenezing kon verbeteren. Cylindrische explantaten werden gelijmd met drie-armige of vertakte lijmen en vervolgens in vitro gekweekt voor 28 dagen. Ze werden vergelijken met fibrinelijm en Dermabond ${ }^{\circledR}$. De lijmsterkte van de drie-armige en vertakte lijmen was 40-50 kPA. Dit was significant hoger dan die van fibrinelijm. Bovendien is dit sterk genoeg voor gebruik voor meniscusreparatie volgens de richtlijnen die opgesteld werden in Hoofdstuk 2. De lijmsterkte van explantaten die met collagenase waren behandeld waren vergelijkbaar. Hierdoor werd geconcludeerd dat behandeling met collagenase geen invloed had op de aanhechting.

Cellen hadden direct contact met de lijmen en het weefsel bleef vitaal gedurende de gehele periode. Bij explantaten die behandeld waren met collagenase was rond de scheur een verhoogde celactiviteit te zien op de eerste dag. Echter, op de $28^{\mathrm{e}}$ dag was de celactiviteit rond de scheur gelijk voor beide groepen. Door de gehele ruimte van de scheur te vullen met lijm, zouden deze een barriere gevormd kunnen hebben voor voedingsstoffen in het medium en daarmee de celmigratie verhinderd kunnen hebben.

Vanwege deze limitaties werd in Hoofdstuk 7 voorgesteld om een gemodificeerde experimentele setup te gebruiken waarbij expalntaten slechts gedeeltelijk werden gelijmd. Het doel van deze studie was om te onderzoeken om weefsel modificatie met collagenase en de toevoeging van TGF- $\beta 3$ aan het kweekmedium zou leiden tot 
een toename van het aantal cellen in de meniscusscheuren die waren gelijmd met de drie-armige en vertakte lijmen. Histologische kleuring van de constructen toonde aan dat de ontwikkelde lijmen niet giftig waren en dat de meniscuscellen in direct contact waren met de lijmen. De toevoeging van TGF- $\beta 3$ aan het kweekmedium zorgde voor cellen in de scheur. Gebasseerd op deze resultaten werd geconcludeerd dat het heelproces van de meniscus verbeterd kan worden door een combinatie van weefselbehandeling met collagenase, bioafbreekbare lijmen en de toevoeging van groeifactoren.

In Hoofdstuk 8 werd een gedetailleerdere in vitro en in vivo karakterizatie verricht van de drie-amige en vertakte lijmen. Er werd gekeken naar de fysiochemische- en hechtingseigenschappen, het degradatie profiel van de in water gecrosslinkte netwerken en de weefselreactie na onderhuidse injectie van de lijmen in ratten. Beide ontwikkelde lijmen lieten zien dat ze voldoende lijmsterkte hadden aan meniscus weefsel (80-100 kPa). De degradatie verliep met name via hydrolyse en na 26 weken bleek dat de vertakte netwerken een hoger massaverlies hadden (ongeveer $22.5 \%$ ) in vergelijking met de drie-armige netwerken (ongeveer $5.5 \%$ ). Beide lijmen hadden een lichte to gemiddelde ontstekingsreactie tot gevolg welke gekenmerkt was door de aanwezigheid van macrofagen en PMN cellen. Er werden echter geen necrose van, of giftige effecten op het omliggende weefsel geconstateerd. Omdat de behandeling van gescheurd meniscusweefsel de beoogde applicatie is, kan worden verwacht dat het gebruik van een paar druppels lijm slechts zal leiden tot een minimale weefsel reactie.

Omdat het 24 uur duurt voordat de materialen volledig gecrosslinked zijn, is een versnelling van het crosslinkproces gewenst. De klinischie toepassingen kunnen hierdoor namelijk gelimiteerd zijn. In Hoofdstuk 9 werd voorgesteld om een aminecrosslinker te gebruiken en een katalysator toe te voegen om het crosslinkproces te versnellen. Met behulp van FTIR werd de crosslinkkinetiek bepaald van vertakte lijmen, vertakte lijmen in combinatie met verschillende concentraties spermidine en de lijmen met als toevoeging van 2,2-dimorfoline diethylether (DMDEE) of 1,4diazabicyclo [2.2.2] octaan (DABCO). Daarnaast werden er overlapsafschuivings experimenten uitgevoerd na het aanbrengen van de lijmen op plakjes 
menicusweefsel en gesimuleerde scheuren in de rundmeniscus. De toevoeging van spermidine en een katalysator zorgden beide voor een versnelling van het crosslinkproces van de copolymeren, met volledige crosslinking na 2 uur. De lijmsterktes in het model met de gesimuleerde meniscusscheuren waren aanzienlijk hoger (3.2-3.7 N) voor de nieuw ontwikkelde lijmen in vergelijking met fibrinelijm $(0.3 \mathrm{~N})$.

Het werk dat beschreven wordt in deze thesis beschrijft de ontwikkeling van nieuwe weefsellijmen voor de reparatie van meniscusscheuren. De ontwikkelde materialen hebben voldoende lijmsterkte aan meniscusweefsel. Ze binden aan het oppervlak via covalente verbindingen en crosslinken tegelijkertijd in de aanwezigheid van lichaamsvocht. De treksterkte, elasticiteitsmodulus en het degradatieprofiel kunnen worden beinvloed door de moleculaire massa van PEG, PTMC ketenlengte en de verhouding tussen de componenten van de lijm te varieren. Deze lijmen waren compatibel met meniscuscellen en weefsel in vitro, en hadden een milde tot gemiddelde ontstekingsreactie tot gevolg in vivo. De behaalde resultaten openen de deur naar in vivo studies in grotere dieren om de doelmatigheid van deze lijmen bij de behandeling van meniscusscheuren te onderzoeken. 


\section{Acknowledgements}

The last four years have passed incredibly quick and it's hard to believe that my $\mathrm{PhD}$ is actually over. I still remember the day in January 2012 when I arrived to Enschede as it was yesterday. It was incredible time, during which I learnt a lot and grew both professionally and personally. I met fantastic people, who inspired me, supported and were always there when I needed them. Without them the past four years would not have been as fruitful, happy and enjoyable. Here, I would like to express my gratitude for them.

Firstly, I would like to thank my promotors, prof. Dirk Grijpma and prof. Pieter Buma, who trusted in me and gave me opportunity to work on this $\mathrm{PhD}$ project.

Dear Dirk, I really enjoyed working with you and I learnt a lot from you. You gave me a lot of freedom in research and at the same time you were always there when I needed a discussion or to put me back on the "right track" when I was getting lost in the interpretation and analysis of the results from the experiments. After discussions with you, I was motivated to work and you taught me not to lose spirit when things were not always going well. I really appreciate your time spent on reading and commenting chapters of this thesis. Thank you for your constructive critics and your enthusiasm and support towards the end of the project and completing this book.

Dear Pieter, thank you for your great support after I moved to Nijmegen and joined your group. You gave me very warm welcome and made me feel like home right from the beginning. Thank you for your support during writing this thesis and for teaching me during our discussions to look on things from different perspectives.

I would also like to thank dr Gejron Hannink, my co-promotor. Dear Gerjon, we started collaborating closely during third year of the project when I moved to Nijmegen. You were always very helpful and open for discussion and your doors were always open, so I could step in to talk. Thank you for being critical about my work, especially writing papers as thanks to that I learnt a lot. Thank you for answering my emails, even in the late evenings on Saturdays and Sundays, and for incredibly fast feedback especially in the last weeks before submission of this thesis.

I would like to extend my gratitude to my promotion committee for their precious time spent on reading this thesis and their presence at the defence. Prof. N. Verdonschot, prof. J.F.J. Engbersen, prof. G.J.V.M. van Osch, prof. T.H. Smit, dr. C.C. van Donkelaar and dr. T.G. van Tienen, it is a great honour for me that you agreed to be members of my promotion committee.

I would like to extend my gratitude to prof. Tomasz Ciach from Warsaw University of Technology, where I did my first steps and attempts of the experiments in the biomedical 
engineering research lab. I am very grateful for the experience I got there and later opportunity to perform my master assignment in the Netherlands. I would also like to thank dr Jos Wennik and prof. Piet Dijkstra, with whom I collaborated during my master project. It was thanks to you that I "fell in love" with research. You inspired me and taught me how not to treat negative results of the experiments as personal failures, rather as lessons and experience.

I would like to express my gratitude to Karin Henrdiks. Dear Karin, thank you for help with all paper work after I arrived in the Netherlands and especially during the time before my defence. I would never manage to deal with these all without you.

My big thanks also to Marc Ankone for being always helpful regarding the work in the lab but also nice chats we had in the lab regarding "life issues", I really enjoyed them!

Thank you Zlata, Hetty, Lydia and Anita for your kindness and help whenever I needed it. I would like to thank my collegues and friends from the BST group. I can undoubtedly say that I was lucky to be a member of this great team. You filled these 4 years with joy and happiness and thanks to you I was glad to get up in the morning and come to work even in the most awful rainy and cold day. I will miss you a lot and I do hope we will keep in touch. Shahriar you are not only a great friend, but also scientific advisor. You were always there ready for discussion, sharing advice, recommending literature and supporting in hard moments. Thank you for that! I wish you all the best for your life together with Hajar and hope to stay in touch with you guys regardless the distance!

I would like to thank Sebastien Blanquer without whom this lab would not be the same. Seb, your great sense of humour and our political discussions, which turned not once into almost fights, I will always remember with a tear in the eye. I wish you all the best with Marylin and Haile and hope you will soon become great French (or maybe Dutch?) professor and win Nobel prize, just as a POLISH scientist Marie Curie-Skłodowska. Maybe you will also become as famous as a great polish composer Fryderyk Chopin $\odot$ Fingers crossed!

Thank you Bade for being great office mate and a friend! I really enjoyed our discussions and watching together movies of Quentin Tarantino! Wish you all the best in Turkey and hope to meet you back soon.

Dear Ilaria de Napoli, thank you for being always such a positive spirit and I really enjoyed these few months that we were living together. Natalia, your incredible personality is something that I already miss! I really enjoyed talks with you and your very direct jokes. Similarly to me, you are always trying to be on diet, but having some emergency chocolate around $(;)$ Wish you all the best for your life together with Felix! Dear Denys you are exceptionally sensible mind, which sometimes during our discussion was clashing with my more emotional approach to life issues. Nevertheless, I really enjoyed our talks and your 198 
black sense of humor. You are a real evil genius :-) Dear Lia, thank you for your kindness and always great spirit. I really enjoy our dinners, shopping and gossip evenings together. Dear Ilaria Geremia, although you joined the group relatively short time ago, we immediately became good friends. Thank you for fantastic evenings with wine, our talks and all great time we had together! I will miss that a lot! Dear Aysun, we were office mates for a while and I really enjoyed this period. Thank you for making me laugh in bad moments and for your snacks, which were always hidden somewhere between remotely-controlled Lamborghini, LEGO Star Wars characters and a football ball on your desk (:). You are amazing girl and I will miss you a lot! Gert-Jan, thanks for our dinners together whenever you were back in the Netherlands and awesome time we had during ESB in Liverpool (after you finally made it to arrive there $(;)$ ). It was never boring with you! Erwin, we were working in the same lab for few years. Even though in the beginning you were quite tough to me as a lab chief, I really enjoyed the hours spent there together on talking, laughing and always complaining a little bit about surrounding world. Bas, we first met when you were a master student of Seb, but very soon you joined the group as a $\mathrm{PhD}$ student. We shared our frustration regarding degradation experiments and I appreciate your help with changing my medium (nightmare!). You were also always ready to help when I was already in Nijmegen and it's thanks to your translation that I have Samenvatting at the end of this book. Big thanks for all that and I wish you all the best with Magda! Dear Magda, you joined BST group and immediately made people stick with you thanks to your great spirit! I am really happy we could stay together for few months and I will miss our evenings with wine and talks. Hope you will soon find out what you want to do in the future! Thank you Zhengchao Guo for your great spirit in the lab! You were never giving up with critics, working super hard and I do hope you will have great success in the future career. Thank you Odyl, Nick, Thijs, Saleh, Jonas, Pia, Tony, Frits, Rachel, mr Si and Mike for great time in the lab and enjoyable coffee, cake breaks and borrels!

I would also like to express my gratitude for my collegues from the ORL lab. Even though I spent much less time in Nijmegen than in Enschede, I really enjoyed time there. Thank you Ineke and Joke for your support regarding all paper and formal things as well as your kindness and smile. It was always nice to meet you Ineke in the morning saying "dzień dobry" and I will miss that. Thank you Dennis for your contribution to Chapter 9 of this thesis. It was thanks to discussions with you that I managed to analyze the whole bunch of data from the mechanical tests. Thank you Leon for your great help and support with histology, last minute orders and also listening to my complaints and Christmas songs when I was playing them in the lab, which you hate $:-$ I really enjoyed our conversations and wish you all the best with your music band as well! Thank you Richard for your work on customizing BOSE to my needs. Without your help performing my experiments so smoothly 
would not have been possible. Thank you Renate, my master student, for your hard work and your enthusiasm to do experiments even when they meant removing hundreds of menisci from the bovine knees. Your work was involved in Chapters $6 \& 7$ of this thesis. I wish you great success in your future life! Thank you Priyanka and Thom for the great time we had during ORS in Las Vegas and later during our trip to Grand Canyon. Thank you Loes for your kindness and nice chats in the coffee corner. Dear Sanaz, thanks for organizing lab events and nice chats we had. Wish you all the best in Australia and wherever you decide to go afterwards. Jan, thank you for your help with operating rats and your input to Chapter 8 of this thesis. It was nice to have you as an office mate! Thank you Karlijn, Marco, Hamid, Erwin, Veronica and Lennert for the nice atmosphere in the lab!

I would also like to express my gratitude to my dear friends, both those who I have known for years and those, who I met during the period of $\mathrm{PhD}$. Dear Kasia and Marysia, you were ones of the first people I met after I started my $\mathrm{PhD}$. We immediately became friends and spent almost all our free time together. You helped me to survive this hard period I was going through! Maria kielbo, I really miss you and hope we will see each other in the future more often! Thus, there is no surprise that I was extremely happy when you Kasia got your PhD position and returned to Enschede. After that we had our solid group with Emi, Basia and Bram. Thank you for the incredible time together. All the dinners, trips, evenings, your help and support in difficult moments, which were not that bad after sharing them with you! Kasia I wish you all best with Emi and I hope you will be my guest in Copenhagen very often as it really takes less time to arrive here from Amsterdam than to Enschede! Dear Basia and Bram, it was especially great to have you as the neighbors, so even in the laziest and cold evenings it was so easy to pass by and meet! I'm so happy for your soon-coming baby boy and cannot wait to become his aunt! I am sure we will stay in touch regardless the distance between! Krzysztof and Marzena, it was always nice meeting you. I'm very happy that now you also live in Copenhagen and we can enjoy time together! Piotr D., Francesco R., Agustin, Riccardo, Marco C. and Giuseppe thanks for all the enjoyable moments we spent together!

I would also like to thank my Italian friends here in Enschede. Dear Caterina and Federico, we had such great times together! I really enjoyed all the dinners, lunches, wine, Christmas cooking and watching Italian masterchef together! You were always there to help, talk and host us! I will really miss you and wish you all the best for your family life with your newly born son Ettorino! I'm sure we will see each other often even though we will no longer be neighbors. Virginia and Giorgio, my dear vegan friends, thank you for the good times together and sophisticated vegan recipes I discovered thanks to you $\odot$ I really enjoyed times together filled with laugh and (only a bit) of sleeping Virginia wherever she could. 
Dear Ola and Wojtek! You gave me really warm welcome when I arrived to Nijmegen and didn't know anyone. Thank you for your support in all the situations, for the great time we had together and for hosting me many times in your house. I always truly enjoy time with you! It was great Wojtek, to share an office with you as well as our daily frustrations and joy. Ola, I will really miss our daily e-mails exchange, lunches, political discussions and shopping!

Pawel, it was really nice to be in the group with you! I enjoyed our coffee breaks and inspiring chats! Wish you all the best together with Gosia and your two lovely kids Hania and Filip. Dear friends from the urology group: Jasmijn, Vicky and Silvia, thanks for all lunches together, which sometimes slightly extended due to our endless discussions and funny chats! Irmina, I really enjoyed our evenings together in Nijmegen and hours spent in the gym trying to get fit:) Wish you happy life together with Bart! I will miss you guys! I would not be such a happy person as I am if it was not for my beloved 3 best friends: Paulina (also known as Drągal), Martyniak and Agata! Girls, there are no words to describe how grateful I am to have you. You were always there for me, regardless the distance and your own problems and struggles. You are like sisters to me and I love you! Ania, Daruś, Jaś T., Olti and Marecki the time showed that even if we don't see each other for a year, then we meet and talk like we last met just yesterday! Thank you for being great friends for all this time! Piotruś, Sito and Pinki it was nice to see you always when I was coming back to Poland, I really enjoyed moments with you!

I would like to express my gratitude to my family, especially my parents, my beloved brother Alek, grandmother Nela and aunt Elżbieta. You were always there loving me, supporting and believing in me. Without you I would not be where I am now! Chciałabym wyrazić swoją wdzięczność i podziękować swojej rodzinie, w szczególności rodzicom, kochanemu bratu Alkowi, babci Neli i cioci Elżbiecie. Dziękuję za Waszą miłość, wsparcie i nieustanną wiarę we mnie. Bez Was to wszystko byłoby niemozliwe!

Matteo, amore mio! I am so happy that I met you and that you were so patient with me in the beginning and you decided to stay in Enschede. It's been almost already 4 years together (and eternity to come)! There are no words that can describe how much I love you, need you and enjoy every single moment with you! I know that I have been very tough recently while finishing $\mathrm{PhD}$, but you were always there for me, travelling every weekend and always trying to make me happy. Thank you so much for that, for your love and continuous support! And now, we are finally together forever! Tu sei tutto per me e non vedo l'ora per la nostra vita futura insieme! TI AMO tantissimo! 


\section{List of publications}

1. Bochyńska AI, Hannink G, Grijpma DW, Buma P. Tissue adhesives for meniscus tear repair: an overview of current advances and prospects for future clinical solutions. Journal of Materials Science: Materials in Medicine 2016;27:1-18.

2. Bochyńska AI, Van Tienen TG, Hannink G, Buma P, Grijpma DW. Development of biodegradable hyper-branched tissue adhesives for the repair of meniscus tears. Acta Biomaterialia 2016;32:1-9.

3. Vergroesen PP, Bochyńska AI, Emanuel KS, Sharifi S, Kingma I, Grijpma DW, et al. A biodegradable glue for annulus closure: evaluation of strength and endurance. Spine (Phila Pa 1976) 2015;40:622-8.

4. Bochyńska AI, Sharifi S, van Tienen TG, Buma P, Grijpma DW. Development of Tissue Adhesives Based on Amphiphilic Isocyanate-Terminated Trimethylene Carbonate Block Copolymers. Macromolecular Symposia 2013;334:40-8.

5. Wennink JWH, Niederer K, Bochyńska AI, Moreira Teixeira LS, Karperien M, Feijen J, et al. Injectable hydrogels by enzymatic co-crosslinking of dextran and hyaluronic acid tyramine conjugates. Macromolecular Symposia 2011;309310:213-21.

6. Bochyńska AI, Hannink G, Verhoeven R, Grijpma DW, Buma P. Evaluation of novel biodegradable three-armed- and hyper-branched tissue adhesives in a meniscus explant model. Manuscript submitted to Journal of Biomedical Materials Research Part A.

7. Bochyńska AI, Hannink G, Verhoeven R, Grijpma DW, Buma P. The effect of tissue surface modification with collagenase and addition of TGF- $\beta 3$ on the healing potential of meniscal tears repaired with tissue glues in vitro. Manuscript submitted to Biomedical Materials.

8. Bochyńska AI, Hannink G, Janssen D, Buma P, Grijpma DW. Development of a fast curing tissue adhesive for meniscus tear repair. Manuscript submitted to Journal of Materials Science: Materials in Medicine.

9. Bochyńska AI, Hannink G, Rongen JJ, Grijpma DW, Buma P. In vitro and in vivo characterization of biodegradable reactive isocyanate-terminated three-armed- and hyper-branched block copolymeric tissue adhesives, in preparation.

10. Bochyńska AI, Hannink G, Buma P, Grijpma DW. Adhesion of tissue adhesives to different biological substrates, in preparation. 
